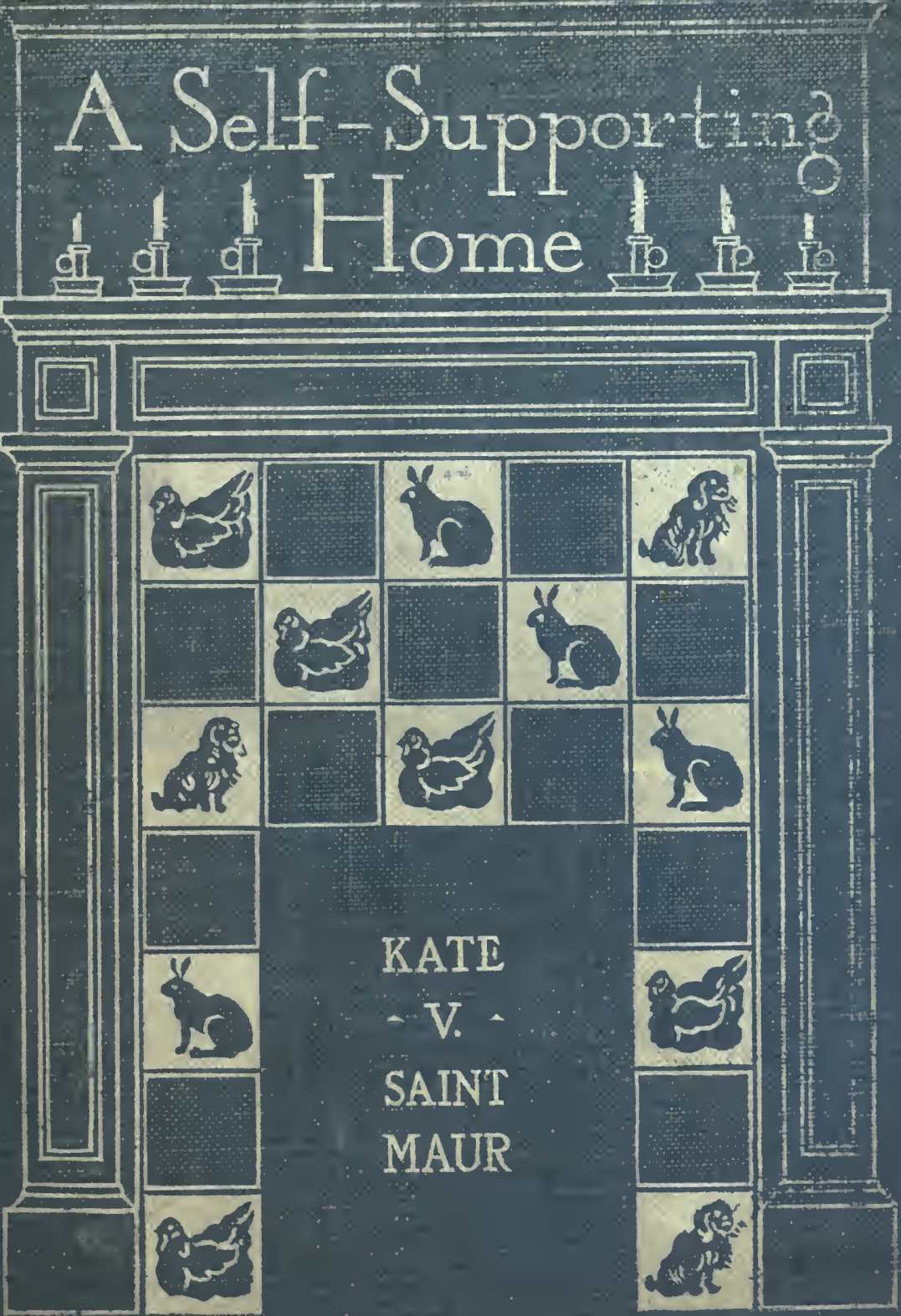




$$
\neq 1536
$$

ton 
Martharn 
Digitized by the Internet Archive in 2007 with funding from Microsoft Corporation 


A SELF-SUPPORTING HOME 
Thes 



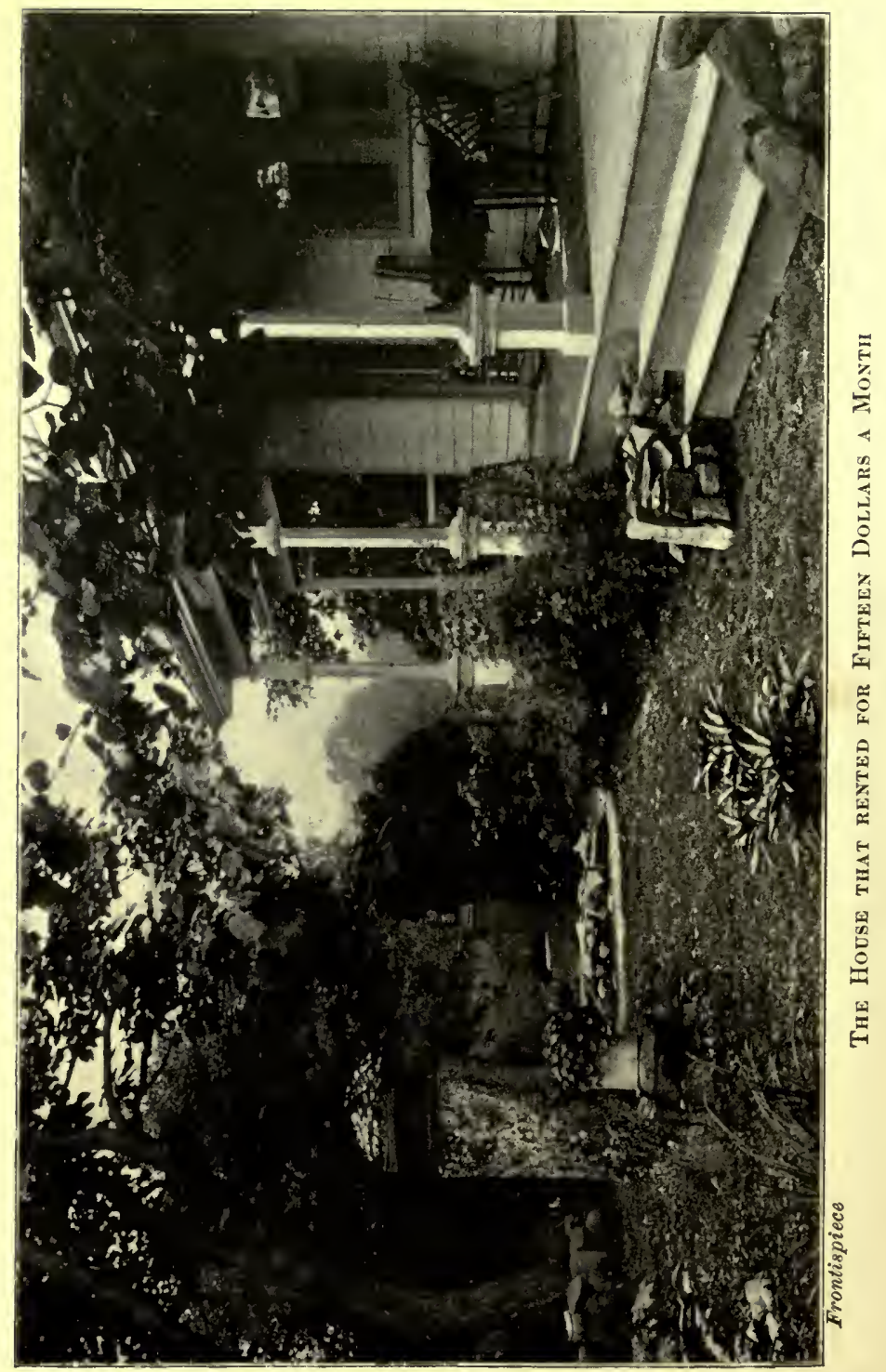




\title{
A \\ SELF-SUPPORTING HOME
}

\author{
BY \\ KATE V. SAINT MAUR
}

WITH MANY ILLUSTRATIONS FROM

PHOTOGRAPHS

\author{
Toem 19ork \\ THE MACMILLAN COMPANY \\ LONDON: MACMULLAN \& CO., LTD. \\ 1905 \\ All rights reserved
}


Coptright, 1904-1905,
by pearson pUblishing co.

Copyright, 1905,

By THE MACMILLAN COMPANY.

Set up and electrotyped. Published November, Igo'5. 


\section{CONTENTS}

CHAPTER I

The origin of the farm - What was reared the first summer - Cost and profit - The accident that established pet stock - Considering the pros and cons of a country life-Suggestions for finding the home - Things which must be bought before leaving the city . .

\section{CHAPTER II}

\section{OCTOBER}

Putting the out-buildings in order - Renovating the poultry-house - Whitewash - Roosting frame - Nest boxes - Space required by hens - Quarantine coops - Barrels as grain bins - Mixing grains - Feeding - Drinking tubs - The cow - Points for buying Learning to milk . $\quad$. $\quad$. . . . 16

\section{CHAPTER III NOVEMBER}

Imperial Pekin ducks - Dry-goods case as a coop - Gathering the eggs - Ponds not necessary - Feed for laying ducks - Pigeons - How to house, mate, feed, and general care - Homers the best breed for squab raising - Scratching material and nuts for poultry 


\section{CONTENTS}

- Selecting the ground for next year's garden PAGE Trimming the orchard-Tending to small fruits Pruning grapes - Covering strawberry beds - The asparagus bed - Rhubarb for cellar forcing - Storing celery and other vegetables - Preparing potting mould

\section{CHAPTER IV}

\section{DECEMBER}

The cow stable - Home-made improvements - Winter feeding - The care of milk and utensils - Churning - The horse as a Christmas present-How I learned to hitch up-Choosing a family horse - Feed, stabling, and grooming - Rabbits - Making the hutches, breeding, and feed - Correct way to handle - Caring for the little ones - Mushrooms in a cellar - Compost for beds - Hints for salads . . . . .

\section{CHAPTER V}

\section{JANUARY}

The honey-bee - Purchasing a colony and hive - Swarming - Smoking - The government of the hive - The age of bees - The queen, mother of the hive - The nuptial flight - Wintering bees - The poultry-yard; making up breeding flocks - Alternating males Chemical analysis of the egg - Balanced rations Guinea-fowls; their market value-Housing and feeding - Finding a nest - Setting the eggs under common hens - Special brood coops - A lost babyFeeding the little ones - How to cook . . 


\section{CONTENTS}

\section{CHAPTER VI}

\section{FEBRUARY}

The incubator - Setting it up on arrival - Correct adjust-

ment - Heating and regulating - Testing eggs Hay instead of roosts for cold nights - Making brood coops, drinking fountains, feed troughs - Planning the garden - List of seeds, vegetable and flower Nursery boxes - Starting flower seeds and potatoes in the house - Hastening rhubarb and asparagus in the garden

\section{CHAPTER VII}

\section{MARCH}

My first experience with incubator chicks - Brooders; advantage of individual machines - Preparing for the motherless babies - Food for the first twenty days - Setting hens - How to know a broody hen Removing from the chicken-house to special coop for the period of incubation - Removing the babies Placing Mrs. Biddy and her family in the brood coop - The right consistency of mould for ploughing Transplanting seedlings to larger boxes - Starting tender vegetables in the house - Planting potatoes; how to cut the tubers - Buying and setting out dormant trees

\section{CHAPTER VIII}

\section{APRIL}

Launcelot Gobbo, our first gander - Geese : breeding, feeding, hatching - Care of goslings and young ducks vii 


\section{CONTENTS}

Young ducks for market; how to catch, avoid frightening - Changing diet for hens - Special whitewash for fruit trees and fences - Spraying fruit trees Bordeaux mixture - Planting vegetable seeds; distance of rows and depth - Bedding out hardy vegetable plants - Uncovering strawberries - The herb bed - Preparing the ground in flower garden . .

\section{CHAPTER IX}

\section{MAY}

Turkeys - Serviceable suggestions gathered on a large breeding farm - Personal experience of feeding, hatching, and rearing the young - Importance of caring for growing chicks - Weight of chicks - Separating flocks for market and stock - Feeding young pullets - The cow and calf - Weaning an unnecessary cruelty - Rearing the calf - Bedding out tender vegetables - Looking-glasses in the cherry trees Starting an asparagus bed - Field corn - Trees in the chicken yards - Setting out house plants in the flower garden

\section{CHAPTER X}

\section{JUNE}

Pheasants - Different breeds - Enclosures, feeding, mating - Bantam hens as foster-mothers - Killing and dressing poultry - Artificial method of fattening in use abroad - The effect of food on flavor-How to pluck, draw, and truss birds for table - Commencing 


\section{CONTENTS}

to sow succession crops in the vegetable garden -

The advantage of the hand plough and cultivatorSulphur for grape vines - Caring for the spring bulbs after flowering is over . . . . . .

\section{CHAPTER XI}

\section{JULY}

Cats of high degree - Home cattery - Mother cats - Kittens - Vermin that attacks poultry; how to prevent and exterminate - Moulting, hastening and aiding, effect on egg production - Increasing the currant and berry patch - Sowing crimson clover for poultry Renovating the orchard ground - Cow peas and clover to eke out the poor hay crop

\section{CHAPTER XII}

\section{AUGUST}

Preparing fowls for the show-room - Washing white birds - Crating and shipping - Capons - My first lesson and last attempt - Their use as foster-mothers Water-cress; starting beds and forcing for winterPlanting new strawberry beds - Some hardy vegetables - Harvesting onions - Planting bulbs in the garden for next year-Starting bulbs in the house to bloom for Christmas - Taking slips from geraniums and other plants . . . . . . . .

\section{CHAPTER XIII}

\section{SEPTEMBER}

Collecting green food for the poultry during the winterBuying new cockerels - Sorting and mating young ix 


\section{CONTENTS}

pigeons - Building up the business side of a farm -

PAGE

How to ship eggs - The new chicken-house-The pig; its sty and general care - Gathering apples and storing for winter use - Hot-bed and cold frame .

\section{CHAPTER XIV \\ POULTRY AILMENTS}

Roup, bronchitis, canker, influenza, all kindred illsGapes; prevention and cure-Scaly legs - How to prevent feather pulling - Cholera - Indigestion Crop bound - Eye troubles - An old cure for gapes . 313

\section{CHAPTER XV}

\section{VEGETABLES FOR TABLE AND HEALTH}

Squash cutlets - Irish stew - Mock duck - Furmity Okra - Pot-cheese, plain and savory - Potato cheese cakes - Curd cheese cakes - Honey cake - Honey drink -Generalities . . . . . . . 


\section{ILLUSTRATIONS}

The House that rented for Fifteen Dollars a Month Frontispiece PACINE RAGE

The Fireplace .

The First Hen ("Mrs. Perry") - Just turned out into

Brood Coop . . . . . . . . . 12

Sheds made into a Chicken Yard . . . . . 21

Powdering a New Arrival . . . . . . 28

Pair of White Wyandottes . . . . . . . . 33

A Fine Coop for Little Chicks . . . . . . 37

A Fine Flock . . . . . . . . . . 44

Yards for Pigeons . . . . . . . . . 48

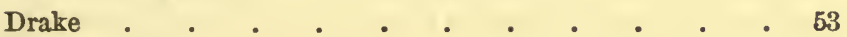

Winter Quarters . . . . . . . . 60

The Right Way to squeeze out the Buttermilk . . $\quad$. 65

Ploughing-Currying . . • • • • • . 69

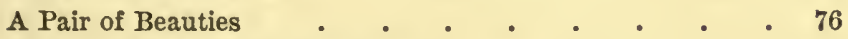

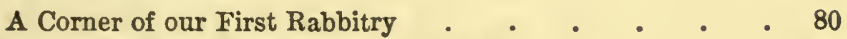

Jacko, who comes and goes as he Likes . . . $\quad$. 85

Looking for the Queen . . . . . . . 92

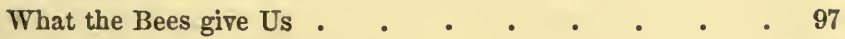

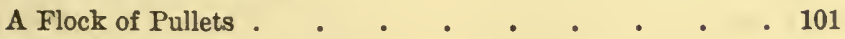

A Pair of White Guinea-fowl . . . . . . 108

Market Birds hatched by Hens and as Tame as their Fostermothers 


\section{ILLUSTRATIONS}

A Sturdy Pair of Plymouth Rocks . . . . . . 117

The Head Herdsman . . . . . . . . 124

Single and Double Brooder House . . . . . . 145

Interior of Sectional Brooder House, One Hundred Feet Long,

heated by Hot Water, used on Large Broiler Plants 160

Father of his Flock . . . . . . . . . 165

Launcelot and his Perturbed Spouse . . . . . 172

Launcelot Gobbo the Wonderful . . . . . . 181

The Right Sort of Pool for Ducks . . • • . 188

Gathering Dandelion Salad . . . . . . . 193

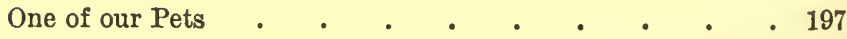

Brooder Yards . . . . . . . . . 204

Feeding - Going to Pasture . . . . . . . 208

Colonizing Plan . . . . . . . . . 213

Pheasant Enclosure . . . . . . . 220

Ring-neck Pheasant . . . . . . . . 229

Useful Coops for Hens and Chicks (Rough Shelters for keep-

ing off Noon-day Sun later in the Season) . . . 236

The Fox Terrier that came to Visit-Tabitha . . . 245

Argent Splendor (a Superb Specimen of his Kind) - Kliner . 252

Mowing down a Weedy Patch for Bedding . . . . 261

A Pretty Corner near the House . . . . . . 268

The Beehives in August . . . . . . . . 277

Vegetables for Dinner . . . . . . . . 284

October • . . • • • • • • . . . 289

Twelve-dozen Egg Box . . . . . . . . 293

Breeding House for Hens . . . . . . 300

The Pigeon Yard . . . . . . . . 304

Pleasure and Business . $. \quad . \quad$. . . 312 
A SELF-SUPPORTING HOME 



\section{A SELF-SUPPORTING HOME}

\section{CHAPTER I}

A SELF-SUPPORTING country home A for persons whose income depends on personal effort within the heart of a great city will seem a Utopian dream unless I relate my personal experiences as to its practical value, which commenced ten years ago. Up to that time I had been a city woman, striving, like hundreds of others, to maintain appearances on a housekeeping allowance which needed coaxing over every little bump of hospitality, to induce the two ends to meet. Through all the petty warfare of bad times, one desire, one hope, was paramount - a country home where plenty should make visitors an unalloyed pleasure. Chance, Fate, Providence, or whatever name is preferred for the Power which shapes our ends, led me to the Pet Stock and Poultry Show, and there it suddenly 


\section{A SELF-SUPPORTING HOME}

occurred to me that, instead of waiting for the acquisition of fortune to realize the desire, the desire might be made to help acquire some of the fortune. It was such a comfortable, invigorating inspiration that it enthused away all the obstacles suggested by a cautious husband, and his consent was won on condition that current expenses were not increased, or capital risked.

An advertisement was inserted in a Sunday paper for a small farm not more than twentyfive miles out, or more than one mile from a depot. At least a dozen real estate agents answered, assuring us that they had exactly what we required. Being unfamiliar with the capacity and fertility of the imaginations of these gentlemen, our faith was great until we had inspected seven or eight wretched places, utterly unlike any ideal home. Then we became convinced that the real estate business undoubtedly affects mental vision and veracity.

However, we eventually discovered a dear 


\section{A SELF-SUPPORTING HOME}

old house of nine rooms, two cellars, a summer kitchen, barn, chicken-house, cow shed, small smoke-house, and twelve acres of land, five of which were covered with apple trees. Near the house were three pear trees, four peach, three quinces, two plum trees, and about half an acre divided between strawberry plants, blackberry and raspberry bushes. It was the haven of our imagination, and could be leased for three years at $\$ 180$ a year, so that, even after $\$ 6$ a month had been added for my husband's commutation ticket, there was still a surplus of $\$ 19$ from the rent of the apartment we. were occupying in town, which, of course, was to be used to defray moving expenses and purchase of stock. The latter commenced with the acquisition of an old Plymouth Rock hen, which my nearest neighbor sold me for fifty cents, because, as she put it:-

"The plaguy thing wanted to set afore weather was settled enough to be bothered with chicks." 


\section{A SELF-SUPPORTING HOME}

I thought differently, and "Mrs. Perry," as we christened her, became the founder of my poultry farm by presenting me with nine strong little chicks out of the thirteen eggs I set her on. Five more broody biddies were bought, and by the end of March I had sixtyseven chicks. During the summer there was an addition of fifteen varied mongrels, and one hundred and forty-eight chicks were raised. The cost of the hens was $\$ 10$, eggs for setting $\$ 5$, feed from August to March $\$ 4$; total outlay, $\$ 19$.

On the credit side, ninety chicks were sold as broilers, realizing $\$ 22$. . So the profit was $\$ 3$ in cash, with fifty-eight pullets for stock, as well as eggs for our own table from May. Ducks commenced, as did everything else, in a very small way; but they were real Imperial Pekins, two ducks and a drake, acquired the second week in March. Their laying started on March 20; and as these birds take all their rest during the winter, paying their board every day with an egg 


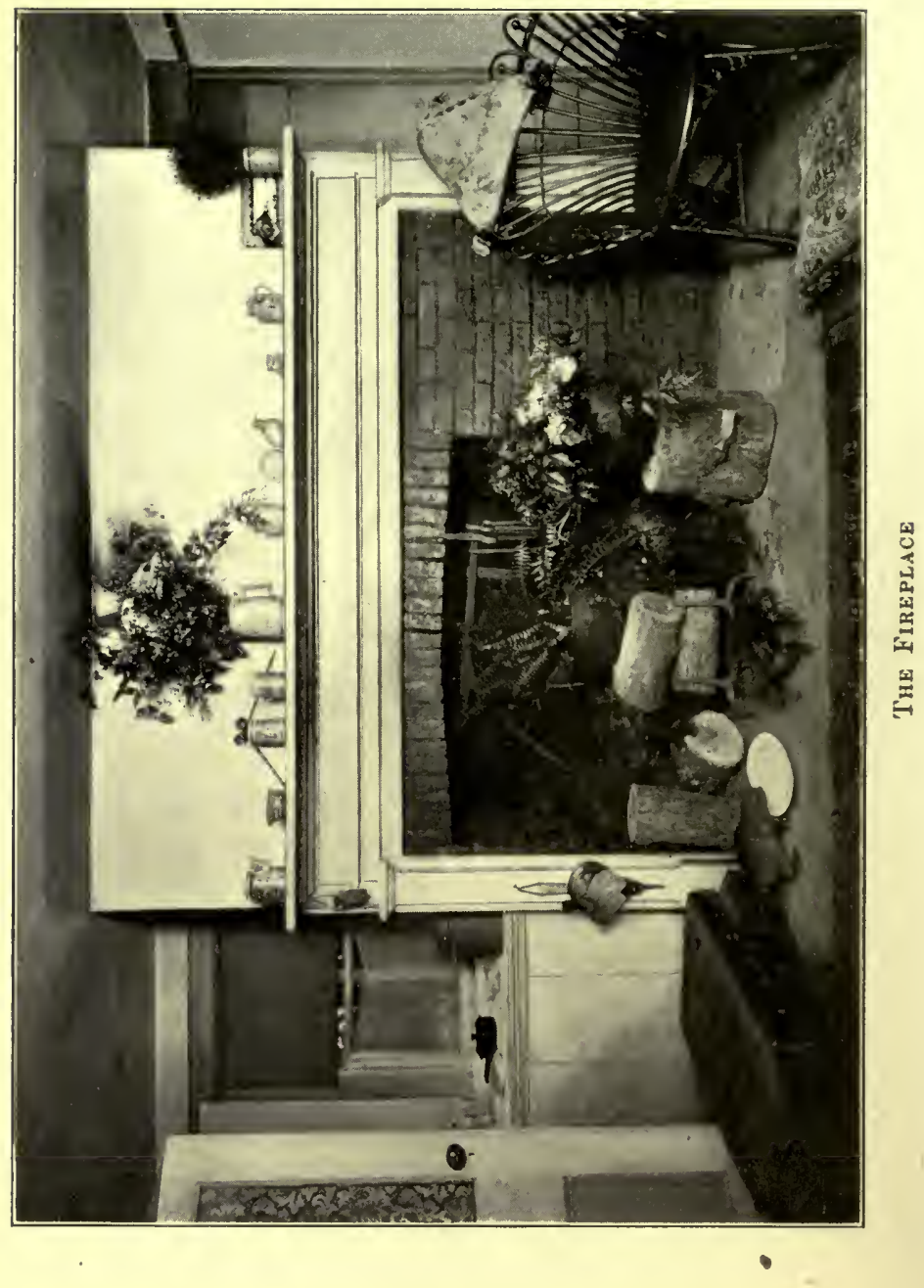




\section{A SELF-SUPPORTING HOME}

through the early summer, by the 26th I had the requisite eleven to put under a hen for hatching, the first ten having been used for cooking.

On June 30, when my ducklings were nine weeks old, a man drove in and offered to buy them at eighteen cents a pound. There were sixteen about the same age; their weight tallied up forty-four pounds, netting me \$7.92.

By November, thirty more had been sold, twelve being retained for stock.

The cost of feeding cannot be given with exactness because no separate account was kept $-\$ 20$ would certainly cover it. The originals cost $\$ 4.50$, so profit on the investment amounted to nearly $\$ 30$.

Three guinea-fowls became my property for a dollar and a half - the owner was anxious to be rid of them. We raised thirtytwo. Six pairs sold, at six months old, at a dollar a pair: we used ten for our own table - they are delicious, very like game; eight were retained for stock. 


\section{A SELF-SUPPORTING HOME}

In April we made our garden. Seeds, including a barrel of potatoes, cost $\$ 10$. May 17 we had radishes, lettuce, and young onions. June 7 new potatoes and green peas graced our table. From that time in quick succession came turnips, beets, cabbage, carrots, sweet corn, melons, okra, cucumbers, beans, tomatoes, and squash, all so delicious in their crisp, cool flavor, unspoiled by packing or travelling, that we became almost vegetarians; but so bountiful was the supply that the surplus, when canned and stored, was sufficient to carry us through the winter. The rhubarb gave us fruit pies in April, after which came cherries, strawberries, raspberries, currants, blackberries, peaches, apples, and pears - all we could use, and plenty to "put up." In fact, with April, living expenses became lighter each week, for many of our rest hours were devoted to fishing on the river which ran through the orchard; the spoils making a pleasant change for breakfast, and 


\section{A SELF-SUPPORTING HOME}

an additional reduction in the butcher's bill.

By October the savings from these sources alone enabled me to gratify my great desire for a cow. The day of her arrival was the advent of the real farm home, which gave the blessed feeling of independent sufficiency. Cereals, hitherto eaten as a sort of duty, became tempting luxuries when surrounded by real cream.

With April also started the pet stock branch of our farming, which will appeal to many women who cannot possibly alter their lives enough to start a chicken farm. We had two Maltese cats and a white rabbit, merely as pets. Early in February, Graykins had four kittens, all of which had been kept because they were so pretty, and Graykins was so fond of them. I had not the heart to consign them to the usual watery grave. About the same time, Bunny had six little pink-eyed babies; but their becoming the foundation of a pet stock business was quite an accident. In fact, these little people 


\section{A SELF-SUPPORTING HOME}

had not received much thought, for I had my first incubator at the time, and the care and attention it demanded shut out all else. (I was rewarded by getting seventy-four little chicks out of ninety eggs.)

The day after they were out, I went up to the city to do a day's shopping before starting the incubator again. Near the ferry, having to pass an animal store, I stopped to look at some puppies in the window; and as I did so, a man opened the door, and I heard him say to the one inside:

"Now don't forget. I must have those little chickens and rabbits by Wednesday morning."

The storekeeper replied, "If I can, sir; but they're hard to get at this time of year."

Before I realized what I was doing, I turned into the store and announced to the astonished man that I had just what he wanted. He at once said:-

"I will give you $\$ 20$ a hundred for white chickens, and 75 cents apiece for young rabbits." 


\section{A SELF-SUPPORTING HOME}

So it was arranged that I should send up fifty chicks and six baby rabbits, for which he would give me $\$ 14.50$. Then, as a sudden thought, he remarked:-

"You don't happen to have any Maltese kittens, do you?"

"Yes; four," I replied.

"Well, I'll give you a dollar each for them."

I said he could have three, for of course I couldn't take all of Graykins' kittens away from her at once.

That $\$ 17.50$ was invested in Peruvian cavies and two more white rabbits, so starting pets as money-makers. By spending merely the money saved through the production of the home, on the home, it became entirely self-supporting by the seventeenth month. Three months later there was a surplus profit each month - not much, certainly, but enough to prove that we had the foundation of a business in our home, should we at any time become entirely dependent upon it. 


\section{A SELF-SUPPORTING HOME}

Think of a family enjoying the comfort of a large house instead of a small apartment, leading a happy, healthy life, exempt from the wear and tear of the city rush and noise - surely an enviable condition under any circumstances. When you realize that all these comforts enabled us, after the first year and a half, to bank the sum previously absorbed by living expenses, you will understand my enthusiasm on the subject of a country home for people of moderate means, which you might have received with doubt, had not this summary of facts been given to prove conclusively what can be accomplished in a short time without capital.

Before deciding to embrace a country life it will be well to consider the pros and cons. The average city man may dread becoming a commuter; but when he realizes the enjoyment and rest found on a comfortable seat in a moderately filled car, the standing, crushed strap-hold of the elevated train will scarcely be regretted. 


\section{A SELF-SUPPORTING HOME}

Children's education is the next "obstacle." Every village has a school, some extremely good; all possess the advantage of not being overcrowded. When the little one has outgrown the village curriculum, at an average distance of ten miles in any of the adjoining districts will be found the high school or college. All suburban lines issue school tickets at extremely low rates. It being conceded that full mental development is impossible unless accompanied by physical and moral growth, the pure air and wholesome freedom of the country must make the best men and women of your children.

The entire category of supposed drawbacks is replaced by benefits and values too numerous to be catalogued here.

October and November are always delightfully bright months, just cold enough to make tramping about in the country vastly enjoyable, and should therefore be utilized for finding and fixing the future home. It is also the best and cheapest time 


\section{A SELF-SUPPORTING HOME}

to purchase birds, fodder, etc., - poultrymen and farmers are anxious to reduce expenses and economize space before real cold weather sets in. Another advantage in moving then, is that roads are in good condition and teamsters are not busy.

A good plan is to study maps of the surrounding country within twenty miles of the city; select a few villages, then write to the station agent or postmaster in each, stating plainly just what size place is required, requesting him to hand the letter to any one having such a farm for rent or sale. Country officials are usually well posted and obliging. When making appointments through the mail to visit places, do so two or three days in advance to insure being met. Farmers seldom send to the village for mail every day.

Every woman, of course, has individual tastes to be considered in selecting a home, so my only suggestion will be this : do not expect or desire modern improvements in a cheap farm-house; they are a snare and a 12 


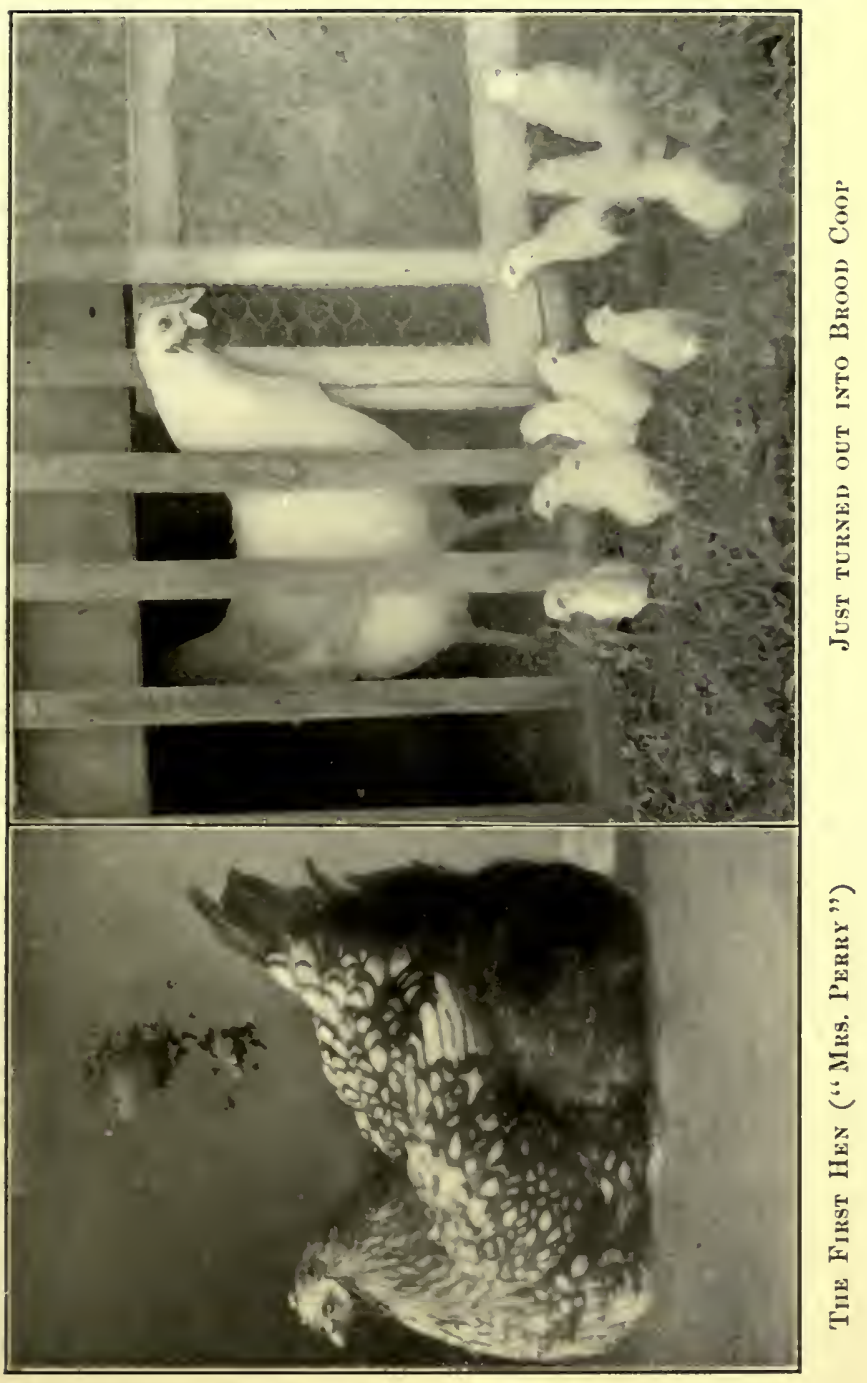





\section{A SELF-SUPPORTING HOME}

delusion, invariably a never ending expense and menace to health. An abundant supply of water, not merely good, but "without fear and without reproach," is essential. Your inquiries about the well cannot be too careful.

The ideal poultry-farm has sandy soil sloping to the south, or southwest, standing well away from neighbors. To a self-supporting home there must be an orchard, cow pasture, strip of woodland, and the ordinary farm buildings.

A lease should have a renewal or purchase clause, and the right to cut small or dead wood for repairing, fencing, and for fuel. Of course this does not mean sacrificing timber, or any power to sell it. Also it must be understood that the right to remove chicken-houses or other buildings you may erect during your tenancy, belongs to you.

Before leaving the city, certain additions to the household belongings should be made as follows:- 


\section{A SELF-SUPPORTING HOME}

A portable bath-tub, lamps, stoves, washtubs, and such tools as are indispensable spade, long-handled shovel, pick, grub-hoe, rake, two saws, scythe, sickle, axe, big hammer, screw-driver, chisel, gimlet, and wheelbarrow.

During my first year of poultry raising, like most amateurs I craved reliable information, and bought, borrowed, and begged many books, so-called authorities on the subject. There was always a page, when there were not several, devoted to each breed of hens. In each case it was the best breed (only there was a reason why it was better not to keep it), lengthy dissertations on the value of protein, carbohydrates, cellulose, in a nutritive ratio in feeds - all very learned and clever, of extreme value to the experienced poultryman, but mere confusing jargon to the uninstructed. Remembering this, my great desire will be to make these monthly schedules of work simple and drastically plain, stating exact quantity, quality, 


\section{A SELF-SUPPORTING HOME}

and methods found by personal experience to be safe and useful - a sort of necessary foundation on which the layman can build knowledge as gleaned from individual experience. 


\section{CHAPTER II}

\section{OCTOBER}

DREsuming the selection is made and

1 the ordeal of moving over, the practical side of the work can now claim attention.

Go over all the buildings carefully. A loose board or rotten stable floor, a jagged point to some projecting post, a loose facing to a manger, are all trifling matters needing only a few minutes' work to fix, but neglected may cause serious accidents. See that all the doors fasten easily and securely.

The chicken-house is usually a dilapidated, dark shed, needing thorough renovation. Commence by having the old roosting poles and nests torn out and burned at once. Do not let them be left lying about. Ceiling and sides must be swept with a stiff broom; corners, ledges, all crevices, well scraped to 


\section{A SELF-SUPPORTING HOME}

remove accumulated dust and dirt. If the floor is earth, half a foot must be scraped off, the surface carted to a remote part of the farm, and scattered broadcast. It is excellent fertilizer for the garden; but as the previous occupants of the chicken-house may not have been healthy, it is safer not to leave it where your birds can scratch in it. Get a quart of crude carbolic acid and mix it with three gallons of naphtha - needless to say, these commodities must be kept in closed cans in an outside shed, secure from children or fire. Take out about a quart at a time, in an open pail into which a brush can be dipped. The interior of the house is to be thoroughly painted over with this mixture, swishing it well into corners. Scatter quicklime on the floor; shut the door and leave the place alone for twelve hours.

Unless it is an exceptionally well-built house, the outside will have to be covered all over with two-ply tar paper, or the red roofing paper, whichever is preferred. In 


\section{A SELF-SUPPORTING HOME}

calculating the quantity required, remember that the dealer's quotation of feet in a roll, is of square, not running feet; therefore a roll of two hundred and fifty feet of the usual yard width would only be about eighty-two lineal feet.

Choose a dry day without frost; start at the bottom, using the caps and nails which are specially made for the purpose; some makers send out sufficient for each roll and include it in the prices quoted. Each row must be allowed to lap over the edge of the preceding one, two inches. Fit up snugly under the eaves of the roof, or, if it is even with the sides, allow ample overlappings; otherwise slanting, beating rains will find a vulnerable spot and cause trouble. Whatever the size of the building, have the greater part of the south or southwest exposure, glass. Ordinary-sized sashes can be bought in or near every village, and are best fixed in grooves top and bottom, because then the whole sash can be pushed back and out of 18 


\section{A SELF-SUPPORTING HOME}

the way on fine days. On the outside, cover the opening with wire netting.

After the exterior of the poultry-house is put into good repair, the interior must be considered.

If the floor appears damp, have a thick layer of stones laid over it before filling in clean earth in place of the surface scraped away. It must be levelled and well stamped down; when finished, the floor must be a foot above the outer ground.

Put a quart of unslaked lime into an ordinary-sized galvanized pail; pour on it enough boiling water to come about three inches below the lime; don't disturb it, and in a few minutes it will boil and bubble; then, with a long piece of stick, stir it into a smooth paste, to which more boiling water is to be added until it is about the consistency of thin cream. Half a small cup of crude carbolic acid and a similar-sized cup of kerosene are then to be stirred into it. This completes a whitewash which, when applied while hot to the 19 


\section{A SELF-SUPPORTING HOME}

walls and ceiling of the chicken-house, makes it wholesomely clean. When this is done, have a platform three feet wide run across the back, or end, of the house, two feet from the floor.

Get hardwood slats four inches wide by two inches thick; from these construct a frame eighteen inches wide and.six inches shorter than the length of the platform. At each corner of this frame put a nine-inch leg. This frame, when stood upon the platform, makes two roosts which, being on the same level, prevent the birds fighting and crowding upon one another, as they always do when the roosts slant, each bird desiring to be on the top rung.

If the house is to accommodate twelve hens, provide six nests a foot square, made in groups of three, with legs a foot high; they are easily handled and removed for housecleaning. Stand them in the darkest and most secluded part of the house. Put a handful of hay and a china nest-egg in 



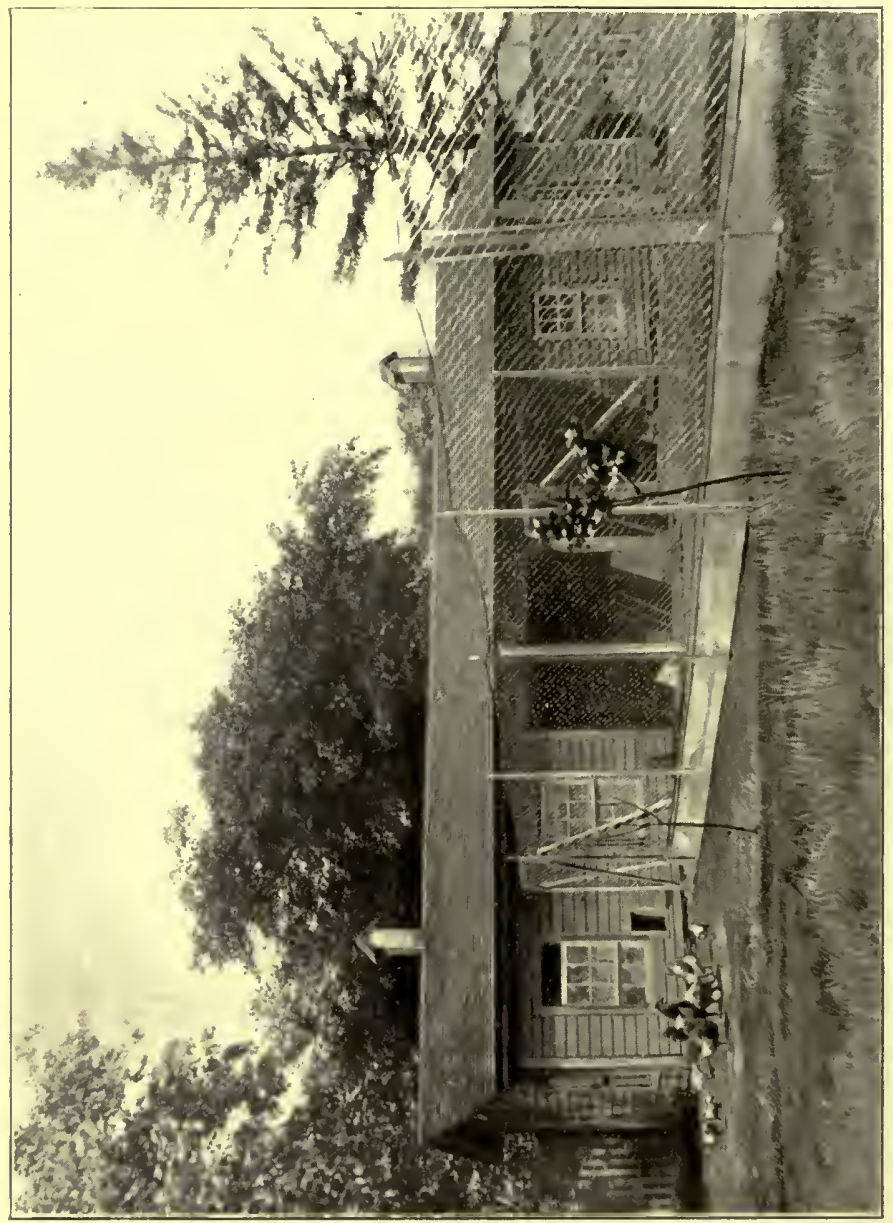

 


\section{A SELF-SUPPORTING HOME}

each. Scatter dry sand, earth, fine ashes, or sawdust on the platform, to prevent the droppings from adhering to the boards; it facilitates cleaning. The entire floor space is finally to be covered five or six inches deep with straw cut a foot in length, common bedding hay, or dried leaves.

The yard is best in front of the house. Straight poles about eleven inches in circumference and eight feet long, cut from the woods, or four-by-four spruce scantling, inserted two feet in the ground and six feet apart, constitute the foundation on which to stretch the wire netting. Make a door into the yard, using very light poles or slats for the foundation and, of course, covering it with wire. Run a baseboard from post to post, and above it two-inch mesh galvanized wire netting, five feet wide. Yards for a house accommodating twelve birds should be at least fifty feet long and ten feet wide.

If time or the restriction on expenditure prohibits the platform, nests, etc., they can 


\section{A SELF-SUPPORTING HOME}

be dispensed with for a time by standing the roosting frame on the floor, taking the precaution to have plenty of the scratching material under it; empty grocery boxes can be substituted for the made nests. Nail the netting as low down on the posts as possible, if baseboards are not used, and throw earth all around the outside. Even the roosting frame could be made from straight saplings.

The cleaning, whitewashing, and making storm-proof must be in no way slighted. Cleanliness, freedom from draught and damp, are essential conditions which must be established before genuine work can be accomplished.

There are some twenty-five distinct breeds of fowls - domestic fowls, that is. Furthermore, there are four or five varieties of each chronicled in the "American Standard of Perfection," as qualified to compete at poultry shows. But as practical utility is the keynote to be struck in establishing a 


\section{A SELF-SUPPORTING HOME}

self-supporting home, the lists must be reduced to those birds which are the best as marketable commodities. In this list will be found Brahmas, Plymouth Rocks, Wyandottes, Rhode Island Reds, and Leghorns. After experimenting with all these and many others, the White Wyandotte, in my opinion, reigns supreme as queen of the "general purposes hen." They are good winter layers, mature early, and either as broilers or roasters are excellent. Having small bones and being of round, compact build, they have plump breasts even at twelve weeks old. Their feathers are worth nearly as much as ducks'. Lastly, they are kept in bonds by a fence only four feet high.

Honesty demands the admission that Plymouth Rocks and Rhode Island Reds are excellent birds; so that my choice is a purely personal matter. Brahmas, having a larger frame, do not make such good broilers. As young roasters they are delicious; but once fully matured, they cannot compare 


\section{A SELF-SUPPORTING HOME}

with the smaller birds as egg producers. Leghorns, which are the great layers in a warm climate, must have the best of housing to keep up their reputation in the East and West during the cold weather, when eggs bring the best prices. A fence ten or twelve feet high is required to control them. This adds materially to the yarding expenses.

A mixed flock of barnyard chickens should not be considered for a moment, because it is impossible to select any rations suited to varied constitutional demands. Brahmas and all the heavy birds will make internal fat, retarding egg production, on rations that would merely keep Leghorns in good condition. This is one of the main reasons why ordinary farmers declare that chickens don't pay, while poultrymen state that they are the most profitable stock.

Wyandotte hens between one and two years old, of good market quality, can be bought for a dollar each; and as you want the eggs this first season principally for hatch- 


\section{A SELF-SUPPORTING HOME}

ing, they will be better than this year's birds, which cost more. The number must be regulated by the size of the chicken-house. Every fifteen birds require twelve by twelve feet of floor space. It is better to have ten birds well cared for than twenty in crowded quarters.

Two cockerels (the name which distinguishes roosters under one year old) will have to be bought in January, when the eggs are to be used for hatching, but are not necessary at first. Before the birds arrive, get two large, empty cases from the grocery store. Remove the boards from the top of each, and make a lid of slats and wire netting. Put hinges, four inches from each end, at the back, and a catch to fasten it down in front, to convert the boxes into coops. Stand them in some outbuilding, light and airy in the daytime, but which can be closely shut up at night. They must be whitewashed inside, and have a perch across the centre, and two or three inches of sand, 


\section{A SELF-SUPPORTING HOME}

dry earth, or ashes on the bottom. These places are for quarantine coops, in which new birds can be segregated, until the necessary precautions have been effected. Fill a flour dredger with any good insect powder; take each bird by the legs, hold it head down, and powder thoroughly, especially in the soft feathers around the thighs and tail; then put it into the coop, where the birds are to be kept for two or three days, during which time they should be powdered every night, to insure their being free from vermin when placed in the chicken-house. Care in always observing this rule saves much future work, and protects the premises from contamination.

The plan of establishing the country house without capital forbids the building of a feed house until success and natural growth compel properly constructed accommodation; which will be the next fall. Until that time, some makeshift must be fixed up; for it is annoying - well-nigh impossible - to have 26 


\section{A SELF-SUPPORTING HOME}

things scattered all over the place. (The summer kitchen was old, and inconveniently far from the house, on my first place, so I used that.)

Inexpensive bins to keep the different grains in can be made from sugar barrels, costing ten cents at the village store. Square lids to cover the whole top are easily fixed. A coat of tar on the outside will make it so slippery, rats and mice can't run up the sides; and rodents dislike tar so much, they won't gnaw through it. With a white distinguishing number on the front of each barrel, they look quite tidy and businesslike. Wherever they stand, put bricks or blocks of wood underneath so that the air can circulate; thus avoiding dampness, which will cause the contents to mildew. When the barrels are ready, buy a bag each of ground feed (oats and corn), white middlings (sometimes called screenings), bran, linseed meal, animal meal, whole corn, and a bale of clover hay. 


\section{A SELF-SUPPORTING HOME}

Before beginning to mix the grains, make yourself a large apron with long sleeves, and a cap that will cover your head all over. The dust clings to hair and clothes like flour, and is difficult to brush off.

Start operations by putting into a dry dish pan two quarts of ground feed and bran and one quart of animal meal. Mix thoroughly with your hands, and empty into barrel number one; repeat until all the materials are used. This is to form the foundation of mash number one.

Now put two quarts of middlings and one quart of linseed into the dish pan, and mix thoroughly. Put the mixture into barrel number two, repeating as before, till all these ingredients are used. This is mash number two. A saucepan with a close-fitting lid, that will hold five or ten quarts, according to the number of hens, is needed for the mashes.

To prepare mash number one, take from barrel number one, one quart of the mixture 28 


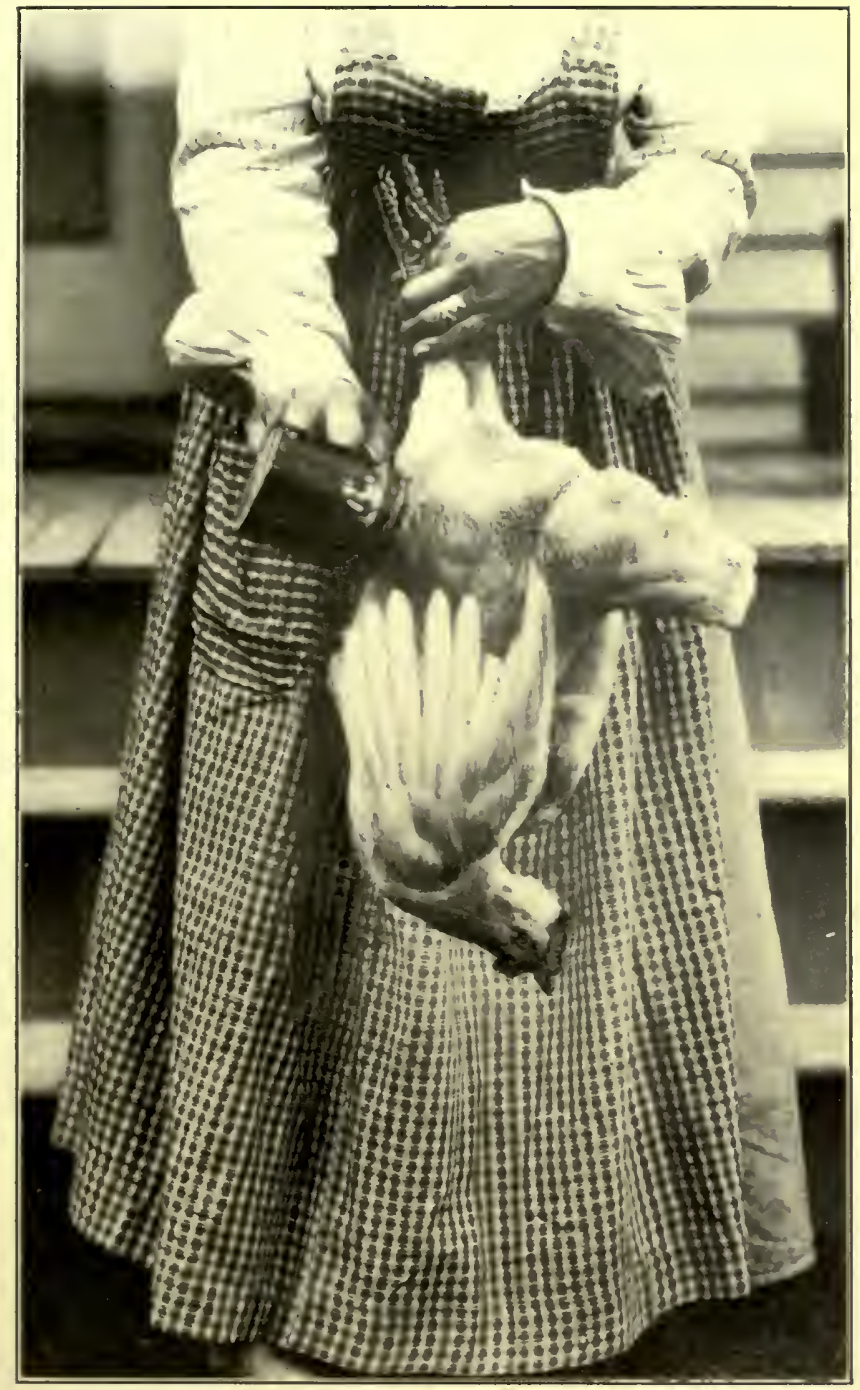

Powderixg a NeW Arrival 



\section{A SELF-SUPPORTING HOME}

for every ten hens. Put it in the saucepan, and just moisten with boiling water - really boiling. Cover, and stand behind the stove until the morning.

Mash number two: one quart of clover hay, cut into half-inch lengths. Place in the saucepan, and pour a quart of boiling water over it. Cover, and stand on back of stove to steam for two hours. Then add a pint of the contents of barrel number two, and let it stand until the morning.

BILL OF FARE FOR TEN HENS

Monday, Wednesday, and Friday mornings, mash number one, with half a pint of millet seed, scattered in the leaves or whatever there is on the floor of the chickenhouse; noon, chopped vegetables; night, a pint of whole corn and a pint of oats.

Tuesday, Thursday, and Saturday mornings, mash number two; noon, cut green corn and half a pint of Kafir-corn, to scratch 


\section{A SELF-SUPPORTING HOME}

for; night, one pint of wheat, one pint of corn.

Sunday morning, mash number one and half a pint of barley; noon, cabbage or turnips cut in halves and fixed between stones to hold them in position and enable the hens to pick out the soft inner part. The noon meal is often omitted on Sunday; and on Monday morning wheat and cracked corn, or barley, are frequently used instead of mash, to save mixing on Sunday night.

The above quantities are those generally accepted for ten birds, but it is impossible to do more than approximate the needs of any unknown flock. The best plan for the novice is to put down the mash and see how much they will eat in twelve minutes, and thereafter give about half the quantity; for their crops should not be filled in the morning, as they must be kept busy all day, scratching and hunting for food. At suppertime, on the contrary, they need all they can eat; especially at the time of the year when 


\section{A SELF-SUPPORTING HOME}

the nights are long and cold. Feed slowly; stop and see that each hen has a fair share. The mash must be just warm, never hot. Feed should be placed in zinc pans or troughs. If these are not procurable, pieces of smooth board three inches wide and two feet long, nailed together lengthways, and a piece four by five inches across each end, make handy little troughs without expense.

By the way, can you use a hammer and saw? If not, start in to learn from any handy boy you know; for a chicken woman must be able to make and mend things. The "stitch in time saves nine" adage must have been created on a farm.

Green cut bone may need an explanation. It means fresh bones from the butcher's, ground in a hand-mill specially made for the purpose, and costing from $\$ 7$ to $\$ 20$, according to size. It is one of the most valuable egg producers known; one pound is sufficient for sixteen hens. When there are very few birds, table scraps can take the place of 


\section{A SELF-SUPPORTING HOME}

animal meal; especially if a piece of raw liver is nailed up in the house once or twice a week for them to peck at.

Have a box about a foot deep and two square, filled once a week with road dust or fine ashes, put in a sunny place for the birds to dust themselves in; also a small one, filled with sharp grit. Hens have no teeth, and must have something to take their place. Neglecting to provide birds with this and green food is the reason why so many amateurs say hens don't thrive when confined to the yards. If there is a stone-crusher in your neighborhood, the smallest-sized stone, such as is used for garden paths, makes a fine substitute for the regular poultry grit. If you have a small boy, he can get an afternoon's fun smashing up all the broken crockery and glass, to aid Biddy's digestion.

There are a variety of drinking fountains sold for so little that it is a pity not to have a few. Still, I couldn't at first, and found that, for the large houses, a butter tub thor- 



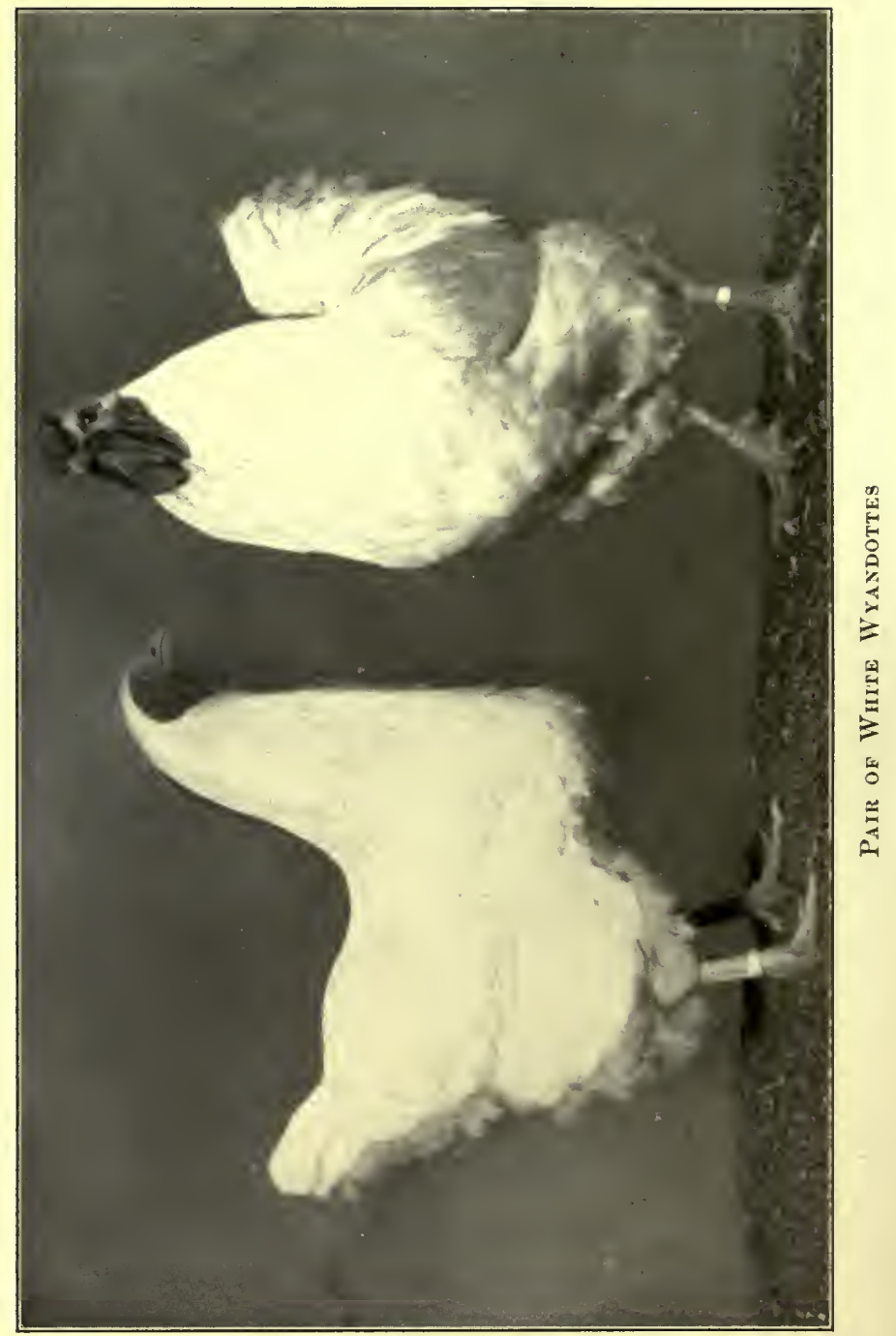




\section{A SELF-SUPPORTING HOME}

oughly cleaned out, and with a square hole three inches by three, cut half-way up on one side, is a good makeshift; for the halftub holds four quarts of water, and Biddy can drink very comfortably out of the hole.

A cat is a much better safeguard against rats and mice than the

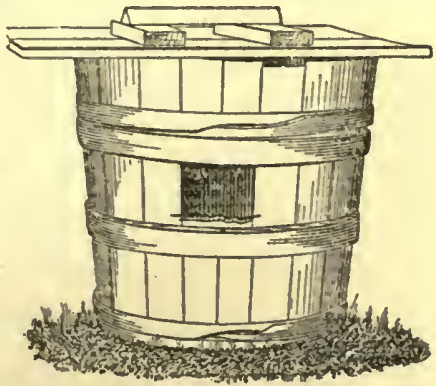
best trap; so keep a good Maltese in the feed house, and another in the barn. Pretty kittens sell for fifty cents, or a dollar, each.

\section{THE FAMILY COW}

Every country place should have its cow; she is the very foundation of its comfort. If you doubt it, just look through the cookery book. Is there any nice, appetizing dish for breakfast, dinner, tea, or supper that does not require milk, butter, or cream? 


\section{A SELF-SUPPORTING HOME}

If you purpose keeping poultry for profit, skim-milk figures largely as a factor in raising little chicks, and fattening birds for table use. In fact, the country home without a cow, is like a coach without horses - so hopelessly stuck does the housekeeper become who tries to provide a varied bill of fare without dairy produce. Away from city markets, a cow is a downright necessity. An ordinarily good. specimen will cost $\$ 40$ or so. Feed during winter, if it must all be bought, will cost perhaps a dollar a week. Feed from April to September will cost nothing, if you have good pasture land.

For the first six months, she will give you ten to twelve quarts of milk a day. After allowing half that amount to be consumed by the family, there will be sufficient cream from the remainder to make five or six pounds of good butter each week. The sour milk, when creamed, makes pot cheese, - otherwise known as cottage cheese, - enjoyed as much by the family as by the poultry. 


\section{A SELF-SUPPORTING HOME}

Even the buttermilk should be treasured, for it has digestive and blood-purifying qualities, of much greater value than half of the patent medicines.

For three months before calving, the milk supply diminishes. It is well to allow the cow to go dry for four or five weeks; but even this apparent loss is covered by the value of the calf. For family use, the Jersey is undoubtedly the best animal, because the milk is so much richer.

\section{POINTS ABOUT BUYING}

A cow with her first calf does not give as much milk as after the second and third; so she can be bought cheaper than when she has reached her maximum yield. A small family can make money if they buy a young cow, and sell her after her third calf, when they should get at least $\$ 15$ more for her than she cost originally. A cow's age can be told by the rings or ridges on the horns, 


\section{A SELF-SUPPORTING HOME}

one appearing for each calf. Choose an animal that has a straight back, big, soft eyes, a rather short face, and a long, thin tail.

The best cow in the world can be spoiled by bad or careless milking; so be sure that you are taught this process by some reliable person. A man who has a milk route would be a good selection, because he is in constant practice. Two or three lessons will give you the theory and method; nothing but practice can make perfect. Watch the milkman closely and carefully, three or four times, and obtain a thorough idea of "how it's done." Thereafter, repetition will enable you to conduct the operation with ease to yourself, and comfort to your animal. Never hurry. Be sure the bag is quite empty; otherwise, you will get less milk every day.

When we first moved into the country, a farm-hand was established on the place. Then we looked around, found a cow, and bought her. The very day she arrived, the man's dignity was offended in some way, 36 



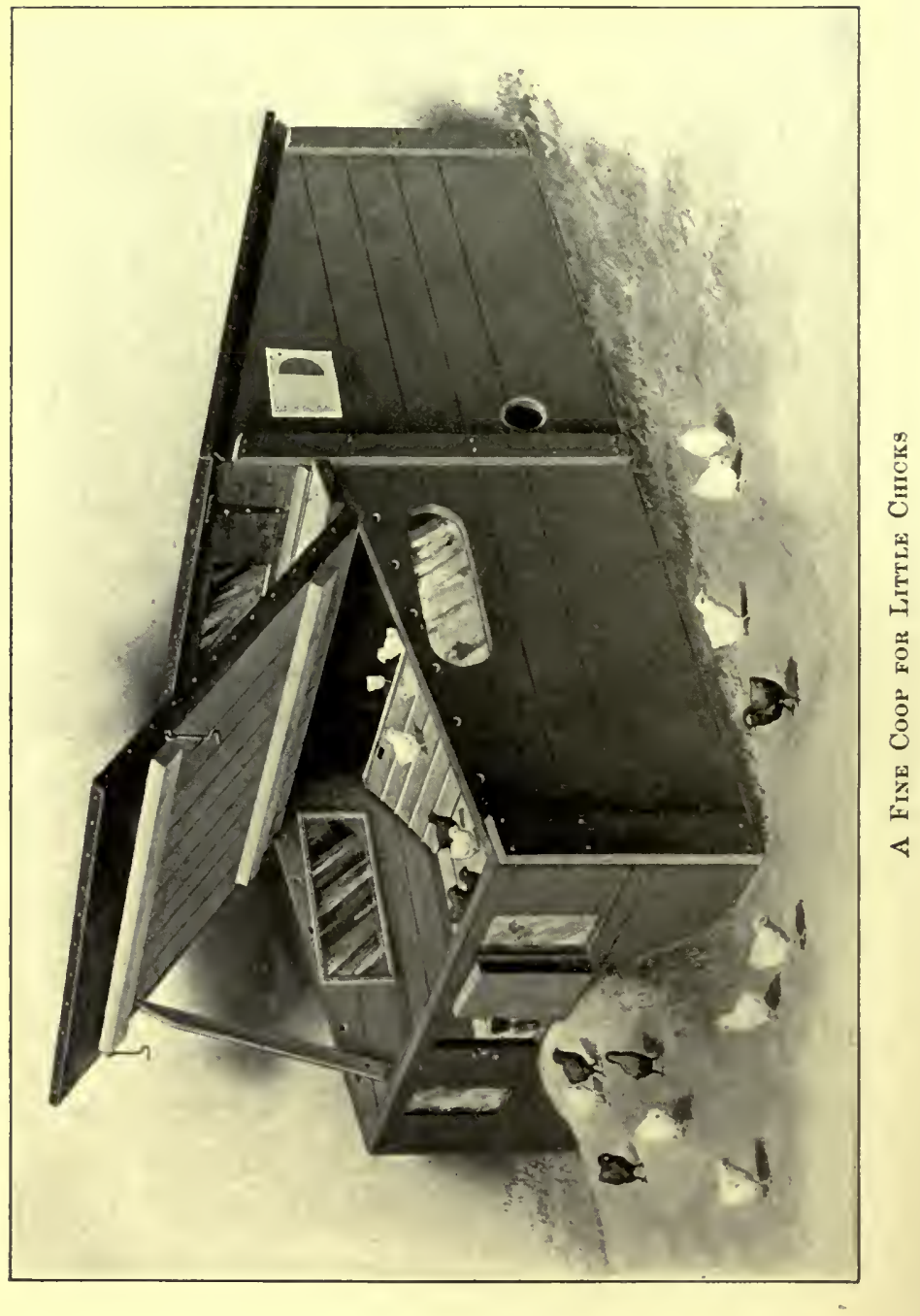




\section{A SELF-SUPPORTING HOME}

and he took his departure. I had seen persons milk, and felt sure it was easy enough; so triumphantly marched up to the barn at six o'clock, sat myself down close to "Cush" (who suddenly seemed to have grown very large), tucked the pail between my knees, and grasping a teat in each hand, proceeded to perform an up-and-down movement perfectly familiar from frequent observation, and - not a single drop of milk rewarded my courageous efforts. My astonishment was great, as the pushing and pulling continued without result. The poor cow's was greater. Why she did not forcibly protest is a mystery. When the perspiration was pouring down my face, and my arms were aching as if $\mathrm{I}$ had been rowing upstream for hours, I looked round and found Rachel (the cow) gazing at me with such a bewildered, pitying expression, that it made me laugh; and I suppose I released the tension of hand and arm, for the milk started to trickle into the pail; and, though it was a 


\section{A SELF-SUPPORTING HOME}

tedious process, it ended satisfactorily for us humans. Fortunately, Rachel could not proclaim her opinion.

Though it took me some time to make milking as easy as it looked, it was never again the torture of the first attempt; and it has always been a source of keen satisfaction to me, that accident compelled me to master actual knowledge of so important a detail of farm duty. 


\section{CHAPTER III}

\section{NOVEMBER}

TF your memory of ducks is of the old1 fashioned "puddler" which spent all its time grubbing in the mud and mire of the creek, wandering far from home, dropping its eggs promiscuously everywhere to feed water rats, and eventually ending an unprofitable life a prey to some carnivorous animal, the Imperial Pekin Duck will be a revelation in its size and beauty. They are almost as large as geese, with plumage which is white, deepening to rich cream at the quill, and bright yellow bills and legs. In fact, they look just what they are - the aristocrats of the duck species. At ten weeks old they weigh from five to six pounds, bringing an average price of 18 cents a pound. Their addition to the farm is not a serious con39 


\section{A SELF-SUPPOR'TING HOME}

sideration, because, beyond the first outlay for birds, there is little expense.

An old shed will do quite well for their home; or, if you have not one to spare, 50 cents will buy a large dry-goods box from the store in your village, which can be converted into a good, serviceable coop - five birds need only three by four floor space. Turn such a case on its side; put two strips of four by four quartering across the bottom, to keep it from the damp of the earth; rip off the top, and cut the ends diagonally across from front to back, so that when the top is replaced, you have a roof with a pitch of half a foot; then take the strips of board that formed the original top (now the front of your coop), and fit them together evenly on the workbench; or, if you haven't arrived at that masculine dignity, the kitchen table. Measure and cut two lengths of single slats to fit across; nail on boards six inches from each end, to form cleats to hold all the pieces together, and form a solid door for the front 


\section{A SELF-SUPPORTING HOME}

of the coop. Cut an opening nine inches square on one side, and fasten the other side to the roof by hinges (strips of leather will answer for hinges). In this way it can be turned back on the roof for convenience when cleaning the coop, and on fine days to let in the sun. Unless it is a very good box, it had better be covered with roofing paper or a coat of tar, to insure a total absence of leaks.

Whatever the house is, it must have clean, dry straw, or some sort of bedding about a foot deep on the floor, renewed every three days. It is not much use to put in nests, for ducks seem to prefer dropping their eggs around anywhere. Put one box, not more than three inches from the floor, in a corner, with a china egg. It will sometimes attract them.

Under any circumstances, care must be exercised in gathering eggs, for ducks generally lay very early in the morning. An egg frozen or badly chilled will not hatch. 


\section{A SELF-SUPPORTING HOME}

Another need for care is necessitated by their habit of laying all over the coop and covering the eggs with straw, leaves, or whatever the floor litter may be. Until I became used to the trick, many were crushed underfoot. If you are going to let the ducks have free range, keep them cooped till about nine A.M., or you will lose their eggs.

A yard fifty feet long and ten wide will be sufficiently large to provide exercise for a small, breeding flock; and the wire netting need only be eighteen inches high, which will not cost more than $\$ 1.50$. Though the fence need not be high, it must be very securely fastened to the ground; for ducks seem to possess abnormal powers when it comes to creeping under anything.

A trio of good, ordinary market stock should be purchasable for about $\$ 7$. Ducks are not like hens - they do not lay all the year round; but when they start, they are attentive to the business of egg production daily, so that a couple of mature Pekins 


\section{A SELF-SUPPORTING HOME}

will provide you with a sitting in six days. As you will want to keep some of the young ones for next year's stock, ask the breeder you buy from to ship you birds two years old, as their progeny is stronger.

Pekins never want to sit; so hens must be used for hatching, until your stock is large enough to fill an incubator in a few days. Artificial duck raising is without doubt the best. There is one farm in Massachusetts that markets forty-five thousand young ducks annually, sells two tons of feathers, and keeps twelve hundred breeders! Would such an immense business be possible in the old way?

Though Pekins don't need water to swim in, they must have quantities to drink, always fresh and clean; which means that drinking pans must be refilled three times a day, and be so constructed as to enable the bird to submerge the whole bill in the water. Why? Because there are two small holes at the base of the bill, which become clogged with feed or mud; and unless they can rinse 


\section{A SELF-SUPPORTING HOME}

these out when drinking, the poor things smother.

A man who had a broiler farm near our place, three years ago, bought a hundred ducks' eggs, hatched out a fine lot of youngsters, and lost every one within two weeks, through using a water fountain in the brooder that was too shallow. As I had lots of ducks at the time, he brought some over for me to see. There was nothing whatever the matter with them, except that their little nostrils were all stopped up with the soft food. So pray remember this very important direction, when you are arranging drinking water for ducks, young or old; they must not be able to get into the pan with their feet or bodies, but their entire, heads must have free entrance.

\section{FEED FOR LAYING DUCKS}

For five ducks take one quart of bran, a pint and a quarter of corn meal, half a pint of beef scraps, one quart of cut clover, and 


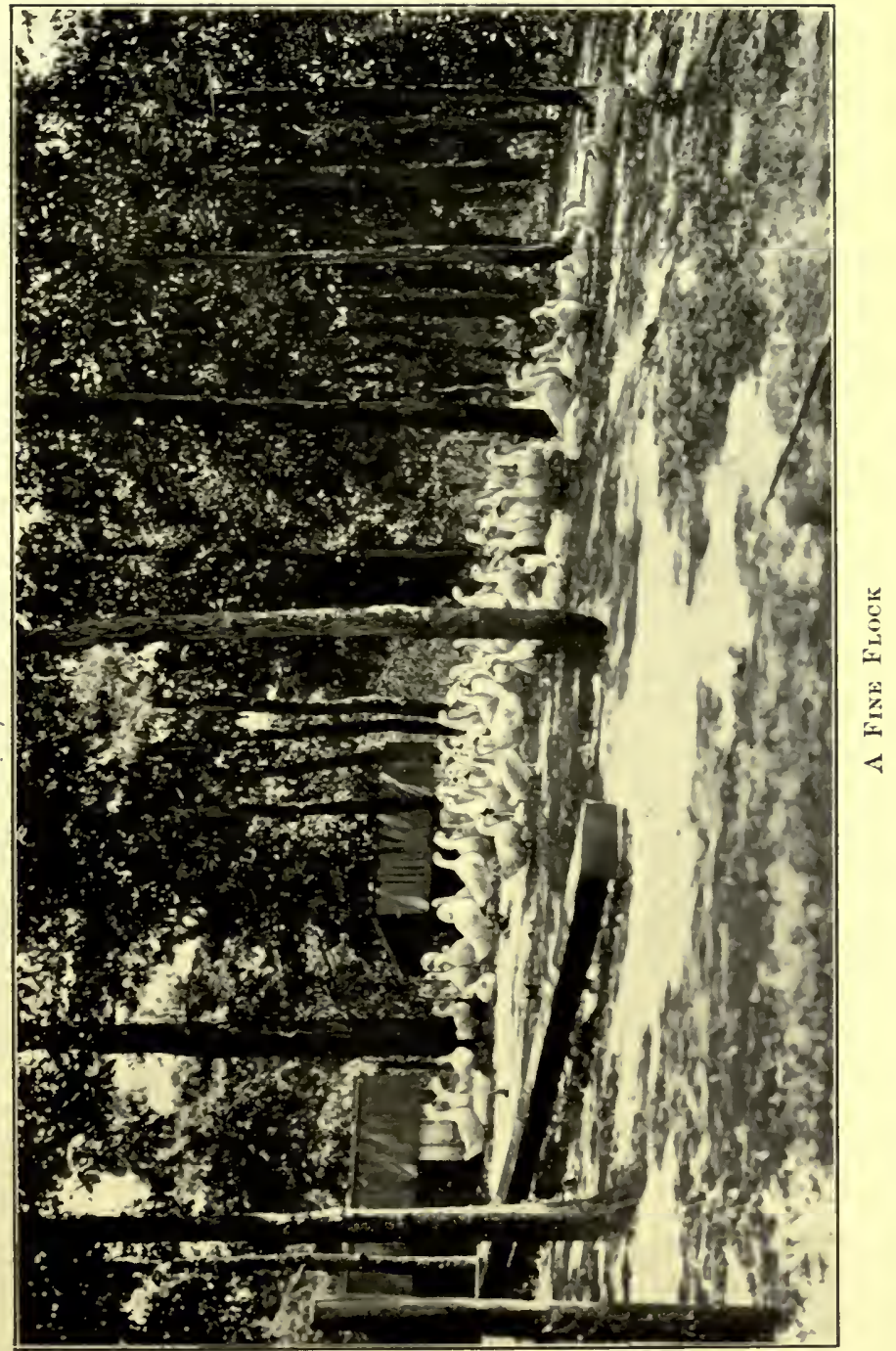





\section{A SELF-SUPPORTING HOME}

half a pint of grit. Scald the clover and steam the same as for hens. Add the other ingredients, giving them the mixture just warm, and a little softer than you would for hens, night and morning. Cut vegetables at noon, unless they are on free range amongst brush and grass; in which case, halve the night and morning rations, and give nothing at noon after April 15.

\section{THE RAISING OF PIGEONS}

There is a constant demand for squabs in all the large markets. During the winter they will bring 40 cents a pair, if you have private customers. Even the wholesale prices range from $\$ 3$ to $\$ 4$ a dozen. The average estimate for feed is 50 cents a year for each pair of breeders; that will give you at least twelve squabs in that time. Calculate for yourself and see if it will not pay.

Use of the old-fashioned row of holes, and nest boxes nailed to the side of the barn, into 


\section{A SELF-SUPPOR'TING HOME}

which every storm beats, entirely prohibits any breeding in the winter. Even in the summer many young ones are sacrificed to the elements.

To insure a profitable return, pigeons must be adequately cared for. A small house, built almost like chicken quarters, eight by twelve, with a yard as long and as high as the cash to be expended on wire netting permits, will accommodate twenty-five pairs. There must be a window facing south; and two feet from the roof in front, an opening two feet long and one high, with an eightinch board running along it inside and out, as a platform for the birds to rest on. This opening should have a shutter to close on very cold nights.

For inside fittings provide small boxes two feet long (empty egg crates are just the thing, the dividing partitions being already there), an eight-inch platform running in front, or a perch extending a foot out in front of each compartment. These individual 


\section{A SELF-SUPPORTING HOME}

houses must be arranged two feet apart all around the walls, about three feet from the floor. Put up two or three roosts in the middle of the floor. Whitewash everything thoroughly, and, when dry, put an earthen nest in each compartment. They cost a dollar a dozen, and are better than any contrivance, because they are so easily kept clean. Cover the floor with gravel. Have a good drinking fountain, into which the birds can get nothing but their bills. Add a pan about two feet square and four inches deep as a bath-tub, to be used in the house in winter, and in the yard in summer. A bundle of hay and straw is advisable; some homers are ambitious and like to make their own nests. Have the ground in their yard ploughed or dug up, fix a few general perches, and all is complete.

You may ask, "Why not fix up the loft over the stable?" Simply because that would necessitate such a high yard that it would cost more than the small house, and 


\section{A SELF-SUPPORTING HOME}

be nothing like so convenient. Further, a covered yard is imperative, if you don't want to lose half your birds in seed and harvest time.

There are many breeds of pigeons, but, for squab raising, homers are quite the best. The young common pigeon weighs only six to eight ounces at market age, and is hard to sell at a dollar a dozen. The homer at the same age, weighs from twelve to twenty ounces, and is a plump, appetizing morsel that sells quickly. Good stock will cost \$2 a pair. Remem15 ber that it is no use to buy birds that are not mates, for pigeons remain in pairs for years unless separated, and if a couple are parted, they often refuse to mate again that season. One unmated male will break up most of the other couples; so be sure and deal with a very reliable person when purchasing your stock. Returns come so quickly, you can afford to be generous in your outlay. 


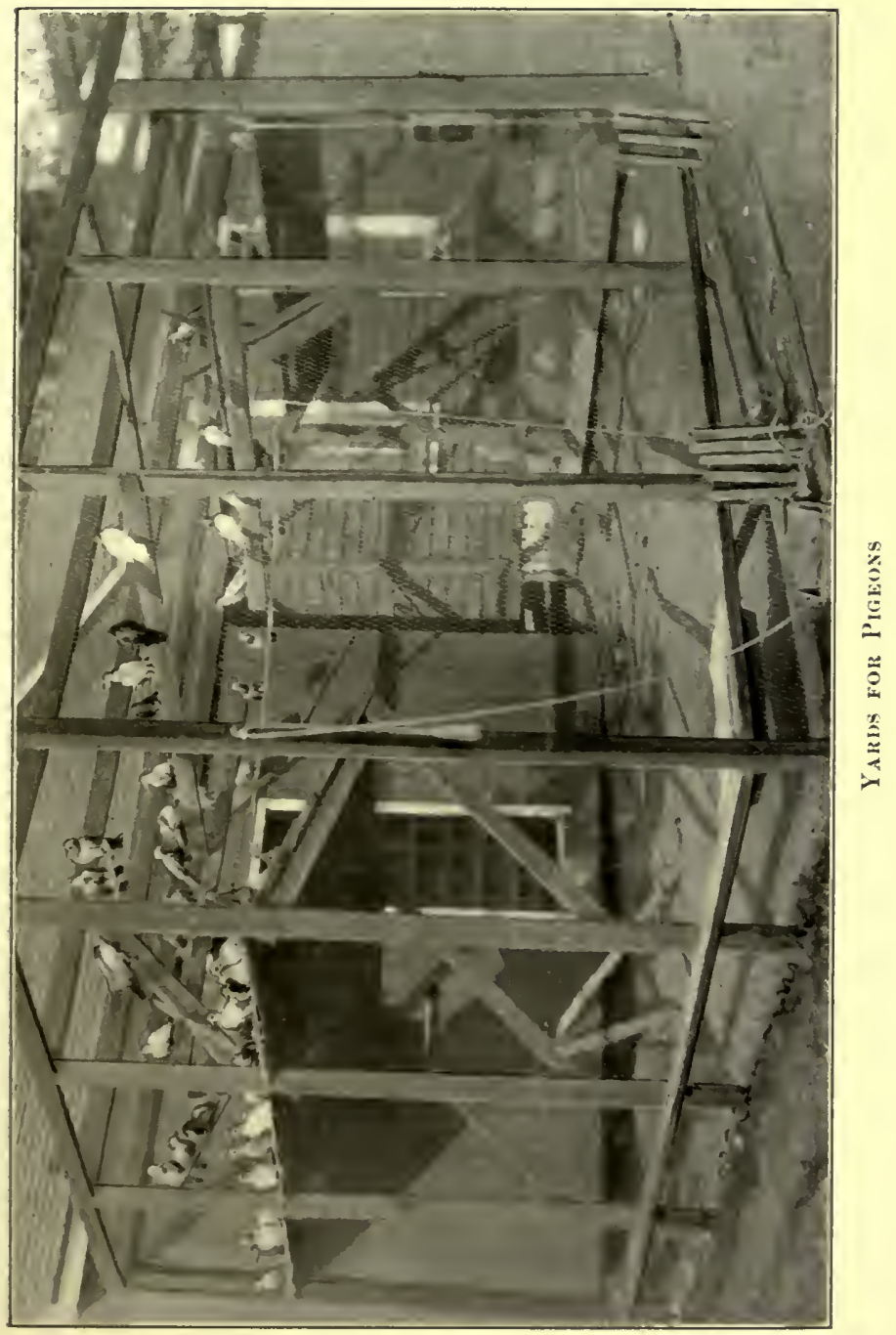





\section{A SELF-SUPPORTING HOME}

As soon as the pigeons become accustomed to their new quarters, the hen will lay two eggs, with a day between. Incubation takes eighteen days. Young squabs are marketable when thirty days old. Before then, the second nest has two eggs hatching by the mother bird. This is why it is necessary for each pair to have two nests.

Pigeons have one great advantage over other poultry for the amateur, they are among the few domestic fowls that feed their own young. Both male and female have the power to secrete a digestive substance, sometimes called " pigeon's milk," on which they feed the nestlings exclusively, at first, adding gradually hard grain, until the young are strong enough to find for themselves.

Feeding the old ones is quite a simple matter. Cracked corn, Canada peas, or Kafir-corn are all good for them; in fact, the three grains mixed and fed daily make a good staple diet. For other feeds, use wheat, hemp-seed, and, one day in the week, 


\section{A SELF-SUPPORTING HOME}

stale bread. Let there be plenty of grit with all the feed, and see that there is always a boxful in the yard and house, and another of broken-up rock-salt.

The house and nests must be kept absolutely clean. Go the rounds once a week and remove all droppings (to be carefully saved, of course, for fertilizing). Empty the bedding from each nest from which squabs have been taken, giving the earthen dish a wash in hot water and soda. Wash out the compartments the nests were in, with whitewash. When dry, return the nest to its place, and put a small handful of tobacco stems or pine needles into it. They make a soft foundation for the egg, and destroy vermin.

The laws in many states prohibit keeping game in cold storage or shipping quail to market. This makes squabs and young guinea-fowls in eager demand by clubs, hotels, and restaurants. If you start with two or three pairs, and keep all the progeny, you 50 


\section{A SELF-SUPPORTING HOME}

should have a goodly number by the following year, as they begin to breed at six months. I once read a calculation which went to prove that, all going well, twelve pairs of birds, at the end of a year, would have multiplied to nine hundred and sixty. An old squab raiser who never keeps less than eight hundred breeders declares that a thousand homers, correctly handled, will yield an annual income of $\$ 1200$.

Hens must be kept perpetually busy, or health and the egg-basket will suffer. Hence the necessity for a bountiful supply of clean material on the floors of their houses during cold weather, when most of their exercise must be taken under cover. Nothing induces so much activity and apparent enjoyment amongst the imprisoned flock, as a bagful of autumn leaves; so gathering and storing them should be among the first things to claim attention after settling on the farm. There are many bright days in November, when such work in the woods is pure delight. 


\section{A SELF-SUPPOR'TING HOME}

If black walnuts or butternuts are to be found, they will lend a real old-fashioned country touch to the Yule-log season. Don't remove the pithy green coats, for they preserve the nutty flavor, if left on until the nuts are required for use. Surplus nuts and pig hickories should all be collected, if time permits; for in midwinter they will afford the hens amusement, if crushed in the bone-mill and fed occasionally at noon.

Inquiry will reveal some farmer in the neighborhood, who has been growing cabbage in large quantities. $\mathrm{He}$ is sure to have a surplus load or two of heads too small for market, that can be bought at this season of the year for one-half the winter price. Hens need green food as much as grain. There are many-ways of storing, but we have found that packing in conical heaps, heads down, and protecting with leaves, or bedding-hay and brush, answers very well, if care is taken not to cover too heavily at first. It would be wise to interrogate the old residents in your 



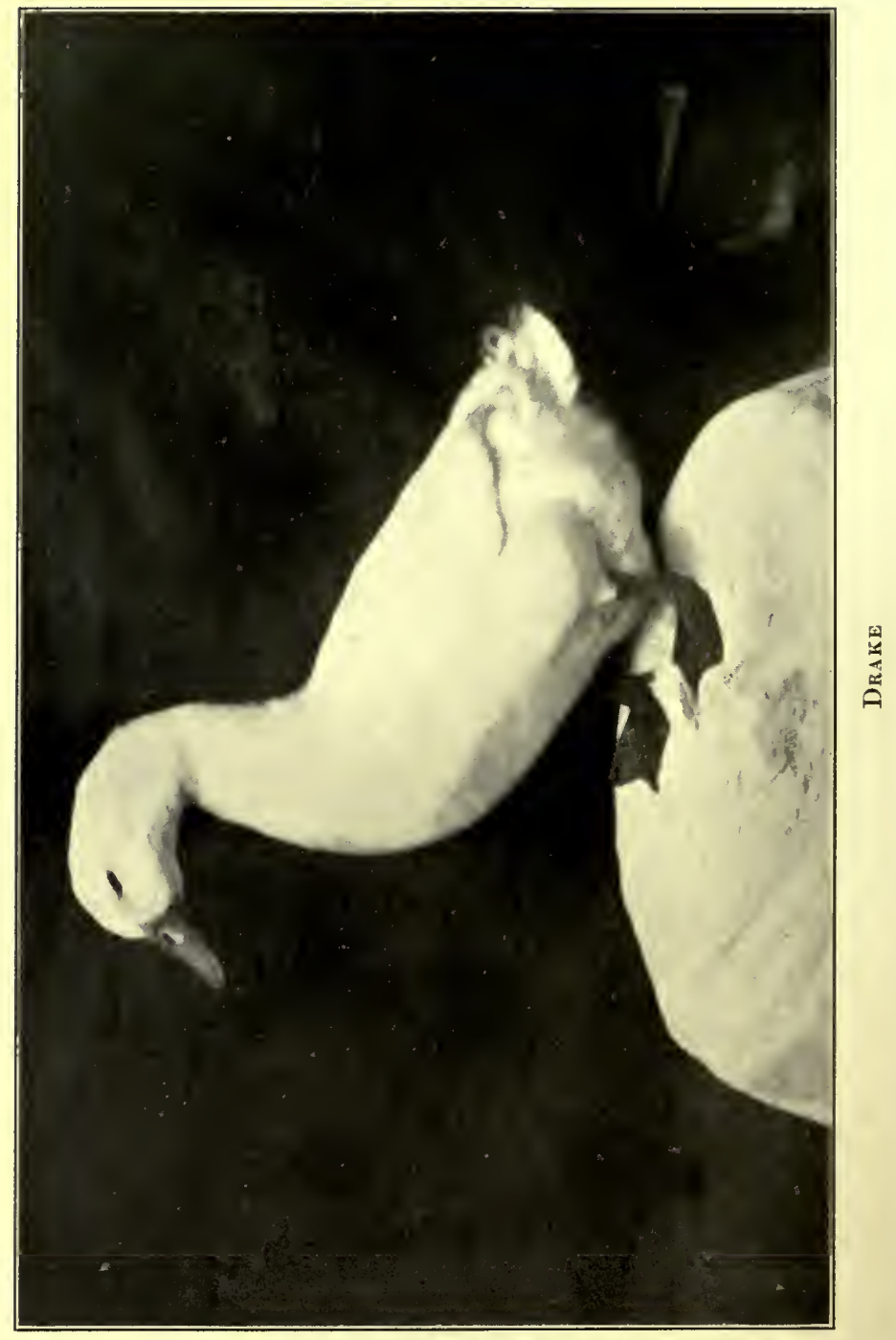




\section{A SELF-SUPPORTING HOME}

immediate neighborhood, as to method and season; for all such work as this must be controlled by climatical conditions, which, of course, vary in every state.

\section{THE GARDEN}

Few of the farms to be rented or bought cheaply have good vegetable gardens. If such is your experience, select a strip of land as conveniently situated to the house as suitability of ground will permit, and have it ploughed at once, so that the frost and air have an opportunity to disintegrate and mellow the clods of earth.

In choosing the site, remember that a slight slope to the south or southeast is desirable. Size must depend very much on whether you intend having a separate berry patch or not. A hundred feet by seventyfive feet will supply an average small family with vegetables for the table, excepting winter potatoes, which should come from the 53 


\section{A SELF-SUPPORTING HOME}

field crops. Protection from the northeast storms should be provided. Cedar or privet is the ideal hedge for such purposes, but it takes money and time; so, whilst it is developing, resort to the serviceable brush hurdle fence.

The fall ploughing should be deep, so as to open the subsoil. This applies to farm land, as well as to garden. It is also desirable to erect posts all around the ground, because there is more time now than in the spring, when a thousand things all clamor for attention at once. Moreover, the ground is in a better condition to dig and pack firmly around the posts, than in the spring, when perpetual alternation between frost and thaw is to be expected.

Orchard trees and small fruits may be trimmed as advantageously now as in the spring. Even the utterly inexperienced man or boy can go through the orchard and cut off sprouts or suckers around the trees, and on the trunks and main branches. Pruning needs practical knowledge; so the first year 


\section{A SELF-SUPPOR'TING HOME}

either employ a reliable man for a few days, or depend on the safe tidying referred to above. Blackberries and raspberries can be safely cut back to the conveniently controlled height of two and a half or three feet, and the old canes trimmed out, as both bear their fruit on the growth made in the spring. Grapes should retain the main or conducting stalk, for which arms one or two feet apart may be conducted on a trellis. Shoots from these arms should be cut back to about two inches, for it is the new growth from these on which the fruit will be borne. Currants and gooseberries must have any really oldlooking branches cut out, as only one- or two-year-old wood is fruitful.

November is too late to plant out new strawberry beds, but old ones will be improved by trimming the rows into uniform width and cultivating the earth between. Before the end of the month, cover the whole bed with hay or straw, and a few corn stalks or cedar boughs to keep it in place. 


\section{A SELF-SUPPORTING HOME}

If there is an asparagus bed, cut all the seed-stalks down, carry away, and burn at once. The ground between the rows will require spading well, levelling the earth down off the rows until not more than two inches is left on the asparagus crowns. Until two years ago we had followed the old-fashioned custom of protecting the beds with manure or straw; but a report of the good results obtained at the New Jersey Agricultural Experiment Station prompted our adopting the new method, which has been most satisfactory.

Rhubarb is nearly always to be found on a farm. Dig up the roots, if any one in the family has as yet inhaled enough pure air to provide the necessary strength to wield a grub-hoe; for nothing else can dislodge the huge, knobby boulders of what looks like iron ore, which many years of undisturbed growth creates. Leave them lying on the surface exposed to any frost that may visit you, for about a week. Then select a few 


\section{A SELF-SUPPORTING HOME}

moderate sized roots, and transfer to the cellar. We cut empty sugar barrels in half, arranged them in a dark corner of the cellar, placed the rhubarb roots in them, packing sand all around the root until the half-tub was full. Thus treated, they yielded a bountiful supply of stalks in January and February. The other roots can be split up into pieces about a foot square, and replanted two feet apart, in rows three feet apart.

Celery, carrots, and such vegetables for home use are best kept in wooden trenches ten inches wide and twelve inches deep, to be divided by a partition of wood every two or three feet; so preventing the vegetables heating, as they would if the entire length of the trench was left unbroken. We have one cellar lined by tiers of these receptacles. Dry, sandy mould, to the depth of about three inches, is put into the bottom of each for the roots to stand in, so keeping the stalks or tubers upright, as when growing. Pack as closely as possible, and the contents will 


\section{A SELF-SUPPORTING HOME}

last, firm and unwithered, until March. Egg or orange boxes can be utilized instead of making trenches, if they are well lined with newspapers.

Potting mould will be required in February, when it is difficult to procure unfrozen materials; so should be prepared now, and stored in barrels in the barn or cellar. Leafmould from the woods is excellent filling for seed boxes, but if distance and weight render it impracticable, make a compost of dried leaves, sod, earth, sand, and old stable droppings, a two-inch layer of each alternated until a depth of three feet is collected. Pack down tightly, water slightly, and leave for a week or so. Then work over with a manure fork, until very thoroughly mixed. Repeated two or three days, this will result in extremely good potting mould to store in your barrels until spring. 


\section{CHAPTER IV}

\section{DECEMBER}

TRY to buy the cow this month for two

1 reasons : first, a good cow which is going to calve in February or March will cost less than a poor one in March or April. Secondly, the yield of milk is on the decrease, making the night and morning task of emptying the udder easier for the amateur; and should it not be accomplished very completely it would not be a very serious catastrophe, as when the cow is in full milk.

Of course a perfect cow stable is impossible for a beginner without capital, but a very good sanitary stall can be arranged in an old stable for a few dollars. Our cow barn was a large shed with an open haymow above, and individual stalls for thirteen cows arranged along the back; the sides, half door, 


\section{A SELF-SUPPORTING HOME}

and ceiling of which were made of hardwood, so they were scoured with strong lye, and dried, shining examples of cleanliness. The floors were next graded half a foot to the back, where a gutter a foot wide and deep was built by inserting three boards below the surface, with a tile drain-pipe at the end, to conduct the liquid to a barrel which was to be sunk into the ground outside the shed. Scouring, grading, making the gutter, and sinking the barrel cost $\$ 3$, as a man was hired for two days.

The earth floor did not meet my ideas of cleanliness, and for a few days it puzzled and worried me. Then I read an account of how "stone" gate-posts could be made out of Portland cement. This suggested trying a coat for the stable floor. A bag of cement was bought, and I proceeded to "flag" my cow stable, and succeeded. To family and friends it seemed a wonderful accomplishment. Really, it was as easy and amusing an occupation as making mud pies in pinafore 60 


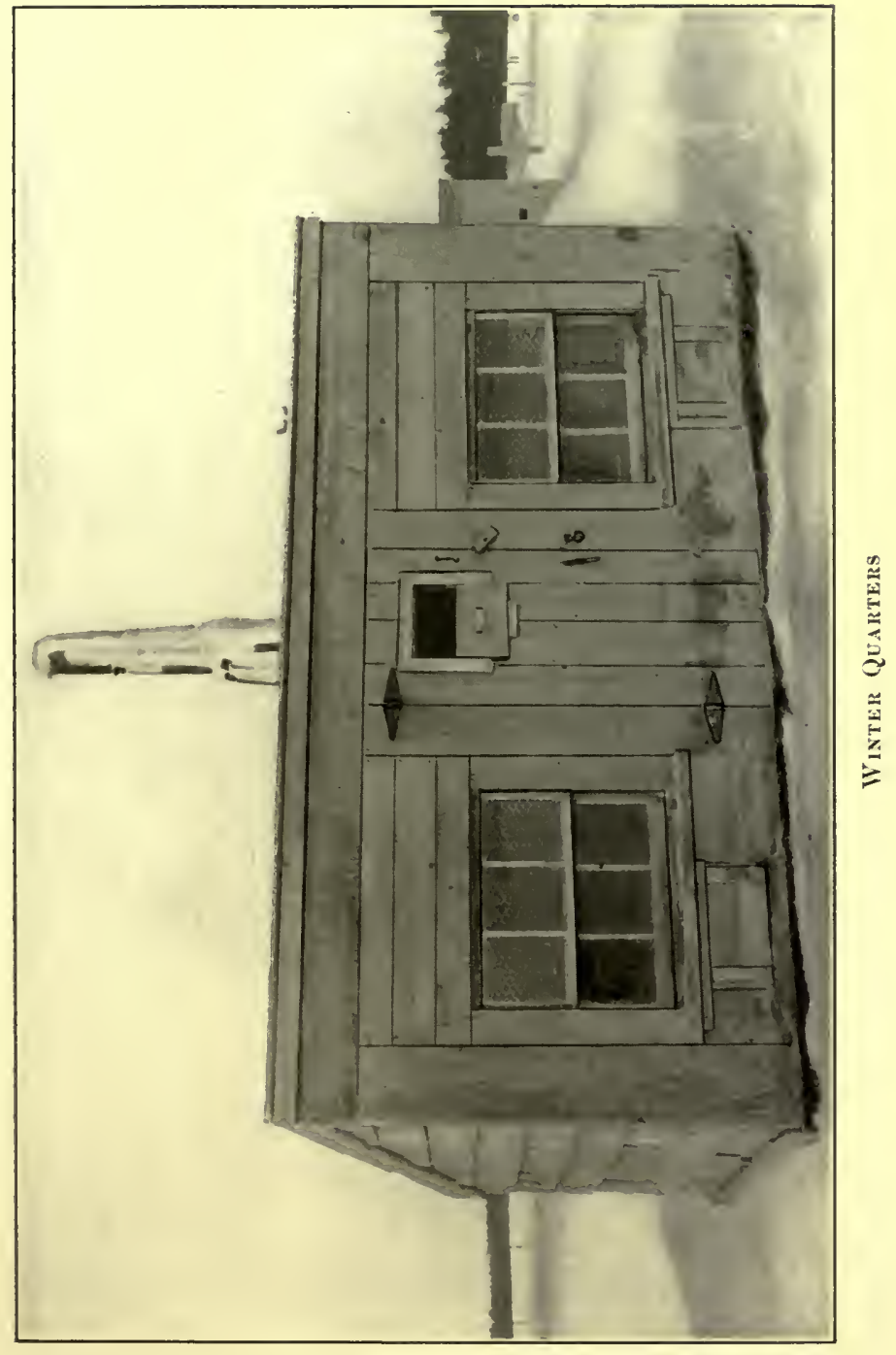





\section{A SELF-SUPPORTING HOME}

days. A board six inches wide, and long enough to reach from the gutter to the front of the stable, was found and placed a foot from the side wall. The cement was mixed according to directions, poured into the space behind the board, quickly smoothed over the surface with a trowel, and left for twentyfour hours to harden. Then the board was moved down another foot and the flooring process repeated, until the whole floor was covered. By placing the board one inch from each of the sides of the gutter, it was possible to give it a "stone" surface. Two boxes, one for water, the other for feed, were treated in a like manner. The whole cost was $\$ 6$, and we had a stable easily cleaned, the most important consideration for the home of Cush.

There are many and doubtless better methods of feeding, but ours answers very well, for our cows give plenty of milk, and are healthy. From October to April, night and morning, a big pail of hay, or corn stalks 


\section{A SELF-SUPPORTING HOME}

which have been chopped into inch lengths; three quarts of boiling water poured over it, and allowed to steam. The night feed is prepared soon after breakfast; the morning feed, before retiring at night. Two quarts of ground food are mixed through it just before feeding. At noon a bundle of hay or corn stalks is given, four times in the week. The other three, half the quantity of stalks, and a pailful of chopped pumpkins or beets. Rock-salt and water are always within reach.

Three times a week a cow should be given a thorough dry scrub with a stiff brush, to keep her skin in good condition. For bedding, use either shavings or straw. If the latter, put it through the feed cutter for convenience, when it is added to the fertilizing compound. Have the stable cleaned before the milking is done in the morning.

Instead of the ordinary milking pail with a spout and strainer, which is difficult to keep clean, we use a plain agate water pail, which has no crevices for microbes to collect 


\section{A SELF-SUPPORTING HOME}

in. Our strainer is made to order, and is like a shallow colander with a wire gauze bottom, over which a piece of doubled cheesecloth is spread before using, of course to be washed and scalded after each straining.

Insist on the pail being brought to the house as soon as milking is over. The milk must be strained at once into shallow pans. Next year, when two cows are kept, a cream separator will do away with the pans; but at first such a luxury would be an extravagance. Keep the pans in an even temperature in a perfectly clean milk room, or light cellar, where no other food is kept; because milk, cream, and butter readily absorb odors which destroy purity and flavor.

The night milk we skim the next morning, so that there is fresh cream for the morning cereal, and plenty of milk for the day's cooking. The morning milk is left for twentyfour or thirty-six hours, and then skimmed, the cream going into the jar kept for the purpose, and the clabbered milk turned into pot 63 


\section{A SELF-SUPPORTING HOME}

cheese. In winter we churn once a week; in summer, twice. Every time a new skimming is added, stir the contents of the jar two or three times around; it assists the work on churning day.

Cleanliness must be rigidly observed. Have a dish-cloth and scrubbing-brush kept exclusively for the dairy implements. As soon as the milk is strained, the pail and strainer must be rinsed with cold water, then scrubbed with hot water; but no soap should be used. Rinse thoroughly with boiling water, and set in the sun and air to dry and sweeten. Before it is used again, rinse with cold water. Insist on the milker washing his or her hands before milking. Should the cow's bag be at all soiled, wash off with warm water, and dry with a soft, clean cloth. The pans must be washed like the pail, but also scoured with salt to remove all particles of stale cream. The churn and all the wooden things should be scoured in cold water and salt, rinsed, and aired in the shade, 



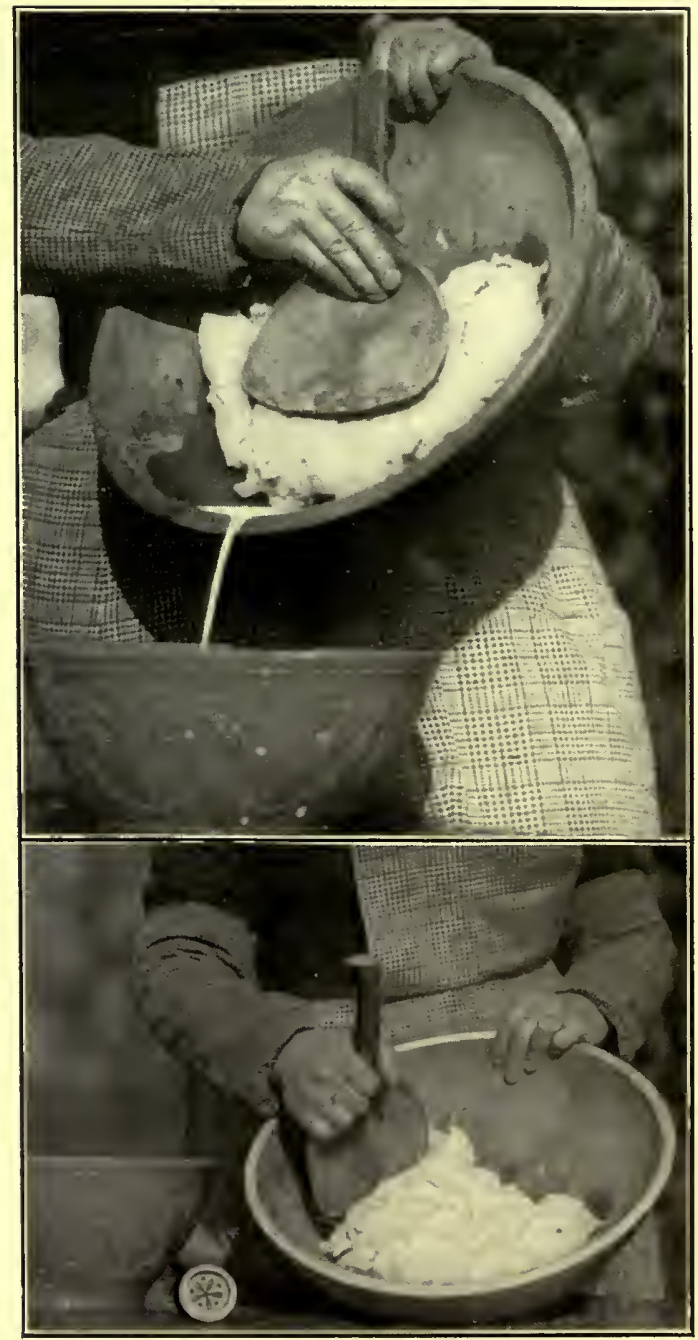

The Right IVAY to squeze out The Buttermilk 


\section{A SELF-SUPPORTING HOME}

and rinsed in scalding water just before using.

Remember that milk is one of the most wholesome, nourishing foods on earth when pure, but that it is perhaps the most dangerous if exposed to any bad odors or conditions of decay; for then it attracts and develops every kind of wretched little microbe.

Churning, like milking, can only be suggested on paper; the understanding of personal experience being required before reliable knowledge can be acquired. If the weather is very cold, the cream jar should be carried into the kitchen an hour or so before churning.

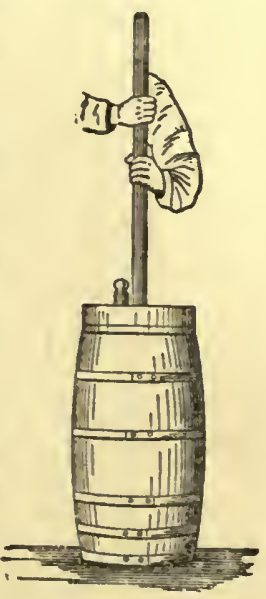
Half fill the churn with boiling water, and let stand a few minutes, and pour out just before emptying the cream into the churn. Then agitate the cream evenly and not too heavily for fifteen minutes when, if the 


\section{A SELF-SUPPORTING HOME}

temperature is right, the cream will have commenced to congeal. Continue a little more slowly, until the particles gather into lumps the size of hickory nuts; after which a few very slow movements of the dasher will collect them into two or three large pieces of convenient size to remove from the churn.

Before commencing to churn, pour very hot water into the wooden bowl; lay the ladle and pats into it. Empty the water; then scoop the butter out of the churn into the bowl, and proceed to press out all the buttermilk with the back of the ladle. Don't rub, but press down against the bowl, making waves in the mass of butter. Then double the sides and ends up into the centre, making it into a solid lump again, which is to be pressed out as before, running the buttermilk out of the bowl each time. Repeat four or five times, or until no more liquid can be squeezed out. Then flatten evenly over the bowl, sprinkle with salt, the quan66 


\section{A SELF-SUPPOR'TING HOME}

tity, of course, depending on individual taste. Work over again once or twice to distribute the salt; then shape as desired for use.

\section{THE HORSE AS A CHRISTMAS PRESENT}

Though our horse was not acquired through the economy or profits of the country home, I am going to explain how she materialized and how we learned to care for her, because it may be valuable to people fortunate enough to possess nice, chummy relatives, or blessed personally with sufficient surplus cash to add this very necessary animal to the stock, without waiting for the pennies to accumulate.

About the middle of the first December we were on the farm, a nice mare, two-wheeled road cart, and harness were for sale. Time of the year, style of the cart, and the fact that the owners would only let the mare go to people sure to give her a comfortable home, made the price so wonderful that I bemoaned 


\section{A SELF-SUPPORTING HOME}

not being able to take advantage of the bargain. Unknown to me, my family all combined forces, and on Christmas morning, when I went into the barn, I was surprised by her whinnying a cheery season's greeting. Poor old Dolly! She had to wait some time for her breakfast, for my pleased delight did not permit practical, everyday necessities like food being remembered, until a sharp stamp of impatience from my new possession recalled me to a sense of the responsibilities of ownership. I could ride and drive, but knew little of administering to a horse's real wants, and the boy, my general assistant, knew less. But where "there's a will there's a way." In a visit to a near-by stock-farm, the owner of which we had become friendly with, lots of useful hints were picked up, and practically applied to Dolly's welfare.

Hitching up, like most new undertakings, was fraught with amusing blunders. A saddle and breeching are innocent looking straps when on a horse's back, but the mo68 


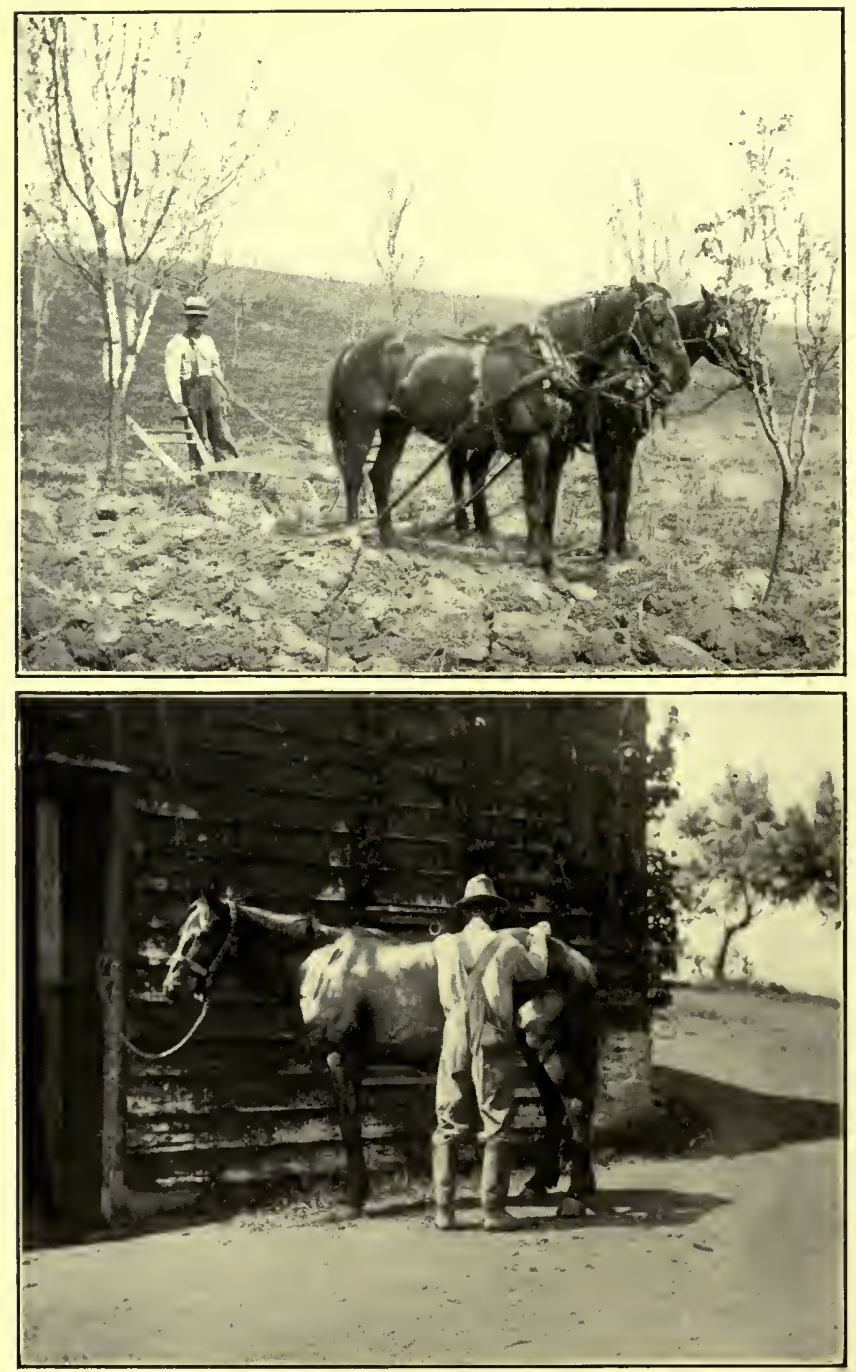

Ploughing - Curring 


\section{A SELF-SUPPORTING HOME}

ment a poor amateur takes them down from a hook and attempts to adjust them, a Chinese puzzle is simple to the conglomeration they present. Nothing but the study of a harness-maker's catalogue which happened to be in the house would have enabled me to straighten out the tangle. Then, when it came to the bridle, finding the right place for Dolly's ears drove her nearly frantic. When at last it was found, the English collar would not go over the bridle; so it had all to be done over again. Dolly not being an angel horse, the drive following these blunders was excitingly memorable; yet when we came home there was a feeling of comradeship between "my horse and me" that removed all difficulties.

From this time on, Dolly, by a hundred clever devices known only to dumb animals, made me understand what she had been accustomed to. For instance, when Saturday evening came and I gave her oats, she sniffed, pawed the floor, then, finding she 


\section{A SELF-SUPPORTING HOME}

was not understood, put her nose into the oats and deliberately began to push them out of the feed box. I looked to see if anything. was wrong, saw nothing, and put in some more oats, for her only to repeat the pantomime. Being stupidly dense, I came to the conclusion that she was not hungry and ceased to bother, commencing to measure out the cow's feed which was kept in the barn. Instantly Dolly whinnied and stretched out her head. At last I comprehended. She wanted mash, not oats. It was mixed and given to her, and eaten greedily. During the next week I hunted up the man who had worked for Dolly's old master and cross-examined him about all 'such details, to find that she had been accustomed to mash on Saturday evening, and several other small oddities of diet, as a pet, had been allowed her.

A medium-sized and not too lightly built horse should be chosen for general purposes on a small farm, so that potatoes, corn, and such crops can be cultivated next summer 


\section{A SELF-SUPPORTING HOME}

without hiring extra help. Don't trust entirely to appearances when purchasing; try to glean some disinterested opinions to guide you. Country folks gossip about horses as much as summer-resort visitors do about the latest arrival.

The stable should be light, well ventilated, and free from draughts. Bed deeply at night, cutting as for the cow's stable, if time will permit. Either give your horse a box-stall, leaving it loose to lie as it pleases, or a narrow stall with a tie rope or chain arranged to work on a pulley and counterweight, so removing the danger of the horse getting chain or rope under its leg when lying down, to hobble the poor beast when getting up again. A stall too wide may tempt a horse to roll. Then the restricted space prevents it being able to regain its balance, and severe accidents are the results. Therefore, allow no medium in your horse's sleeping apartment, for in this instance it would not be happy or safe.

Grooming is of the utmost importance. 


\section{A SELF-SUPPORTING HOME}

An old cavalry soldier, who begged a night's shelter and stayed with us a whole summer, gave me many valuable lessons on this subject. First, don't bring a horse out of the warm stable and ruthlessly strip off a thick blanket, exposing the whole body to the cold, whilst you work with the slow movements of the inexperienced. Instead, unstrap the front of the blanket and turn it half-way back. Then, being careful not to slap the currycomb on to the horse, work as quickly as a firm, even, but light pressure will permit, much as you would use a flesh-brush on your own body. Every few minutes rap the side of the currycomb sharply against the floor or wall. The collection of dust and dandruff-like powder which will fall out from between the teeth must awaken any one to the necessity of cleaning a horse thoroughly and regularly.

After the currying is accomplished, take up the brush and rub, scrub, and polish until the hair shines. Then replace the front 72 


\section{A SELF-SUPPORTING HOME}

of the blanket, turning up the back half over the shoulders, until the hind quarters match the front in shimmering cleanliness. Tail and mane require a coarse comb and brush, sold especially for the purpose. Next, wring a sponge out of warm water and wipe the horse's face, removing any lodgement at the corners of the eyes or mouth. Keep a rough, clean cloth for drying and polishing the face, or a moderately hard brush. Never use a currycomb or large brush on the face, for it is difficult to avoid catching the bristles against the eyes or lips. Pick up each foot in turn and with a blunt, smoothly rounded piece of iron or steel clean out the hoof, being careful not to injure the soft, gristly growth in the centre, which forms the frog.

Cultivate the habit of talking to your horse when cleaning, hitching, or feeding. No matter how good a man you may have, lose no time in acquiring the knowledge that will enable you to intelligently care for your horse should the necessity arise. Make it a 


\section{A SELF-SUPPORTING HOME}

rule at grooming time to take the horse some treat, - a carrot, a lump of sugar, or piece of bread, - whichever may be its individual preference. It makes the horse friendly, checks any chance of neglect or impatient temper on the part of the man being visited on the horse; moreover, it enables you to give the day's orders without loss of time to either.

Your rations are four quarts of oats and six pounds of hay, night and morning; noon, two quarts of oats, varied by a bran mash on Saturday night, made by pouring one quart of scalding water on to four quarts of wheat bran, into which a tablespoonful of 'salt has been mixed. Prepare at noon, which gives it plenty of time to steam and become nearly cold before supper, as all mash feed should be barely warm when fed. Our horse and cattle have water always before them. If your stabling does not permit that, water twenty minutes before feeding; and when the weather is very cold, take the extreme chill off the water before offering it 


\section{A SELF-SUPPORTING HOME}

to the stock. Allow a horse one hour for breakfast, and not less than half an hour for dinner. Punctual meal hours, sufficient time in which to consume the food, and a few minutes undisturbed rest afterward insure health and willing work.

A horse travelling two or three miles a day should be shod every six weeks. After the first of December it is safer to keep your horse rough shod; else, some morning, the commuter may miss his train because the ground is so slippery it is difficult for the horse even to walk. After driving, let the horse stand half an hour before feeding or watering. Be thoughtful and kind to your horse, and it will be the greatest help and pleasure to your home.

\section{RABBITS}

White rabbits are the best to start the pet stock branch of the farm, because they do not cost more than a dollar each when of mature age, and there is always a ready mar- 


\section{A SELF-SUPPOR'TING HOME}

ket for the young ones in every large city; dealers being willing to pay 25 cents apiece at all times, and from 50 to 75 cents at Easter. Mrs. Bunny usually rears five families during the year, making an average of thirty little ones, which, counting minimum prices, makes it safe to estimate a $\$ 6$ addition to the home income for every mother rabbit.

Each doe should have a hutch two and a half feet long, two feet wide, and two high. We get the empty cases in which shoes are shipped to the general store in the village, at a cost of 5 cents each. By turning them on the side, a hutch of just the right dimensions is obtained, needing only a door, the frame of which can be easily made from shingle slates. Cut two pieces the exact length of the case, two pieces the exact width, rule a pencil line two inches from each end, place a fine saw lengthwise over the line, and cut the lath evenly half through its thickness. Then, with a sharp pocket-knife or chisel, remove the severed portion; so making the 76 


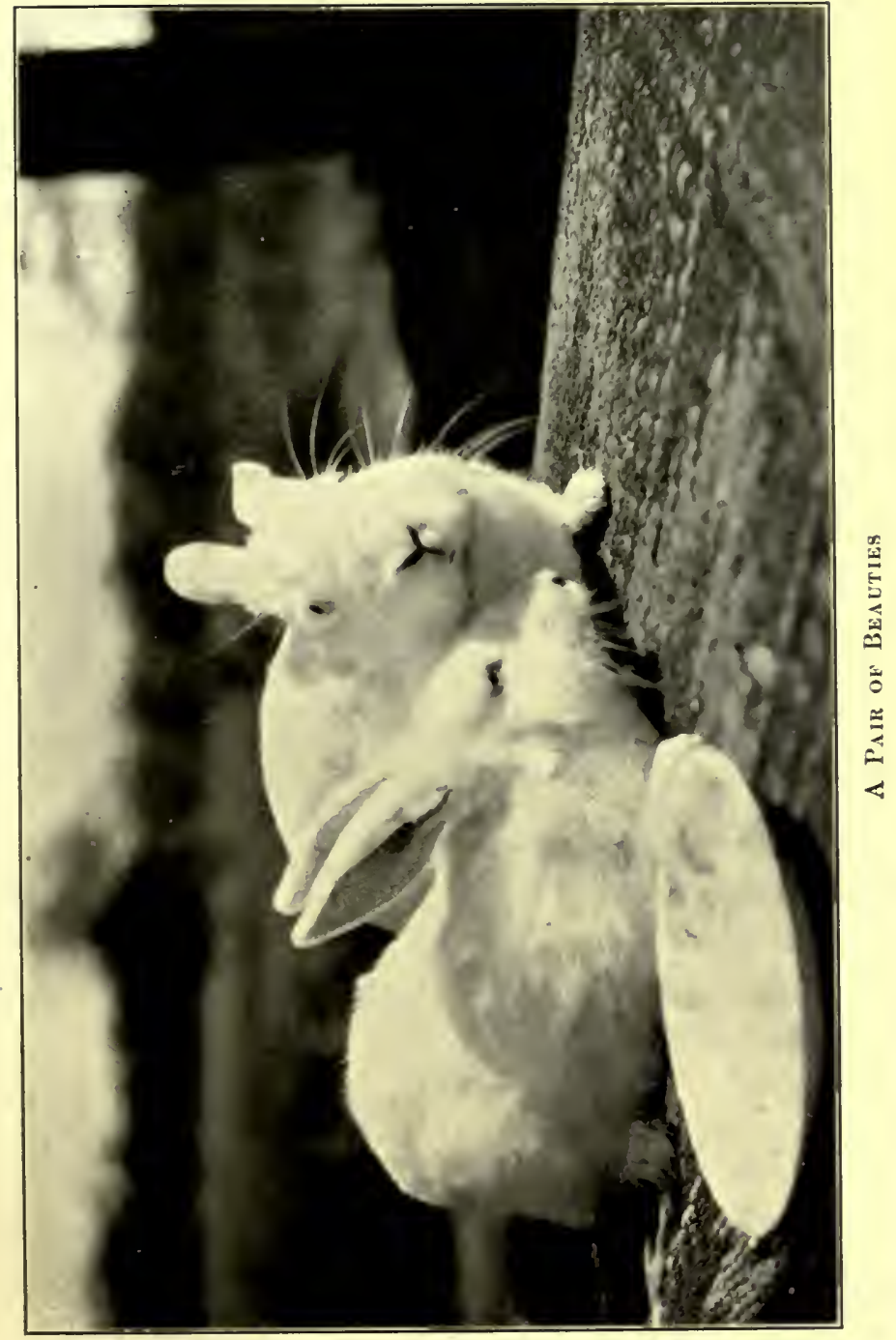





\section{A SELF-SUPPORTING HOME}

corners join without either side of the frame being uneven. I believe in carpenter's vernacular the process is referred to as a "mortise joint." When the frame is finished, cover with one-inch wire netting, and attach to the bottom of the hutch by hinges placed four inches from each end. A screw hook and eye at the top make a secure fastening. Bore three holes, half an inch in diameter, in the back corners of the floor of the hutch, and it is ready for its furnishings, which consist of a nest box fourteen by twelve inches in size, with an arched hole seven inches high and four wide cut in the front, and two small pans for feed and water. Brown earthen butter crocks, or the zinc dishes used in parrots' cages, are the best. If the latter are chosen, screw-eyes must be put into the side of the hutch in which to hook the pans. A row of such rabbit houses can be kept in the barn or woodshed, if a bench two feet high is made of rough boards for them to stand on. When placing the hutches, let 


\section{A SELF-SUPPORTING HOME}

them slant slightly to the back, so that all moisture may drain through the holes.

Five does and a buck are sufficient to commence with. Put each into a separate hutch, and after they become accustomed to their surroundings let each doe in turn visit the buck's hutch for a few hours or a day. Should they fight viciously, return the doe to her own hutch until the next week. Never risk putting the buck into a doe's hutch, for they usually resent the intrusion with tooth and nail. Soon after Mrs. Bunny returns to her own hutch, she will commence to gather up the bedding in her mouth and carry it into the nest box. When it is filled with the hay, she hollows out a round hole in the centre, which she then lines with fur pulled from her own body. After thirty days it will be occupied by sightless, furless little creatures; but not a hint will Mrs. Bunny give you of the fact until, the nine days of infantile ugliness being past, she allows them to run out into the hutch for a few minutes at a time. 


\section{A SELF-SUPPORTING HOME}

Then you may chance to get a glimpse of one hurrying out of sight when you go to feed them; but not until the sixteenth day do they really play about and eat solid food.

When six weeks old, all the babies can be taken away from the mother and placed in a large hutch for two or three weeks, to gain strength and self-reliance before leaving home.

If you wish to increase your stock, keep one or two baby does from each family. They can be kept together in one hutch until four months old, after which they should be allowed to have individual establishments. This will, of course, necessitate the purchase of another buck to prevent in-breeding. After successful results have made you an enthusiast on the rabbit subject, there are many varieties which can be gradually added to the establishment; but don't attempt Himalayans or Dutch until you have mastered some of the problems of paternal influences on color and markings. 


\section{A SELF-SUPPORTING HOME}

The floor of the hutch should have a thick layer of sawdust, common bedding hay, or dried leaves - whichever is easiest to procure. It doesn't matter, so long as the hutches are thoroughly well cleaned out twice a week, and Mrs. Bunny is provided with bedding for nest building. Avoid touching the small box when cleaning, after the doe commences to fill it, until the babies are three weeks old. Then empty out the nest and replace with loose hay. Give the does clean, empty bedrooms a week after each family is taken away from them.

When obtainable, their principal food consists of the lawn cuttings, clover, plantain, dandelion, oak leaves, lettuce, the cob leaves of sweet corn, - in fact, almost all garden stuffs, - and a small handful of oats once a day. In winter give hay, oats, and corn mixed, apples, carrots, tops of celery, etc. Avoid turnips or cabbage, because they make the odors from the hutches very disagreeable; and cabbage is dangerous for 80 


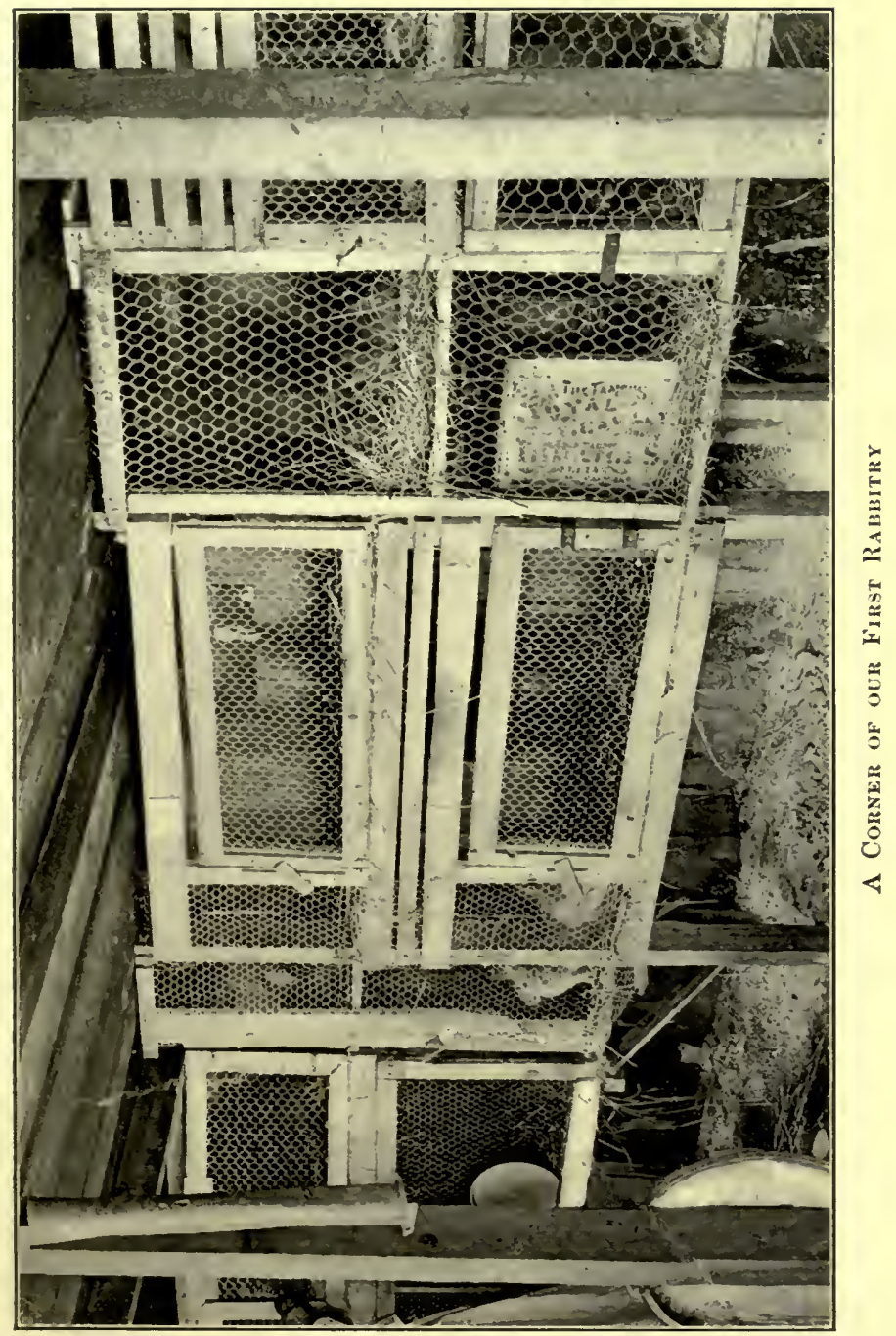




\section{A SELF-SUPPORTING HOME}

young rabbits, giving them what is called "pot belly," usually meaning sudden death. The safest rule about all vegetable food is to watch the droppings, which should be dry, round pellets. If they are soft or run together, stop greens or grass, feeding only hay and oats. Give weak, cold tea instead of water to drink. A piece of stale bread or dry toast is also good. A doe should have a little bread and milk each day, from the time she begins to build her nest until the babies are three weeks ${ }^{\circ}$ old. Carrots are also especially good for her during this time. A week before the little ones are taken from her, feed a sprig of parsley every other day, so preventing any fear of milk fever. When the acorns commence to fall, collect a supply and keep in a large glass jar for occasional distribution during the winter, for they are an excellent tonic and keep the stock in good health. A piece of oak or spruce with the bark on will be greedily stripped if put into the hutch during the 


\section{A SELF-SUPPOR'TING HOME}

spring and fall. Once a week all the year round add a pinch of salt to the drinking water, which must be supplied fresh every day. Rabbits are thirsty animals, and neglect to provide them with an abundant water supply is dire cruelty.

Only a little less cruel is the custom of lifting rabbits by their ears. Just imagine what the torture must be when the entire weight of the animal's body is suspended from such a sensitive nerve centre as the ear. The strain to the spine is so great that the lightest blow will instantly cause death. The correct way to lift all the rabbit family is by the skin directly over the shoulders, which draws up the hide evenly all over the body, so distributing the weight and preventing their struggling. The baby fellows I lift up bodily between both hands, having found it much the easiest and best way.

Rabbits make such amusing pets that I advise you to select one and allow it to have the liberty of the lawn and house. Don't 


\section{A SELF-SUPPORTING HOME}

imagine that their natural habits make this impossible. I had a Belgian hare which was thoroughly housebroken, and now we have a white gentleman who scratches at the door when he wishes to come in, and at breakfast time will jump on my knee and eat his oatmeal and cream, jumping down and trotting off when we leave the dining-room, unless the day is very cold or wet, when he lies down before the fire with the cats and dogs and takes a comfortable siesta.

\section{MUSHROOMS}

The owner of a well-ventilated cellar, either in town or country, can provide the table with mushrooms. It is strange that so few people attempt to grow these delicious and nutritious vegetables, for really nothing is easier. Even before we became farmers we grew these valuable foods. With the flat we occupied went two bins in the cellar, one for coal, the other for wood or storage, the latter 


\section{A SELF-SUPPORTING HOME}

we used as a mushroom house. As it was near the heater that supplied hot water, just the atmosphere needed was provided. Around the top of the bin were open slats, and the cellar was so exceptionally well ventilated that fresh air circulated freely - one of the imperative conditions for success. Any

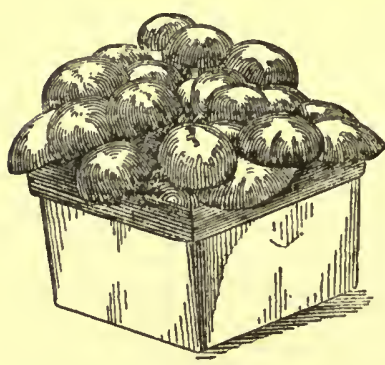
dark place where the temperature will not fall below fifty-five will answer the purpose as a makeshift quarters in which to raise enough of this famous food fungus for home consumption. Once again, recourse can be had to the ever valuable grocery store for some cases; about two feet wide and one deep is a convenient size. They can stand on the ground and in tiers above, so space can be well economized.

Our first trial was made in a box three feet long, and of the above width and depth. We bought a single pound of spawn at 15 84 



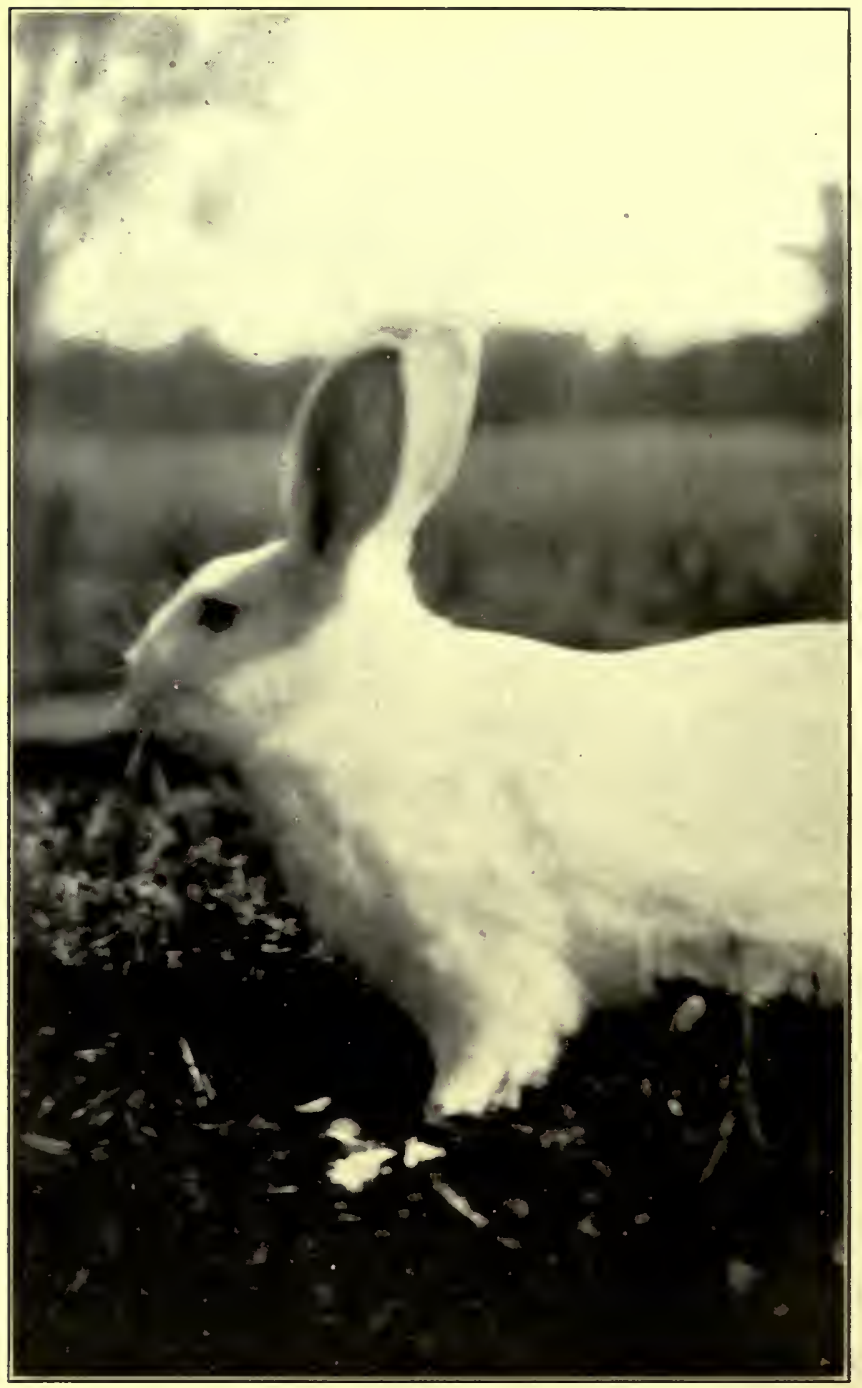

JACKo, Who COMES AND GOES AS HE LIKES 


\section{A SELF-SUPPORTING HOME}

cents, planted it, and gathered in ten pounds in February, when they were at 50 cents a pound in the market. The compost to fill the boxes is composed of fresh stable droppings and mould from sod ground in proportions of two pails of the former to one of the latter. Our janitor procured and mixed it for us for a dollar. Put a layer about four inches thick all over the box, pat it down evenly, then add another layer, and that down until you reach a depth of eight inches. Insert a thermometer. In two or three days, the heat will rise to a hundred or over, and then decline again. When it reaches ninety, make holes about an inch in diameter, six inches deep and a foot apart, all over the box, into which drop pieces of the spawn about as big as a thimble. Smooth over the top to fill up the holes, pat down smooth again, wait ten or twelve days, then top dress with two inches of fresh loam all over the surface. Press down smoothly, sprinkle very lightly with water, and cover 


\section{A SELF-SUPPORTING HOME}

with three or four inches of cut hay, straw, or leaves.

From five to six weeks later, you should be able to gather a good supply. This bed will continue to yield during three or four weeks. Then remove the straw, add another two inches of fresh earth, sprinkling and recovering, when another crop will start. Later, when the "home" is paying sufficient dividends to build a proper mushroom house, I shall explain more advanced methods of running what is a really profitable branch of fancy farming.

\section{HINT FOR SALADS}

Place three boxes a foot and a half wide, two feet long, and four inches deep, on an old table in a south or southwest window. Sow half of each box with mustard seed (sometimes called pepper grass) and the other half with cress seed. Allow four days between the sowing of each box, and after ten days you have a succession of material for adding to salads or sandwiches all through the winter. 86 


\section{CHAPTER V}

\section{JANUARY}

HONEY BEES AS WAGE-EARNERS

TF the rent of the farm selected for the 1 self-supporting home is $\$ 15$ or $\$ 20$ a month less than the apartment or house occupied in the city, remember that, after deducting the "Goodman's" commutation ticket, every cent for the first few months must be devoted to purchasing the nucleus of the stock which is to render the home self-supporting. After the hens, ducks, and pigeons are established, money can be devoted to guinea-fowls and bees, two members of a farm colony which bring heavy loads of grist to the mill, and demand little in return.

Few city people realize that apiculture has developed into a practical money-making industry during the last twenty years, until 87 


\section{A SELF-SUPPORTING HOME}

now the average amount of honey put on the market each year is upward of a hundred million pounds, representing a money value of from $\$ 8,000,000$ to $\$ 10,000,000$.

In a favorable locality one hive, with its average colony of thirty-five thousand workers and a queen, will turn out from thirty to forty pounds of honey, besides the fifteen or twenty necessary to feed the hive through the winter.

A few hives, in an ordinary country district, should each bring in a clear $\$ 2$ a year profit at the lowest estimate. On a poultry and fruit farm where clover, sunflower, and millet are grown for the poultry, the yield of honey should be much larger, if the apiary is restricted to twenty or thirty hives. Their care will infringe but little on working hours. They feed themselves, so expense is confined to the necessary new hives for the fresh colonies, comb foundations, and other equally small outlays.

If you commence by purchasing a colony and hive that has been well cared for during 88 


\section{A SELF-SUPPOR'TING HOME}

the winter, they will come out strong in the spring, the queen will start laying again, and each day thousands of bees will be born, soon causing the hive to be so vastly crowded that the old queen and a swarm will issue from the parent hive, leaving the young colony in possession of the home and stores.

If the old queen has had her wings properly clipped the season before, she will not be able to fly, so will be found on the ground near the hive with a group of bees around her, and the principal swarm not very far away. Approach very quietly, and place a small wire trap over the queen (the traps are sold by all bee supply firms, and cost 25 cents, I think). Then place the trap in the opening of the hive you desire the swarm to occupy, cautiously approach the full swarm, and with a soft broom sweep the bees into the hive, if the position they occupy makes it possible, as in the picture. If not, use a box or pan and carry them to the hive, and empty them in front. They will soon com- 


\section{A SELF-SUPPORTING HOME}

mence to occupy the new home. The slide of the queen trap can be opened, and the bees inside will settle down to business. Should the queen not have been clipped, the swarm may all go up in a tall tree, or even travel some distance and be lost, unless some one is watching. For this reason, it is well to have the hives located where they are easily seen from the house, and make a rule to inspect once or twice every day during the early spring. When the swarming fever has taken possession of the occupants, you will notice bees going in and out of the hive in a state of excitement, a sort of bustle that will convey the information that something unusual is going on inside the hive.

You may wonder that I have said nothing about stings during this hiving process. The truth is, before leaving the old home, all the bees that are going out with the queen load themselves with so much honey to insure food for themselves and the royal mother, as well as with propolis, - a sort of gummy var90 


\section{A SELF-SUPPORTING HOME}

nish which they use to stop up cracks or cover rough surfaces, - that they are rarely able to sting; but if nervous, you can subject the main bunch to a few whiffs of smoke. A queen never uses her lance except on a rival queen. This condition, of course, does not obtain at other times; so before such work as removing and replacing sections or foundations, the smoker must be lighted. When burning freely blow a few whiffs of smoke into the entrance and about the corners of the hive. This stupefies the bees, and renders manipulation of them and an invasion of their domain comparatively safe; though it is always advisable to wear a veil made of mosquito netting, to fit on the hat and hanging well down on the shoulders. Gloves can also be worn. But the Italian bee, the best to keep, is such a gentle little creature that familiarity will end in the gloves being discarded.

After the abdicating queen and her following have left the old hive, there remain 91 


\section{A SELF-SUPPORTING HOME}

some few thousands of imperfectly developed females of mature age, called "workers," a few hundred males called "drones," a few thousand young workers, and many thousands of eggs reposing each in its own particular cell. The most perfect system of government prevails in the hive, each individual insect having allotted duties, which are apparently intuitively understood, accepted, and conscientiously performed in unerring routine, from the hour of birth. When the baby breaks from its cell, it walks out into the busy world of the hive, and, after a few hours, dips into an unsealed cell of honey and sips its first meal, not, however, to be selfishly consumed by its own body, for the larger portion of this honey is secreted and, after a little, is converted into a predigested milky food, the quality of which this wonderful little nurse has the power of regulating as it wanders from cell to cell feeding the one-to-seven-days old larvæ. Occupants of royal cells receive the most carefully digested 


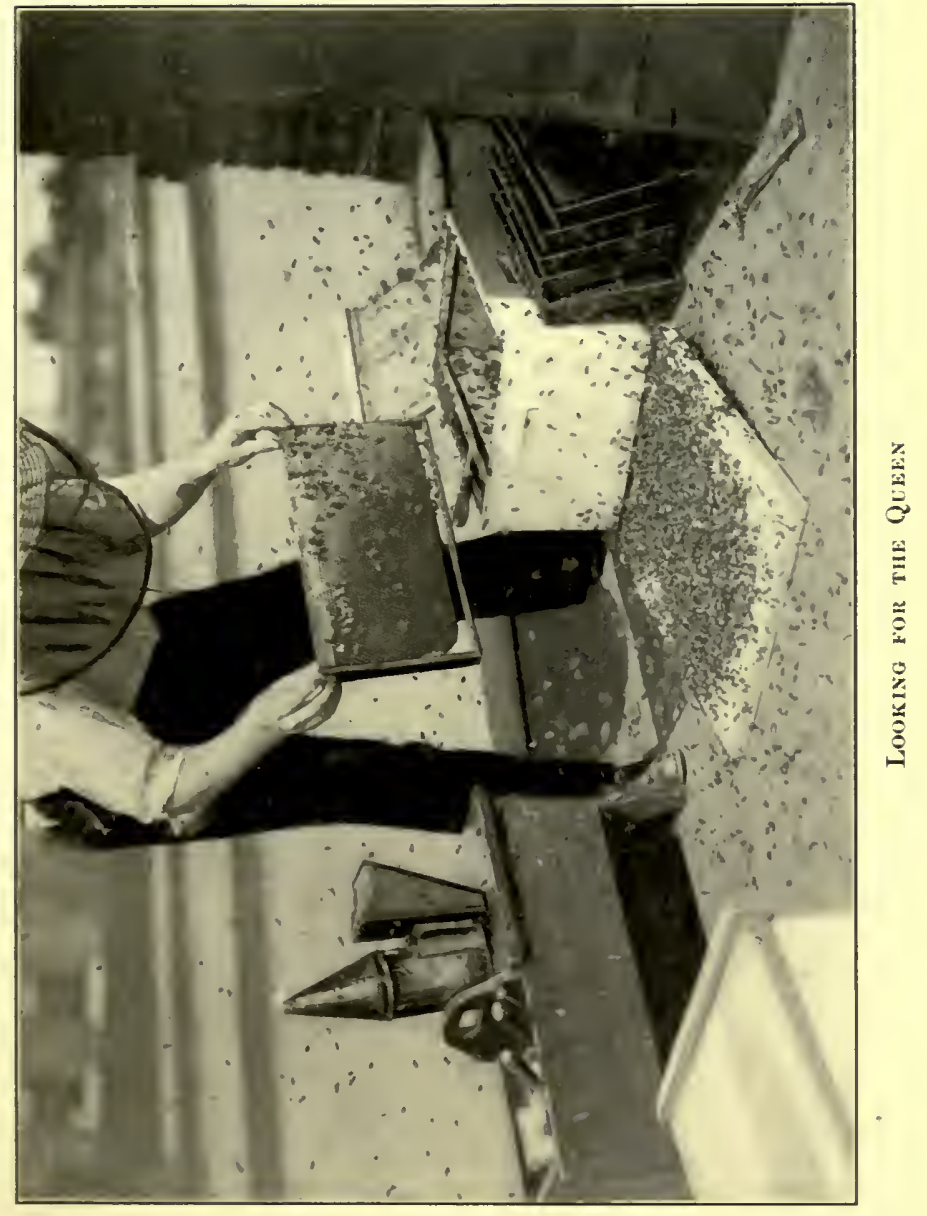





\section{A SELF-SUPPORTING HOME}

food; next in quality come the workers; then the drones. At the end of six days, the cells are capped over by workers with a paper-like surface, and the well-fed, wormlike occupant is left for eleven or twelve days, during which time it develops shape and strength to gnaw its way out. After the six or seven days of nursing duty, come six or seven days of building combs and cleaning the hive; and then, being strong enough, the worker commences gathering honey, a task so arduous during the summer that her life terminates within three months.

The first young queen to issue from her cell after the old queen's abdication becomes the reigning sovereign, maintaining her right by might, tearing down all queen cells, and killing any young princesses who are making their entry into existence. For about a week she marches around, monarch of all she surveys, exempt from all toil or duty; then she issues from the hive, takes a few circles about, and returns. Probably on the same day, or 93 


\section{A SELF-SUPPORTING HOME}

on the day following, she will take what is called the nuptial flight, meet some drone in midair, and return some hours later to become sole mother of the hive, and to be so treasured by the colony that they feed her on royal jelly all her life, wash and tend her with the most jealous care. During every twenty-four hours of a good season, when honey and pollen are plentiful, a queen lays from two thousand five hundred to four thousand eggs.

The drones, as the name implies, are lazy fellows, not even earning their own living, and are tolerated by the busy workers only during the summer of plenty, being ruthlessly killed at the first approach of scarcity.

Our apiary started with two hives and their dormant occupants, bought at an auction for \$3. Of course it was rather a reckless investment, because neither the auctioneer nor I knew anything about bees; therefore the contents of the hives was a profound secret. The price being so ridicu94 


\section{A SELF-SUPPORTING HOME}

lously small, it seemed wise to risk the chance of adding such busy workers to the home.

I knew nothing about wintering bees, but as they were standing upon a bench in the orchard, I had them carefully lifted into a spring wagon, instructing the driver to walk his horses the mile and a half to our farm; which he did for one dollar. Not knowing just what protection was required, we put a large packing case on its side in a sheltered corner of the garden, and set the hives inside it. As the extreme cold weather commenced soon after, some boards were joined together by means of battens top and bottom, and stood up in front of the case, on which it rested at the top, sloping out a few inches on the ground, so that it kept the snow from drifting in, yet allowed ventilation.

March 15 the boards were removed, and we watched with much anxiety for the bees to appear. Days went by and we were convinced that the hives were empty or the inmates frozen to death, but on the last day of 


\section{A SELF-SUPPORTING HOME}

the month, a few sleepy-looking bees emerged, flew about for a short time, and returned, evidently giving a favorable report of the weather, for the next day a continuous stream issued forth and hovered around the hives. Many of the winter evenings had been devoted to studying bees and their care, so I had rudimentary knowledge enough to realize that as there was little, if any, natural food for thern to gather, it would be advisable to mix a syrup of sugar and water, and put it into shallow dishes near the hives, the motive being to supply sufficient nourishment to stimulate brood rearing.

Not knowing what knowledge the previous owner had possessed, the fear presented itself that the queens might not have had their wings cut, so, as I had no desire to lose a swarm or climb to impossible heights after them, I screwed up my courage and prepared to attempt the task of finding and clipping the royal ladies. I had no smoker, so a bundle of hay, slightly damped, was put 96 


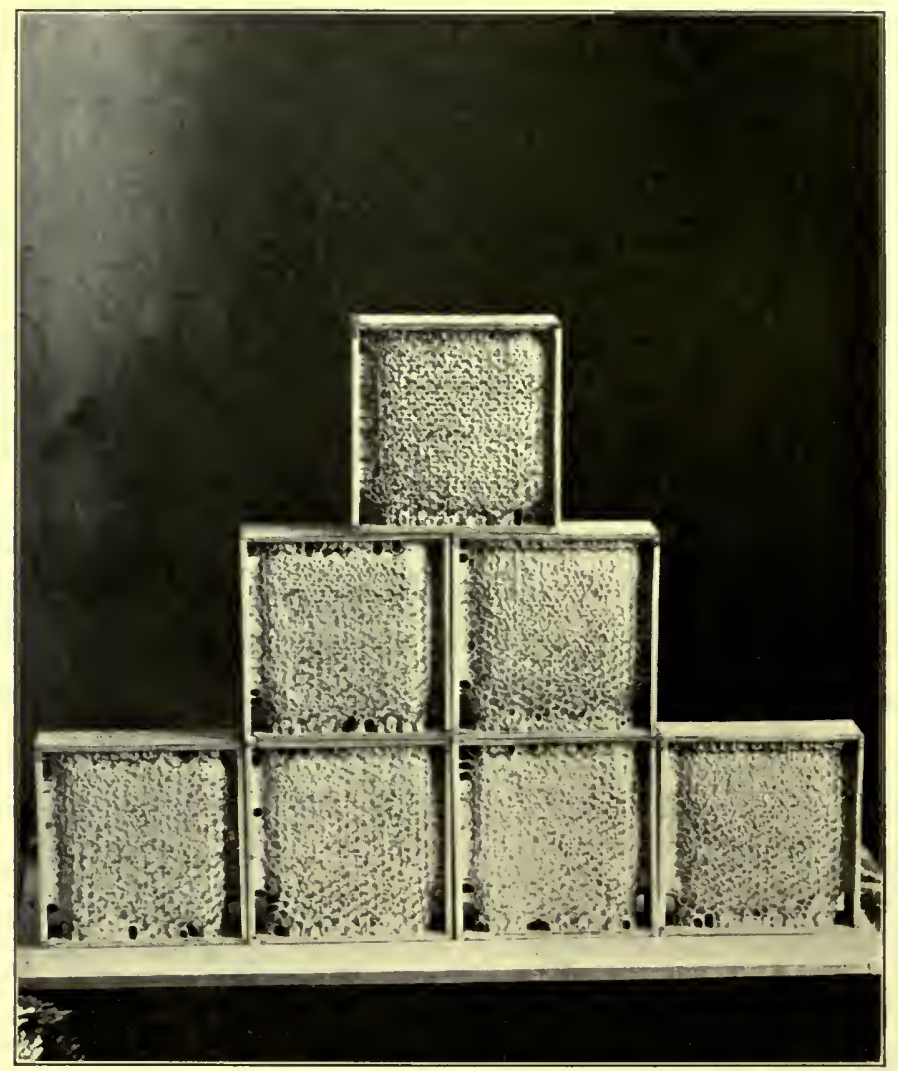

What THE BeEs give U's 


\section{A SELF-SUPPORTING HOME}

into a five-pound lard pail, which had had a row of holes bored round the bottom and in the lid, so that, when the hay was lighted and the lid put on, it would just smoulder, making a dense smoke issue through the holes. The contrivance seemed all right, and there was smoke enough to blind me; yet when I cautiously removed the top of the hive and commenced to take out a frame, bees swarmed all over my head and shoulders. Fortunately, I retained sufficient presence of mind to remain perfectly quiet until the farm boy, who had been watching near by, 'got a large bundle of hay, fired it and almost roasted me before the bees were sufficiently stupefied to allow their being brushed off and the lid of the hive replaced, for the horrible combination of fright and smoke had rendered me quite incapable of further investigation.

Through all this stupid blundering I only received one sting, but that so amply illustrated what might happen that discretion seemed the better part of valor. I deter$\mathbf{H}$ 


\section{A SELF-SUPPORTING HOME}

mined the hive should be left in peace until a real smoker was procured.' Two weeks elapsed before the handy bellows-like machine arrived. It cost 75 cents, but the comfort of being able to puff as much smoke exactly where it was wanted, instead of into one's own eyes and throat, was worth many times the amount.

Until I actually discovered the queen, it seemed doubtful that I should recognize or be able to handle her even if I did. However, when seen, her noble ladyship cannot be mistaken. Her shape and color are so different to all the others. The delicacy of her body makes handling her rather a nervous proceeding, but a little care and a pair of fine manicure scissors renders it possible for even such an amateur as I was to perform the operation without hurting her.

When sending after the smoker, we ordered five hives "in the flat," which means the material all cut and ready to nail together. These cost $\$ 9.75$, and were easily built, as 98 


\section{A SELF-SUPPORTING HOME}

the proper-sized nails and instructions came with them.

The first summer we had two swarms, one from each hive, early in the season. This being all the increase we cared for, a weekly examination was instituted to remove all sections filled with honey, as soon as the busy little workers had sealed them. Our first experience at wintering bees having been quite satisfactory, it has never been changed, except that the shelters are now made with slanting roofs like a chicken-house, and the last two winters being so extremely cold, hay has been packed round the hives.

Any one living near New York should take advantage of the apiary established by the government in Van Cortlandt Park. It is well-stocked, and the keeper is there expressly to answer questions and explain to interested visitors all the different conditions of the working bee colony.

Philadelphia has the same advantage at the Root Apiary, situated near the toll-gate 


\section{A SELF-SUPPORTING HOME}

at Jenkintown. Here an appointment should be made two days ahead, to insure the keeper being in attendance.

Even if you do not care to undertake another business, at least keep one colony for honey for home consumption.

THE POULTRY YARD

The breeding flocks must now be made up. If possible, confine every fifteen hens in separate enclosures, and for each two such enclosures buy three cockerels. Put one in each, and provide a small separate coop and yard for the third one, alternating the three birds each week.

If thirty or forty hens must be kept together, buy six cockerels. Put three with the hens, and keep the other three all together in a small yard, alternating each trio every week.

If all the hens are running free, still alternate the males, for by doing so no favoritism can be shown. 



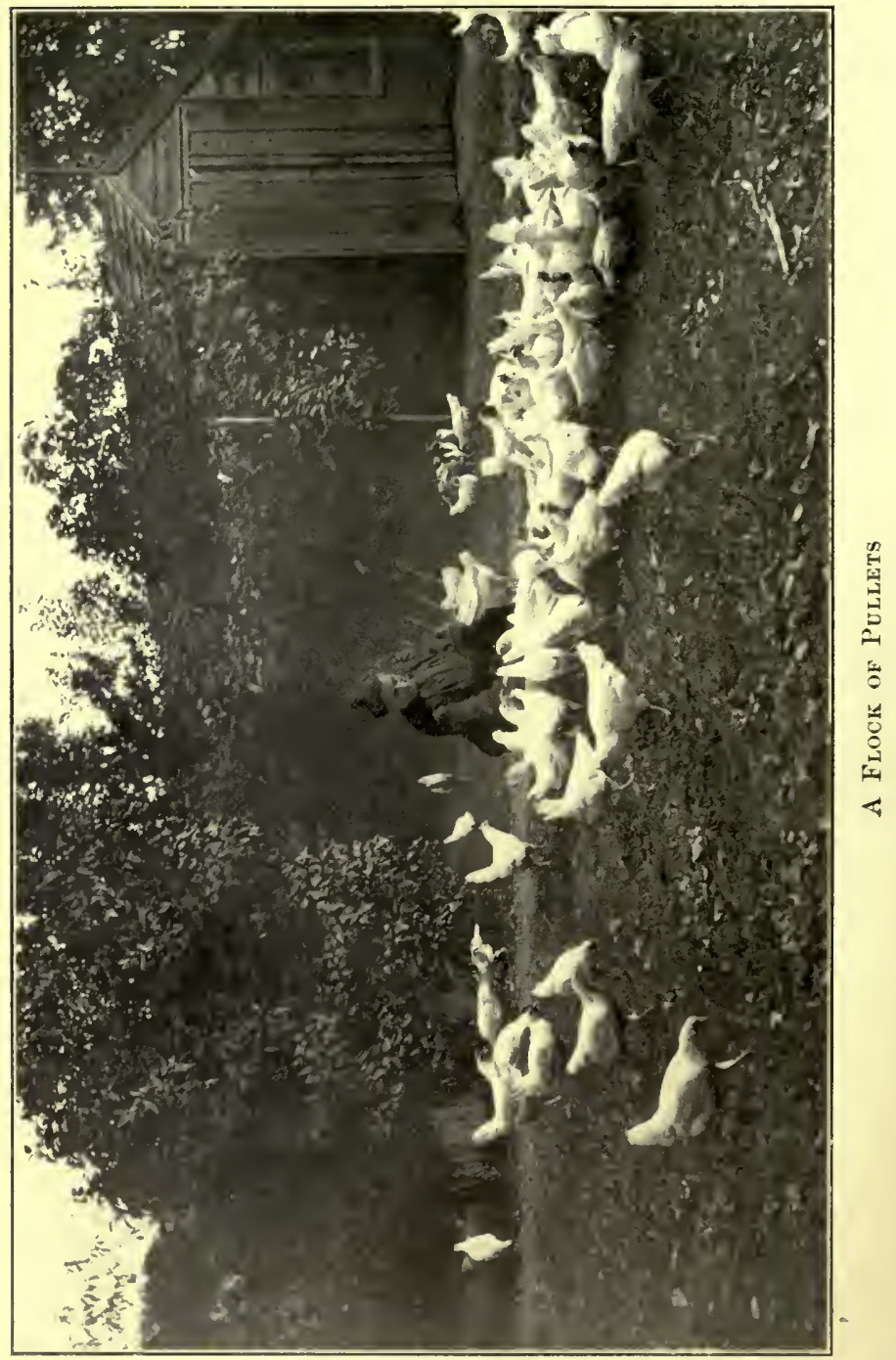




\section{A SELF-SUPPORTING HOME}

A variety of food is absolutely necessary for strongly fertilized germs from which vigorous, healthy chicks are sure to come.

The best way to convince you of the advisability of following my coming suggestions for winter feeding will be to give, in a condensed and simple form, the chemical analysis of the egg:-

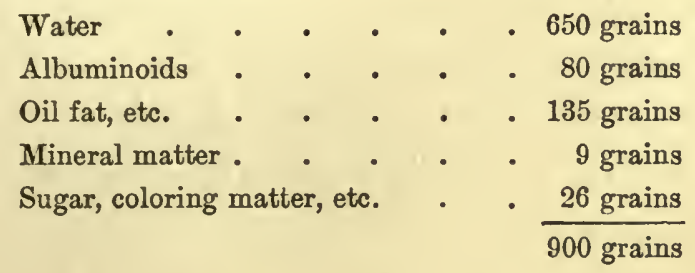

The remaining hundred parts of the thousand of an egg are used in the shell, which contains about fifty grains of salt of lime, and about fifty grains of pure uncombined lime (calcium oxide), the remainder being carbolic acid, water of crystallization, etc.

Perhaps a short explanation of even this simple analysis may be helpful. Albuminoids are the flesh-forming parts of food, 


\section{A SELF-SUPPORTING HOME}

usually alluded to as nitrogenous. Oil fat, etc., are merged under the heading of carbon, necessary for fat and warmth. Mineral matter consists of lime, soda, potash, magnesia, sulphur, etc.

Please don't imagine that the simplifying process of this analysis is any reflection on your knowledge and understanding. It is prompted entirely by the hazy condition such reading matter used to leave my poor brain in, when I began seriously to study cause and effect in poultry culture. Experience, however, showed me the common sense of much that, at first, seemed theoretical jumble, because of the involved technical terms; so as I read and digested different authorities, a notebook was compiled for my own use, containing the gist of each article, in the simplest terms possible, to convey the information. During the last nine years practical tests of the value and benefit to be derived from each individual item have been made. When, as sometimes happened, a 


\section{A SELF-SUPPORTING HOME}

statement did not "prove," it was cut out; so now I flatter myself there is little left in the book which is not tested, tried and true, fully worthy of attention, for it will save you much groping in a wrong direction.

Knowing the material necessary for the egg, no one ought to be foolish enough to expect Biddy to produce a goodly supply, unless she is provided with the necessary ingredients. Farmers complain that hens lay all the eggs in the spring, when they are hardly worth the trouble of marketing, but the moment the price goes up, they stop. Well, it's the farmer's fault. In the spring, hens that run loose get every element necessary to the formation of the egg, but in the cold weather insects and green foods are scarce, and want of material stops production.

Having, I hope, convinced you of the common-sense advantage of balanced rations, the next consideration is what ordinary, farm-grown feeds best and most cheaply supply Biddy's wants. 


\section{A SELF-SUPPORTING HOME}

We will start with the foods which give the greatest quantity of lime, because it is needed for shell and some fractional part of the mineral matter in the white and yolk, which is most essential, as it is converted during incubation into bone for the developing chicken.

Clover hay, linseed meal, and wheat bran contain about six pounds of lime in every hundred pounds. Turnip tops, beets, carrots, and all grasses, also have a goodly percentage.

Flesh comes from nitrogenous or albumenal foods, first of which are beef, linseed meal, middlings, bran, clover hay, oats, wheat, skimmed milk. Fat and heat we get from carbonaceous provenders, of which corn and buckwheat come first, closely followed by oats, wheat, rye, clover hay, linseed meal, and milk unskimmed.

Mineral matter - lime, soda, potash, magnesia, sulphur - is principally formed by the action of digestion, reducing the matter containing these ingredients to ash. 


\section{A SELF-SUPPORTING HOME}

The usual troubles assailing poultry on general farms come from the feeding of only one of any of these elements; so poor Biddy has to eat all flesh and no warmth, or all fat and no flesh. Kill a bird that has been fed on corn only, and it will be heavy with layers of internal fat, but showing a very poor depth of breast meat. Balancing rations trying to equalize flesh, fat (warmth), and mineral - is not a very hard proposition when the values of even a few grains and plants are realized.

Having read so far, you will now realize that clover hay, linseed meal, bran, wheat, oats, beef scraps, and skimmed milk contain almost all the equivalents for summer weather food. The addition, therefore, of corn, buckwheat, or rye in cold weather are safe and simple if given only as warmth makers. Never allow the proportion to exceed what is needed for that purpose, or fat will be made and stored internally, neutralizing all your other care. In other words, 


\section{A SELF-SUPPORTING HOME}

the hen fed on corn only, in order to accumulate the ten parts of flesh and twenty parts of fat needed for the egg, will be compelled to acquire fifty parts more fat than she requires.

Now do you see why corn is both dangerous and expensive as an exclusive food, though as a fuel provider on a cold winter night it has few equals?

Green bone and water alone now remain for consideration. The former is without doubt the best of egg foods, qualifying as it does in nearly all the needed elements. Fresh bone from the butcher can be bought for about two cents a pound, and contains the natural meat juices, - blood, gristle, oil, and mineral matter, - in soluble condition, which renders it easy of digestion, especially for birds. Almost all the components for eggs, - white, yolk, and shell, - in the most concentrated form, are there, so if eggs are to be profitable, it must not be neglected. When it is impossible to obtain the green or 


\section{A SELF-SUPPORTING HOME}

fresh bone, the ground, sold especially for poultry, can be used, though it is not half so satisfactory, because the drying process which it has to submit to before grinding leaves little but the phosphate of lime and earthy matter, which clover and bran furnish in a better form. At least half the egg is composed of water, surely reason sufficient for impressing the importance of a pure fresh supply, always accessible, in clean dishes.

The foregoing will enable those who want to make up combinations, from materials at hand, which will include the necessary elements to select for themselves.

\section{THE GUINEA-FOWL}

A trio of ordinary guineas costs about \$2, the pure white, $\$ 4$ or $\$ 5$. They need no special house, all that is necessary for their comfort being a roost high up in a shed. If left to themselves they take to the trees, and 


\section{A SELF-SUPPORTING HOME}

in all probability will get frozen if the winters should be very severe, so the safest plan with new birds is to cover the front of a shed with two-inch wire netting, just tacking it up lightly, so that it can easily be removed at the end of two or three weeks, when they are accustomed to their new quarters.

While they are prisoners, feed the trio two or three times a day; about half a pint of mixed wheat and cracked corn night and morning, and at noon about half the quantity of grain, with a little chopped meat or ground bone, alternating with vegetables. All this food should be cut quite small, or the guineas will not eat it. Like other birds, they must have a constant supply of sharp grit and fresh water.

They are extremely shy, very wild, and suspicious of strange persons and places. Hence the necessity of their long imprisonment. The old home once forgotten and the new one adopted, this very trait, which seems at first disadvantageous, renders them as valuable guardians of your property as 


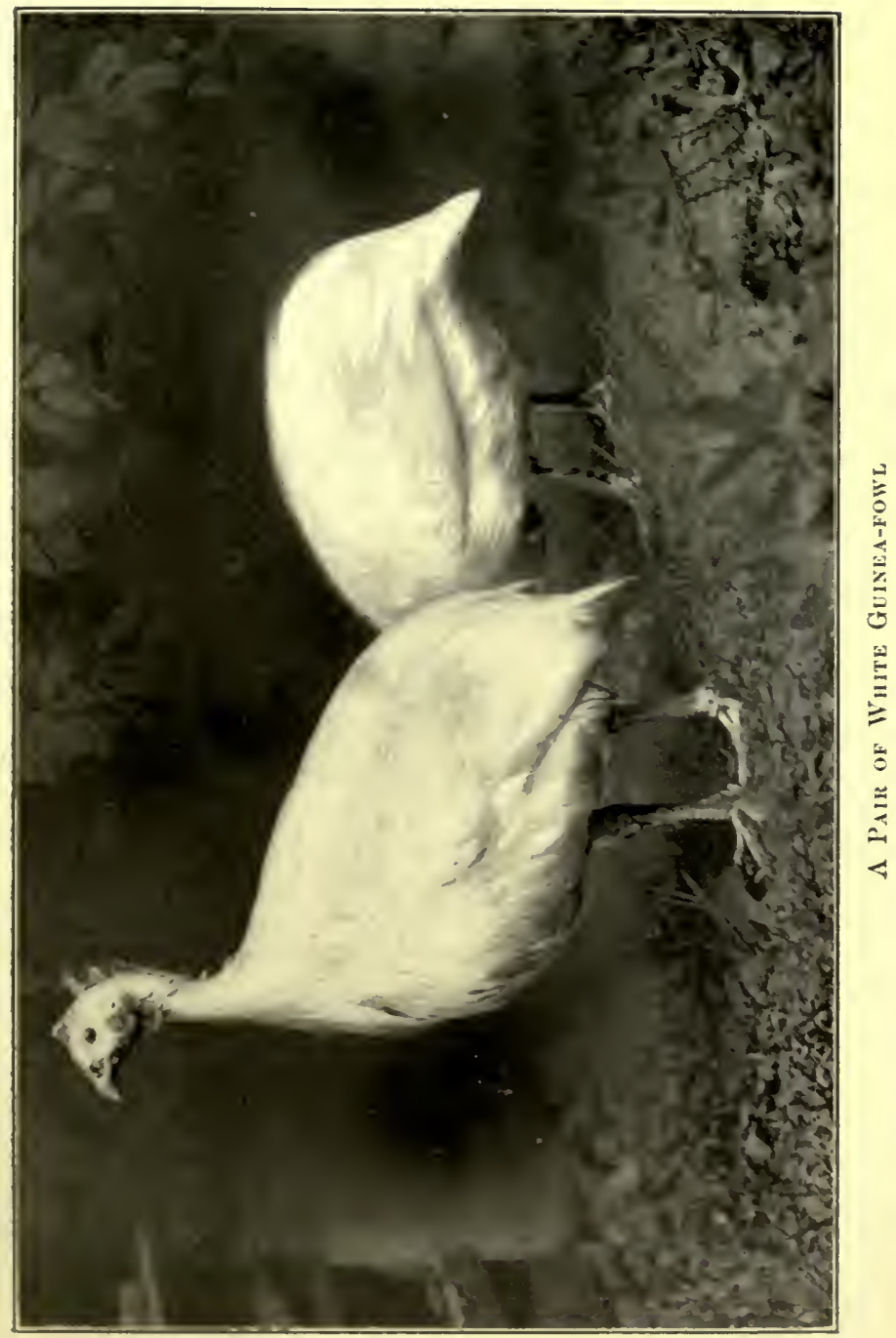




\section{A SELF-SUPPORTING HOME}

the watch dog, in fact, so far as the poultry is concerned, better, for they seem to possess intuition of a hawk's approach, and their shrill cry frightens the chicken thieves more effectually than a gun.

My stock began with a trio from which the first summer we raised thirty-two. We sold four pairs at six months old for a dollar a pair, used eight pairs on our table, and kept eight for stock.

As a market commodity they have been growing in favor for the last five years, since, like squabs, they take the place of game during the closed season.

Guinea-fowls commence laying when the first warm days come in April. As it is their natural instinct to be very secretive about laying, some patience and diplomacy are necessary to locate their nests. The usual spot selected is a hollow in the ground, by the root of a tree or fence post well screened by brush. Don't attempt to approach it while they are in sight. Go away, and re- 


\section{A SELF-SUPPORTING HOME}

turn later armed with a long-handled spoon. The eggs are almost the color of the earth and often covered with fallen leaves, so it needs a sharp eye to detect them. Be very careful not to touch the nest with your hand. Guineas seem able to scent the human hand about the nest, they can also count up to three. For that reason leave that number of eggs in the nest, removing the others with the spoon to insure there being no telltale clew left to arouse Mrs. Guinea's suspicion.

When you have fifteen stolen eggs, get a box a foot square, turn it on the side, and across the bottom of the open front nail a slat, behind which place a nest of soft hay. Stand this nest box inside (at one end) of another box, two and a half feet long, with sides a foot or more deep. Make a cover of wire netting for the large box, to open like a lid. Scatter sand on the floor, nail up a small drinking pan in one corner, and you have a safe, rat-proof coop for Biddy and the eggs. Another motive for the outer box 


\section{A SELF-SUPPORTING HOME}

is that baby guineas are so very little, so wild, and so easily frightened, that they are apt to quit the nest as soon as hatched, get lost, become chilled, and die.

It takes from twenty-five to twenty-six days to incubate guinea eggs. The brood coop to be used the first two weeks should be on the same principle as the nest boxes, and even when they are on the grass run, you must exercise the greatest caution to avoid anything like cracks and crevices in or around the sides, for they are such mites, and have such capacities for getting through the eyes of needles, that special care is necessary. If some knot-hole or some depression in the ground has escaped your vigilance and a baby does stray off, go about two yards away and remain perfectly still. Don't be impatient. It may be ten minutes before you hear anything. Then, unless all hope is over, you will hear a plaintive little cry. Do not move until it has been repeated three or four times, and you are quite sure where 


\section{A SELF-SUPPORTING HOME}

it comes from. Then make a sudden dive and secure the truant, which is usually under a tuft of grass or in some little hole. If you move about while hunting for him, there won't be a sound, and you may search all day with little success.

BILL OF FARE FOR BABY GUINEAS

Give nothing for the first twenty-four hours, then the daily bill of fare should be as follows: First feed, 7 A.M. - Crushed hempseed, half a cup; stale bread crumbs, half a cup; moisten with raw eggs.

Second feed, 9 A.M. - Millet seed.

Third feed, 11.30 A.M. - Chopped onion tops, half a cup of corn meal that has been steamed as for chicks, half a teaspoonful of crushed mustard seed, mixed and fed crumblingly.

Fourth feed, 2 P.M. - Pinhead oats, crushed a little finer than it is when bought. Fifth feed, 5 P.M. - Liver that has been 


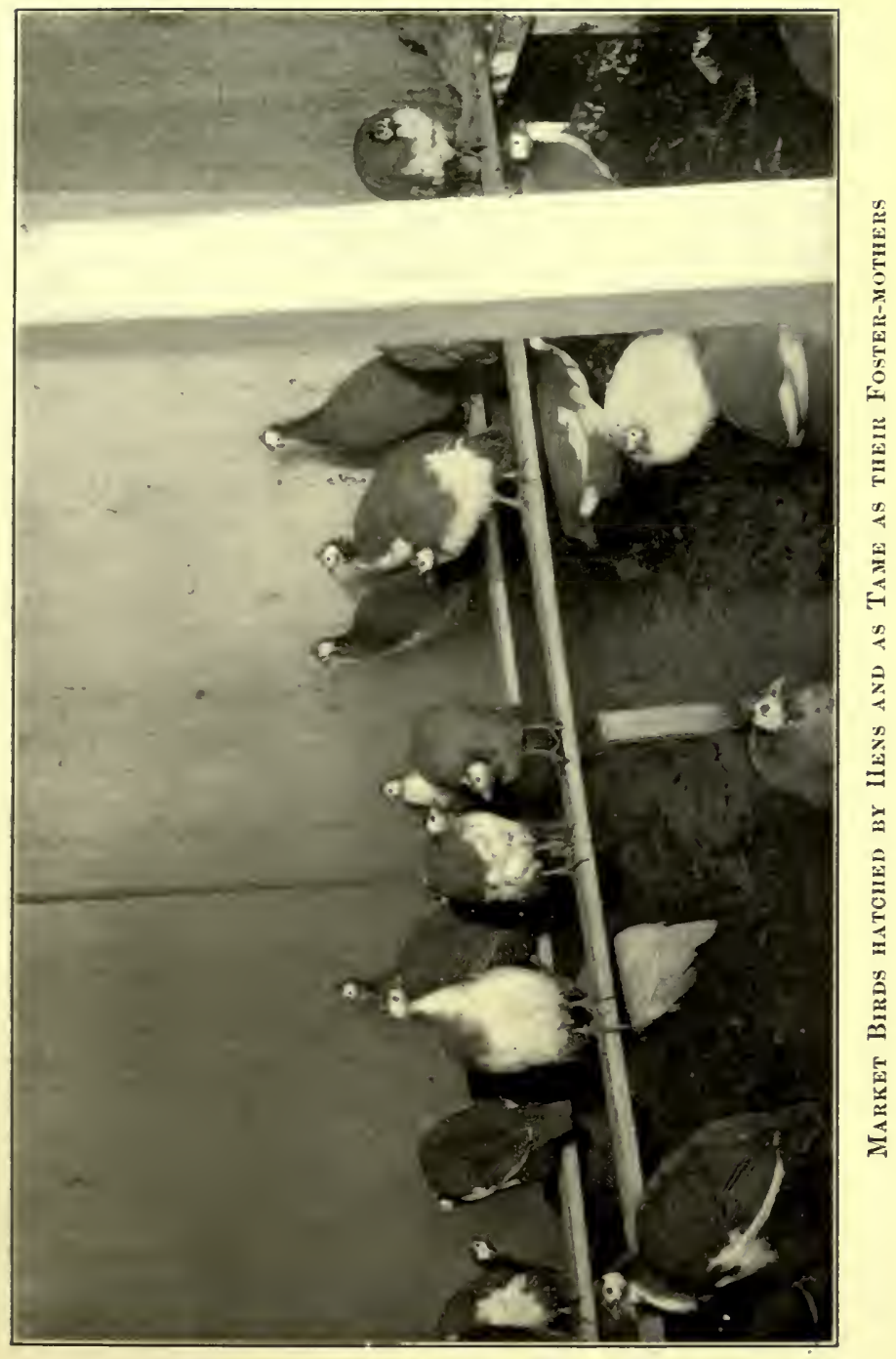





\section{A SELF-SUPPORTING HOME}

half-boiled, cracked wheat and corn, equal parts.

These bills of fare can be varied with pot cheese, custard, chopped lettuce or apple, bread crumbs moistened with milk, hardboiled eggs, but every day they must have meat (more than chicks need), and pepper or mustard seed crushed and fed in soft wood. Keep a small pan of powdered charcoal and sand in the run, and, of course, water in a drinking fountain that will allow only the beak to get wet.

The first eggs I stole out of old "Coquelin's" nest (that was the name we gave one of the first guineas we had) I placed under a little bantam hen, and she brought off every one. When she tried to leave them after six weeks, she and I both discovered that to hatch guinea chicks was a much greater responsibility than any ordinary hen ever contemplates. Their mother is their mother, and can be nothing else until the following spring. Then they mate, and mamma is 


\section{A SELF-SUPPORTING HOME}

deserted. That whole summer those nine guineas would sit solemnly round that little bantam while she laid, and they always trotted into the chicken-house and roosted on either side of her. That is one of the reasons why it is good to hatch these little birds under hens, - all trouble in getting them to behave like domestic house-living birds is solved.

For home and our own consumption, we cross the speckled and white varieties, because it improves the color and flavor of the flesh, which resembles that of the English grouse so closely that we consider guineas one of the luxuries country life has supplied us. Our method of preparing is simple, but most appetizing.

Birds killed at least twenty-five hours before required. A generous tablespoonful of butter, an onion split in four, a green pepper divided in a like manner, are placed in the body of the bird, which is then trussed, covered with salt pork, laid in a roasting-pan 


\section{A SELF-SUPPORTING HOME}

breast down. After twenty-five minutes of a quick oven, the pork is removed, bird turned on to back, covered with a dredging of flour, pepper, and salt, then replaced in the oven to brown. The result is a deliciously flavored delicacy when served with brown gravy made from giblet stock in which an onion, stuck with cloves, half an inch from the end of an unpeeled lemon, peppercorns, and salt, have been simmered. Strain, and add half a wine glass of port wine, a tablespoonful of red currant jelly. Bread sauce also accompanies roast guinea-fowl, to accentuate the resemblance to game. 


\section{CHAPTER VI}

\section{FEBRUARY}

THERE is a feeling of responsibility about 1 the acquisition of an incubator that seems to inculcate a practical business spirit most satisfactory to the evolution of a selfsupporting condition; so do not hesitate to buy one, even if a few dollars have to be borrowed from the master of the house or the emergency fund.

Early spring broilers are so profitable that every effort should be made to produce them. Hens cannot be depended on to hatch in February - or even March, if the weather remains cold; and chickens, weighing from three quarters of a pound to a pound and a quarter when dressed, will bring 50 cents a pound in March and April.

The up-to-date incubator is so well made 



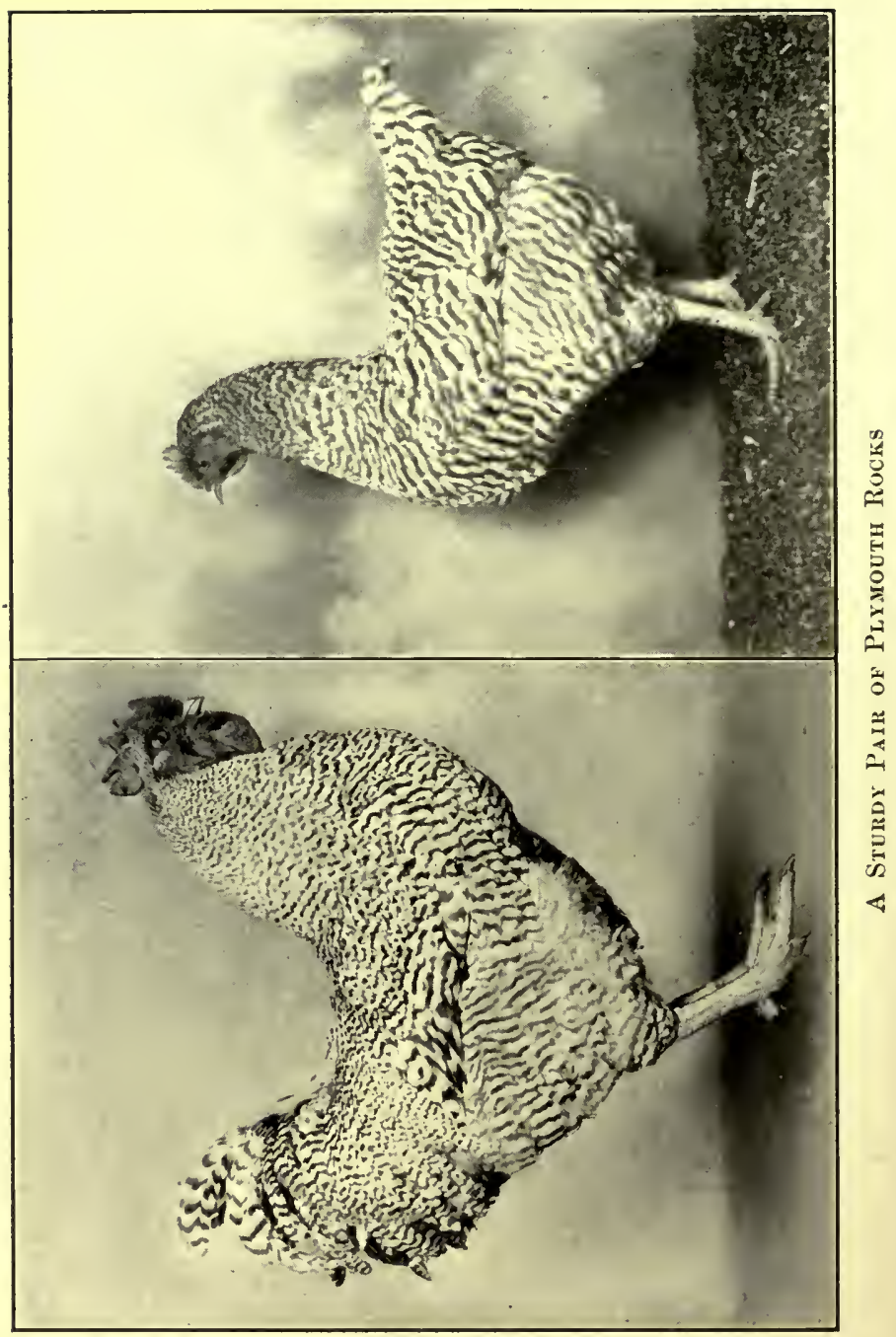




\section{A SELF-SUPPORTING HOME}

and so easy to operate that any one with ordinary intelligence and straight common sense need have no fear of undertaking the care of it.

There are many different makes of incubators; some are heated by steam, others by hot air. Personally, I prefer the latter,

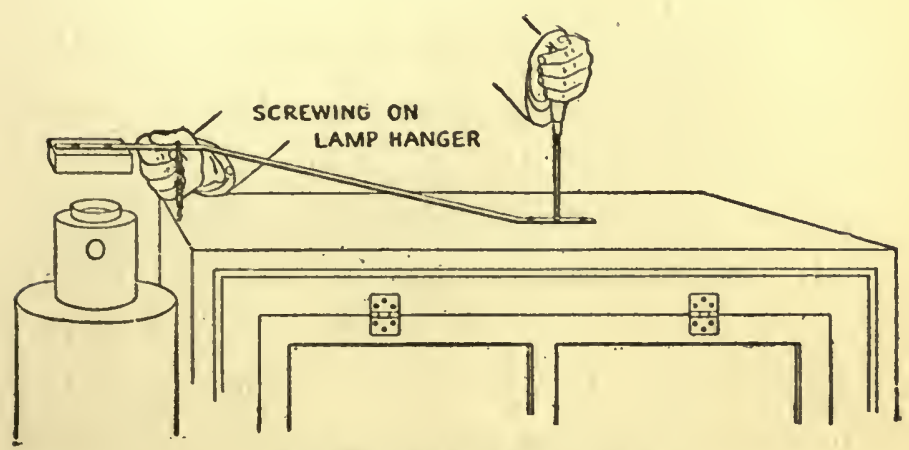

'The Machine Ufside Down

as there are no water tanks to spring leaks. A machine holding one hundred and twenty eggs is a convenient size, and costs about $\$ 20$ from any of the best firms.

For safety during transit, incubators are shipped with the legs, lamp-stand, ther- 


\section{A SELF-SUPPORTING HOME}

mostat, or regulator-arm being attached; so, after uncrating the new machine, the first consideration is to connect these parts. Screws of correct size are sent, and the easiest method of proceeding is to turn the machine upside down on the floor and fix the lamp-stand in place, being careful that the block of wood at the end of stand, on which the lamp really rests, is immediately and evenly below the opening of the heater chimney. After the stand or support is in place, should the block lean to the right or left, the support, which is made of metal, can easily be bent while the machine is upside down. Try putting the lamp in place, to ascertain if the angle of support is correct to insure the neck of chimney fitting evenly round the burner. The slightest inaccuracy in the contact of the two circles will cause the lamp to smoke; soot will accumulate and ignite, and in all probability it will end in consuming machine and contents in the middle of the hatch. 


\section{A SELF-SUPPORTING HOME}

After the lamp-support is in place and properly adjusted, put two empty boxes about twenty-four inches high, a little over a foot from and parallel with the back and front of the incubator, which is to be lifted up and turned over to rest on the boxes whilst the legs are put in place. Be careful that they fit evenly against the machine; then make a hole with a small gimlet where the manufacturer's marks indicate the screws ought to

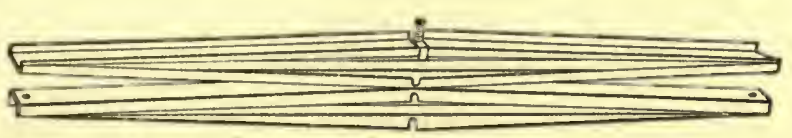

'Thermostat

be inserted. The punctures must be perfectly straight, as any diversion would prevent the screws going "home truly" and in all probability throw the legs crooked.

The next important item is accuracy in connecting the thermostat, which goes inside the machine, to the regulator-arm, which fits into a pivot at the top of the machine, and which is accomplished by means of the wire 


\section{A SELF-SUPPOR'TING HOME}

connecting rod, on whose nicety of responsiveness to pressure depends the self-regulating possibilities of the modern incubator. Unless its passage through the several attachments is uniformly even and free from friction, the value of the thermostat is lost. This will be obvious when the method of controlling heat is understood.

The thermostat is composed of a combination of such materials as aluminum and steel.

\section{The Regulator-arm}

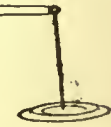

Being extremely sensitive to heat, it expands and contracts with every fluctuation of temperature within the incubator. The regulator-arm has a counterbalance ball at one end and a metal disk at the other, and when it rests on the pivot which is fixed at the top of the machine, the disk should be suspended directly over the lamp chimney. The connecting rod has two nuts at the top, and one 


\section{A SELF-SUPPOR'TING HOME}

at the lower end; the latter is removed entirely, and the former loosened to the extremity of the rod, before it is run through the regulator-arm and pivot on the exterior, and through the hot air space and thermostat in the interior of the machine; at which point

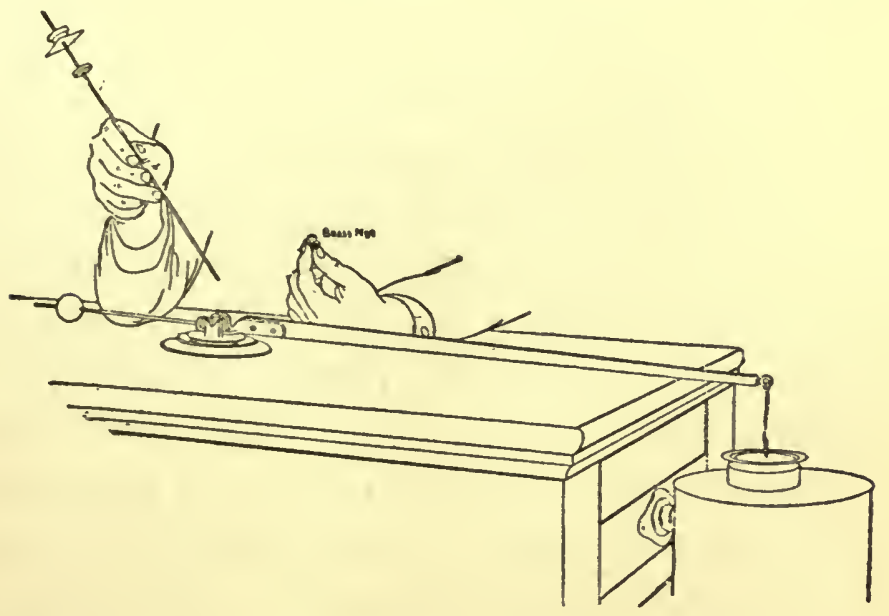

the lower nut is replaced and screwed up to hold the thermostat closely against the burlap ceiling of the egg-chamber.

After the lamp is lighted and the machine heated to one hundred and two and a half 


\section{A SELF-SUPPORTING HOME}

degrees, the top or regulating nut on the connecting-rod, immediately above the regulatorarm, is screwed down until the disk is raised one-fourth of an inch above the chimney such adjustment being considered by manufacturers and expert operators as most desirable for incubation. The machine once being "set" for this degree of temperature, any excess of heat causes the thermostat to expand, which makes it press on the lower nut of the connecting-rod; so instituting a tension that influences the regulator-arm at the point of balance, raising the disk over the lamp chimney in sympathetic conjunction with the thermostat.

Reverse the condition to a dying lamp or sudden cold wave, and of course the thermostat contracts, and general release of pressure allows the regulator-arm to resume a normal balance, which permits the disk to lie closely down on the chimney. It will be readily conceded that on a correct adjustment of the machine before starting the hatch depends 


\section{A SELF-SUPPORTING HOME}

the operator's peace of mind and subsequent success.

An appropriate location for the incubator also needs due consideration. The cellar, if well ventilated and dry, is the best place; but underground places in farm-houses, in which fruit or vegetables are stored, cannot be properly aired in frosty weather. A room on the first floor is the next best location, if it can be spared, for then the window can be opened a little from the top every day, no matter what the weather. Draughts must be avoided; they are apt to drive the air in one direction in the egg chamber, when it should be evenly distributed over all the eggs. This same trouble will arise unless the machine stands evenly. A carpenter's spirit level should be used when the machine is set up, to insure this.

The incubator being properly located, fill the lamp, light, and hang in place, using only a moderate flame at first. Leave all the ventilators open for a few hours, to thoroughly 


\section{A SELF-SUPPORTING HOME}

air the machine; then close and proceed to adjust the regulator so that an even temperature of one hundred and two and a half degrees, with the disk one-fourth of an inch above the lamp chimney, is steadily maintained for twelve hours before setting the eggs. Patience and scrupulous exactness at first will save accident and loss later.

When the cold trays and eggs are first put in, the temperature will run down, but do not turn up the lamp or alter the regulators. As the eggs gradually become warm, the thermometer will creep up again. After the first day, the trays must be taken out every night and morning, and the eggs turned and allowed to cool to ninety degrees. The time allowed for the process must be regulated by the atmosphere of the room; if very cold, five minutes may be enough; if moderate, twenty or thirty may be needed. They must not be allowed to chill, but the more airing they get under that point, the stronger the chickens when hatched. 


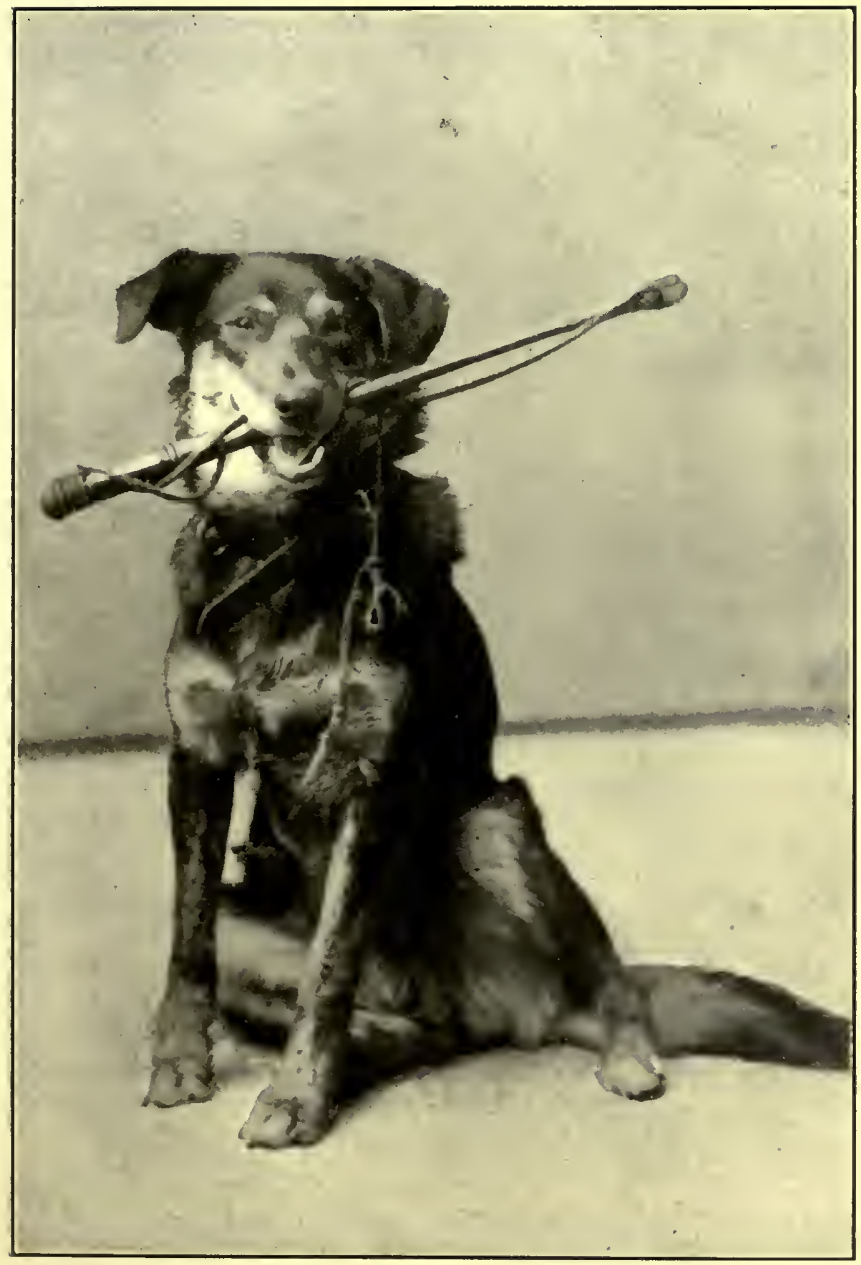

The Head Herdsuax 



\section{A SELF-SUPPOR'TING HOME}

The eggs should be tested on the seventh and fifteenth days. This is best done by a block-tin device sold by all incubator companies.

Infertile eggs appear quite clear when placed before the spot through which the light shines. They can be used, when boiled hard, to feed the young chicks when they arrive.

Weak or dead germs are difficult for the amateur to distinguish, so sacrifice two or three that look pale and

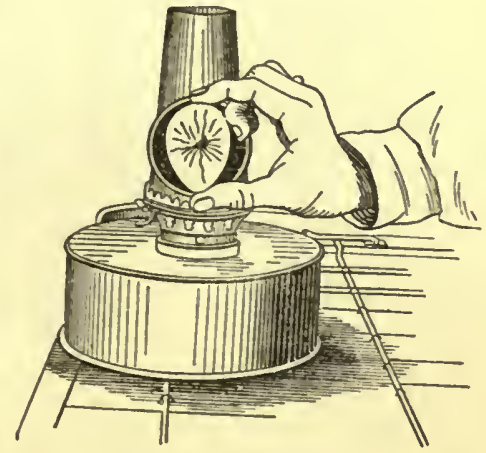
undeveloped in contrast to strong, unmistakably vigorous ones. Break the doubtful ones into a saucer and study closely. If there are many you are doubtful about, mark them with a pencil and test again on the tenth or twelfth day. When an egg containing a strong germ is held up to the 125 


\section{A SELF-SUPPORTING HOME}

light of the tester, a solid spot about the size of a pea, from which vinelike tendrils extend, can distinctly be seen floating about the centre of the egg. Dead germs, on the contrary, usually adhere to one side. Only experience enables one to test with certainty.

You may ask, why risk taking any out? The answer is, a dead germ causes the whole egg to decompose. The shell being porous, the harmful gases escape into the incubator and poison the air on which the embryo chicks feed.

To regulate the necessary ventilators is even more difficult than to keep the heat even. The guide is the air space at the top, or large end, of the egg. If this expands too quickly, there is too much ventilation; if too slowly, there is not sufficient. The safest way to study this point is to get one or two broody hens, set them at the same time as the incubator, then ventilate so as to have the incubator eggs exactly equal to those under the hens.

After turning the eggs and replacing in 126 


\section{A SELF-SUPPORTING HOME}

the machine on the morning of the nineteenth day, do not open the door again until the twenty-second day. To a beginner, this is a most difficult exercise of patience. More chicks found dead in the shell are due to

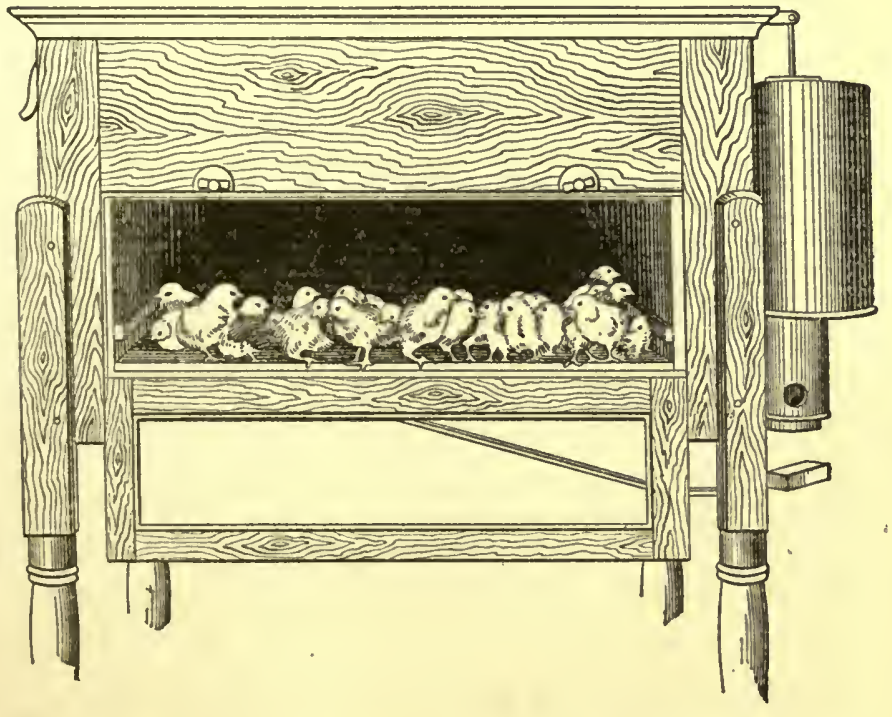

opening the door and taking out those newly hatched, than to any other cause. This late opening allows the moisture to escape just when it is most necessary. 


\section{A SELF-SUPPOR'TING HOME}

\section{POULTRY YARD}

The mature hens which are to furnish the eggs for the incubator need special care. Should the weather be excessively cold, it will be advisable to remove the roosts and fill the corners with large piles of bedding hay. Natural instinct will make the birds climb to the highest available spot to roost, which will compel them to crouch on the hay, where their own weight will gradually sink them sufficiently to provide a warm bed and prevent all danger of frozen combs and feet, which is much to be desired, not only from a humane standpoint, but selfishly; for anything which militates against the hen's tranquillity and comfort affects her productive powers.

The best supper for zero nights is undoubtedly the much-condemned whole corn. Fill shallow pans early in the afternoon, and place in the oven to heat; but remember that when fed, it must only be warm. Fill drink128 


\section{A SELF-SUPPORTING HOME}

ing pans three times a day with water from which the chill has been removed; leave fifteen minutes, and empty. Keep up the supply of crushed bone and lean meat and some sort of green food; then there will be more fertile eggs and stronger chicks.

Our first February on the farm was one continuous snow-storm, rendering out-of-door work impossible. So, realizing that even with our incubator and brooders at work, some families would have to be reared under hens, leisure daylight hours were occupied in building coops, the dimensions of which were:-

Two feet wide, two and a half deep, two feet high in front, and one and a half in back, roof to extend three inches beyond the sides all around. The floor fits inside and has two cleats of four by four, nailed on three inches from the back and front, and,extending an inch and a half out each side. The sides of the top, too, have corresponding pieces cut out, so that the coop fits down over the edge of the floor on to the cleats. 


\section{A SELF-SUPPORTING HOME}

To clean you have only to lift the coop off the floor; and the cleats raise the coop from the ground, so preventing it from being damp. In front, cut an opening nine inches high, seven wide, and make a slat door to fit over it, which will allow the chicks to run in and

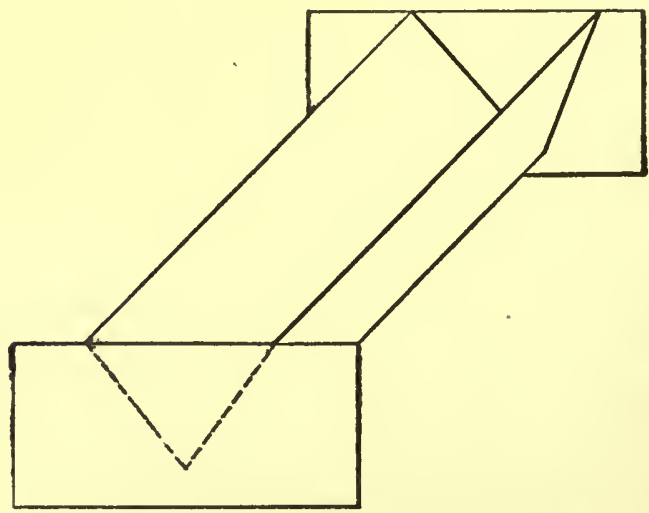

Feed Trodgh made from Four Straight Pieces of Board

out. Hang the door inside the coop from the top. This has the advantage that the hen can't push it open, but when she is to come out, it can be hooked up out of the way, leaving the outside of the coop free for the night door, which should be made of 


\section{A SELF-SUPPORTING HOME}

half-inch wire netting, to allow ventilation and prevent chicks from getting out or night prowlers from getting in. To make the house quite safe from summer showers, cover with roofing paper or paint.

If you have many families, time will not allow all to be provided with such model dwellings; so you may have to resort to a barrel tipped over on its side. If so, prepare some stakes, which will be needed on each side to fix it when placed for use. To make it habitable, throw three or four shovelfuls of dry earth into it, and on that some cut hay. Make a gate of slats for the front to keep Biddy in, and cover all over the top with roofing paper, putting a straight strip about four inches deep across the top of the front, to prevent rain from beating in. A light piece of wood put up against the slat door and held in place by a stone will close up safely for the night.

Individual drinking fountains will also be required, and though the correct galvanized ones cost only thirty-five cents for the quart 


\section{A SELF-SUPPORTING HOME}

size, many become a consideration; so wellmade cans, such as syrup or tomatoes come in, should be collected and cleaned, and a hole a little larger than a pea punched half an inch from the edge. This can be accomplished by placing the point of a large nail against the inside of the can as it lies on the work-
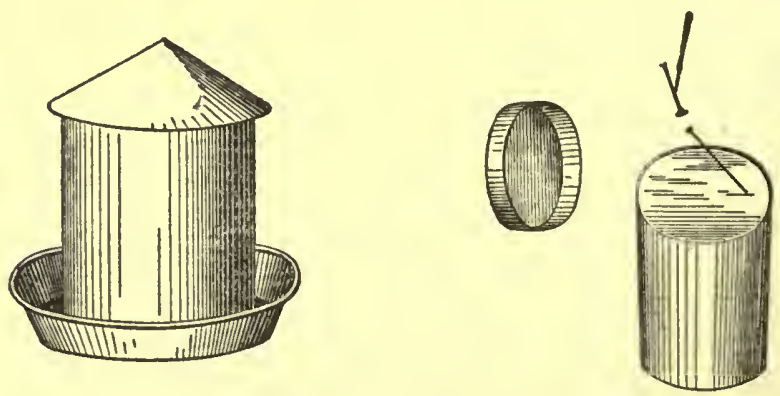

bench, and hitting the head a sharp blow with the hammer. Deep pie plates one inch wider than the circumference of the can were bought at seven cents each, and converted the old can into a self-feeding water fountain, in which no chick could possibly commit suicide or even get itself wet enough to cause chill and bowel trouble. 


\section{A SELF-SUPPOR'TING HOME}

The long evenings gave us plenty of time to plan the garden on paper and make our seed lists, all of which saved time when it was of greater value. Every family will, of course, have especially preferred vegetables to take precedence over others, so individual taste alone can determine the allotted space for each variety. Our selection plan was made with due regard for table, pickles, and preserves, all of which it bountifully supplied. Therefore if your discrimination on such subjects is too undeveloped
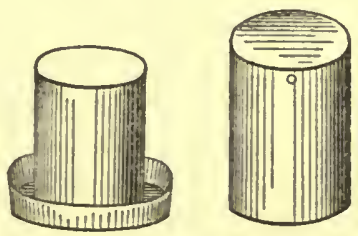
as yet to be trusted, accept our experience this year; by next you will know how to reconstruct it to your personal needs. When planning out on paper, the second crop should be considered as well as the spring sowings. Then there will be no uncertainty and loss of time later. 


\section{A SELF-SUPPORTING HOME}

\section{Vegetable Seeds}

$1 \mathrm{pk}$. of "Bovee" Potatoes for early garden crop • . \$ $\$ .75$

$1 \mathrm{oz}$. Carrots, "Oxheart" . . . . . . . . . . . . .

1 pkg. Cauliflower, "Early Snowball" . . • . . . . . .

1 pkg. Celery . • • • • • • • . 10

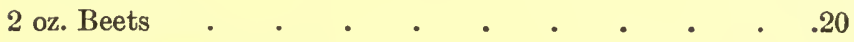

1 pkg. Brussels Sprouts • • • • • • • $\quad$ • 10

1 pkg. each of "Jersey Wakefield" and "Autumn King"

Cabbage • • • • • • • • • 15

1 oz. Kale, "Dwarf Green" . . . . . . $\quad$. $\quad$. 10

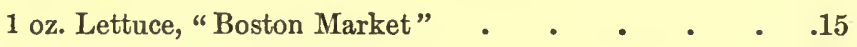

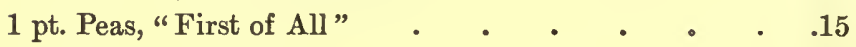

$\frac{1}{2}$ pt. Peas, "Petit Paris" . . . . . . . $\quad$. 10

1 qt. Peas, "Champion of England" . . . . $\quad$. $\quad$.

1 pkg. Turnips, "Early Flat Dutch" . . • . . . . . •5

1 pkg. Turnips, "Purple Top Aberdeen" . . . . . . . .

1 pkg. Turnips, "Ruta Baga" . . . . . . . . . . .

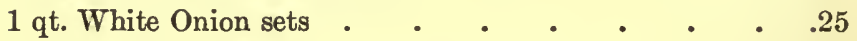

1 qt. Red Onion sets . . . . . . . $\quad$ • $\quad .25$

$1 \mathrm{oz}$. "Prizetaker" Onion seed for next year sets . $\quad .20$

1 pkg. Cucumber, "White Spine" • • • • . .10

1 pkg. Egg Plant, "N. Y. Spineless" . . . . $\quad .10$

$1 \mathrm{pkg}$. Tomato, "Crimson Cushion" $\quad$ • $\quad$ • $\quad$ • $\quad .10$

1 pkg. Pepper, "Ruby King" • • • • • • . .10

1 pkg. Musk melon, "Delmonico" • • • • • . .10

1 pkg. Squash, "Long Island" (summer) . . . $\quad .10$

1 pkg. Squash, "Gregory" (winter) . . . $\quad .10$

1 pkg. Green Bush Bean, "The Longfellow" . . . .10

$1 \mathrm{pkg}$. Pole Lima Bean, "Leviathan" . . . . . .10

1 pkg. Okra, "Long Green" . . . . . . . . . . . . . .

1 oz. Radish, "Scarlet Turnip" . . . . . .10 


\section{A SELF-SUPPORTING HOME}

1 pkg. Corn, "Country Gentleman" . .15

Herbs - 1 pkg. each - Parsley, Sage, Summer Savory,

Thyme, Marjoram, Aniseed, Wormwood, Saffron,

Tansy

$\cdot \frac{.40}{\$ 4.95}$

\section{Flower Garden}

$1 \mathrm{pkg}$. Ricinus (castor oil plant) . $\quad . \quad$. $\$ .05$

1 pkg. Japanese Tassel Asters. • • • • • • 15

1 pkg. Balsam . . . • • • • • • 10

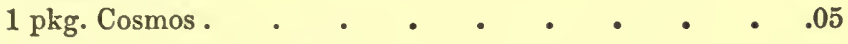

$1 \mathrm{pkg}$. Hollyhocks • • • • • • • • 10

1 pkg. Larkspur • • • • • • • • • $\quad .05$

1 oz. Nasturtiums, Tall • • • • • • • 15

1 oz. Nasturtiums, "Tom Thumb". . 15

1 pkg. Pansies . • • • • • • • • 05

1 pkg. Pinks . . . . . • • • $\quad .10$

1 pkg. Salvia, "Scarlet Dragon" . . . . . . . . . 05

1 pkg. Stocks • • • • • • • • • .05

$1 \mathrm{pkg}$. Sweet-william $• \quad \cdot \quad \cdot \quad \cdot \quad \cdot \quad \cdot \quad .05$

$1 \mathrm{pkg}$. Verbena $• \quad \cdot \quad \cdot \quad \cdot \quad \cdot \quad \cdot \quad \cdot \quad \cdot 10$

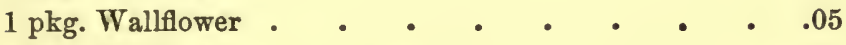

$\frac{1}{2}$ pkg. Sunflower - • • • • • • $\frac{.15}{\$ 1.40}$

One of the advantages of sending for seeds early is that you are sure to get the varieties selected, whereas later in the season "the best" is frequently sold out, and you will either be sent old seed, or some inferior va- 


\section{A SELF-SUPPORTING HOME}

riety as a substitute. Another advantage is not being kept weeks for seed which should be in the ground. Send for your supplies to an old established firm; "bargains" are the most reckless waste of money.

If the "Home" is to be an ideal haven of rest, it must be pretty. Economy will prohibit buying plants for the flower garden the first summer, but exercising a little forethought now will enable you to have a lovely display of flowers all through the summer at a normal cost. Procure some shallow boxes from your grocer. They should not be more than three inches deep, and about a foot and a half long and a foot wide. If it is not possible to get what you want, saw a six or seven inch box in halves, using the lid as a bottom for the second box. It will be well to provide quite a number of these boxes, as you will want them for vegetable seed unless you have a hotbed - a luxury which is hardly to be indulged in the first year.

Drainage is essential in the boxes to be 136 


\section{A SELF-SUPPOR'TING HOME}

used as nursery beds; so, unless there are cracks between the strips of wood at the bottom, bore holes with a bit or a red-hot poker; then fill up to within half an inch of the top with the compost made in November. Let the boxes stand a few days in a warm room, to induce any weed seeds which may be lurking in their depths to germinate; for it is much easier to destroy these pests before the boxes are planted than after.

Have the mould thoroughly pulverized before sowing, and prepare an extra quantity to use for covering the seeds. This I do by halffilling a rather fine colander and shaking it over the box until there is an even layer over the seeds. The average small flower seed should not have more than the fourth of an inch over it. A board that will fit inside the box should be firmly pressed down to insure the seeds being firmly embedded in the mould. Otherwise the air gets round, dries up and kills the first frail germs of life. After planting and patting down, 


\section{A SELF-SUPPORTING HOME}

sprinkle lightly and stand the boxes on a south or southwest window in a living-room where the temperature averages sixty degrees. Until the seedlings show above the ground, it is advisable to keep a sheet of window glass over them, raising slightly at one end at the middle of the day for ventilation. If the nights are very cold, throw a woollen cloth or newspaper over and around the sides of the boxes, to avoid frost.

The seeds to be started this month are, for the flower garden: hollyhocks, wallflowers, pinks, pansies, verbenas, stocks, sweet-williams, nasturtiums, salvia. When ordering seeds, specify that annual hollyhocks and wallflowers are desired, else you will get no blossoms the first year from these plants.

For the vegetable garden: cabbage, cauliflower, Brussels sprouts, and lettuce.

For the last two years we have filled about two dozen empty paper cases in which breakfast cereals come with rich mould, and in the middle deposited half a potato. These 138 


\section{A SELF-SUPPOR'TING HOME}

are watered and placed near the cellar windows, where they sprout and become sturdy plants by the time the ground is fit to work in the garden, when the cases are cut in all directions with the point of a sharp knife, care being taken not to disturb the mould in any way. A hole is made in the ground and the box submerged. Soon the force of the growing plants demolishes the rotting paper of the box; the tubers continue to develop without check, and furnish new potatoes for several dinners in May, when they are luxuries and so duly appreciated.

Rhubarb and asparagus can be considerably hastened in the garden by covering clumps with barrels which have had the heads knocked out, or empty cases. Whichever are used, the treatment is the same. Place the "protector" firmly over the plant, and bank up leaves or straw and stable manure all round the outside. At night or on very cold days, cover the top of the shelter with burlap, glass, or oiled muslin. 


\section{A SELF-SUPPORTING HOME}

The latter is easily fixed and can be used for such a multitude of purposes both in the garden and about the poultry houses, that if you can spare the time, make a few differentsized frames of shingle slats; cover them with cheap muslin, using half-inch wire nails and stretching the muslin as evenly as possible. Then with a paint brush give the whole surface a coat of linseed oil. When it dries, you will have a capital imitation of a hotbed sash, which is light to handle, not easily broken, nearly as transparent as glass and quite as protective. 


\section{CHAPTER VII}

\section{MARCH}

MY first experience with incubator chicks 1 was undertaken without any equipment. Needless to say, it was accident, not design, which led me into such a rash proceeding; for even the enthusiasm of an amateur has its limits. The farm was still in the primitive condition of depending on old biddies for all hatching, when the peace-banishing gift of one hundred and sixty-three chicks was bestowed on me by a young fellow who had started an incubator and who, on the very day the chicks were coming out, was compelled to return to the city.

The fluffy little fellows looked so pretty that I was delighted with my present, until the problem of keeping them warm through the night had to be solved. After much 


\section{A SELF-SUPPORTING HOME}

cogitating, cut hay was scattered on the bottom of two large wash-tubs, which were placed before the open fire in the dining room. Then we heated bricks, wrapped them in flannel, and placed two in the centre of each tub. As the chicks were put in they cuddled up to the warmth, apparently utterly oblivious to its stony lack of feeling. A strong string was stretched from handle to handle, to prevent the heavy blanket with which the tub was to be covered from sinking down and smothering its tiny inmates.

All was peace and quiet for about half an hour; then a series of discontented chirps started in both tubs. Investigation revealed the fact that the bricks were nearly cold. What would retain the heat? Two gallondemijohns were filled with boiling water, and replaced the bricks; peace reigned, and forthwith $I$ resigned myself to arising once or twice during the night to refill. Suddenly a commotion started in one of the tubs. The blanket was removed to discover the 


\section{A SELF-SUPPORTING HOME}

cause. One of the demijohns had cracked, and the poor babies were floating about in hot water, from which they were rapidly scooped out by the handful, and deposited on the hearth-rug to dry, apparently not much hurt. Hot water obviously was not safe. Once more, what would retain heat?

A flash of inspiration suggested baked corn. It was one A. M. before a sufficient quantity could be made hot enough, but it did keep warm till seven o'clock. Baked corn proved so safe as a warmth retainer, that for a week all went well. Then, the half-dormant infant period being passed, it became evident that outdoor air and exercise were necessary during the day. A hundred and sixty-three chicks do not seem very formidable when confined in a brooder; but oh, their mighty numbers when sudden capture became necessary in a thunder-shower ! The exercise would have profitably employed a large class of physical-culture students perhaps, but wrestling alone with such living. 


\section{A SELF-SUPPORTING HOME}

atoms of quicksilver reduced me to a skeleton, and ninety unfortunate chicks to untimely graves.

My tale of disaster has been told only to warn any misguided creatures who think they can manage without a brooder.

For the beginner, with only one or two incubators, the individual brooder is undoubtedly the most convenient, because the long house, fitted with boilers and hot water or steam pipes, necessitates a large outlay. First, there is the building and plumbing; then the whole house has to be heated, even if only one section is being used. Last, should any accident happen to the boiler or fire when the house is filled with chickens, all suffer.

The individual machines are divided into two classes, there being only $\$ 2$ difference between their prices. The out-door is really the cheapest, because it can be used in any light, sunny shed, or in the house in cold weather. 



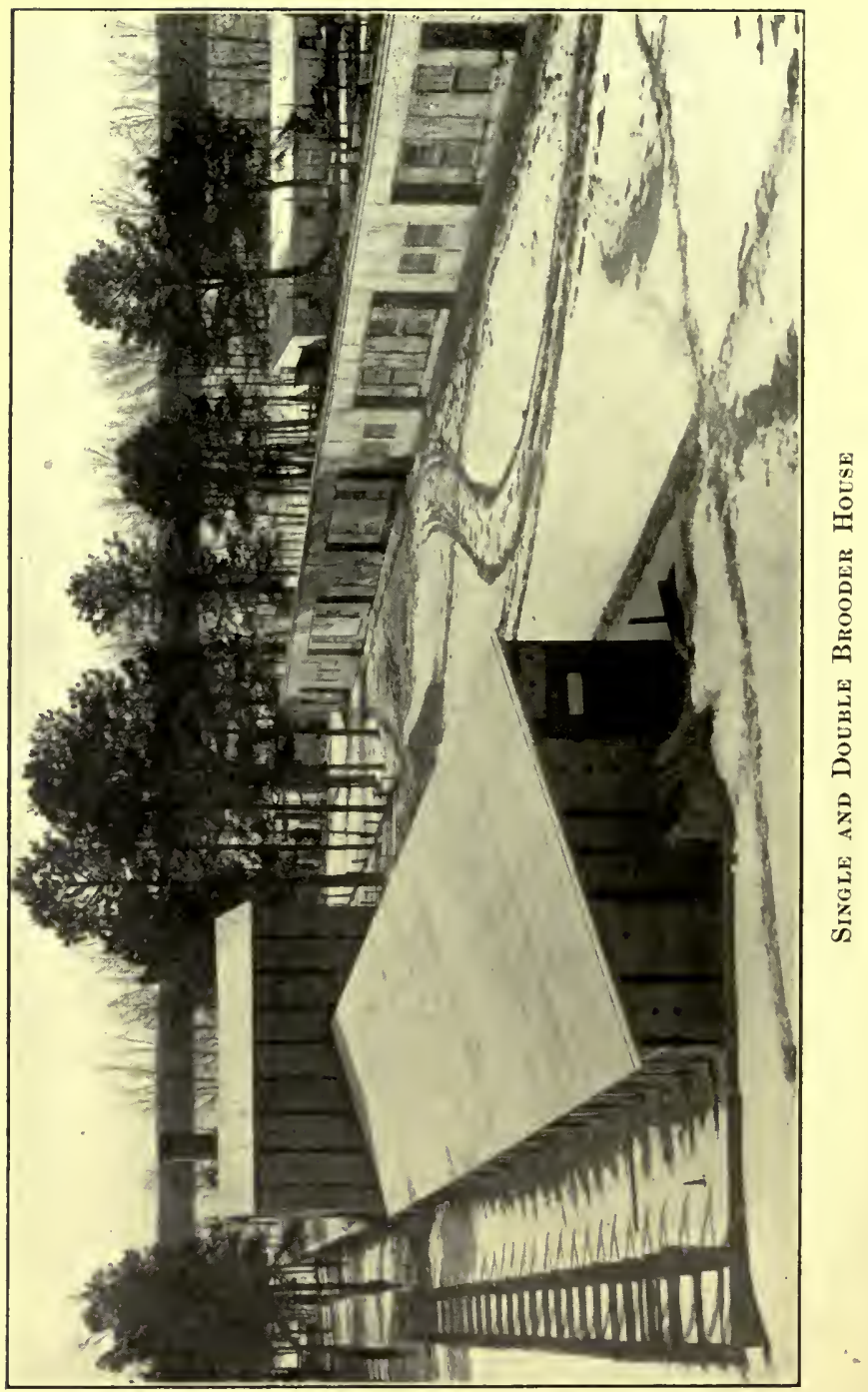




\section{A SELF-SUPPORTING HOME}

Every incubator which holds one hundred and twenty eggs will require three brooders of the hundred-chick size to rear its output, even if only seventy-five per cent of the eggs hatch, because a brooder of that size can accommodate only fifty chicks when they are two weeks old, and twenty-five when they are three weeks old; and the second lot will hatch when the first are twenty-three days old, if the machines are kept running closely. Crowding is disastrous. The round hover used in nearly all the brooders now does away to a great extent with the crushing up into corners; but if the temperature is allowed to run down, there is a natural tendency to crowd into a bunch, which usually results in the unfortunate weaklings of the lot being crushed to death. Another objection to large brooders is the impossibility of keeping the air in them fresh during long, cold nights.

In preparing the brooders, mix an ounce of crude carbolic acid in a pailful of white- 


\section{A SELF-SUPPORTING HOME}

wash, and give the brooder a coat on the inside. When dry, fit a piece of carpet or felt all over the floor of the sleeping compartment, and make a slip cover of cotton flannel to go over the hover and floor, fastening it down with large drawing-pins in each corner. Have two of these slip covers to each brooder, and change at least three times a week, having them washed and boiled each time they are removed.

The outside or feeding room is best carpeted with cut hay. We keep the sweepings of the hay-loft for this, as it is fine, and keeps the small chickens busy scratching for food and seeds.

If a fountain is to be used, stand it on a piece of wood to keep it out of the dust, of course being sure that the chickens can reach it. If you have no fountain, fasten a small cup to the side of the brooder; but do not think that a cup or dish on the floor is easier and just as good, because half an hour after it has been put in you will find it minus water, 


\section{A SELF-SUPPORTING HOME}

filled with the cut hay' or whatever you use, and the floor wet and mussy.

At the front of the feeding compartment is a small door to open and let out the babies into a run, which should be made of slats and one-inch wire netting - as wide as the brooders, six feet long, one high, and the top made to open like a box-lid, for convenience.

Everything being ready, start the lamp burning, at first leaving the doors, or lids, open about an inch. Close after a few hours, and get it running steadily at ninety-five degrees, for twenty-four hours before you expect to use it. Remember that too much or too little heat is as dangerous in a brooder as in an incubator. Many beginners will use the greatest care in hatching the eggs, and then spoil everything by neglecting the chicks in the matter of heat, and so lose them by the dozen.

Commence with ninety-five degrees; the second week lower gradually to eighty-five, decreasing that till it is at seventy at the end 


\section{A SELF-SUPPORTING HOME}

of the fourth week. Always take the temperature from the thermometer under the hover.

Most brooders have some means of shutting off the sleeping room from the play room, which must be closed before putting in the chicks, for at first they could not endure the low temperature of the outer room; but unless prevented they will run right away from the heat and get chilled. So they must get gradually accustomed to their surroundings.

If, however, your brooder does not have this arrangement, just close the opening with a clean old blanket, or even newspaper; but do not use a board - it may tumble down and hurt some of the babies.

Being in the brooder, all that they need for twenty-four hours is fine gravel and charcoal, scattered on the flannel covering the floor. For the first few nights it is advisable to see that all the little folks are safely under the hover curtain, for, having no mother to 


\section{A SELF-SUPPORTING HOME}

cluck them to bed, they are apt to go to sleep in one of the outer corners.

Never neglect airing the brooder at least twice a day. Any carpenter can make an extra cover for the hover like the one which comes with the brooder; it is a simple matter to tack a fringed piece of flannel or felt round it, and having the two, one can be exposed to the sun and air for hours every day, without inconveniencing the chicks.

FOOD FOR THE FIRST TWENTY DAYS

Nothing for the first twenty-four hours, because the yolk of the egg, which is absorbed into the abdomen, must be digested and assimilated before any other food is taken, or the bowels become congested, dysentery sets in - or at least indigestion; the result being slow-growing, scraggy chicks, which are a misery to themselves and a disappointment to their owners.

The second day, hard-boiled eggs, chopped 149 


\section{A SELF-SUPPORTING HOME}

fine without removing the shell, and mixed with equal parts of dry bread crumbs; to each cupful, add one dessert-spoonful of powdered charcoal.

For three weeks, "little and often" should be the rule. We feed five times a day, - the first meal at five-thirty, six-thirty, or seven o'clock, according to the light. This meal consists of pinhead oatmeal, cracked wheat, cracked corn - all passed through a fine sieve; nine o'clock, stale bread which has been baked in the oven and coarsely ground in a hand-mill, just moistened with milk that has been scalded; eleven-thirty, boiled liver and green sprouts of onions - half a cup of each, chopped fine, to one whole cup of dried bread crumbs; at two o'clock more milk and crumbs, lettuce, or tender greens, chopped fine; from four to half-past, all the dry mixed grain they will eat; fresh water three times a day.

I have never had any cases of gapes among my chicks, and I attribute it to the constant. 


\section{A SELF-SUPPORTING HOME}

use of green onion tops or sprouts. Crumbs and milk, or any moist food, must be fed on a flat plate, shallow galvanized pan, or strip of board, and removed after ten minutes to insure nothing being left to get sour. Dry grains should be scattered on the play room floor to keep the little fellows busy hunting it, the main object being to promote exercise and avoid overloading the crop.

Should there be any weak chicks in the brood, with pinched, pasty-looking beaks too large for their faces, remove them to a small box and care for them in the house, or have the courage to end their lives in a merciful way; for such birds are usually descended from overfat or roupy parents, and are likely to develop consumption or some other disease. which may spread through the flock.

Another chick trouble is diarrhœa. Scalding all milk used has a tendency to check this. A rusty nail or a few drops of tincture of iron in the drinking water is also good, as well as being a tonic. Should the drop- 


\section{A SELF-SUPPORTING HOME}

pings adhere to the feathers, and cause the vent to be pasted up, remove the obstruction by bathing with warm water. Keep the patient warm and mix a little poppy seed with its food. A few days' care will effect a cure, unless the case is hopeless.

Natural incubation must not be neglected, for no matter how many modern inventions for converting eggs into chickens the "Home" may boast, Biddy takes precedence for rearing future stock, and for hatching small numbers of ducks, geese, or turkey eggs.

Do not think that Biddy must be allowed to remain in the nest she claims in the chickenhouse, for such an arrangement always breeds trouble; every hen will desire to lay in that particular nest, even if there are twenty others vacant. Then, if Mrs. Biddy is of a pugilistic disposition, there are fights and broken eggs. If she be of the angelic type, and allow intruders to crowd into her nest, she gathers the eggs to her motherly breast, and the warmth soon renders them unfit for table use. 


\section{A SELF-SUPPORTING HOME}

To avoid all trouble of this kind, devote some small building to the exclusive use of sitting hens, where they will be free from all disturbing influences. Arrange nest boxes, with hay in them, all around the sides. In the centre of the floor two boxes filled with fine ashes for the sitters to bathe in are needed, as well as a drinking fountain and a pan filled with whole corn mixed with sharp grit four portions of the former to one of the latter. Fill up the pan and water fountain every morning. Cut a large turnip or cabbage in half and fix it between stones, so as to keep the cut side firmly uppermost; then whenever hunger assails any of the occupants of the house, they can eat and return to their nests without attention from you.

Droppings must of course be removed every day, and the ash baths emptied and refilled twice a week.

There is also another time- and troublesaving device: we now use a sort of cage three feet long, two feet wide, and one and a 


\section{A SELF-SUPPORTING HOME}

half high, made of shingle slats covered around the sides, ends, and top with twoinch mesh netting, which is placed over the nest when the hen is first set, if she seems at all restless. Some hens always have to have the cage kept over them, or after feeding they go into the wrong nest, leaving their own. Obviously, when the cage is used, food, water, and all the needs must be placed inside.

Now the question arises, how to know when a hen is desirous to sit. I still remember with shame my own studipity on this simple point.

Among the first hens I owned was an old Plymouth Rock that soon claimed special notice; for every time I went to feed she came flying off a nest, and an egg met my delighted gaze. Two eggs a day from one hen! It was phenomenal! Such a thing was never heard of! Day after day for two weeks!

Then one day the old Dutch woman who 


\section{A SELF-SUPPORTING HOME}

came to do the wash was hanging out the clothes when I went to feed at noon. Pride prompted me to point out the record breaker and explain her wonderful value.

Old Reika grunted out:-

"Nein - dose Rocques aind't no gut, only to sedt."

"Only to sit," was my haughty comment, "why, she lays two eggs a day!"

"Himmel sturmwetter!" Oh, the look of amused contempt on that old Dutch face! "Maybe she kheeps de nechst vorhm aber, but it vos some oddhor vaoul vot lays dose eggs - don't it ?"

Reika was right. My wonderful, recordbreaking hen was nothing but a broody old Biddy hen with such a greedy disposition that she flew off the nest every time food came in sight.

Profit by this experience.

When you see the same hen on a nest each time you go into the coop, it is a sign she is getting broody. If she is still there 


\section{A SELF-SUPPORTING HOME}

when you lock up for the night, she is ready to be set. Some broody hens do not get off the nest at feed time. Under these circumstances, you must slip your hand under the hen and abstract whatever eggs you can feel. This needs courage, for some hens peck and scold in a way that is alarming to a city woman. Others keep quite still until your hand is near, then dash off the nest, shrieking and screaming until every bird on the premises joins in the uproar.

Being sure of a broody hen, go into the house when it is almost dark, stoop down in front of the nest, and place your hands over Biddy, the thumbs meeting between the shoulders, the fingers passing over the body and picking up the feet. In this way she is easily removed without any fright being caused to the other inmates of the house. Carry her outside, then hold by the feet, head down, as illustrated in the cut facing page 28, and proceed to dust her feathers thoroughly with insect powder from 


\section{A SELF-SUPPORTING HOME}

the dredge. When it has been well rubbed in, gather her up in your hands in the same position as when you took her from the nest, and hold her until she is quiet again. Then place her over the nest and free your fingers from her claws, letting her feel the eggs, releasing her gradually as you feel her settle down on the nest.

All this handling must be accomplished as nearly as possible in the dark, and as it is not always convenient to do it during the short time of dusk, a lantern must be fixed up for night work; paint all but a strip of the glass with black paint.

As the moving and powdering are likely to make the hen restless, three or four china nesteggs are put into the nest at first; then, when she has settled down to business, it is an easy matter the next evening to change the dummies and slip real eggs under her. The ordinary sitting of hens' eggs is thirteen in number, but a large hen can safely be given fifteen, especially as the weather becomes warmer. 


\section{A SELF-SUPPORTING HOME}

About the seventh and fifteenth days after the sitting has begun, the hen should again be powdered.

Always try and set two or more hens at the same time. You can then give the two clutches to one hen, returning the other hen to the chicken-house, where she will soon begin laying again.

When Biddy has been sitting twenty-one full days, listen; if you hear a twitter in the morning, wait for the evening before slipping your hand under her to remove the dry chicks. If it is evening before you hear any sound, wait until the next morning.

The object in removing the young ones is that the hen, in moving around to help the later chickens out of the shell, may not be able to avoid trampling on and injuring those already out. At the same time clear the nest of broken shells, for there is danger that a broken section may get fitted over a pipped egg, - the term used for the first little chipped hole made by the baby's bill 


\section{A SELF-SUPPORTING HOME}

when trying to break out of its prison, thus excluding the air and smothering the occupant.

The newcomers must be wrapped in flannel, put in a basket, and kept warm behind the kitchen stove. Wait twelve hours longer; then take all the chicks, remove the hen to her future home, fasten her in, and give her all her babies and a good feed of corn. Place before the coop a run three feet long, made of slats and half-inch wire netting or boards a foot high, so the little ones cannot wander away and get lost.

Coops are best kept in the full sun till the middle of April. After that, place them under a tree for shelter and shade. All grass under and around them should be cut short, so that dew and rain will dry off as quickly as possible and make it easier for chicks to eat. Each family should be six feet away from all the others, for some hens will wreak dire vengeance on any baby that is foolish enough to mistake home and mother. 


\section{A SELF-SUPPORTING HOME}

\section{THE GARDEN}

If the weather is fine, the last two weeks of March should see the patch of ground intended for the vegetable garden ploughed and harrowed, as was explained in Chapter III, November. It is advisable to do this in the fall when possible, but many beginners going on to the farm for the first time this spring can still have a good garden if no time is lost in starting it.

Have well-rotted stable manure scattered over the surface before ploughing, which should be deep at first. After two or three days' airing, plough again, running the furrows crosswise; then harrow and roll and harrow again until every clod is broken up. Thorough preparation of the soil should never be shirked, for it is more than half the battle. Let me caution you not to have the ploughing done if the ground is wet. Much of the disappointment which city people experience in their first summer arises 


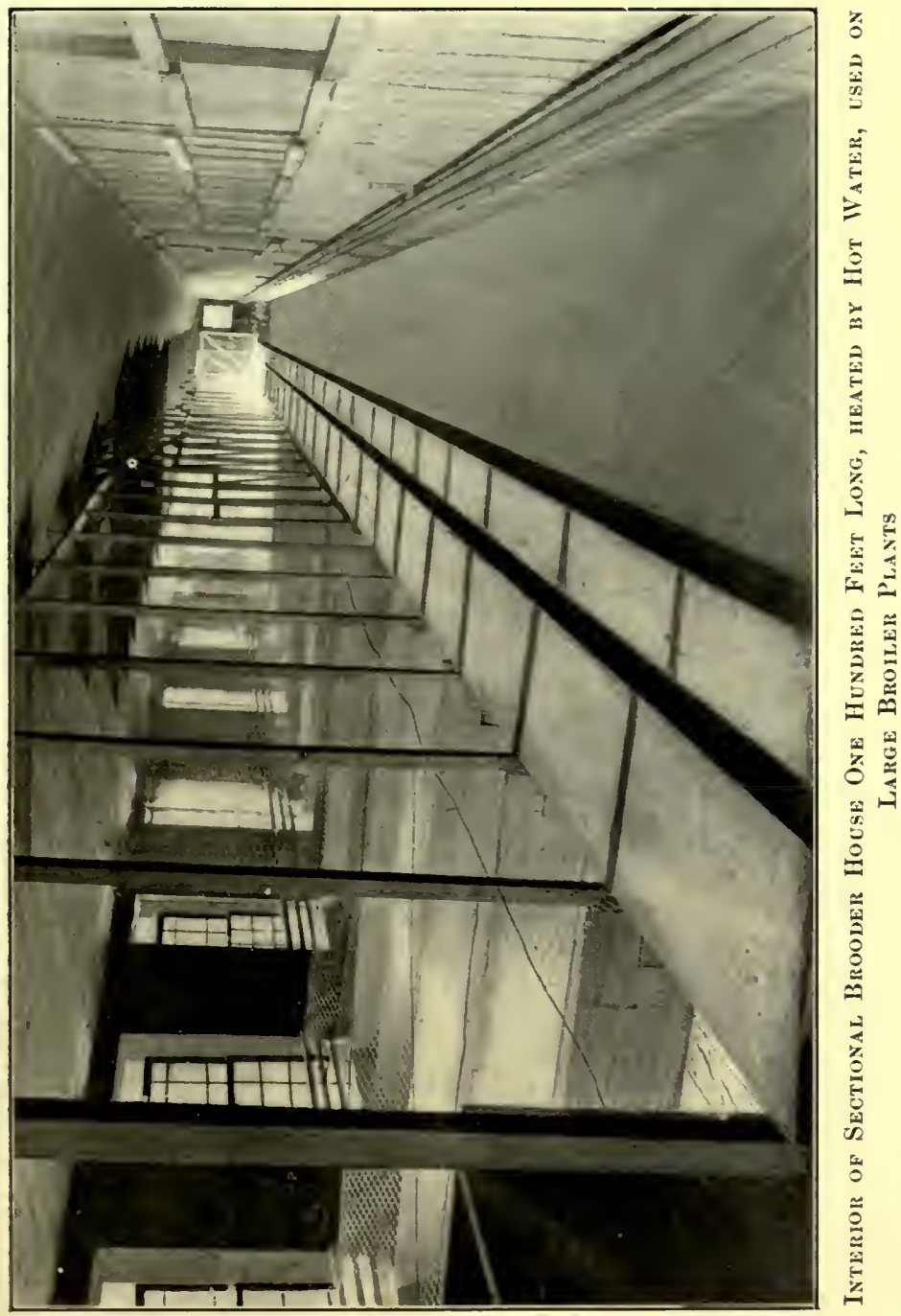





\section{A SELF-SUPPORTING HOME}

from the natural desire of the amateur to get to work. Earth ploughed, dug, or hoed when wet or soggy will bake and crust all summer. The right consistency can be ascertained by picking up a handful and squeezing it. If it remains a solid lump, it is too wet; but when it presses together easily and as readily falls apart when released, it is just in the right condition to work, will turn a clean furrow, and will readily crumble under the harrow.

Flower and vegetable seeds planted in the nursery boxes last month will need watching from the middle to the end of this month; for what is called "damping off" is very apt to appear. It can be easily detected by the sickly appearance of the seedlings, followed by a shrivelling or burning of the stem close to the earth. The moment the danger signal is noticed, prick out into fresh boxes of corresponding size, or a trifle deeper. The seedlings need not be planted more than half an inch apart. Prepare the mould in 


\section{A SELF-SUPPORTING HOME}

the boxes the same as you did for the seeds; pat down, and make the holes in which the baby plants are to be put with a toothpick, firming the earth around them gently with the forefinger of each hand. Should no suggestion of debility appear among the seedlings, still prick out into fresh boxes when the second leaves unfold.

The seeds of tomatoes and peppers should now be started in nursery boxes, precisely in the same way as were the flower seeds last month. If weather permits, ground for oats and potatoes should be ploughed during the latter part of the month. Sod ground is desirable for potatoes, so if there is a strip of grass land which needs renewal, have it well ploughed, harrowed, and marked off in rows a foot and a half apart.

Almost every old farmer has a theory about the way and size to cut a potato for planting. After listening and trying several methods, we have come to the conclusion that cutting large tubers in four, and small 


\section{A SELF-SUPPORTING HOME}

ones through the centre lengthwise, is much better than dissecting carefully to separate every eye, and then use two pieces when planting; especially as the innumerable experiments tried at the agricultural stations have revealed the fact that eyes gather nutriment for sustenance and growth from the potato itself, until the sprouts develop stems that form joints - at which point rootlets start; proving beyond doubt that unless the piece of potato planted is large enough to adequately feed the eye or eyes it may contain, the root growth which is required to furnish the subsequent tubers with food must be weakened. We plant one quarter to every foot in the row, and cover from four to five inches deep, selecting ground which has been heavily manured the year before, and scattering wood ashes on the surface after the seeds have been covered with earth.

We have two old-fashioned open fireplaces in which logs are burnt, so have a 163 


\section{A SELF-SUPPORTING HOME}

bountiful supply of ashes, all of which are saved in barrels for this use. The two years when we grew a large quantity of potatoes for market, a sawmill was being operated in the woods, the engine of which was fed with the waste logs; and we bargained for the ashes at fifty cents a load. Failing this source, commercial fertilizer specially prepared for potatoes had to be bought. Thorough cultivation is necessary to insure a good crop. Soon, say seven or eight days after planting, run the harrow over the field, which will kill the embryo weeds and level the surface. As soon as the plants show, cultivate again; but, of course, this time only between the rows and with an ordinary cultivator. Repeat at frequent intervals.

It is estimated that it takes fifteen bushels of potatoes, after they have been cut into quarters, to plant an acre, which should return one hundred and thirty bushels of salable potatoes - by which is meant large 164 



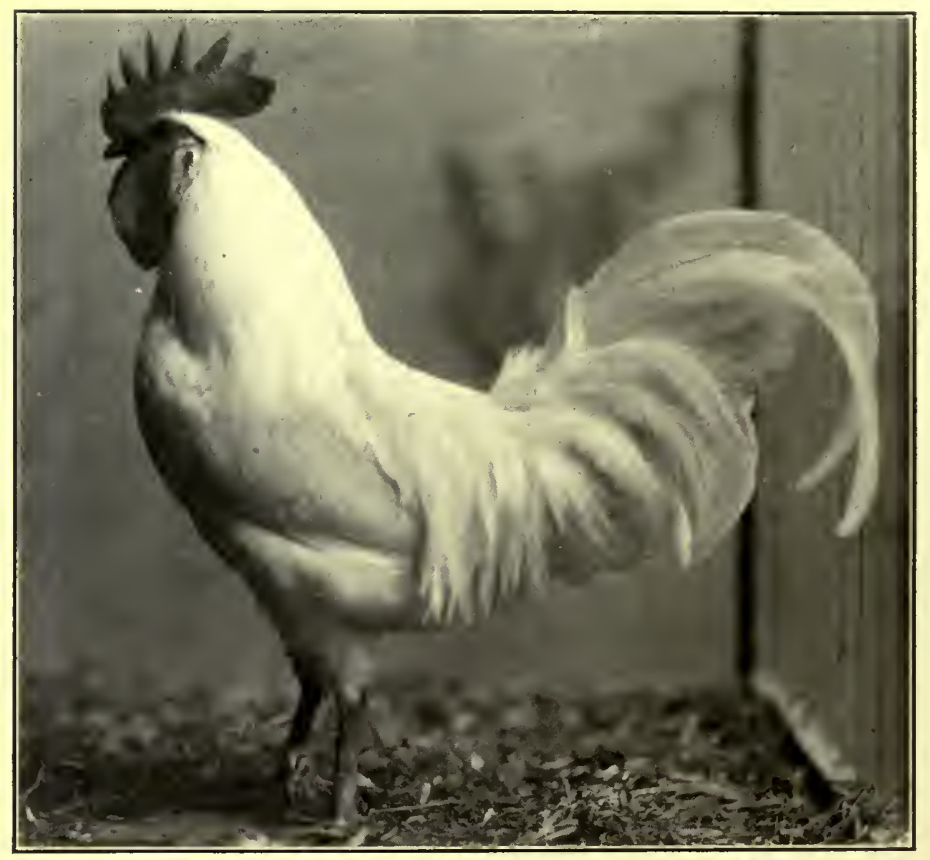

Father of his Flock 


\section{A SELF-SUPPORTING HOME}

and medium-sized potatoes, small ones not entering into the calculation. In an ordinary crop there will be in all probability about thirty bushels of these dwarfs, which are excellent fattening food for poultry and pigs when cooked and mashed up.

Dormant roses and small fruit trees should be bought before the 15th of the month. They are cheaper than growing plants later in the season, and being free from sap and earth round the roots, cost much less to ship. Plant where you desire them to permanently stand, as soon as the frost is out of the ground. Twenty-four hours before planting we stand the roots in a pail of water, which softens and makes them pliable - an advantage when spreading them out in their future home. 


\section{CHAPTER VIII}

\section{APRIL}

TF only for the feathers, a few geese should be 1 kept. Lots of pillows are such a comfort, and a well-fed, well-cooked goose is a welcome change in midwinter. Moreover, green geese (birds under ten months old) are always in demand during the holiday season, being as universally used by the Germans for Christmas fare as are turkeys by Americans. My first essay at goose rearing was made with five eggs, bought for five cents apiece from a Swede who was ploughing for us. An old Brahma hen was intrusted to incubate them, and faithfully performed the duty until I lifted her off the nest on the thirtieth day, to find only three eggs. The others, evidently, had been broken or stolen. Of those remaining, two were unmistakably bad; 


\section{A SELF-SUPPOR'TING HOME}

the third slightly chipped, but showing no sign of life.

Not having outlived the amateur's desire to cosset every feeble spark of life, I carried the egg down to the house, held it over a steaming kettle to soften the dry, hard shell, which I gradually chipped off, revealing an apparently lifeless, under-sized gosling, which I subjected to a combination of steaming and baking until, just as effort was about to be discontinued in despair, it kicked - a feeble, die-away sort of kick certainly, but it stimulated my desire to save its life, which was eventually granted; but the result was such a miserable-looking object for weeks, that, had it not been for the odd, intelligent personality of the poor little wretch, I fear its existence would have been summarily curtailed.

It persisted in continually waddling after me, squatting down suddenly at my feet as soon as I came to a stand-still, and looking up with a comically satisfied expression which 


\section{A SELF-SUPPORTING HOME}

compelled attention. During the days of ugliness and uncertainty of sex, innumerable uncomplimentary names suggested by appearance or oddities were bestowed on the poor creature, who eventually shamed perspicacity by developing into a beautiful white gander, and became known to our friends as Launcelot Gobbo the Wonderful - the appendix being earned through his capacity for developing and acquiring tricks.

First of these was to knock at the back door punctually at seven o'clock each morning for his breakfast. On being admitted he would march to a side table where he had been fed when a baby, climb on to a chair which stood by it, and sit solemnly with his beak on the edge of the table for a few seconds, softly muttering as if saying grace, then stretch up his neck and caw for his oatmeal, which had to be sweetened and creamed as for our own eating. Launcelot seemed to comprehend that eating with the family necessitated a nicety of deportment; 168 . 


\section{A SELF-SUPPORTING HOME}

for never was he anything but a courteous gentleman during the short visits he elected to pay the house. Outside, he would descend to the mischievous, noisy Gobbo of Shakespearian history.

When he was quite little I used to lay him on his back in my hand, just for the fun of seeing him go to sleep contentedly in such an ungooselike position. As he grew older, he would come on to the piazza, and voluntarily assume the position on the mat at the dining room door, keeping his eyes open, and cawing the moment any of the family appeared - probably realizing that the trick attracted such attention as assured his being stroked and petted. Nothing more ridiculous could be imagined than the big, awkward bird waddling up to the mat, flopping down, and deliberately turning on his back. It was a performance that never failed to astonish and amuse visitors; but when the vacation time brought a juvenile friend of ten years old to stay with us, the 169 


\section{A SELF-SUPPOR'TING HOME}

climax of absurdity was reached through her rewarding him with chocolate creams. The unaccustomed flavor highly delighted him, for he would lie for any length of time in the hopes of receiving more candy. This prompted the little lassie to undertake his education; and before school recalled her to the city, Launcelot would lie still with a black baby dolly cradled on one wing, and a dilapidated sailor-boy on the other; wear a ribbon harness and draw a doll's carriage; eat ice-cream, drink coffee, and run for a ball as well as a dog.

The next spring, fearing he would be lonely, we bought an old gray goose, who showed a most supreme contempt for her young husband's various accomplishments, even resorting to corporal punishment, whenever he rolled over on to his back. Such an ill-assorted pair seemed hardly appropriate founders of practical stock; yet fifteen of their twenty children raised that year sold in December for $\$ 2 \$$, which being spent in 


\section{A SELF-SUPPORTING HOME}

three geese and a gander gave us a quartet of breeders that have never earned less than $\$ 130$ a season.

Geese, being grazing creatures possessed with a vicious habit of nibbling down to the roots of sod, cannot be allowed the run of the farm, and ordinary yards would soon become defiled and barren. So a strip of newly cleared land or old pasture should be converted into a compound for their exclusive use.

One domestic gander will tend from three to five geese. If more than that number are to be kept, each family should have individual establishments, stationed as far apart as the dimensions of the compound will allow; putting up a fence to enclose thirty or forty feet around each coop, and placing feed and water cans within them. At the expiration of a month they will acknowledge it as home, and cling together faithfully as one family; then the fence can be removed, as, clanship once established, there is little 


\section{A SELF-SUPPORTING HOME}

fear of serious combat occurring amongst the ganders.

Stakes three feet long of cedar with one end cut to a sharp point and hammered into the ground will do to fasten the wire netting to for the enclosure. Nails and caps that come for putting on roofing paper are the best to use, because easily removed. The stakes can be utilized afterward in the garden, and, of course, the netting is always being required. A few old, half-rotted stumps placed in the compound will afford the geese amusement and occupation, which prevents moping when they discover their freedom has its limits.

If the compound is spacious and the grass thick, a feed at night will be all the birds need; but as the pasture fails, breeding stock must be regularly and judiciously provided for - the object being to keep up strength and vitality, so insuring early and fertile eggs, but to avoid food which might mitigate the desired condition. Breakfast can be turnips, beets, cabbage - or any other veg- 


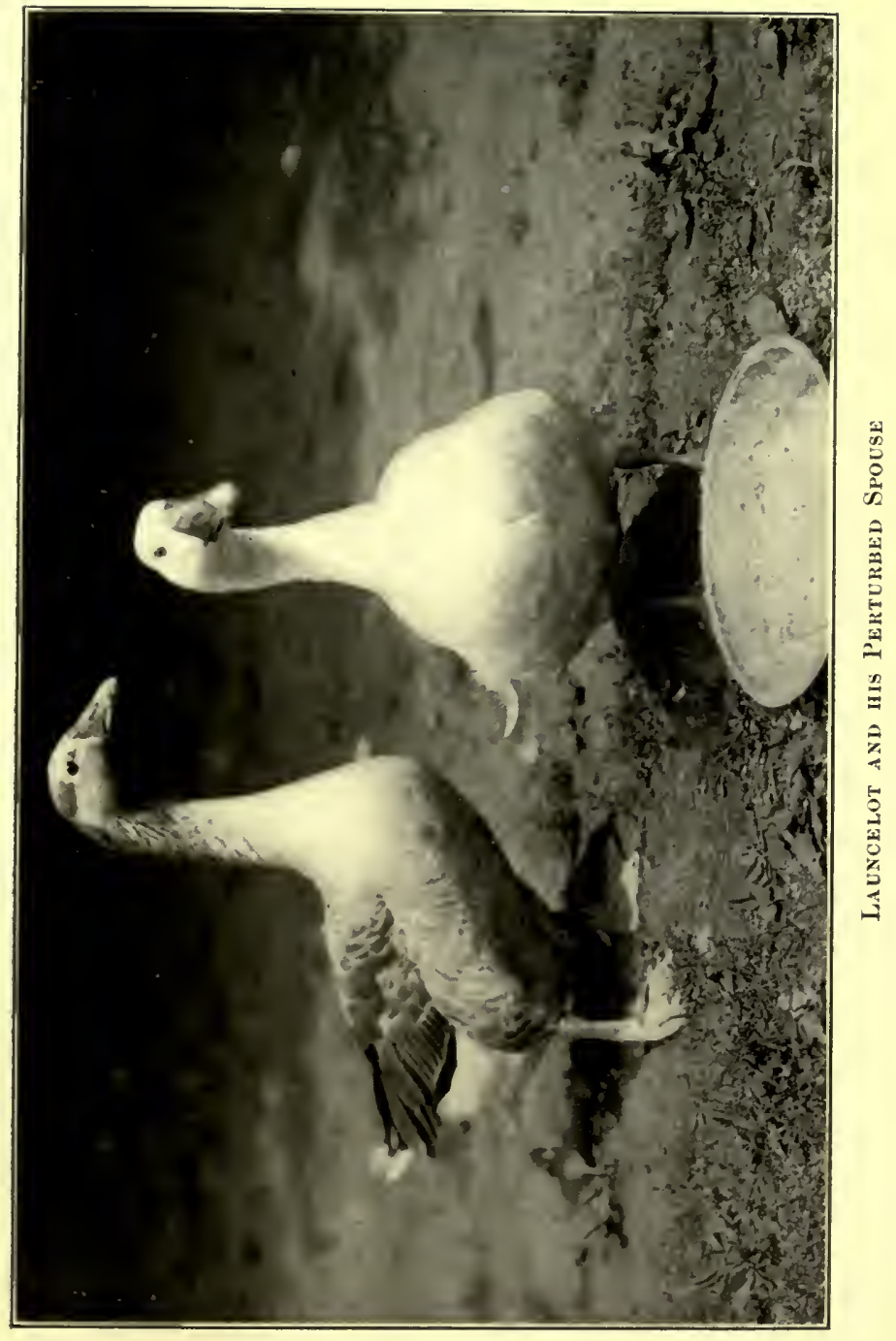




\section{A SELF-SUPPORTING HOME}

etable excepting potatoes - boiled, mashed, and mixed with an equal quantity of wheat bran and a fourth of ground feed. At noon, cut and steamed clover hay, or chopped vegetables. At night, about half a small cupful of wheat or corn for each bird. Three times a week add meat meal to the mash, or feed green cut bone at noon. Like all other poultry, they must be supplied with sharp grit, old plaster, or air-slacked lime.

A goose usually selects a nest in February. A hollow in the ground filled with hay or a shallow box on the floor will be readily adopted. Before commencing to lay, the goose lines her nest with down plucked from her own breast; and after laying, the egg is covered first with down, and then with whatever may be within reach of her bill. The first fifteen eggs should be stolen from day to day as laid, cautiously removing the covering and replacing it when the birds are safely out of sight; as both goose and gander will strenuously resent any interference with the nest, 


\section{A SELF-SUPPORTING HOME}

and a blow from the wing of either is seriously unpleasant. Should a goose become broody early in the season, remove her from the nest and incarcerate in a wire coop within the compound, where she can see her mates. Within a few days all desire to sit will have left her, and after a few days of freedom she will commence laying again.

The second clutch of eggs she should be allowed to retain, for goslings hatched under the oily moisture of a goose's breast are stronger, and so desirable for future stock. It is the want of this humid warmth, when ordinary hens are used to incubate such large eggs, that necessitates sprinkling the eggs two or three times; and when possible, making the nest on the ground, or at least cutting the sod and placing it at the bottom of any wooden box used as a nest. The eggs take from twenty-eight to thirty days to incubate. Goslings require virtually the same feed and general care as young ducks, the only difference being an increase of grass 


\section{A SELF-SUPPORTING HOME}

and vegetables; so we will combine young ducks and goslings.

When ducks' eggs have been hatched under hens, they need only be allowed to brood them for three weeks, unless the weather is very cold; in which case leave their mother for another week. Never give duck intended for eating a free range; it toughens and prevents them from fattening. On the other hand, those intended for stock should be allowed plenty of room to roam in after they are four weeks old, to insure strength and growth.

Young ducks and goslings must starve for the first twenty-four hours of their existence. Bill of fare for the first week is as follows: half a pint of pinhead oatmeal, cracked wheat or stale bread crumbs, two hardboiled eggs chopped fine, half a cup of coarse sand, all mixed and just moistened with scalding milk. Feed five times a day, as much as they will eat in ten minutes.

Second and third weeks: half a pound of 175 


\section{A SELF-SUPPORTING HOME}

ground oats, the same of coarse sand, two tablespoonfuls of beef meal, a pint of finely cut green clover, rye, or cabbage moistened with scalded milk. Feed four times a day.

Four to six weeks: boil a quart of hulled oats for an hour, add one pint of corn meal, wheat bran, half a pint of fine grit, the same of beef scraps, one quart of clover or any green food. Feed four times per diem.

Six to ten weeks: one quart corn meal, one pint wheat bran, a pint of boiled oats, pint of beef scraps, half of grit, tablespoonful of charcoal, pint of clover. Feed three times a day. Then they should be ready to kill.

Those to be kept for stock have the same ration until three weeks old; then they are given equal parts of ground feed and bran moistened with milk or water. Feed twice a day, if on free range; if yarded, add half a cup of beef scraps, cut clover, or vegetables to double the quantity of grain.

Young ducks are very nervous and will not forget a scare for weeks. You can persuade 


\section{A SELF-SUPPORTING HOME}

them to go in any direction if you work slowly and quietly. Hurry excites them, and they will rush shrieking in every direction except the one you would have them go. Don't allow any one to run them, for it will put them back from one to three weeks and waste just that amount of feed. This is a point upon which positive and repeated demonstration enables me to speak with special authority.

One summer we had a yard of youngsters almost ready for market, when a friend came down to spend Sunday with us, bringing a young fox terrier with her, to give him a day's exercise in the country. Our own dogs are taught to take their exercise in the woods, but Mr. City Terrier evidently found it slow, for during dinner there was a great clamor. On a poultry and pet stock farm, if one animal sounds the note of alarm, everything joins in and there is a conglomeration of peafowl, guinea-fowl, hens, ducks, geese, and dogs, all shrieking in fright and in different keys.

We laid down our knives and forks, looked $\mathbf{N}$ 


\section{A SELF-SUPPORTING HOME}

at each other in horror, rushed wildly out to locate the trouble, and were met by Rover, the head of my four-footed police, and piloted to the ducks' quarters, to find the terrier visitor in the pen of the ducklings, to his great amusement and their distraction. Needless to say that was the end of his day's healthy exercise; he was securely locked up until it was time to go home. It took all the soothing I was capable of to quiet the ducklings. They were off their feed for days, and it was fully two weeks before they got back to weight. With the old ducks there is the danger of their rupturing an egg, which is sure to cause trouble, perhaps death; or of breaking a leg, which means killing.

When they have to be handled to weigh or kill, a small portable "yard," three feet by two and a half, made of laths and wire netting, is used. It has a gate at one end, which is placed at the gate of their inclosure, and those wanted are driven slowly into it. and it is then drawn quite away from the pen. 178 


\section{A SELF-SUPPORTING HOME}

The space being small, it is comparatively easy to capture them. To avoid alarming the whole farm, you take them up bodily and hold their bills.

Do all work of this sort among your stock as gently as possible, talking to them in a soothing, reassuring way all the time. Nothing averts so many accidents as accustoming your stock to associate your voice with safety. This is true not only with poultry and pet stock, but with all animals generally.

\section{THE POULTRY YARD}

The hens must now be put on lighter diet. Whole corn at night can gradually give place to wheat, two parts, cracked corn, one part. Morning mash can have an increase of ground oats and a corresponding decrease in corn. Take advantage of all spring greens, remembering that grass must be cut into short lengths; otherwise, the hens, in their eagerness to get the desired change of diet, will 


\section{A SELF-SUPPORTING HOME}

swallow long pieces, which are apt to cause them to become crop-bound.

Be especially careful about removing droppings under the roosts, and use kerosene oil and carbolic mixture on the perches, nests, etc. Cool, fresh drinking water should be before them all the time. Dust baths will be more constantly in use now than earlier in the season, so should be refilled with clean cool ashes or dry earth two or three times a week. (Let me caution not to use wood ashes anywhere round hens or chicks, because, should they eat them, bowel trouble will be the result.) Whitewash the house outside, and allow plenty of ventilation.

The same strenuous cleanliness must be observed in the pigeon-house. These warm days all sorts of bad odors arise from unsuspected places; so go through stables, sheds, and cellar, scattering lime in corners - out of the stock's reach, of course. It will purify the air, and kill hundreds of embryo insects. 


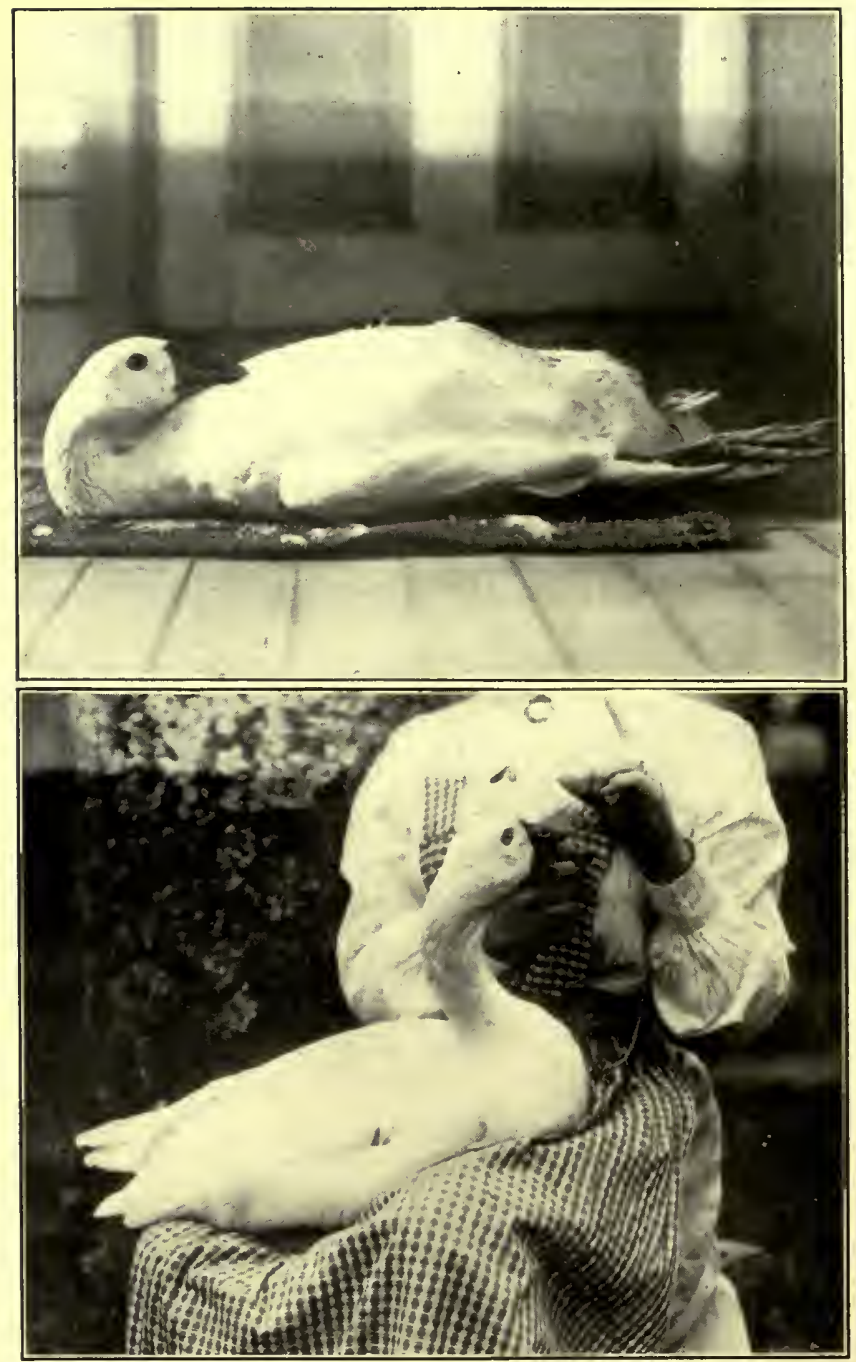

IAUNCELOT GoBHo THE WONDERFCL 


\section{A SELF-SUPPORTING HOME}

\section{THE ORCHARD}

Fences and the trunks of orchard trees will be benefited, and the tidiness of the farm greatly accentuated, if whitewash is freely applied. For this outside work, slack half a bushelful of lime in boiling water, add two pounds of sulphate of zinc, one pound of common salt, and half a pound of whiting thoroughly dissolved. Mixed to a proper consistency for use with skim-milk, this is a whitewash that withstands summer rains almost as well as paint. Before applying to the fruit trees, give them a dressing with what is called Bordeaux, to destroy, or better still prevent, any of the fungoid diseases attacking them.

Unless suckers and dead wood were removed last fall, hasten to demolish all such encumbrances now. Before the tree breaks into leaf, a thorough spraying should be given; for which, of course, a properly constructed sprayer will have to be purchased. 


\section{A SELF-SUPPORTING HOME}

The first we had was just a portable pump with a seven-foot hose and pole, the entire outfit costing only $\$ 5$. It was useful, but quite inadequate for an orchard of large trees. Three years ago we indulged in a much more elaborate pump, with a lead extension pipe, for which we gave $\$ 11.50$; and had a large barrel swung on a pair of front wheels of an old wagon. Poles were fastened to the sides for shafts, so that a horse could be hitched to it, converting what had been a laborious duty into a light occupation.

The Bordeaux is made by mixing four pounds of copper sulphate, four pounds of lime, in fifty gallons of water. This is for fungoid diseases. Later, for the general spraying, add four ounces of paris green. Please understand that spraying must be done before the blossom breaks forth, and again after the fruit has formed; but never when the blossom is in a transitory condition.

Caterpillar nests, which look like bunches of cobwebs up in the branches, should be 182 


\section{A SELF-SUPPORTING HOME}

burnt out. Tie some old woollen rags on a long pole, pour kerosene oil on them, light, and hold under the nest until it is entirely consumed. Currant bushes need spraying once or twice before blossoming; otherwise they will usually be attacked by a small, green caterpillar which destroys the leaves. Dig the ground round the roots, and keep clear of weeds by hoeing once a week throughout the summer.

Blackberry and raspberry canes, currant and gooseberry bushes, young apple, pear, plum, or peach trees, must all be planted before the 15th of the month.

Seeds planted in boxes last month need pricking out into small individual pots or larger boxes.

\section{THE GARDEN}

Supposing that the ground was ploughed and harrowed last fall or last month, and the posts put in place for the fence, the wire netting can now be erected and hand culti183 


\section{A SELF-SUPPORTING HOME}

vation started. Spare no pains in preparing the ground row by row, as wanted. Rake again and again, removing every stone and weed root; then scatter commercial fertilizer on the smooth surface and work thoroughly into the soil with a rake.

The garden line is indispensable if uniform accuracy is to be maintained, and without it weeding and cultivating of seedlings is almost impossible. Two cedar stakes a foot and a half long with one end whittled to a point, and a strong cord as long as the garden securely tied to the other end, will answer all purposes.

Hurry in the early potatoes, if they were delayed last month - of course including those started in the cereal boxes. The space intended for carrots requires extremely good cultivation, for the soil must be thoroughly pulverized. Seeds are small, and slow to germinate under natural conditions; so we tie them in a piece of cheese-cloth, steep in water for twelve hours, then hang up in a 


\section{A SELF-SUPPORTING HOME}

warm room to drip and dry sufficiently to prevent their clinging together when being planted, which must be done before they become really dry. Another aid we furnish these delicate seedlings is dropping a radish seed every six inches, because they germinate quickly and throw a strong seed-leaf which breaks the crust over the row, and allows the fragile carrot sprout free access. Allow two feet from the last row of potatoes, stretch the line, and with a pointed stick draw a shallow drill in which to scatter the seed. Covering must not be more than a fourth of an inch, and press down firmly. Between each row of carrots allow one foot. Steep and use only half the seed at the first, planting the remainder twenty days later. With good ground and cultivation, you should have carrots for the table about the last week in June.

Two and a half feet space must divide carrots from beets. Prepare ground as before, but make the drill a full inch deep, dropping seeds half an inch apart, rows two 


\section{A SELF-SUPPORTING HOME}

feet apart. Should be ready for use first week in June. Keep half the seed for late planting.

Early turnips can start another two feet along. Drill half an inch deep, rows a foot apart. First of All peas are semi-dwarf, but yield much better if given some support. We plant every two rows seven inches apart, in a drill one inch deep; and when the peas are two inches high stick brush between the rows, so making a solid hedge of vine when developed. Twin rows should be two feet apart.

For onion sets make drill an inch and a half deep, placing the sets upright and from four to six inches apart. Firm the earth all round, and the fourth of an inch over them. These will furnish early onions for cooking and the main winter crop. For onion seed, the soil cannot be too carefully prepared, for, like carrots, they are long in germinating and extremely fragile. A few radish seeds can again be used as pioneers. The reason 


\section{A SELF-SUPPORTING HOME}

for troubling with seed at all is twofold: it furnishes small green onions for the table, and sets for next season at a minimum cost. Instead of commercial fertilizer, the poultry droppings are used for onions, being reduced to a powder by grinding in an old chopping machine. Sprinkle freely within one inch of the centre of the row, and from three to four inches each side of it. Unless rain falls within a few days, water very thoroughly with a sprinkler. Hen droppings seem especially desirable for all bulbs and tubers.

Lettuce seed requires well-enriched soil. Drill a fourth of an inch deep, rows one foot apart.

Radish seed for a small family should be sown in five-feet lengths, at intervals of ten days. Cover seed one third of an inch, rows six inches apart.

From the time seeds are put into the ground, cultivation must be continual; raking between rows being frequent enough to destroy embryo weeds. Ten minutes' light work with 


\section{A SELF-SUPPORTING HOME}

a rake before weeds develop will save hours of hard labor with a hoe. Cultivation is required, not only to destroy weeds, but to supply air, and encourage all the moisture from the subsoil to travel upwards, so nourishing the plant roots as they develop and preventing the soil baking. Not cultivating the ground round plants is as injurious to their health as shutting a child in a room without ventilation.

Lettuce, cabbage, and cauliflower plants, started in the house in February, should now be planted out. Prepare the rows as for seed, set the line up; then carry out the nursery box and water it thoroughly - otherwise the soil will fall away from the roots as you take the plants out. With the pointed stick used for marking the rows, make holes directly under the line - nine inches apart for lettuce, a foot for cabbage and cauliflower. Put a little water into the hole; then with a small trowel or large kitchen spoon "scoop" a plant out of the box, trying to 188 


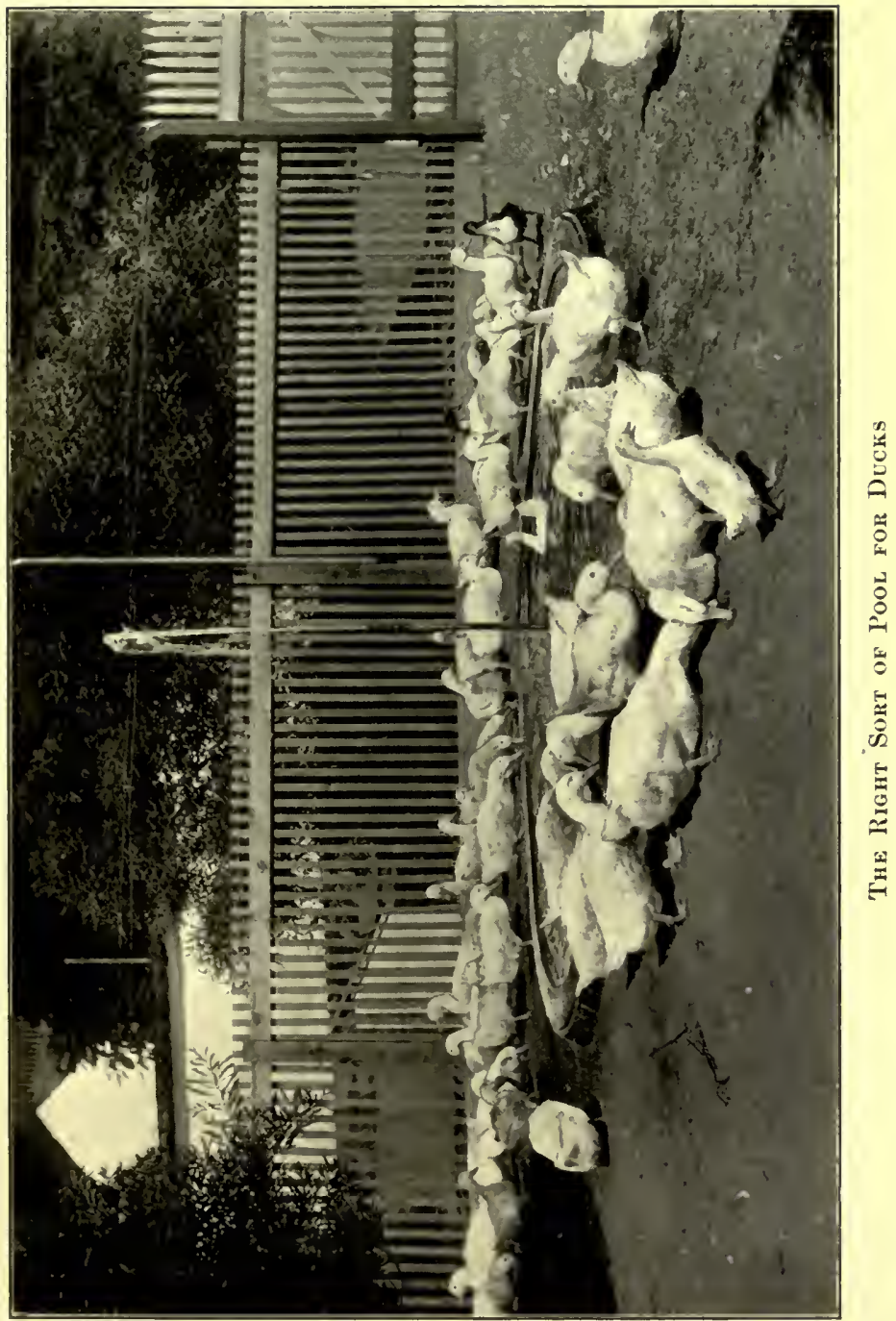





\section{A SELF-SUPPORTING HOME}

take all the earth occupied by the rootlets of that individual plant. Carefully transfer from the spoon into the hole, allowing it to sink up to the first leaves. Pack the earth around the root and stem; water copiously; then draw dry earth up over the wet surface to prevent the moisture from evaporating or a crust forming. To promote root growth, cut off half the length of the outer leaves with a pair of sharp scissors. If possible, provide some protection from the midday sun until the plants are established.

The straw, or whatever the strawberries were covered with last fall, must now be removed from the crowns of each plant; or if they are in matted, continuous rows, open right along, but keep the covering close up to the roots at the sides. Leaving the covering on the bed prevents weeds springing or moisture escaping. Should there be late frost, it also protects the roots; and lastly, the fruit when gathered is free from sand or dirt, so the flavor has not to be spoiled by washing. 


\section{A SELF-SUPPORTING HOME}

Melons and cucumbers started in the house about the first of the month will be goodsized plants to put out in the middle of May; and fruit can safely be expected three or four weeks earlier than from seed sown in the open ground in May.

All my seedling and planting experience has been gained in the vicinity of New York, and will not, of course, apply to extreme North or South; but an old rotation safe to follow is: Peas, spinach, onions, potatoes, cabbage, lettuce, and radishes, when the peach blossoms. Turnips, carrots, corn, and beets, when the oak leaf breaks from its bud. Beans, cucumbers, melons, squash, and okra, when the blackberry blossoms.

Lay out an herb bed. Our grandmothers thought much of their value, and in the country, where doctors and drug stores are not next door, they may serve for persons as well as stock.

To season dressing for duck, goose, and pork, sage is all important; not less are 190 


\section{A SELF-SUPPORTING HOME}

savory, thyme, and marjoram for chicken, turkey, lamb, and mutton stew. Aniseed and catnip have prevented many a sleepless night with the baby. Wormwood, saffron, and tansy belong to the poultry principally. Lavender and rosemary give the linen and wearing apparel a delightful odor, and keep away moths. Our, grandmothers knew a lot of things which meant real home comfort, and should be so far removed from insignificance as to reach the point of reverence.

The novice in country housekeeping may not know that many of the wild plants of early spring make delicious greens and salads, and possess medical qualities which it is positively sinful to neglect. The narrow plantain leaves, if stripped from the stem, boiled, and served like spinach, are delicious.

A most appetizing salad can be gathered in any field with a sharp knife. Cut out the tender leaves which form the hearts of all dandelion roots, add a few sorrel leaves, wash, place in a cloth, shake off all the water 


\section{A SELF-SUPPOR'TING HOME}

as you would with any other salad, cover with French dressing, and rejoice that you have ceased to be a city dweller.

FLOWER GARDEN

Dig and fertilize the beds so that they are in order for May planting. There are few flower seeds or plants which it is safe to put out before then; sweet peas being the one delightful exception of my experience. A long narrow mass shows their beauty to the greatest advantage. We have a bed two feet wide running diagonally between the front and back lawn, from which blossoms are to be gathered all through the summer. Select the desired position, and have one foot of the surface soil removed. Then scatter a heavy covering of old barnyard manure, to be dug in to the depth of another foot. Replace the soil previously removed, mix in more manure, so that when finished the bed is well enriched and broken to the depth of two feet. The seeds are best pushed into the soil, two inches 



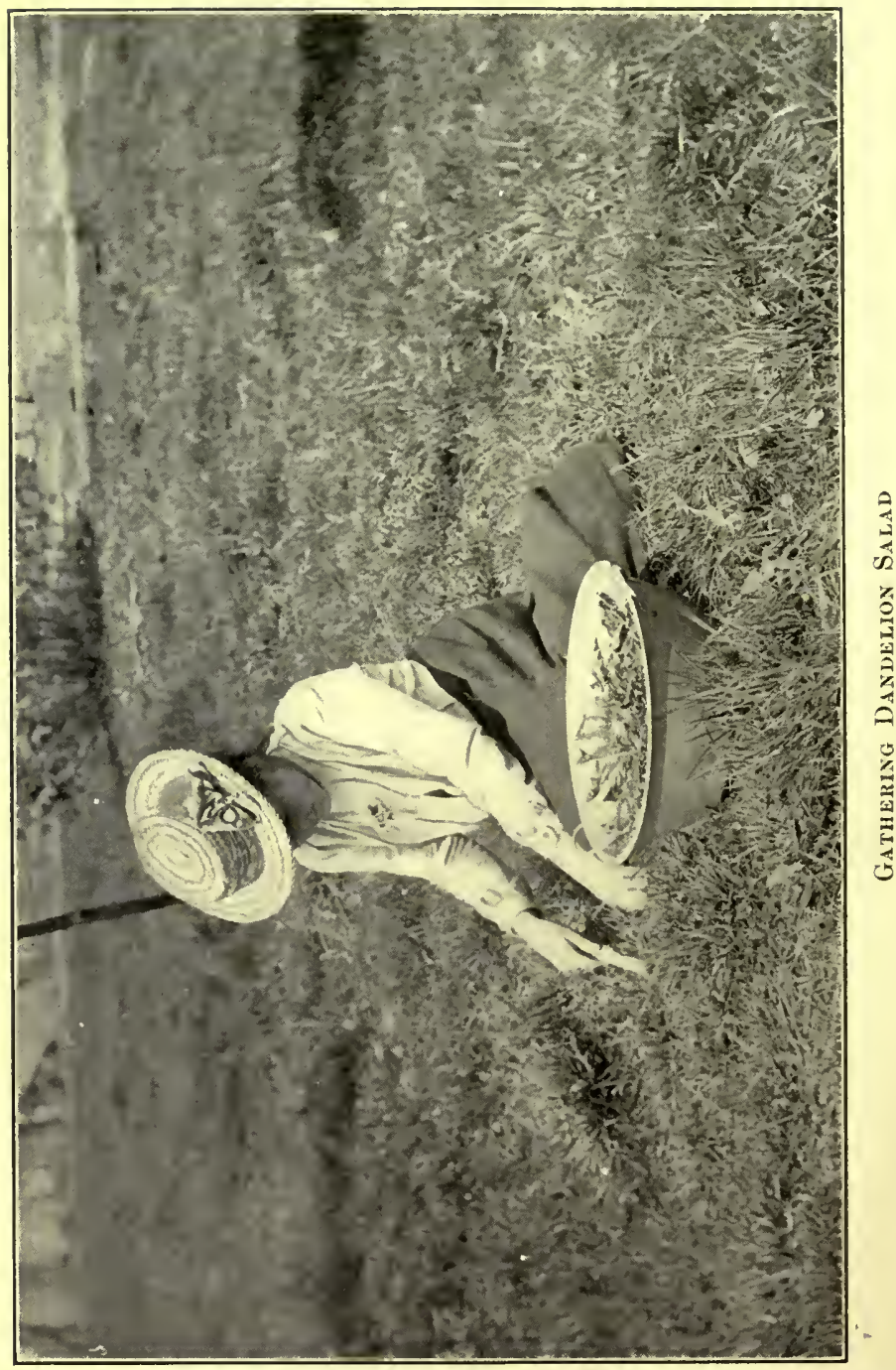




\section{A SELF-SUPPORTING HOME}

below the surface and half an inch apart, patting down the top very firmly. This may all seem a great deal of trouble, but sweet peas positively will not flourish in poorly prepared beds. A really good galvanized trellis, ten feet long, with stakes at the end and in the middle, can be bought for 75 cents; or straight, medium thin cedar poles and chicken wire can be utilized.

Peonies, shrubs, and all established plants must be dug round and fertilized before the 15 th of the month.

\section{THE BARN}

With the first days of April the grass commences to spring, and it will benefit the cow to get out into the pasture from nine in the morning until three in the afternoon; but not until the 15th of the month is it wise to commence cutting down stall rations. From that date noon feed can be omitted, and night and morning gradually decreased, until by the 1st of May she depends entirely on the pasture. 


\section{CHAPTER IX}

\section{MAY}

F course every self-supporting home will desire to raise its own national Thanksgiving dinner; therefore turkeys must augment the stock. The prevailing idea that these birds are difficult to raise compelled our outraging patriotic customers for several seasons, until my admiration for a beautiful white gobbler at a poultry show brought about an introduction to his owner, and subsequently an arrangement to spend a week on his farm, studying in actual operation the methods of feeding and brooding formulated during the twelve years he had made a business of marketing turkeys.

The farm was situated on the side of a hill, sufficiently imposing to be called a mountain by the New England folks. To one side of the house and barn sixty acres were heavily 


\section{A SELF-SUPPORTING HOME}

wooded. Perhaps fifty yards down the slope was a clearing where stone had been excavated years before, leaving about an acre of shale-covered ground backed with rocks twenty feet high at the summit, and sloping down at the sides to the natural contour of the mountain. In the pre-commercial days the small flock of turkeys which were left almost entirely to their own devices found this rock-sheltered spot, adopted it as a breeding ground, nesting in the brush and rearing such a goodly number of youngsters season after season, that when repeated poor crops made the farmer resolve to turn his attention to poultry farming, he wisely allowed himself to be guided by the old bird's instinct, and adapted the chosen land to growing requirements rather than risk moving the stock to other, personally more convenient, quarters. Some half acre of the ground was enclosed with wire netting and divided into three immense yards in which strange birds were to be controlled and young reared. 


\section{A SELF-SUPPORTING HOME}

During the winter months, when most flocks of turkeys are left to forage for themselves, these people give theirs the best of care to insure strong, fertile eggs. A very general mistake seems to be neglect of the breeding stock, for it is a waste of time to hatch eggs so poor in vitality that the results die off after a few days' miserable existence. It's true turkeys live almost exclusively on insects; but frost destroys this natural food supply, which makes it imperative that meat and bone should be fed. The master of the farm laughed at me when I confessed that I had always believed that a little corn at night was all they needed. He told me that after January 1 his birds received regular meals. Two mornings a week their breakfast consisted of boiled oats with chopped meat added; on other days scalded clover, hay, and ground feed. Supper is of whole corn and barley, alternated with cracked corn and Kafir-corn in moderate quantities, as breeding birds must not get too fat. 



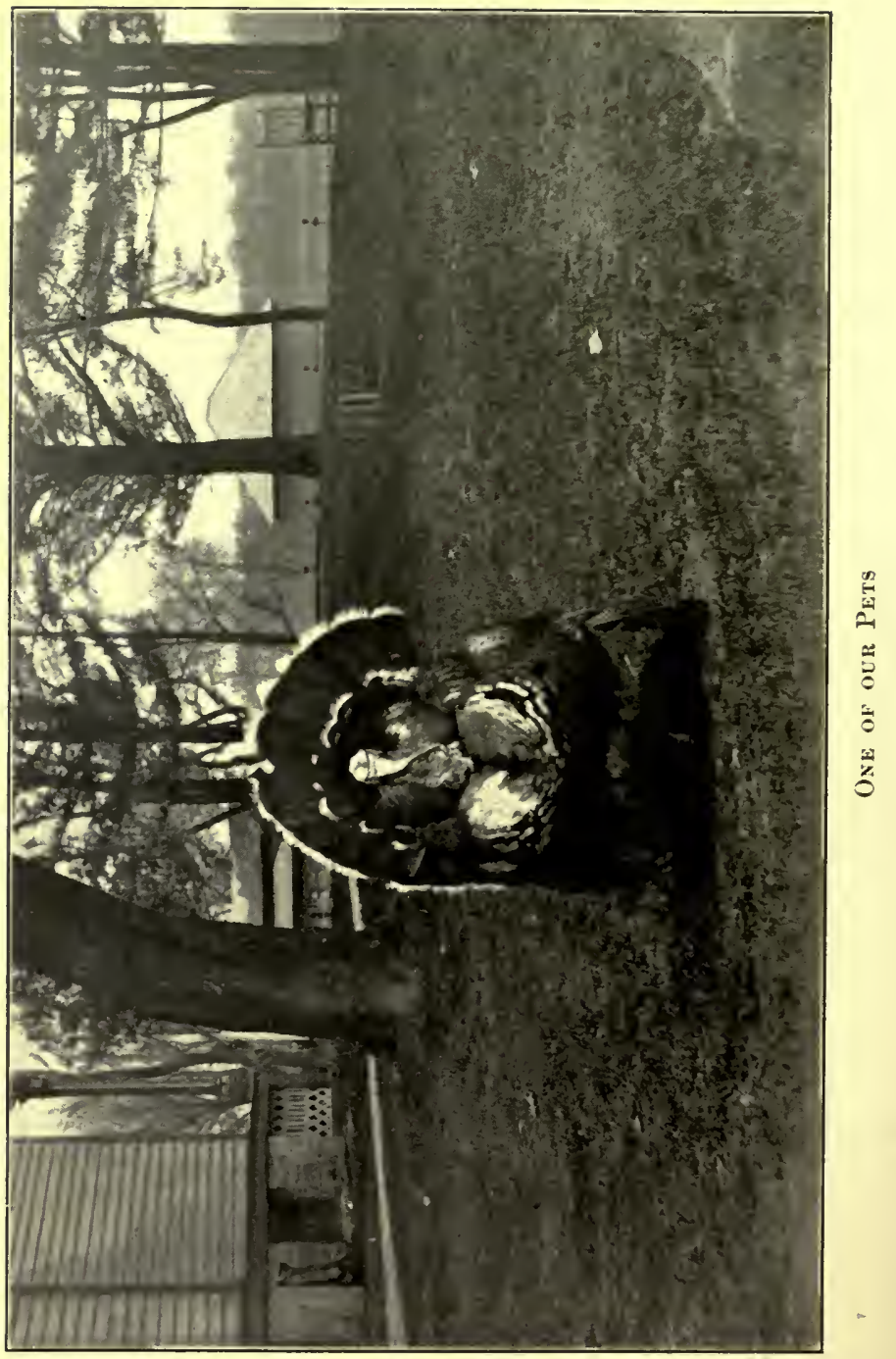




\section{A SELF-SUPPORTING HOME}

Early in the spring flocks of eight turkeyhens and a gobbler were placed in two of the yards, the original five old females and gobbler left on free range; so there were twenty-one hens to gather eggs from, all the first being stolen and set under common hens; but when it grew near the end of the season and the turkey-hens began to get broody, they were allowed to sit.

If permitted to obey their own inclination, young turkeys will gobble up an amount of food they have not the power to digest. Little and often must be their feeding rule. The owner of the farm I am writing of thinks that his great success is due to the land on which his birds are kept, - the rocks and gravel never getting damp enough to hurt the young birds, excessive care not to inbreed, and periodical introduction of wild blood.

My own experience was with White Holland turkeys. For small flocks this strain seems preferable, being much more domes- 


\section{A SELF-SUPPORTING HOME}

ticated than the Bronze. We covered an open shed with wire netting, made two nests out of half barrels, screening them thoroughly with cedar boughs, putting up a roost which measured ten inches around; then procured a trio of birds, and kept them shut up for three weeks, at the expiration of which time the wire netting was removed after dark one night. It sufficed; the birds always roosted and laid there, never wandering far away. I have been told by a most reliable informant that thin roosts on which heavy birds do not feel safe are most frequently the cause of turkeys preferring to sleep in trees.

I adopted the plan of setting the eggs, which take twenty-nine days to incubate under ordinary hens. Having no old stone ground on my farm, a strip of high ground partly covered with brush was fenced as a compound; and from a near-by stonecrusher several loads of waste gravel were carted and deposited in the most sheltered 


\section{A SELF-SUPPORTING HOME}

corner. For green food we depended almost entirely on what we fed, and raised them as easily as young chickens. We kept them in the enclosure for nine weeks, during which time their feed was very like that of young chicks. After the first week, cottage cheese, boiled liver with onions and garlic, all chopped and mixed with pinhead oatmeal, crumbled corn-cake or boiled barley, and, of course, scalded clover. I am a strong believer in green onions or garlic for all young birds, they keeping the liver active; and any farm can easily provide them.

Until two months old, the most imperative requisite for turkeys are freedom from damp, and cleanliness. Therefore, you can imagine my astonishment when, going up to a farm on business, I saw a large gray goose coming from the barn followed by a large clutch of young turkeys. I questioned the farm lady and was told that she was a very old goose, the only one on the place, and 199 


\section{A SELF-SUPPORTING HOME}

kept merely because she had been the boys' pet. One day they found her sitting on a nest of eggs, and knowing, of course, that as she was a solitary person the eggs would not hatch, they removed them to prevent her sitting. All being busy people, and not especially interested in pet stock, no more was thought of the poor old goose's maternal desires until four weeks later, when she appeared with a brood of turkeys who accepted her as their mother. The only solution is that being deprived of her own, she stole a turkey's nest and hatched the eggs; and, I believe, succeeded in rearing her odd family to profitable market age.

\section{POULTRY YARD}

The last chapter fully explained our system of caring for infant chicks, whether born under artificial conditions or developed under the breast of a motherly Biddy in the good old-fashioned way. Real in- 


\section{A SELF-SUPPORTING HOME}

fant things receive every care because they appeal to the sentimental feeling possessed by all humanity for babies. They grow, get long legged, ugly, uninteresting, and are neglected disastrously. Don't let this happen, for it jeopardizes success and diminishes profit.

It is not necessary to say that chickens for market should be plump; but it will be helpful to state their ten-weeks-old weight should be in the close neighborhood of a pound and a half. To acquire this, they must be kept growing in frame and flesh, so that they double in weight every ten days up to the fortieth day. After that, their increase is neither so fast nor sure, but they must be kept going. If they fall back now, it will not only postpone summer sales, but delay egg production next fall.

Carefully cull the chicks, keep the best to augment egg production next fall; let the others go to market.

Chickens over eight weeks old intended 201 


\section{A SELF-SUPPORTING HOME}

for the market should be confined in yards with coops three by six feet, with a couple of roosts not more than a foot from the ground. One of these coops will comfortably house thirty chicks. Two or three incubator firms manufacture and ship them all ready for use, for $\$ 6$ each; but you can make quite respectable ones out of piano cases or large-sized packing boxes, roofing paper, and wire netting, which will cost from $\$ 1.50$ to $\$ 2.50$. These coops are best without floors, and all that is necessary in the way of cleaning is their removal to a fresh spot once every three days. If, however, the land is damp, a floor is necessary. The three deadly enemies to poultry all begin with the same letter-D-damp, draught, and dirt.

For future layers I choose those most active in manner, most compact in build, with good-sized, bright eyes. There is a certain something about a chicken which suggests the profitable fowl of the future, 202 


\section{A SELF-SUPPOR'TING HOME}

but definite, actual points are hard to catalogue. If you are really interested in fowls, you will feel what I mean better that a hundred thousand words could explain; and if you are not, a hundred thousand thousand would not tell you.

Do not allow cockerels in your flock if you can help it; but when they are young, mistakes are easy. When they occur, rectify as soon as discovered. Even chick pullets do not flourish if males are in the flock; therefore keep all the latter in the market enclosure unless, of course, you have been breeding from choice thoroughbred birds; in which case, the best of the cockerels must be kept to sell in the fall as stock.

The best place to erect the young pullets' enclosure is in the orchard, for the patches of sun and shade it furnishes seem just what they want. Failing that, or a spot that has some brush on it, you must put up a few shade boards. Cut four thin cedar posts four feet long, point one end, hammer them into the 203 


\section{A SELF-SUPPORTING HOME}

ground at equal distances, adding a roof of light timber; or even nail some young cedars across and cover with brush.

The food of young pullets must be varied to keep them growing, continuously but not too rapidly, because sturdy, strong frames are necessary. Hulled oats, animal food, either meat, meal, beef scraps, or scraps from the butcher, - wheat, and cracked corn should be the staple.

In the morning mash a quart each of ground oats, corn meal, animal meal, two quarts of bran, all mixed and moistened with water. If you feed fresh scraps from the butcher instead of any of the animal meals, give them at mid-day, mixing the mash with milk if you have it, adding green cut bone twice a week.

Naturally, if the pullets cannot be on a grass run, you must provide them with green food - cut grass, plantain, clover, lettuce. All birds must have green stuff. If you have a large enough place to allow the 204 


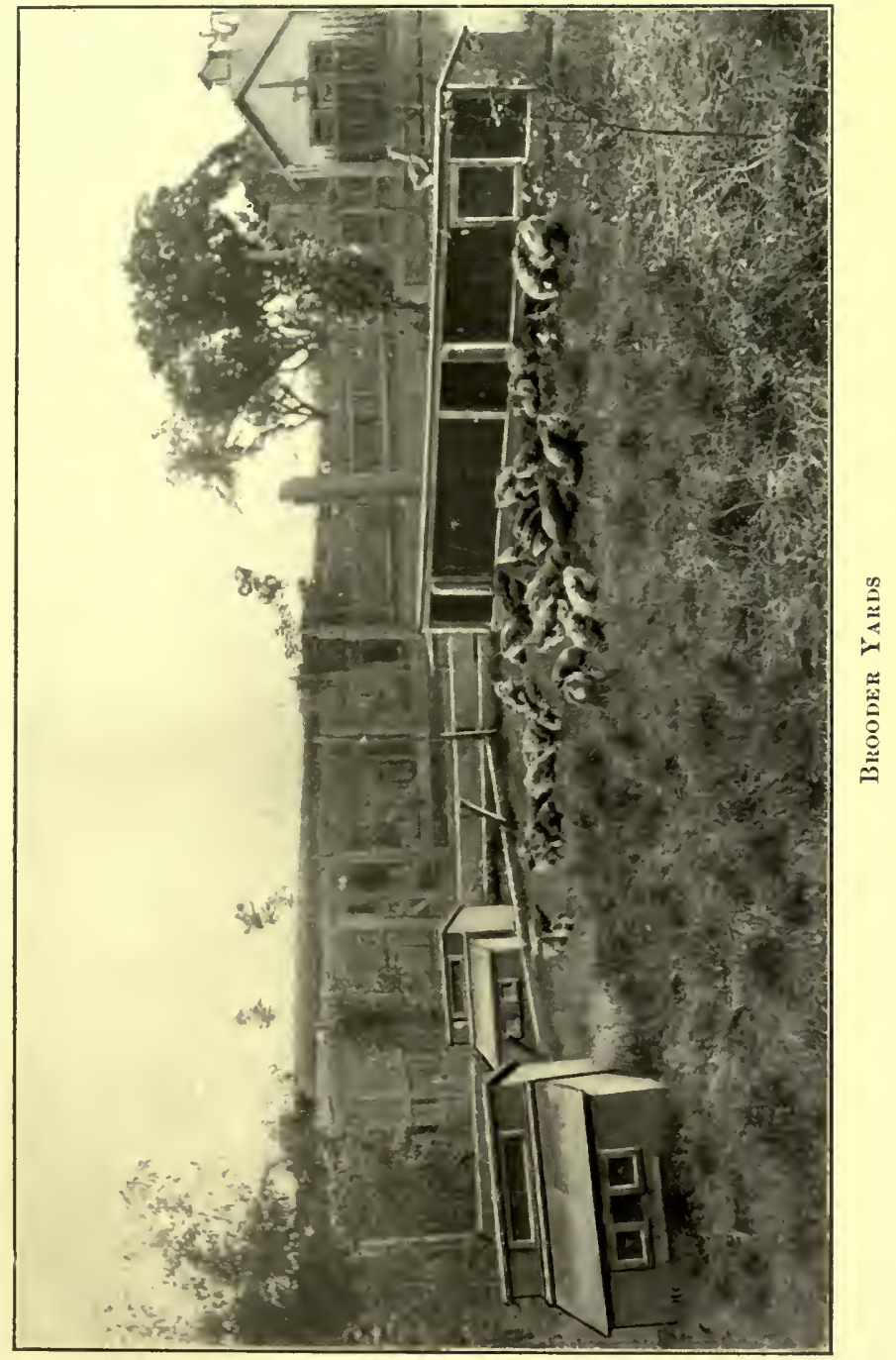





\section{A SELF-SUPPORTING HOME}

young pullets to be kept on the colonizing plan without any enclosure, so much the better; but the roosting coops must be at least fifty feet apart, with fresh, cool water in thoroughly clean fountains, and good sharp grit close to the coops. On the care of these youngsters depends next winter's eggs and profit, so do not grudge it.

Market chickens go into the enclosure provided for them and must receive different feed, as they now want flesh rather than either frame or muscle. Keep the pen well sorted out, shipping as the chickens come to the pound-and-a-half and two-pound weight.

\section{COW AND CALF}

As the time drew near for the coming of the calf, a frightful anxiety assailed me. What ought to be done? What should not be done? She was still giving us four quarts of milk night and morning. A visionary idea kept floating through my memory of 205 


\section{A SELF-SUPPORTING HOME}

some one having said she ought to be "dried up" six weeks prior to the event; but if true, how on earth could it be accomplished, when the man from whom we had bought her had said most emphatically, "Be sure to milk dry, or she'll get milk fever"?

The boy of fifteen, who was my only assistant, I had taught to milk; so from him no advice could be expected. At last it occurred to me that a few judicious questions to old Reika on wash day would probably elicit the desired information. So, even remembering the contempt my ignorance had previously called forth, I resolved to smother pride and consult the oracle; for the rough old Dutch woman possessed a fund of versatile knowledge and humane sympathy that made her advice invaluable to man and beast alike when miles away from a doctor or a veterinary. So much of my "gumption" originated with the quaint old person, that it seems only just to publicly acknowledge my debt, though Reika will never know it. 206 


\section{A SELF-SUPPORTING HOME}

To return to Cush: It is well to gradually lower the supply of grain feed some six weeks before she is due; but take no severe means of drying up the milk. Rachel, our first cow, would slowly decrease in quantity during the last two months, but not go dry until within about ten days of the allotted time, which varies from two hundred and seventy-four to two hundred and eightyseven days; but her daughter, Daisy, never went entirely dry. Still, I could not discover that it made the slightest difference in her later milking. As the ground feed is diminished, wheat, bran, and oil meal take its place, - three parts of the former to one of the latter; and noon feed consists of chopped vegetables only. For spring calving turn the cow out to pasture as early as possible; for the young grass and weeds possess medical properties which no mere human knowledge can substitute. Unless the weather is extremely unclement, allow the cow out-of-door exercise and plenty of fresh air at all times of the year.

207 


\section{A SELF-SUPPORTING HOME}

Have a stall or temporary accommodation prepared for the calf, as far removed from the cow's stall as possible. Where or whatever it is, it should be light and well ventilated, positively free from damp, projecting or jagged nails or timber, and well bedded with clean, sweet straw.

After the two hundred and seventieth day, it is well for the cow to have free access to her stall all through the day and, of course, to be housed at night. Her bed should be deep and clean. Dirty stables are the usual cause of blood poisoning and all the kindred troubles of dam and calf. Always leave the cow untethered at such times. Rarely is any assistance required, though we keep a close watch, and prolonged restlessness is taken as a signal of distress, which we attempt to relieve by offering a warm drink consisting of a pail of water into which a handful each of bran and oil meal have been stirred.

When the calf is dropped, unless the cow 208 

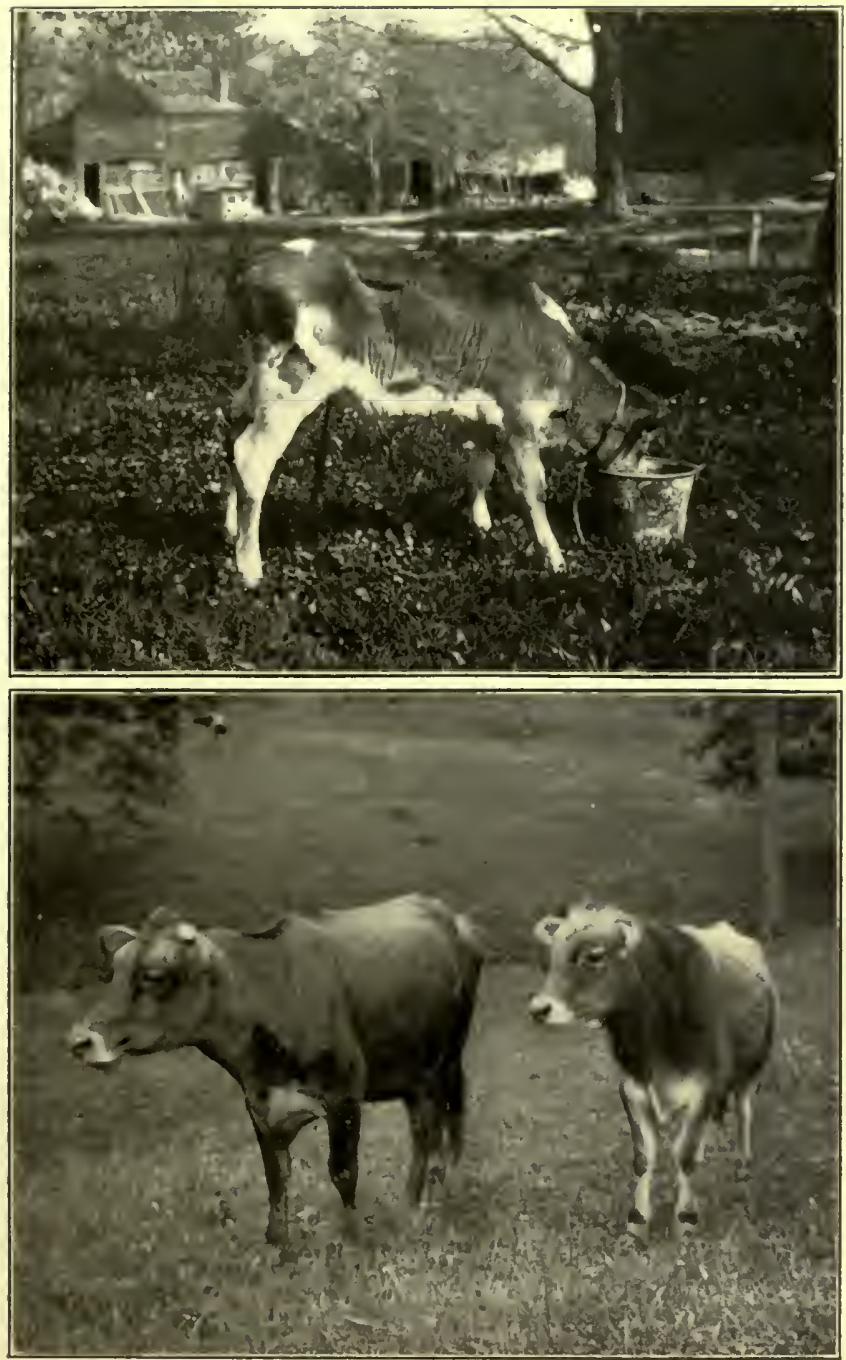

Feeding - Going to Pasture 



\section{A SELF-SUPPORTING HOME}

commences to lick it at once, scatter a little salt over its body, which will attract her to the duty. When the calf looks dry, remove to its own stall, again offer the cow a warm drink prepared as before, and let her first feed consist of chopped pumpkin with bran scattered over it. Rub and knead the udder with a firm, gentle touch for a few minutes; then milk. For a few days it will be well to milk at least three times a day, morning, noon, and evening. After winter calving, let the return to full feed be as gradual as was the decrease. Spring and summer cows can go back on to pasture the second day.

By taking the calf right away from the cow before it has nursed at all, the trouble and cruelty of weaning is spared you and the animals. The prevailing custom of leaving the calf with the cow three or four weeks, and then ruthlessly separating them, should never be tolerated. The first milk taken from the cow must be given to the calf, as 


\section{A SELF-SUPPORTING HOME}

it possesses certain qualities necessary to arouse digestive and other functions of the body.

Teaching a new-born calf to drink is a much easier matter than trying to persuade it, when four weeks old, that a pail is a substitute for its mother. Moreover, at that age, it possesses strength enough to make its teeth and impatient butts anything but pleasant. The new-born baby will, within a few hours, be assailed by hunger; and not having acquired a knowledge of nursing, or even a consciousness of mother, it can draw no uncomplimentary comparisons between maternal and pail methods or quality of the proffered sustenance, which consists for three days of milk as taken from the cow. Second three days, half-skim, halffresh milk.

Feed five times: Breakfast, six o'clock; lunch, nine-thirty; dinner, twelve; tea, three; supper, six-thirty. Quantity, about three pints to a meal. Second week, all 


\section{A SELF-SUPPORTING HOME}

skim milk, warmed to resemble new milk. Third week, one quart of ground feed and one quart of oil meal, boiled in four quarts of water for one hour, strained, and the liquid divided amongst the day's meals. Give only half the lunch feed, adding the deducted quantity to breakfast and supper. Fourth week, skip the nine-thirty lunch altogether. Fifth week, three o'clock tea also merges into supper. Keep up the three feeds a day until nine weeks old, when the calf will commence to nibble hay, and should have a little of the best in the barn. At noon give a drink of milk and water, about equal parts. From this time on, the milk can be gradually decreased, being replaced by more well-boiled feed; but remember that it is better to underfeed than to overfeed a heifer calf, for the desire is to make strength and bone rather than flesh.

We teach the babies to drink by dipping two fingers into the pail and then, holding the hand palm upwards, rubbing the mois- 


\section{A SELF-SUPPORTING HOME}

tened fingers between the calf's lips until it can be persuaded to take the fingers into its mouth, when a little milk is poured into the palm of the hand and, of course, trickles down the fingers into the baby's mouth. As it commences to suck, the hand is lowered into the pail under the milk, and as the comforting influence of the feed is experienced, the fingers are slowly withdrawn. Almost always this is vigorously resented, and the performance has to be repeated many times before the whole supply of milk is consumed; but usually patient perseverance will be rewarded by the calf becoming self-feeding within a week. I have had some that would suck up the milk from the pail after the first introduction; others that would have tried Job's patience.

One thing must be thoroughly understood, or your troubles will be many: Never try to save time by allowing the calf to retain your fingers all through the meal. Such indulgence would be as difficult to correct 212 



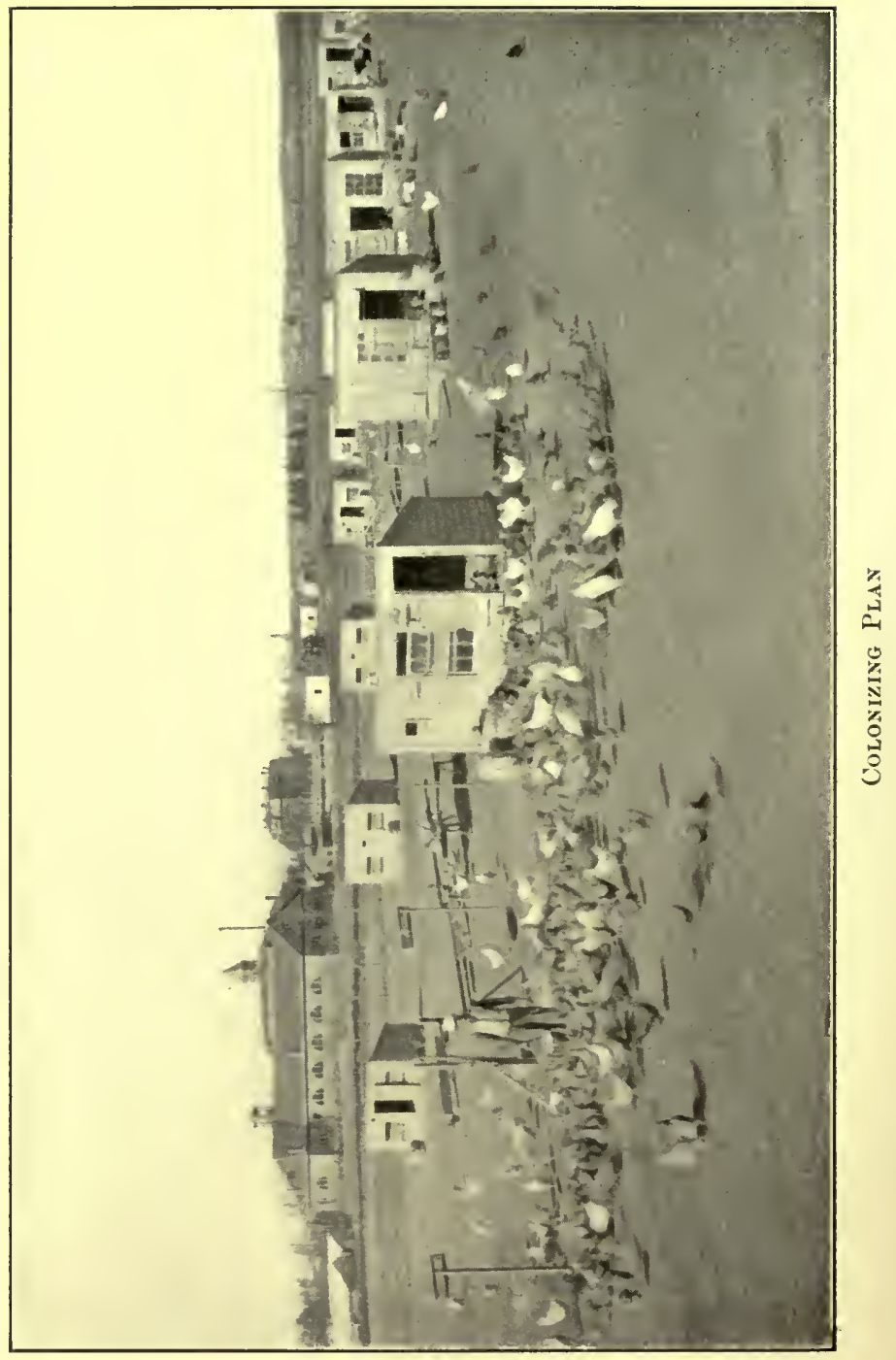




\section{A SELF-SUPPORTING HOME}

as weaning from its mother. I made this mistake with Daisy, and she was an unmanageable terror when, at five weeks old, I attempted to enforce discipline. She would stand as quiet as the proverbial lamb until she detected my fingers slipping away; then a sudden baa, a simultaneous plunge, would upset pail, milk, and my poor self. After two weeks of disastrous battle, we had to starve her into submission.

\section{VEGETABLE GARDEN}

Tomatoes, peppers, and egg-plants should be bedded out about the 20th of the month. Tomatoes and egg-plants stand two and a half feet apart, each one in ground very heavily enriched to a depth of three feet and a circumference of two feet. Pursue the same method of planting as for cabbage, except that instead of cutting the leaves across, nip out the two heart leaves of each plant. Checking top growth makes 213 


\section{A SELF-SUPPORTING HOME}

the plant branch and form a stocky bush instead of spindly top growth that will break under the weight of fruit when it forms.

Prepare "hills," as the allotted space for wide-spreading plants is still misleadingly called, in the same way and distance as for tomatoes, and sow cucumbers, white squash, winter squash, and muskmelon by the 12th of the month, five seeds to a hill. Press into the soil about an inch deep and two inches apart.

Okra should be planted in rows, seeds three inches apart, one inch deep. Sweet corn, ditto. Lettuce sown in the open ground last month will want transplanting for heads. The green-pod beans are planted in a continous row, seeds two inches apart, one inch deep. Make a shallow furrow as for peas.

Thin out carrots to an inch apart in row. Turnips and beets, five inches apart. Keep every inch of broken ground cultivated and. 214 


\section{A SELF-SUPPORTING HOME}

free from weeds, and onions well earthed up to the roots.

Toward the end of the month suspend small looking-glasses here and there in the cherry trees, from a piece of string about a foot long, so that they will turn and twist with every breath of wind. They can be bought for 5 cents each, and the perpetually changing reflections scare the birds away and save many pounds of fruit.

If there is no asparagus bed on the farm, now is the time to rectify the neglect. Fifty. feet by seventeen will be about enough. Trenches three feet deep should be dug every three feet, a layer of manure a foot deep placed at the bottom, part of the earth returned, another layer of manure, the whole to be well mixed and thoroughly pulverized. In fact, the trenches should be prepared as for sweet-peas. Fill the trenches to within six inches of the top, seed, and cover to the depth of four inches. When the young plants are two or three inches 


\section{A SELF-SUPPORTING HOME}

high, fill up the trenches to, or a little above, surface level. Seed will only cost 15 cents, and a few dinners of small stalks can be cut next year, a really good supply the second year, and the third a full crop from which three cuttings can be made. If, instead of seed, two-year-old plants are set, they will cost $\$ 1.50$ a hundred, and not give a very superior return.

Plant sunflowers in all the odd corners and devote a small patch to them, not just to enhance the ornamental appearance of the place, but as a welcome change in feed for the poultry on winter nights, when it will furnish them with as much fat to be converted into warmth as does whole corn.

Field corn should be planted by the 15th, and if poultry is the main consideration, the Early Butler is the best variety because the kernels are small.

If there are no trees in the chicken yards, they can still be planted. Plums, peaches, and cherries are all good fruits for the purpose, 216 


\section{A SELF-SUPPOR'TING HOME}

as the constant ploughing necessary to keep the yards clean for the hens stirs the earth round the trees and turns in well-fertilized surface earth, supplying the trees with valuable food. Then hens, by eating the windfalls, decrease the source of insect life and the enemies which usually attack plums. In return the trees will afford the hens welcome shade from summer sun.

\section{FLOWER GARDEN}

It will be safe after the 10th or 12th of the month to set out all ordinary plants. If you have house plants to bed out, water some time before taking from the pots to set the mould. Then turn the plant upside down in the left hand if size permits, putting three fingers each side of stalk of the plant, and with a pencil or small stick push from the bottom through the drainage hole, until the whole contents is loose and rests on the hand. If it is a solid mass of matted roots 


\section{A SELF-SUPPORTING HOME}

when the pot is removed, press slightly between your hands before planting in the hole which must be prepared to receive it.

If you have specially fine plants that you desire to keep for next winter in the house, instead of removing from their pots, make a hole large enough to bury the pot above the rim; for by so doing the roots are kept in control, making it easier to remove the entire plant in the fall and repot for house with little check.

All the seedlings which have been raised in the nursery boxes can also be bedded, and most of the annuals sown. Pansy seeds sown in the open ground now will bloom late in the fall when the plants now being bedded have run out. Chrysanthemums should be planted out now for fall flowering, and slips taken plentifully from old plants which have been flowering through the winter in the house.

Watch the rose-bushes closely for insects. Whale-oil soap and rain water, gently sponged. 


\section{A SELF-SUPPORTING HOME}

under the leaves, is the best preventive of green fly. Get a tight barrel, put about a pailful of the cow's droppings into it, fill up with rain water, stir thoroughly, let it stand for twenty-four hours, and then use the liquid around the roots of the roses. Repeat the tonic once a week. 


\section{CHAPTER X}

JUNE

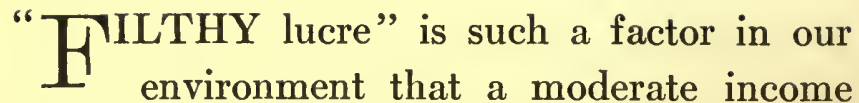
usually prohibits the beautification of our domains, reducing us to the colorless monotony of mere tidiness, excepting in rare instances when nature has been recklessly bountiful in her gifts. This is the case with pheasants, which have the rare combination of being ornamental and profitable; which makes them a necessary addition to the country home of self-supporting aspirants, instead of a prohibited extravagance.

If you have never seen a pair of golden pheasants sunning themselves on a fine day, you cannot realize what a desirable acquisition a pen of these glorious Oriental birds is to the garden or grounds; but as we are 220 


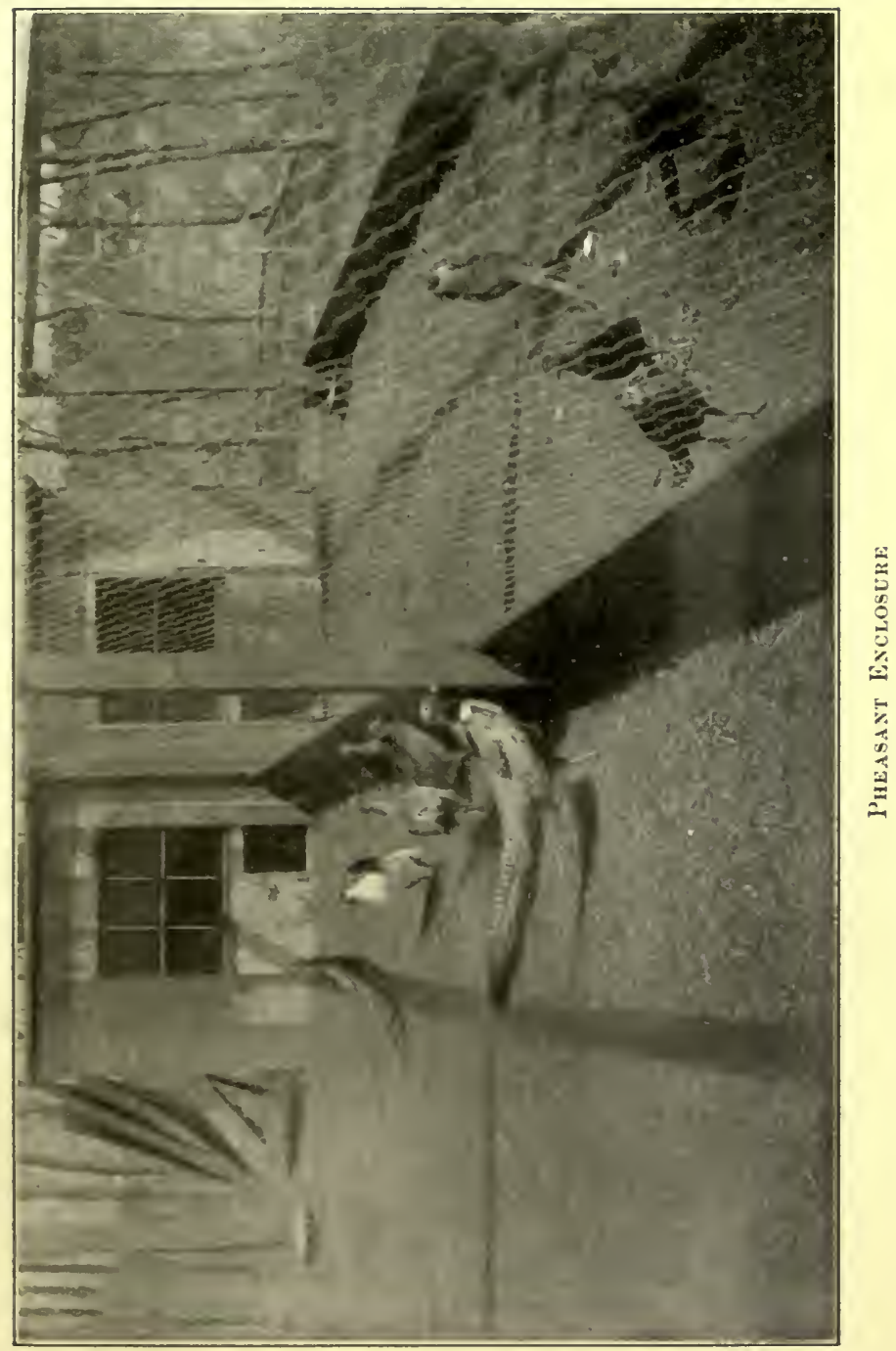





\section{A SELF-SUPPOR'TING HOME}

pledged to the practical, not the æsthetic, their market value must receive first consideration.

Aviaries have become so universal since fashion decreed that a wealthy man must own a country estate to be among the élite, that the demand for birds of handsome plumage far exceeds the supply. The Lady Amherst, Reeves, Golden, Silver, and some half dozen other fancy pheasants head the list of favorites.

Then a big estate is not complete without game preserves for the lords of creation to shoot over; so, like our English cousins of high degree, Americans now spend large sums each year in stocking their woodlands with game, this consisting chiefly of the plebeian members of this same pheasant family, known as the English and Ring-neck. This makes it advisable to keep at least one pair or trio of ornamental pheasants for aviaries; and of the common for stocking preserves.

My personal experience has been confined to the Golden and the Ring-neck. A Sea221 


\section{A SELF-SUPPORTING HOME}

bright bantam, which earned the name of "Little Mother" because of her abnormal spirit of maternity, hatched four of the five Ring-neck eggs purchased in April of our first year on the farm. Not knowing the extraordinary capacity of this special baby for disappearing through any available crack as soon as hatched, only one was rescued alive; but another banty was set late in May on another five eggs, and she brought off three, which were given to the "Little Mother" to brood. One got killed, but the other two and the "solitary suvivor"' of the first brood safely reached maturity. The "survivor" being a male and the other two sisters, they were kept together and demonstrated that a trio do as well as pairs when in captivity. The ten eggs cost $\$ 3$, the enclosure $\$ 3$, a year's feed probably $\$ 2$.

The next summer we sold fifteen eggs at 25 cents each, and raised twelve birds. Two males sold for stock at $\$ 3$ each, three hens for $\$ 2$ each; two pairs were exchanged to pre- 


\section{A SELF-SUPPORTING HOME}

vent in-breeding. The three odd ones were sacrificed to Christmas cheer, but even with such extravagance, a cash balance remained of $\$ 7.75$, and the stock for the next season's output was trebled.

Of course the first consideration must be a bantam hen with motherly longings. If your farm or the neighborhood cannot supply her, search must be made for a small mongrel hen. Arrange the nest as suggested for guinea eggs to prevent loss by the little fellows getting out when first hatched and being chilled to death or lost. Both guinea and pheasant chicks possess such adventurous spirits that the moment they break out of the shell their desire seems to be exploration of the world at large, which usually means death within the hour.

\section{BROOD COOP AND RUN}

The brood coop and run must be just as carefully constructed. Allow the hen to re223 


\section{A SELF-SUPPORTING HOME}

main with the little ones just as long as she does not peck or fight them. A gentle biddy we keep in the brood coop until the babies are about six weeks old, when the whole family is removed to the large enclosure intended for the permanent home; and it is seldom that the hen is removed until late in the fall.

There is a general idea that pheasants are delicate and hard to rear, originating, doubtless, from the fact that all game birds possess the dainty pride which necessitates hygienic surroundings for the breeding quarters. Subjected to the slovenly inattention accorded to the hen on ordinary farms, the pheasant pines and dies. Constitutionally they are hardy, healthy birds, exempt from most of the diseases common to poultry. Dry, sandy soil, sloping slightly to the south to insure natural drainage, and well shaded by vines or low-growing brush, is the most desirable site for their captivity. Failing such natural conditions, select the most favorable situation, comparatively near the house. Have 


\section{A SELF-SUPPORTING HOME}

the ground ploughed and, if it is heavy, clayey soil, remove about a foot in depth, fill in to ten inches with coarse-cut stone, and top with fine gravel at least six inches above the surface level; this will insure freedom from damp and at the same time provide a porous floor which every rain will cleanse.

\section{HOW TO MAKE ENCLOSURES}

The dimensions of a simple, serviceable enclosure are:-

Length, twelve feet; width, six; height, four. Eight posts are required, six feet long and six to eight inches in circumference; thirty-six feet of twelve-inch timber for the foot-board; thirty-eight feet of four by two for the top rail; two shingle slats; half a roll of one-inch wire netting four feet wide; a pair of hinges, and a catch for the door.

The cost of all this can be approximated only, materials vary so much in price; but it certainly would not exceed $\$ 6$, even 


\section{A SELF-SUPPORTING HOME}

allowing 75 cents for a workman to dig the post holes. Make them two feet deep. Erect a post at each of the four corners; one midway on each side; two, two and a half feet apart, at the centre of one end for gate posts. Nail on the foot-board all around; do the same with the top rail, which must have two strips across from side to side four feet apart. Now cover this entire scaffolding with netting, except, of course, the space for the gate, which is to be made from the shingle slats covered with wire netting.

If artificial drainage has had to be resorted to, it will be an advantage to erect posts and place foot-boards before filling in the stone and gravel. No house is required, but a shelter of some sort should be provided with a perch under it, so that the birds are protected from storms when roosting.

Gourds grow so quickly that if the seed is planted around the outside of the enclosure, the vines will soon provide sufficient shade. 


\section{A SELF-SUPPORTING HOME}

A few cedar boughs in one corner will provide the shelter in which these shy, secretive birds love to hide at the approach of any strange presence.

If you desire to be extravagant, erect a round, rustic enclosure on the front lawn and invest in a pair of mature golden pheasants to occupy it; for of all the varieties this is the most amusing and attractive, because of the activity of the birds and their apparent desire to show off their beauty. The male has an orange and black throat, a golden back, steel-blue wing coverts, green shoulders, and a vivid red breast, so that he has every excuse for his vanity.

For mere ornament, the males of three or four fancy species can all be kept in one enclosure and will live peacefully; but never attempt to keep two or more pairs together, for Mr. Pheasant has such a jealous, pugnacious nature, that a battle to the death is sure to ensue. 


\section{A SELF-SUPPORTING HOME}

FEED FOR YOUNG PHEASANTS

Give the usual nothing for twenty-four hours; then corn meal, stale bread crumbled (half a cupful), one tablespoonful of silver sand, one tablespoonful of crushed mustard seed, teaspoonful of maw seed (poppy seed), one hard-boiled egg chopped fine. Mix all together and feed every two hours between 6 A.M. and 4 P.M. for three days; after which milk curds, crushed wheat, pinhead oatmeal, chopped lettuce, green onions, and broiled liver can be added to the bill of fare.

A change of diet sharpens appetite, so use discretion in alternating the latter dainties. Meat, vegetables, or fruit are all necessities to these birds, and when possible should be supplied in the more natural form of grubs, insects, and berries. Ants' eggs are among their favorite foods, and are easily obtained by digging into the middle of an ant-hill. Meal grubs can also be created by slightly moistening meal, then keeping it in a mod228 



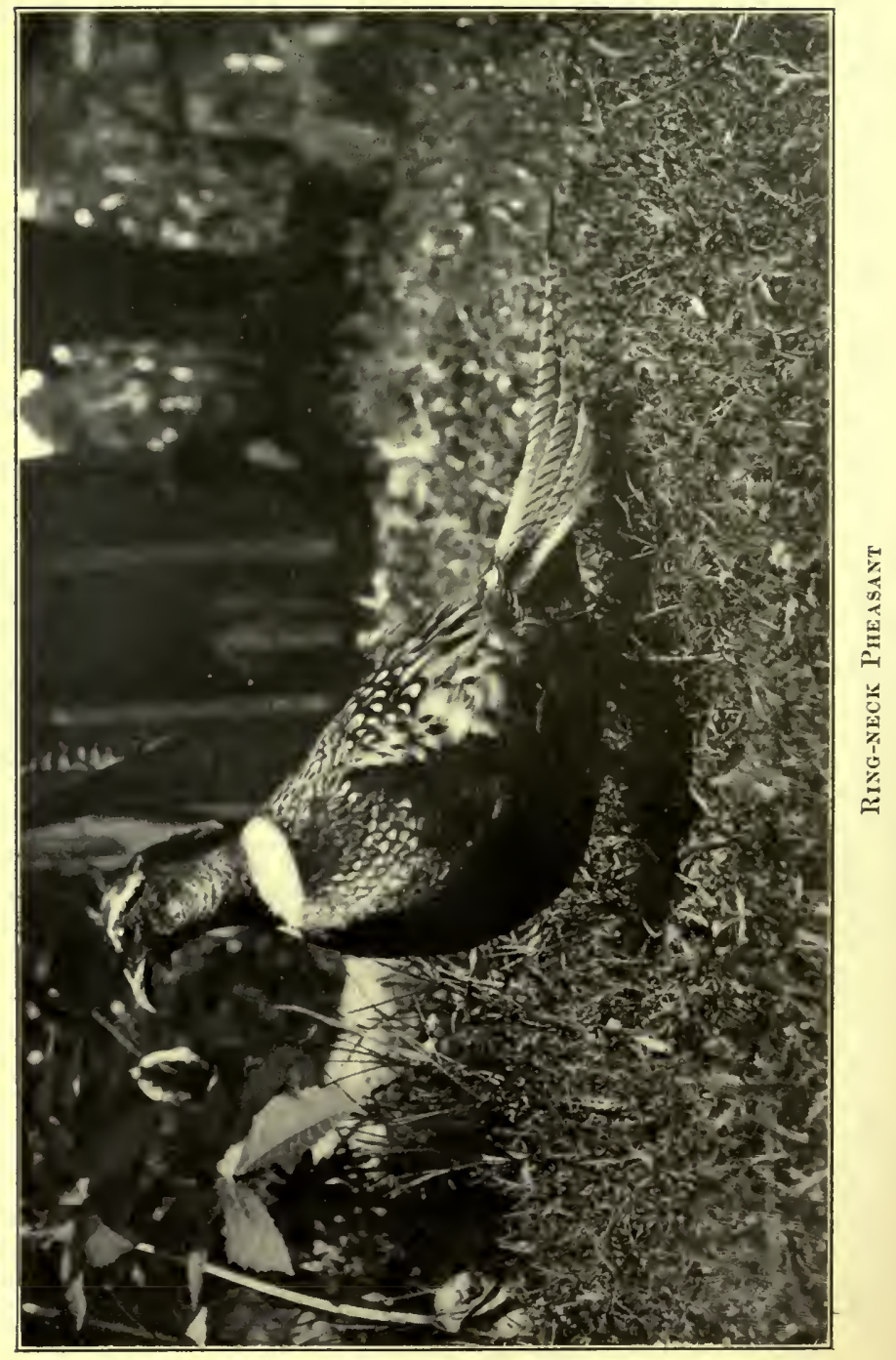




\section{A SELF-SUPPORTING HOME}

erately warm place; but do not, I implore you, try to breed meat maggots. An old breeder assured me that young pheasants would not thrive without them and, in my ignorant enthusiasm, I sent for a sheep's head and hung it up in the empty corn crib with a pan underneath, and for days the pure country air, which was to give us all new life and strength, became tainted with a charnellike smell. On the fourth day I screwed up my courage to the sticking point and, armed with a long spoon, valiantly mounted the steps of the crib and walked into-

There were horrid, squirmy things in the pan. I tried to scoop some of the dreadful crawlers, though my internals objected most vigorously. It is impossible to say how it happened, but somehow the spoon tipped and the contents fell on my dress.

Any one hearing the wild shriek that followed and seeing my mad rush to the house would have imagined that all the fiends from Hades were after me. Really, it was the 229 


\section{A SELF-SUPPORTING HOME}

nearest approach to downright hysteria I was ever silly enough to indulge in. Do not try to see how brave you can be. It is not worth it. Pheasants thrive quite well without charnel-house diet.

After the eighth week, cracked corn, wheat, barley, Kafir-corn, rape, - in fact, all the small grains, - are staple food for the rest of their lives, and can be left always before them in self-feeding boxes, for they are not gluttons and never eat too much.

Once a day a crumbly mash containing meat and green stuff of some sort should be fed if the birds are to be kept in good breeding condition.

\section{KILLING AND DRESSING POULTRY}

Even for home consumption it is desirable to fatten, kill, and dress poultry knowledgeably. It makes such a difference to nutriment and flavor.

Fattening, as understood in France and some parts of England, is a semi-artificial 230 


\section{A SELF-SUPPORTING HOME}

process. Birds - capons and turkeys principally - are confined in small individual coops and fed heavily on moderately soft mash for two weeks, by which time the appetite commences to fail and artificial stuffing is resorted to. A funnel-like appliance is inserted in the bird's mouth and pushed down into its throat; then a liquid food is poured in the crop until it is filled. The very large commercial fattening establishments use an apparatus which looks something like a street knife-grinder's machine, and is worked in the same way by the attendant's foot, only. instead of turning the wheel the treadle action controls a pump which forces the feed out of a tank down a tube into the bird's crop. Both excellent methods, possibly, but after seeing them in operation, I confessed to preferring a little more humane and wholesomely old-fashioned way of providing delicacies for our table.

We have coops six feet long by two and a half wide, with yards six by ten, into which 


\section{A SELF-SUPPORTING HOME}

from five to ten birds are placed three weeks before killing. Fowls of a year old when properly prepared make good roasters; taken from the general yard, they are tough and fit only for soup. Cockerels of ten or twelve weeks old will, by special fattening and inactivity, become plump very quickly. The roost in a coop is only a foot from the floor; yard and floor of coop are of firmly trampled earth, with no loose gravel, sand, or scratching material of any description, the object being to keep the birds as placid as possible.

Morning, noon, and night mash is fed, as it is more easily digested and assimilated than whole corn. The first ten days the mash consists of one quart of ground feed, onethird of a teaspoonful of salt, one pint of boiled and mashed carrots, potatoes, or beets, mixed and moistened with skim milk. Last ten days, one quart of corn meal, one dessertspoonful of powdered charcoal, one pound of potatoes, and two onions, boiled and mashed. Mix all together and make quite 232 


\section{A SELF-SUPPORTING HOME}

soft with skim milk in which beef suet has been boiled. Suet is only about 6 cents a pound. Half a pound chopped fine is sufficient for two quarts of milk. Simmer for fifteen minutes. Feed in V-shaped troughs as much as the birds will eat in fifteen minutes. It must not be allowed to stand before them continually, or they will become satiated. It was an old Frenchman who gave me this hint about suet, which is excellent, making the flesh deliciously tender and juicy.

The effect of food on flavor has been set forth as most important in the New York Market Journal. They call poultrymen's attention to the fact that the exquisite flavor of the canvasback duck is due to the wild celery it feeds upon. The delicious Congo chickens owe their superior excellence to the pineapples they eat. The grouse meat of the far Western plains is aromatic with the wild sage.

The feeding for mere weight or size will, in the near future, give place to the higher art 233 


\section{A SELF-SUPPORTING HOME}

of gratifying the palate. The capon now ranks high above ordinary poultry without any special methods of feeding. How much greater must its superiority be when fed for flavor as well as for tenderness and size! Now and then some enthusiastic thoroughbred raiser will descant on the merits of his favorite breed, - " their tender, juicy flesh and rich, highly flavored eggs, not to be compared with the 'dunghills' long ago discarded," - forgetting that the "dunghills" were truly named, and that from hard scratching in the barnyard for a living resulted the small, tough bodies and ill-flavored eggs complained of. His thoroughbreds have a yard to themselves, are fed on the choicest grains and grasses, and have only pure water to drink. Feeding for flavor must sooner or later become a generally acknowledged part of poultry culture.

After the fattening has been successfully accomplished, correct killing and dressing must follow to insure excellence. Twenty234 


\section{A SELF-SUPPORTING HOME}

four hours before killing birds are removed to individual coops a foot and a half square, with wire netting sides, floor of slats half an inch apart, and legs two feet high. The open flooring and elevated position allow the droppings to fall through and out of the bird's reach. For twelve hours they have milk before them all the time, but no food. Last twelve hours nothing but water to insure the crop being empty.

The most humane and best way of slaughter-

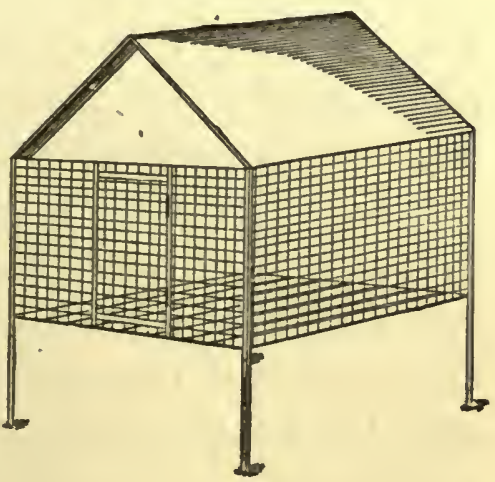
ing the poor things is to have a string with a noose at one end suspended from a beam in some outhouse. Slip the bird's feet through the noose. Instruct the operator to stand with his back to the bird; take the body under his left arm, breast uppermost, the head in his 235 


\section{A SELF-SUPPORTING HOME}

left hand; open the beak by pressing at the sides between thumb and finger, and with a French killing knife stab up into the extreme back of the roof of the mouth. Give a quick turn to the left and withdraw the knife. Leave the bird suspended for a few minutes before taking the feet from the noose.

Plucking must be done at once. Commence with the long wing and tail feathers; then from the shanks, down the inside of the thigh, and over the breast to the neck. Take only a few feathers at a time; grasp as closely to the skin as possible, and pull quickly towards the head. At first it may be difficult to remove the feathers without tearing the skin, but a little assurance and some practice will render it quite easy. After the feathers, all pin-feathers or quills have to be extracted. Then hang the bird up to become quite cold before drawing; but don't delay more than two hours.

Cut off the head with a sharp knife, leaving about three inches of the neck, slit the skin at 236 


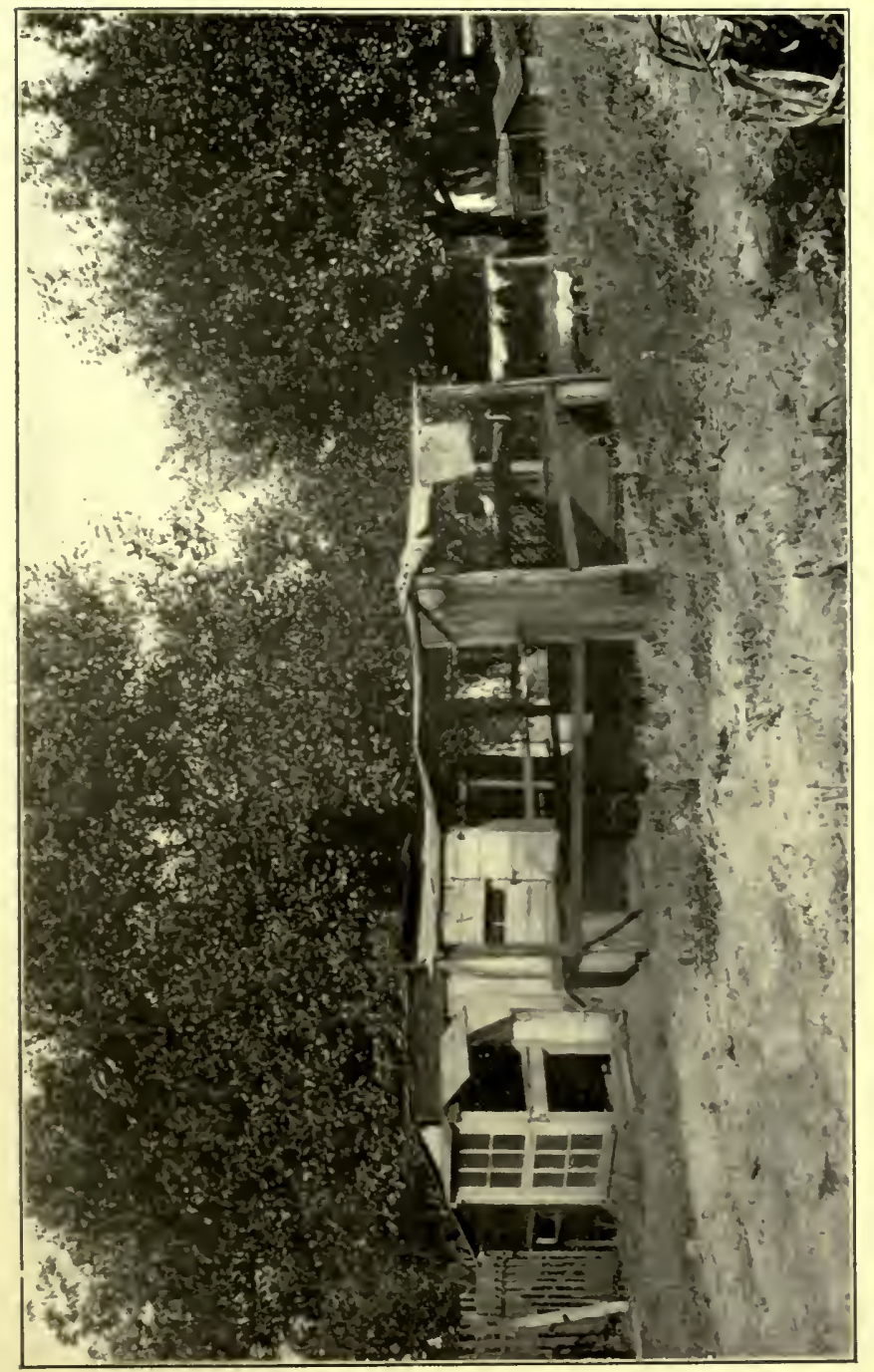

年

c

3

\%

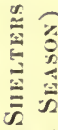

$\equiv$

-

$\approx$

c

Ð

z

?

$\equiv$

돈

क

空 



\section{A SELF-SUPPORTING HOME}

the back lengthwise, push back, and cut out the neck-bone close to the body. With the point of the knife sever the membrane which holds the windpipe to the breast, cut off the shanks, make a straight cut from the end of the breast-bone, being careful to sever the skinny flesh only. Continue to cut in a circle round the vent, and the bird can be drawn without any unseemly exposure or soiling of the flesh.

Place a peeled onion or piece of charcoal in the body, and hang up in a cold cellar for twenty-four hours. Following the above method of drawing leaves the bird unmarred; and the neck skin being folded under the back after the stuffing has been put in holds it firmly in place for roasting and carving. The few stitches necessary from the breastbone down do not show when the bird is trussed. The gizzard and liver must be carefully severed from the remaining parts to avoid breaking the gall-bag, which is a small sac lying between the two parts of 


\section{A SELF-SUPPORTING HOME}

the liver. Hold the gizzard with the narrow, smooth line that runs on one side uppermost. Lay the edge of the knife on the line and make a small, shallow cut, which will reveal a gray-colored inner bag that is to be removed intact; hence the necessity for the cut being shallow.

It has not yet become the general market custom in this country to draw and truss birds at once; but private customers will quickly appreciate the improvement in flavor that immediate attention to cleanliness makes; and before long I firmly believe that the present custom of keeping and shipping undrawn birds will be condemned by the health authorities. When birds are going to customers, instead of being sent in a sprawling condition, they are trussed as for roasting, leaving a piece of charcoal inside to insure perfect sweetness.

Ducks are treated in the same way, except that we give them watercress and green celery during the fattening process. The 238 


\section{A SELF-SUPPORTING HOME}

former we have a quantity of, both wild and under cultivation; and the latter is sown broadcast, just to cut green for this purpose.

Ducks' feathers are worth 18 cents a pound; White Wyandottes', from 14 to 16 cents a pound. In both cases only the soft body feathers are meant. If you desire to keep them for home use, make cheese-cloth bags about a foot and a half square; half fill with geese, duck, or chicken feathers. Have ready a tub of warm suds; to every four quarts add one teacupful of the following mixture: Two ounces of ammonia, a teaspoonful of saltpetre, and a quart of rain water thoroughly amalgamated. Wash the bag of feathers by sluicing up and down in the tub for about half an hour. Squeeze the water out as nearly as possible without wringing; then hang in the full sun, shaking the bag and reversing the ends by which it hangs until the contents are quite dry. It may take two or three days. If so, take 


\section{A SELF-SUPPORTING HOME}

them into the house as soon as the sun goes down, repeat the washing and hang during midsun hours for perhaps a week, by which time the feathers will be fit for pillows.

\section{VEGETABLE GARDEN}

Succession crops commence with this month. The turning of the soil and subsequent cultivation of all planted crops can be accomplished more thoroughly and in much less time if a hand plough is used. They are made with adjustable handles and a full complement of attachments for cultivating, hoeing, raking, planting, and seeding. The entire outfit will cost about $\$ 12$, but can be reduced by dispensing with individual attachments until the handle, wheels, and plough only remain, which cost in the neighborhood of $\$ 3$. We dispensed with the "seeder," which is the most expensive attachment. The other implements complete cost us $\$ 9$, and for five years have 240 


\section{A SELF-SUPPOR'TING HOME}

been in constant use from April to November. Really, it seems one of the indispensables for a home garden where women folks and children take an active interest in the work.

Early peas, lettuce, and radishes will all be used by the 20th. Clear out the vines, scatter fertilizer on the surface, and run the hand plough up and down the row two or three times. Rake, mark off with line as before, and use for the second sow-

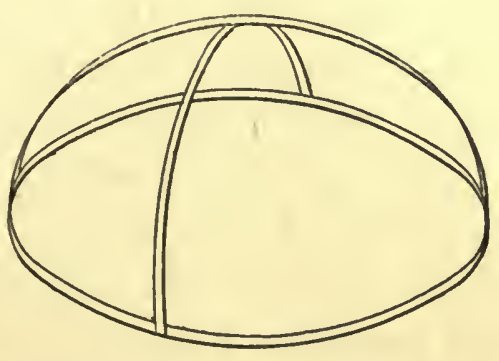
ing of carrots in place of peas, peas where the lettuce was, beans taking the place of radishes.

Stake the tomatoes and prune down the branches slightly. Cucumbers, melons, and squash planted last month will need protection from insects. Get some old barrel hoops; cut one in halves and tack on a whole hoop, crossing the two halves in the centre. 


\section{A SELF-SUPPORTING HOME}

Stretch mosquito netting all over the arched foundation, stitching the edge securely to the round hoop, and you will have a protector as effectual as any of the expensive wire contrivances sold for the purpose.

Prevention being better than cure, it is advisable to scatter powdered sulphur lightly on grape-vines to avoid mildew. Thinning out the fruit in June will insure better-sized and better-shaped branches. Leave only two to a branch, and with a pair of sharppointed scissors cut out the small grapes from each bunch. All fruits are improved by moderate thinning.

This is the best time of the year to go over the strawberry beds, and "start" as many plants as you wish for a new bed. An old English method which we have employed to advantage is to set the baby plants, which form at the end of the runners, in the earth between the rows without severing them from the parent plants, which sustain them until they have devel242 


\section{A SELF-SUPPORTING HOME}

oped strong roots of their own, a process which takes about three or four weeks, during which time the ground for the new beds should be well manured and dug deeply.

\section{FLOWER GARDEN}

The spring bulbs, such as narcissus, tulips, crocuses, lilies-of-the-valley, usually found in most old farm gardens, often suffer death from the inexperienced city tenant cutting down the leaves when the blossoms fade, instead of allowing them to turn quite yellow before removing; for whether the strength of the dying leaves goes back into the roots or not I don't know, but most surely the bulbs die if the foliage is cut down whilst green. Dahlias and cannas of all sorts must go in at once. Spare time to water the young plants every evening if the weather is dry, for they need lots of moisture to produce flowers. 


\section{CHAPTER XI}

\section{JULY}

CATS of high degree, like toy dogs, are always salable. Being charming pets, their addition to the home savors more of pleasure than of a business responsibility. Our original Maltese cats had beautiful silvery coats and well-shaped heads, with large amber eyes accentuated by the black rims which encircled them. For this reason, their kittens found a ready market at $\$ 1$ each. After the first sale, all such money was saved until it amounted to $\$ 10$, when a Persian kitten of excellent family, but only seven weeks old, was for sale.

I bought it for $\$ 12$, a year later paid $\$ 15$ for her to visit a cattery which owned a celebrated king, and a few months later realized $\$ 45$ from the sale of three kittens. 


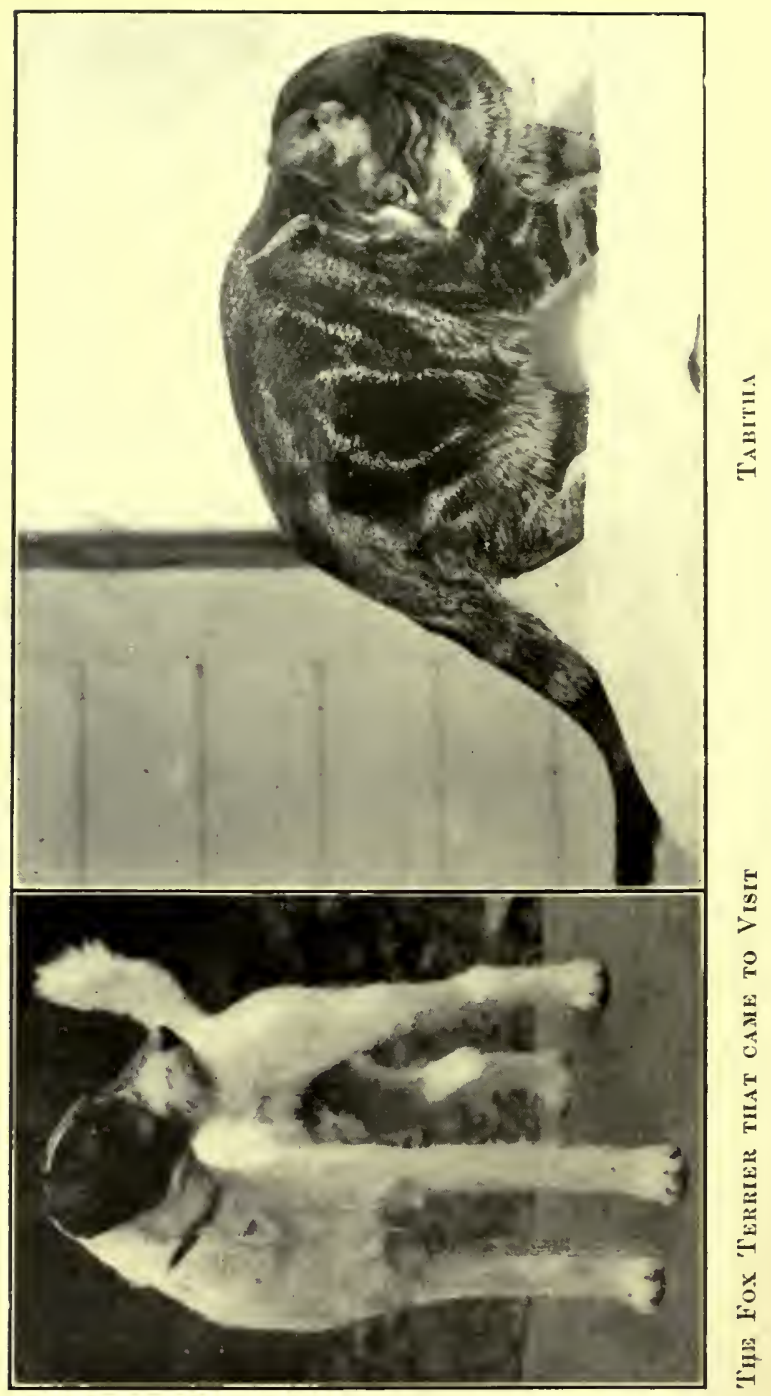




\section{A SELF-SUPPORTING HOME}

The fourth was kept, because it seemed wise to establish a cattery. Another $\$ 5$ from the sale of more Maltese kittens was added to the $\$ 45$ and a king bought. Thus our plebeian mouse-catchers bought and maintained the aristocratic felines, until they were fairly established as money-makers.

If you have taken the hint given in the first instalment of this series about pretty Maltese cats in the barn and feed house, you will soon have a cat fund to speculate with. Commencing as I did, with a kitten, necessitates a loss of time; and frequently a fairly good Persian mother puss can be bought for $\$ 50$, that will present you, inside of four weeks, with kits that will sell in about six months for $\$ 10$ or $\$ 15$ each.

The only objection to this latter plan is that cats are faithful creatures, and changing home and owners may cause fretting which will weaken both mother and kittens. So perhaps the medium course of purchasing a young cat would be the safest to advocate, 245 


\section{A SELF-SUPPORTING HOME}

for she would become reconciled to the change of home before the necessity of sending her for service arises.

\section{A HOME-MADE CATTERY}

If you are accustomed to cats and will exercise vigilant care, a solitary animal can be allowed the run of the house; but when multiplication commences, a cattery is advisable. For a long time mine was a room which had a window opening on the slanting roof of a small extension. From the top of the window to the ground and five feet beyond the extension wall, an inclosure of wire netting was made, on the order of a flying yard for pigeons. From the extension roof to the ground, a wide slab of wood with the bark left on was placed, making a runway which afforded the inmates much amusement and exercise. An old cherry tree near by shaded one side of the roof and yard; so even on hot days there was a cool spot for afternoon siestas. 


\section{A SELF-SUPPORTING HOME}

The furnishings of the room consisted of a square of rag carpet and boxes about two feet square without lids, in which a pad, such as is used for babies' cribs, was placed; these made warm, draught-proof beds. In the summer the boxes, turned upside down and covered with double strips of Turkish towelling, provided individual, airy sleeping places.

From the centre of the ceiling a clothbound ball was suspended by a long string. In one corner a long-handled lash whip was fastened. On the wall was a cage of birds; near the window a deck chair. In two corners were zinc-lined boxes, a foot and a half square, six inches deep, and half filled with ashes, on a strip of oil-cloth. In another corner was a butter crock for water and a couple of plates for food. The ashes were changed every day and the cloths or pads taken out, shaken, or hung on a line, weather permitting, to air. 


\section{A SELF-SUPPORTING HOME}

\section{DIET FOR CATS}

Breakfast consisted of one strip of fat bacon about an inch square for each cat, and a pint of skim milk for three. Dinner: lean meat (generally gravy beef, or liver which had been stewed in the oven) mixed with whatever vegetables we had had on our own table. Supper: milk as in the morning. Butcher days - Wednesdays and Saturdays - they had a fresh bone with about an ounce of meat on it. I know most breeders will be horrified at this, as they generally advocate chopping the meat fine. This seems all wrong to me. Cats have splendid teeth, which were certainly intended for use. Leaving the meat on the bone insures proper mastication; which stimulates the flow of saliva, the greatest aid to digestion.

The strip of bacon is prompted by the fact that all the kitchen cats we ever had have always begged a piece when it is cut for breakfast; and after eating it they will 248 


\section{A SELF-SUPPORTING HOME}

go straight to the milk, drinking it with the greatest relish; then they wash themselves industriously. Moreover, I think the salt and fat act as a medicine, for our cats are never afflicted with worms - one of the worst troubles breeders of high pedigreed cats have to contend with.

Diet is varied as often as possible, fish or chicken taking the place of other meat, with rice pudding, bread and milk, a piece of sponge cake or toast at supper-time.

A bunch of catnip, green or dried, is given once a week.

The cage of birds may seem a strange adornment for a cattery, but there is a reason for it. Cats bred to sell as pets are much more attractive to the average purchaser if accustomed to caged birds and trained not to molest them.

The deck chair was for my own comfort. I love cats, and took my hours of rest and amusement in the room. Another of my fads was to have all our pussies friendly with 


\section{A SELF-SUPPORTING HOME}

the dogs. These little items of education are as easily taught as cleanliness, and save kitty all sorts of misery when she goes to a strange home.

\section{HOW TO KEEP THEM DAINTY}

The coats of your cats should be kept in the best possible order. Nothing seems to insure this better than daily brushing, which prevents tangling and breaking. If they are healthy and the beds kept clean, they rarely look dirty. If by any chance they do acquire smudges, rub bran into the fur and brush it out; the soil soon disappears.

Fleas are pests to be dreaded for all furry pets in warm weather; so take time by the forelock, and by rigid care in the cattery check their approach. Once established, it is impossible to exterminate them without injury to the cats. The floor of the room should be washed three times a week with water to which carbolic acid has been added. Vermin powders I don't like, because they 250 


\section{A SELF-SUPPORTING HOME}

invariably nauseate the poor animal, who, objecting to the foreign substance in her coat, tries to remove it by licking. A weak solution of spirits of camphor can be dabbed on the cat's skin if the hair is divided in small patches, as one would apply a tonic to the scalp, and will render it unpalatable to Mr. Flea.

\section{KITS AND THEIR CARE}

About mating: A young queen is apt to become restless and unusually playful when five or six months old; but as she is entirely too young to go visiting, keep her under close guard until the unaccustomed anxiety to go out passes. It will be advisable to write to two or three catteries, giving your cat's pedigree and personal description, so that they can judge if they have a king to whom it would be desirable to send her. Then you will be prepared with all necessary information, and can take or ship your queen when the journey can no longer be 251 


\section{A SELF-SUPPORTING HOME}

postponed. If the young cat can be held back until after a year old, it allows full time for development; but after nine months of age it often does a healthy, strong queen more harm to fret and fidget than to assume the strain of maternity. Therefore, individual cases must determine the most desirable age.

The usual litter - four kittens - are too many for any puss mother to nourish well; so, as Persians are too valuable to be consigned to a watery grave, a foster-mother should be arranged for. This is an easy matter if you have plenty of cats about the farm buildings. We bought a tiger kitten as a playfellow for our first Persian. They invariably have kittens about the same time, and Tabitha adopts the Persians as a matter of course, Kliner relinquishing the care of her babies with all the indifference of a fashionable beauty, until they become interestingly pretty. Then my lady seems to take a mother's pride in them. 


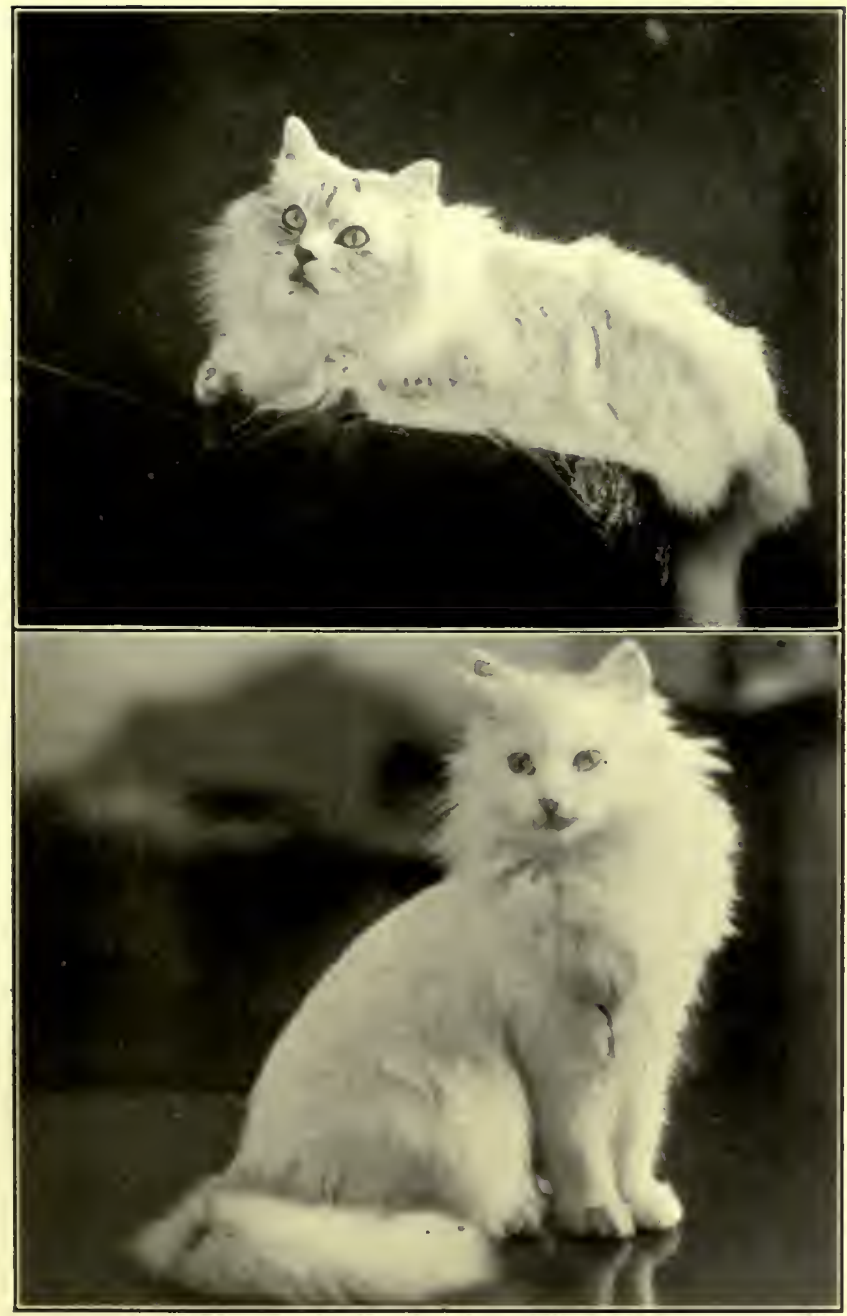

Argest Splexidor (a Superb Specimex of his Kind) - Kiner 


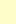




\section{A SELF-SUPPORTING HOME}

Some cats become very excitable and restless as the time approaches for their babies to arrive. Under such conditions, use every means to soothe and quiet the patient, by keeping other cats away and inducing her to drink a little hot milk. If there is a dark cupboard in the room, it is likely to attract at such times and makes the best of bedrooms. If there is not such a fixture in the room, a large box with curtains will answer the purpose. Of course, kings should not be permitted access to the room at such times. Mother cats will need restricting to their special quarters from about the second week of motherhood until the fifth, or possibly the sixth.

Health and strength are endangered if more than two families are permitted in the year. I prefer kittens to arrive in early spring and fall, for then they have an opportunity to develop before the severe heat or cold prevents outdoor exercise.

Cats love human companionship, and if 253 


\section{A SELF-SUPPORTING HOME}

you have children who are fond of animals, it is a good plan to allow the cattery to be used occasionally as a play-room. Of course this suggestion does not apply to little ones under five years of age, who would pull and tease the cats. Some of the best kittens I ever saw were the constant playfellows of two little girls, aged respectively eight and ten, who dressed them up and made doll-babies of them. The kitty-cats seemed to enjoy it as much as the children, who fed, cleaned, and took full care of them. The original mother puss had been a present to the children, and money from sales was banked for them; and, I assure you, at the end of five years it had developed into a very nice little nest-egg.

\section{THE POULTRY YARD}

Insects are the most disagreeable feature of poultry keeping, but must be discussed, as it needs the greatest vigilance just now 


\section{A SELF-SUPPORTING HOME}

to prevent their developing uncontrollably during the coming winter, when the birds may have to be imprisoned for days at a time during heavy snows. Few amateur poultry raisers know that there are several distinct varieties of vermin which seem specially created to torture fowls into an unprofitable state of debility.

The man who examines his fowls and, finding them free from vermin, congratulates himself, little guesses that after dark an army of blood-sucking, fiendish mites swarm from every crack and crevice of old or neglected houses to steal the vitality of his fowls.

Theobald says there are eighteen varieties of mites. Dr. Woods (one of the best authorities) assures us only five are commonsomething to be thankful for. The bird tick, Dermanyssus Avium, an imposing name for something not larger than a grain of sand, usually infests pigeon lofts; but as it is carried by all wild birds, the nests of 255 


\section{A SELF-SUPPORTING HOME}

martins and swallows often introduce it into the barn, where it is a great source of annoyance to cattle and horses. When empty, it is almost colorless; but having sucked blood, it changes to bright red, then to almost brown. So close to this comes the gray or red mite, or poultry tick, that they are almost identical, the only difference being that the poultry tick is slightly larger, and usually much more plentiful. Coops that have been used year after year for brooding frequently harbor such quantities that baby chicks are tortured to death by them. They are pale grayish in color, with darker patches showing through the skin. When filled, they vary from dark red to almost black.

The necessity for fighting these minute pests will be apparent when it is known that Dr. Woods tried the experiment of keeping a dozen of the latter in a box, and that in two weeks they had increased to hundreds.

Another general mistake which causes endless trouble is the idea that a house which 256 


\section{A SELF-SUPPORTING HOME}

has not been in use through a winter is freed from vermin. It is an authenticated fact that two years' starvation has as little effect on these horrid little wretches as the most severe frost. They just sleep through uncomfortable times, and awake refreshed and eager for prey.

Another unsuspected menace to poultry is the harvest mite, or jigger. These insects normally feed on plants, abounding in blackberry patches and tall weeds; but, swept off by passing birds, animals, or even humans, some species immediately bury themselves in the skin of the unfortunate victim. This is fatal to the insect, but raises a large blister which itches intolerably, often causing inflamed patches sometimes mistaken for chicken-pox. I once had a small dog driven nearly crazy by them. Vinegar, or carbolic acid and water, will stop the itching and remove the inflammation. It is safest to have hens avoid any infested place, or if you live in the Southern states, where they are most 


\section{A SELF-SUPPORTING HOME}

common, keep the birds yarded during July and August, when they are most prevalent.

All mites and ticks being much alike, there is nothing to be gained by further description. To guard against the bedbug class of mite - the first two species - fumigate the houses with sulphur or tobacco once every two weeks when possible. All through the winter apply liquid lice killer, - kerosene oil and carbolic acid mixed, - and when weather permits in summer and fall, whitewash thoroughly.

The hen chigoe, or American hen flea, is small and not unlike other fleas, except that it does not hop, but walks like a fly. Dark, damp quarters serve for breeding-places for their eggs; so let in all the sunlight possible. If there are any parts of the house inaccessible to sun, scatter air-slacked lime on them.

These are fair samples of the often unsuspected enemies which must be fought constantly. Don't wait to know that such 258 


\section{A SELF-SUPPORTING HOME}

creatures are lurking in the coops and houses; take it as an established fact, for it is one of those cases where prevention is better than cure. The common louse, which is inseparable from fowls, is far less harmful than the minute night wanderer, for the simple reason that everybody who keeps poultry wages ceaseless war on lice with insects, powders, dust baths, etc.

\section{MOULTING}

The season at which hens moult has such a direct influence on the production of winter eggs that poultrymen have devoted much study to the subject. Unless a bird moults early in the fall, it is impossible to get it into condition before the really cold weather, for the growth of new feathers requires so much oil there is none left to provide animal heat; so the food which should be converted into eggs has to furnish the warmth necessary to keep the bird alive. 


\section{A SELF-SUPPORTING HOME}

After many experiments, it has been generally conceded that by withholding food entirely for three weeks, and then feeding heavily the rations suitable for the formation of feathers, the moulting season can be controlled. The last week of the month mature hens are turned out on free range to forage for their own living. About the end of the second week in August flocks are returned to their respective yards, roosters being kept in a separate enclosure until the breeding pens are made up in January.

Feed a morning mash of equal parts wheat bran, ground feed, and oil meal. Noon : meat scraps, vegetables, or some sort of green. Night: wheat, corn, and oats mixed. The first few days give only half meals, as the excessive heavy feed might cause indigestion after the semi-starvation. By the 10th of September the birds should be in possession of full new coats of feathers and robust health. Three weeks after reyarding change the diet to regular egg rations, cut260 



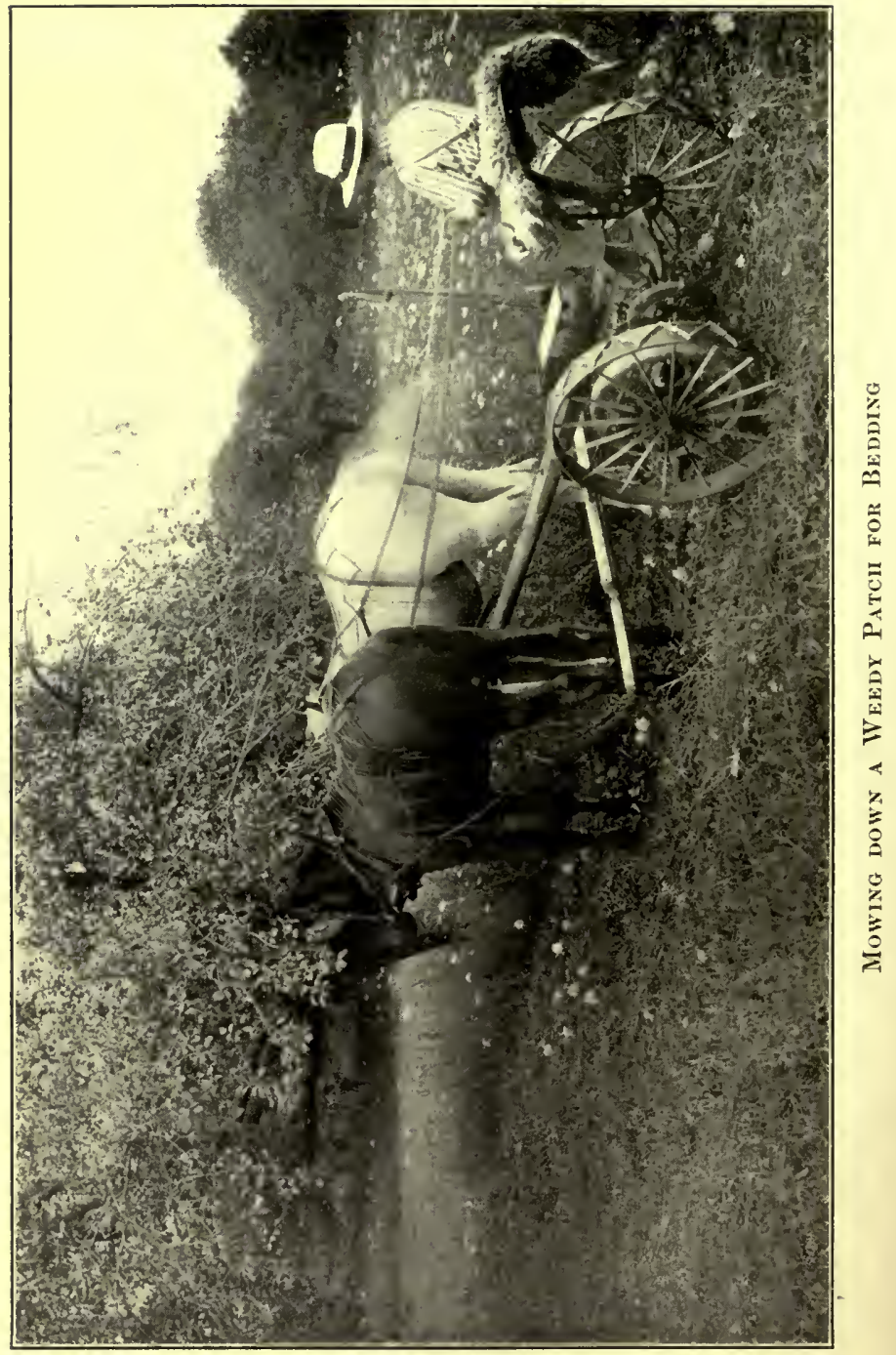




\section{A SELF-SUPPORTING HOME}

ting down the corn and oil meal, using clover hay, wheat, and green bone as staple ingredients. Old hens, not to be kept through the winter, should be disposed of before they commence to moult, for then it will be impossible to fatten them.

Keep a close watch on cracked corn during July and August. It is likely to become mouldy, and if fed in that condition, it will cause sour crop and bowel trouble.

\section{VEGETABLE GARDEN}

If you wish to increase your currant or berry patch for next year, there is no necessity to buy new plants if there are already a few good varieties on the farm. Follow the old English plan as recommended for strawberries last month. Bend down some of the outer branches until a part can be pegged down to the ground without breaking. Forked branches from green trees are the best stakes to use. Cut them with the forked 261 


\section{A SELF-SUPPORTING HOME}

parts about four inches long, and the main stick two or three. Point the ends of the forks and peg down the branch at an easy angle from the bush. Draw the earth up round the fork, and about the first week in August the branch can be severed from the bush close to the peg, and an individual plant will be the result.

As the green beans, peas, summer cabbage, lettuce, etc., ripen and are consumed, clean out the vines, cultivate, enrich, and replant the ground. Winter cabbage, fall spinach, celery, leeks and Brussels-sprouts - all the foregoing are gross feeders and demand heavy fertilizing with well-rotted stable manure. Leeks stand six inches apart in the rows; Brussels-sprouts, a foot. Celery rows should be four feet apart to allow space for the deep "earthing up" later in the season. When setting out celery plants great care must be taken to spread rootlets, but only the root must be buried, for if the heart of the plant is covered, it will. 262 


\section{A SELF-SUPPORTING HOME}

not grow. Pack the earth firmly round the root and water copiously and then cover with dry earth.

\section{FLOWER GARDEN}

July is almost a "standstill" month, yet a little work will assure late flowers. Balsam and nasturtium seeds, sown now in sheltered spots, will bloom till the end of November. Cutting off blossoms before they commence to fade will induce geraniums, fuchsias, stocks, etc., to throw up new flower stalks. You can take slips from all plants during this month. Permanent vines should be tied up to trellises as the new wood grows.

\section{FARM CROPS}

Any odd half or whole acres adjacent to the poultry houses, available for planting, should now be turned over and seeded with crimson clover, to aid the supply of green food in late fall and early winter. If the 263 


\section{A SELF-SUPPORTING HOME}

orchard should be old, worn-out ground, plough and sow clover now to turn under in the spring. It will renovate the ground and feed the trees, as clover is a legume and attains its nitrogen from the air, conveying it to the soil; so that land on which clover has been grown will need only a phosphate top dressing the following year, even for such greedy plants as cabbage and celery.

Should the hay crop have proved poor, crimson clover and cow-peas sown early this month will be ready to mow and cure the last of August or the first of September, if it is a late season. Either make good hay for poultry and stock, having about the same food value as wheat bran.

\section{THE COW}

The cow suffers severely from flies and heat during the sultry days of July and August, especially if she has to be tethered. Loose in a fenced pasture, she can rub the 264 


\section{A SELF-SUPPORTING HOME}

pests off against the bushes, and any lot worthy the name of pasture should have a pond or stream for her to wade into; but when fifty feet of rope or chain limit her wanderings, be thoughtful enough to select a shady spot for her tenting ground, and keep fresh, cool water within her reach. Before turning her out in the morning, brush off with some one of the good fly lotions; and on the few record-breaking days which visit us every summer, soak a burlap horseblanket in water and throw it over her; the evaporation will keep her cool. If that seems too much trouble, at least let her have a comfortable siesta in a darkened stable from one o'clock until three-thirty.

It is the single cow which usually suffers the most, so it is comparatively easy to relieve the trouble. A herd compels a properly fenced pasture, where they are free to wander at will. Selfishly, the cow's comfort should be attended to during the summer, for she will give more and better milk. 


\section{CHAPTER XII}

\section{AUGUST}

BEYOND the gratification of receiving public assurance that your birds are " the real thing," a show-room indorsement increases profits considerably. It changes the value of thirteen eggs from the ordinary market, 25 or 40 cents, to $\$ 2$; occasionally even $\$ 5$.

Every poultry man and woman should thank the clubs and fanciers who have successfully established shows all over the country. They arouse general interest in good birds, which bring the very cream of profit to the breeder industrious enough to study the standard and develop, point by point, until a near approach to perfection is reached.

How is this to be accomplished?

Of course there must be some thorough266 


\section{A SELF-SUPPORTING HOME}

bred birds of whatever kind you intend to devote your energies to, as a foundation on which to work.

Many people seem to think that a thoroughbred means show specimens - a great mistake. You may have a bird which has been hatched from an egg laid by a champion, but which develops a wry tail, comb, wattles, or ear-lobes all out of proportion, or numerous other faults which disqualify for show purposes. These are the birds which swell breeders sell for a dollar or a dollar and a half. They are, in all probability, from the best of stock, and judicious mating may enable you to rear winners. "Blood will tell" is nowhere more positively demonstrated than in bird or animal culture. It is better to buy faulty birds of a celebrated strain than a perfect "accident," for its progeny is nearly sure to show some, perhaps all, the mongrel of its ancestors.

The law of improvement demands a study of faults and shortcomings rather than good 267 


\section{A SELF-SUPPORTING HOME}

points. Extremes meet and form a perfect whole simply explains the line to follow. Further to exemplify: A hen with legs too short and a comb too large should have for a mate a bird whose legs are a little too long, comb a little too small, rather than a perfect specimen who would have no tendency in these directions to counterbalance the hen's weaknesses.

Again, you should have a fairly good lot of hens to select from. Commence by picking out the very best; study her closely; find the fault or faults, and select four or five others from the same pen with similar shortcomings, so that in considering the cockerel to be yarded with them there will be a general benefit. Naturally, if you can afford to start with a trio of prize winners, much time and labor will be saved.

If you have been breeding from nearly perfect birds this summer, your preference of youngsters will be easily made; and as one can never be quite sure of development, single out nine or ten of the most promis268 


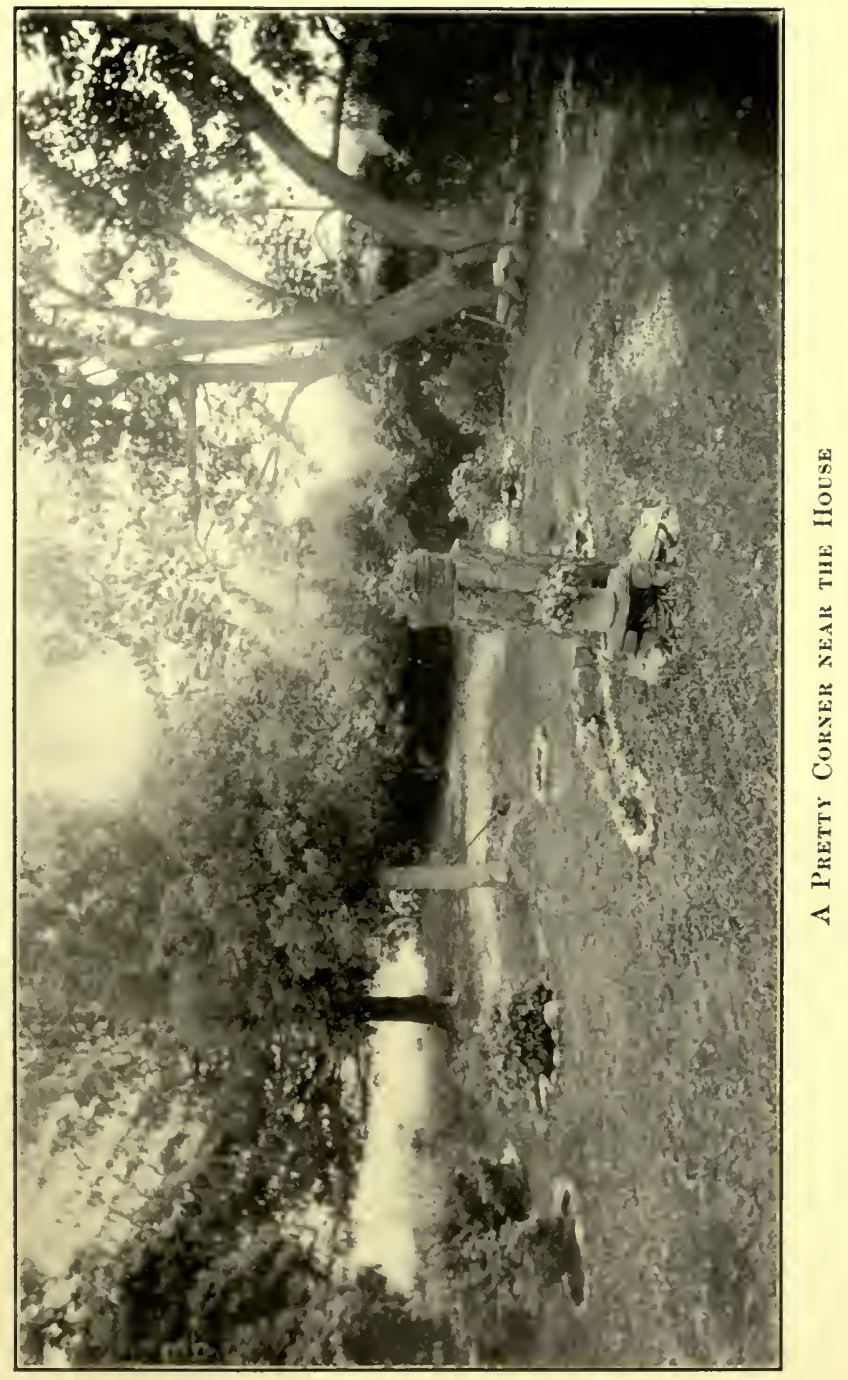





\section{A SELF-SUPPORTING HOME}

ing, even if you only purpose sending two or three to the show room. Put them into small quarters and gradually accustom them to being handled. A little patience will soon get them used to eating out of your hand. This prevents their being frightened when put up for public admiration, or during the judge's handling and examination. Gradually lessen their pen space till they have no more room than in the exhibition coop. Such treatment prevents your birds fretting and pining; insures their showing to the best advantage and returning home in good condition.

On the other hand, take birds straight from a large yard and place them in the restricted quarters of a show-room coopthey fret, won't eat, flutter, and fight to get out when any visitor to the show stops to look at them, so that their beauty has no chance of demonstration. The poor judge has to tussle with fluttering wings, and has to half guess the points.

These things are frequently neglected by 269 


\section{A SELF-SUPPORTING HOME}

the amateur; rarely by the old exhibitor, who has learned the advantage of having birds or animals sufficiently self-possessed to be "cute and cunning."

Remember, too, one good point won't count without general symmetry and condition.

Every breed has its standard weight. Space forbids full quotations, but here are a few of the most popular:-

\begin{tabular}{|c|c|c|c|c|}
\hline & ROOSTERS & HeNS & Cockereis & PULLETS \\
\hline $\begin{array}{l}\text { Plymouth Rocks . } \\
\text { Wyandottes . } \\
\text { Light Brahmas }{ }^{1} \text {. } \\
\text { Langshans . } \\
\text { Andalusians . } \\
\text { Minorcas . . }\end{array}$ & $\begin{array}{l}\text { Lbs. } \\
\qquad \begin{array}{l}9 \frac{1}{2} \\
8 \frac{1}{2} \\
\text { I } 2 \\
\text { I0 } \\
6 \frac{1}{2} \\
8\end{array}\end{array}$ & $\begin{array}{l}\text { Lbs. } \\
\qquad \begin{array}{l}7 \frac{1}{2} \\
6 \frac{1}{2} \\
9 \frac{1}{2} \\
7 \\
5 \frac{1}{2} \\
6 \frac{1}{2}\end{array}\end{array}$ & $\begin{array}{c}\text { Lbs. } \\
8 \\
7 \frac{1}{2} \\
\text { 10 } \\
8 \\
5 \frac{1}{2} \\
6 \frac{1}{2}\end{array}$ & $\begin{array}{l}\text { Lbs. } \\
\qquad \begin{array}{l}\frac{1}{2} \\
5 \frac{1}{2} \\
8 \\
6 \\
4 \frac{1}{2} \\
5 \frac{1}{2}\end{array}\end{array}$ \\
\hline & $\begin{array}{c}\text { ADULT } \\
\text { TOMS }\end{array}$ & HENS & COCKERELS & Pullets \\
\hline $\begin{array}{l}\text { Bronze Turkeys } \\
\text { White Holland }\end{array}$ & $\begin{array}{c}\text { Lbs. } \\
36 \\
26\end{array}$ & $\begin{array}{c}\text { Lbs. } \\
20 \\
\text { I } 6\end{array}$ & $\begin{array}{l}\text { Lbs. } \\
25 \\
\text { I } 6\end{array}$ & $\begin{array}{c}\text { Lbs. } \\
\text { I } 6 \\
\text { I0 }\end{array}$ \\
\hline
\end{tabular}

1 Dark Brahmas are a pound lighter all through than light Brahmas. 270 


\section{A SELF-SUPPORTING HOME}

\begin{tabular}{|c|c|c|c|c|}
\hline & GANDER & Goose & $\begin{array}{l}\text { YOUNG } \\
\text { GANDER }\end{array}$ & $\begin{array}{l}\text { YOUNG } \\
\text { GOOSE }\end{array}$ \\
\hline $\begin{array}{l}\text { Tousouse Geese } \\
\text { Embden Geese } \\
\text { African . } .\end{array}$ & $\begin{array}{c}\text { Lbs. } \\
20 \\
20 \\
20\end{array}$ & $\begin{array}{c}\text { Lbs. } \\
\text { I } 8 \\
\text { I } 8 \\
\text { I } 8\end{array}$ & $\begin{array}{l}\text { Lbs. } \\
\text { I } 8 \\
\text { I } 8 \\
\text { I6 }\end{array}$ & $\begin{array}{l}\text { Lbs. } \\
\text { I } 5 \\
\text { I } 6 \\
\text { I } 4\end{array}$ \\
\hline & DRAKE & Duck & $\begin{array}{l}\text { YOUNG } \\
\text { DRAKE }\end{array}$ & $\begin{array}{l}\text { YouNG } \\
\text { Duck }\end{array}$ \\
\hline Pekin Ducks . . & $\begin{array}{c}\text { Lbs. } \\
8\end{array}$ & $\begin{array}{c}\text { Lbs. } \\
7\end{array}$ & $\begin{array}{c}\text { Lbs. } \\
7\end{array}$ & $\begin{array}{c}\text { Lbs. } \\
6\end{array}$ \\
\hline
\end{tabular}

Rouen Ducks, one pound heavier all through.

The Standard of Perfection instructs judges to deduct two points a pound for any deficit from standard, or one-half point an ounce for any excess over standard in bantams. In all varieties of turkeys, geese, and ducks having weight clauses, three points per pound are deducted for any deficit from standard.

This short summary will prove the importance of weight. First the frame of the bird must be the right size, so that sound, firm 271 


\section{A SELF-SUPPORTING HOME}

flesh will cause it to tip the scales at the right mark. Overfattened birds lose shape and condition. Many birds of good size, shape, and build fail to receive awards because of condition and plumage, more the result of feed and care than breeding. I have seen a bird take first prize in one show, and at another, later in the season, when out of condition, be passed over entirely.

From time of selection, feed good sound food three times a day - just the amount they will eat clean in ten minutes. Never throw down unlimited supplies, or they will get overfat and lazy. A quarter of the whole grain each day should be hemp or sunflower seed, to make the feathers bright and glossy. A good mash feed for the last few weeks is rice or wheat boiled in milk. If your birds are white or light colored, shade them from the full rays of the sun, for it has a tendency to tan white feathers and impoverish the quality of the buff plumage.

The day before shipping light-colored fowls 272 


\section{A SELF-SUPPORTING HOME}

of any sort should be washed. Don't gasp. It's not by any means a difficult undertaking, but must be done thoroughly, or the result is anything but pleasing to behold. An ordinary wash-boiler makes a good bath because of the oblong shape. Put enough warm water into it to cover the bird. Make a lather of good white soap. Stand the fowl in the water and soak for a few minutes. With a moderately soft brush scrub down and across the feathers, but never upwards. Go at it with a will - don't be afraid; and work as quickly as you can. When every spot is removed, hold up the bird and have some one empty and refill the bath with clean water; rinse, repeating the scrubbing downwards to remove the soap. Repeat this process with a third and fourth water. On the rinsing depends the success of this washing. When every vestige of soap has disappeared, stand the bird on a tray and dry with a soft towel. Next, brush downwards with a fairly stiff, 


\section{A SELF-SUPPORTING HOME}

dry brush; then place in a drying cage. This is easily made of wire netting sides and top, with a wooden floor, a perch across the centre for the bird to roost on, high enough to prevent its tail touching the floor. Cover the floor with three inches of sawdust, so that all droppings will immediately be absorbed. The cage should be placed in a warm corner out of all draught, and in a surprisingly short time the feathers will begin to web and fluff out.

Let me warn you - if the water is too warm, the fowl may faint. Do not be alarmed. No permanent harm will result. It will revive immediately if the head is well doused with cold water. Get all the dirt off the legs and feet; next morning rub just a touch of vaseline over the extremities to soften and brighten them.

The shipping coops should be large enough for the birds to stand upright in. As most shows are held in cold weather, cover the open parts with strong, unbleached muslin. 


\section{A SELF-SUPPORTING HOME}

Personally, I think the exhibitors should accompany the birds, or send a trusty attendant to all shows. Such a course assures better care on the journey, and enables you to care for their health during the trying time of close confinement which competing for honors condemns the birds to. Your presence often procures better bench accommodations, insures coops which are free from dust, clean drinking cups, and all the small details which help a good appearance.

\section{CAPONS}

Capons have never been half as much used in this country as in Europe. Now, however, they are growing in popularity and must not be ignored. I tried it on my farm, . but gave it up, for the operation suggested the dissecting room far too closely to be endured by me.

We were visited about five years ago by an English poultry expert, who insisted that 


\section{A SELF-SUPPORTING HOME}

no poultry farm, properly so called, was complete without capons and the means to fatten the birds artificially. His arguments were so convincing, that $\$ 50$ were despatched to England for a machine to do the stuffing. Caponizing instruments were bought, and my first lesson was taken on a dead cockerel. That seemed only a little worse than drawing a bird for table use. My English friend assured me that I would think nothing of dissecting a live bird when used to it. The next day he picked out six cockerels, each about three months old, and had them brought over to the feed house. The day before a small table had been sent over and prepared for the proceeding; one must be able to move the birds wherever the light is at its best.

The fowl surgeon took one of the two pieces of cord, which had been expressly prepared with a slip-knot at one end and a weight at the other. Slipping the loop twice over the bird's feet, he placed it on its left side on the 



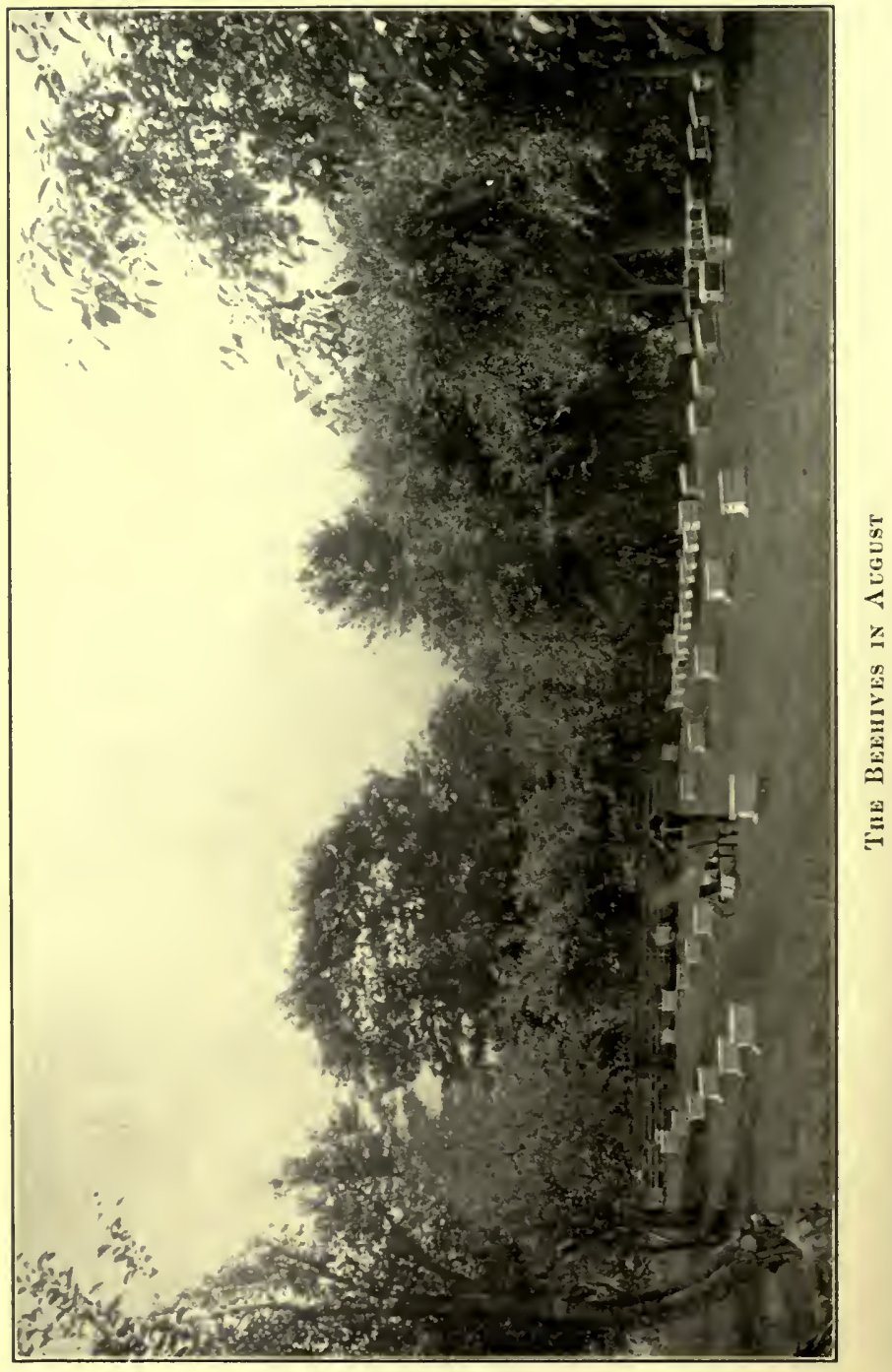




\section{A SELF-SUPPORTING HOME}

table, with the weight hanging over the end; then pulling the wings up and outward, the loop of number two piece of string was slipped over them, weighted, and the weights allowed to hang down. The next move was to wet the side of the bird exposed with cold water, to prevent bleeding and make the feathers lie flat when pushed back. All this was comfortably interesting, but when he reached for the knife, there was a feeling of very distinct uncomfortableness. The businesslike voice of my instructor explained that the skin must be pulled down with the left hand, and the knife inserted between the first and second ribs. He made the incision quickly, about a quarter of an inch. The poor bird squirmed, necessitating a momentary pause. This always occurs, the bird working its ribs up and down; however, it soon resumed tranquillity when the cut was lengthened an inch.

About this time I became strongly impressed with the fact that I had ribs of my 


\section{A SELF-SUPPORTING HOME}

own, every one of which seemed highly sensitive. My head felt odd, too. A peculiar tightness across my forehead seemed to be dragging my temples toward each other. Mr. Expert put down the knife. My condition began to improve, but went all to pieces again when an instrument called the "spreader" was inserted. Detail upon detail was explained, with cautions to avoid cutting the backbone or an artery. My internal feelings became horribly appalling; stars of various sizes danced all sorts of jigs in front of my eyes. My flesh got all goosey, and if our dear old cow had not, at this moment, created a blessed interruption by breaking out of the pasture, I should have disgraced myself forever by flopping over right in front of Mr. Expert. Very urgent business was promptly arranged that prevented my returning to the feed house, and it afterward happened that things so turned out that it was absolutely impossible for me to make an opportunity for another lesson. 


\section{A SELF-SUPPORTING HOME}

This experiment warrants my counselling any woman who has not qualified as a trained surgical nurse not to try caponizing. If you are near a big city where there is a large market and special demand for them, a little tactful questioning of the people who buy these specialties will enable you to find some man who understands the work and can be hired to visit your place for a small fee and save you from attempting what must be uncongenial, to say the least of it, to any woman.

The six cockerels which were operated on enabled me to test the value of caponizing from personal observation; and I am convinced that where there is a market for the best, there is money in capons.

Late-hatched chickens operated on in October will make splendid table birds the following April, and during the interim can take the place of brooders for incubator chicks; for one of the advantages of caponizing cockerels is the gentle, placid nature 279 


\section{A SELF-SUPPORTING HOME}

they develop. Put a capon on a nest at night, and tuck as many as eighteen chicks just out of the incubator under him, and he will wake up next morning with every quality of an ideal mother, scratching for and feeding his babies in the most approved way; and further, he will never dream of deserting his family - they have to be taken away from him.

In this way he more than pays for his food while growing, which he does rapidly, reaching ten or twelve pounds in weight; and as the frame retains the normal size, the addition is all meat of delicious flavor, as tender as a squab broiler, bringing from 20 to 25 cents a pound.

My six capons raised two hundred and eleven chicks from January to April, and then sold for $\$ 1.80$ each as roasters.

The advisability of adding this branch of the business to the farm must entirely depend on the possibility of getting the work done and the certainty of a market demand. 280 


\section{A SELF-SUPPORTING HOME}

\section{WATER-CRESS}

Water-cress is easily forced for winter use or market, and if you have private customers for eggs, you can sell the wintercress, too, at 10 or 12 cents a bunch. The spring brook which supplied us with cress during the spring and summer ran under a low log bridge. Chancing down the wagon road late one January, we were astonished to see fresh green sprigs of cress flourishing under its meagre protection. The hint suggested trying to protect enough of the stream to provide our table the next winter.

In October brush was piled some two feet high on each side of the stream, for a distance of five or six feet. Late in November a sort of hurdle of thin cedar poles was made, and extra branches securely tied on to prevent the wind from dislodging them. When completed, the hurdle was placed over the stream, each end resting on a brush pile. Though primitive, this ar281 


\section{A SELF-SUPPORTING HOME}

rangement proved beyond doubt that forcing water-cress is practical.

The stream was inconveniently located; so, having an unfailing spring at the back of the orchard, we determined to make new cress beds. The first step was to have the spring dug out and walled up three feet. On each side a trap, or small sluice, was inserted, and from the outer side of the wall ditches three feet wide and deep were dug; the bottom was covered with four inches of sand, and the beds were ready for planting.

The sluices were opened to saturate the bottom of the ditch. Then all but the merest trickle of water was shut off, until the roots, which were brought from the old stream, had gained a firm growth in the sand. Then a steady supply was let in sufficient in quantity to keep about half a foot of water constantly running through the ditch. November 1 the full length of the excavation was covered with hot-bed sashes, which kept our cress productive all 282 


\section{A SELF-SUPPORTING HOME}

through the winter, and brought so much "grist to the mill" that the ditches, which were originally only ten feet long, were subsequently extended to over a hundred.

When it is impossible to get roots for transplanting, as we did, I have been told by a reliable person that seeds sown in shallow pans filled with sand and kept moist will quickly produce plants which can be transplanted successfully.

\section{VEGETABLE GARDEN}

Seeds of lettuce, cabbage, and cauliflower should be sown in the open ground now to transplant to the cold-frame later, which insures hardy, well-developed plants to set out next spring.

Strawberries can be planted during the whole month and will be established before frost. Commence to draw earth round the celery roots with a hoe, and prepare it for next month's "hilling up." Spinach and 283 


\section{A SELF-SUPPORTING HOME}

Scotch curly greens should be sown now for early spring use.

The onion tops, if still green, should be bent over to the ground. It is quickly accomplished by walking along the rows and striking down the tops with the back of a hoe. The turning over stops growth and hastens ripening. When the tops are yellow and dried-looking, dig up the bulbs on a dry day and leave them in the full sun for two days; then store in shallow boxes, or on shelves in a dry, cool outhouse, until frost; when they must be covered with a heavy layer of straw or moved to a warm cellar.

Two or three frames will be found very useful for drying fruit and vegetables. Ours are six feet long, three feet wide, covered with one-inch wire netting; and we stand them between two trestles when in use.

If you slip paper grocery bags over the bunches of grapes, tying the top of the bag together with a piece of string round the stalk, the flavor will be much improved 284 


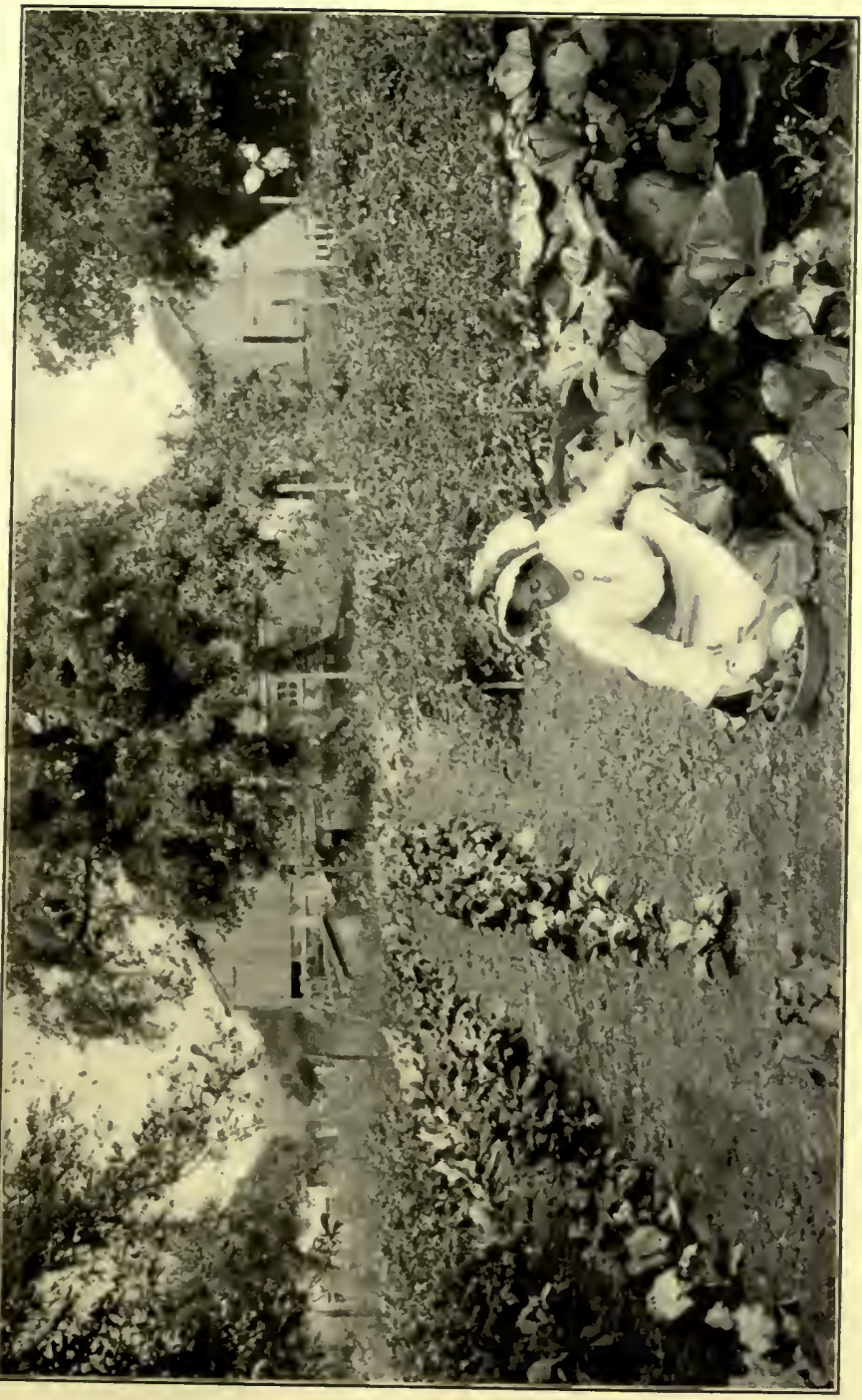

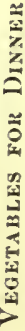





\section{A SELF-SUPPORTING HOME}

and the birds cannot steal the fruit as it ripens.

Weeds should be vigorously attacked this month to prevent their seeding and infesting the ground for next year. Brush which . is encroaching round fences and in odd corners can be destroyed now more easily than at any other time of the year, because the sap and strength is nearly all in the top growth at this season; therefore cutting down to the earth's surface robs the roots of winter nourishment, and they invariably die of inanition.

\section{FLOWER GARDEN}

Prepare or plant a border or bed of bulbs. They will herald spring next year in your flower garden almost before the snow melts. Finding the first snowdrop or crocus is such a real joy that it seems wrong not to spend the little time and cash necessary to start them. Once established, they will come up year after year. If the earth is heavy, mix 285 


\section{A SELF-SUPPORTING HOME}

sand and leaf mould with it. Dig deep, and plant snowdrops and crocuses two inches deep; hyacinths, narcissi, and tulips, four inches deep.

A window box or pots can be started now for Christmas blossoming. Fill with rich, sandy loam; press the hyacinths and kindred bulbs about half their depth into the earth, snowdrops and crocuses to just beneath the surface. Keep the boxes or pots in a dark cellar where the temperature will not rise above fifty degrees, and in seven or eight weeks they will have developed strong roots; then they can be brought into a warm room, well watered, and placed in a light window, where they will soon commence to make top growth.

Slips taken from geraniums, fuchsias, begonias, and roses now will make good plants for bedding out next summer. A shallow dish filled with sandy mould, or individual pots, can be used for starting them. Until well established, the earth 286 


\section{A SELF-SUPPORTING HOME}

must be kept perpetually moist, or the delicate roots will die out and the slips perish. Rose slips should be cut from branches grown last year. Geraniums and such plants, on the contrary, are better taken from recent growth, where the slip can be easily snapped off by bending. 


\section{CHAPTER XIII}

\section{SEPTEMBER}

CCRATCHING materials and green $\checkmark$ food for the fowls and chickens should now be thought of, or else they will go short in the winter and the egg crop will diminish. Dandelion, plantain, chickweed, and all such green things, gathered and packed into barrels with a board fitted tightly to the inside on which a heavy weight is placed, will remain in a fresh, succulent condition far into the cold season. This will save expense, materially increase the egg yield, and insure fertility. Ferns and weeds, cut now and dried, will enable you to be generous with litter during the cold months.

September should find all the pullets "singing." Keep them busy, get them to laying steadily before the really cold weather comes. Are the old houses all in order? 



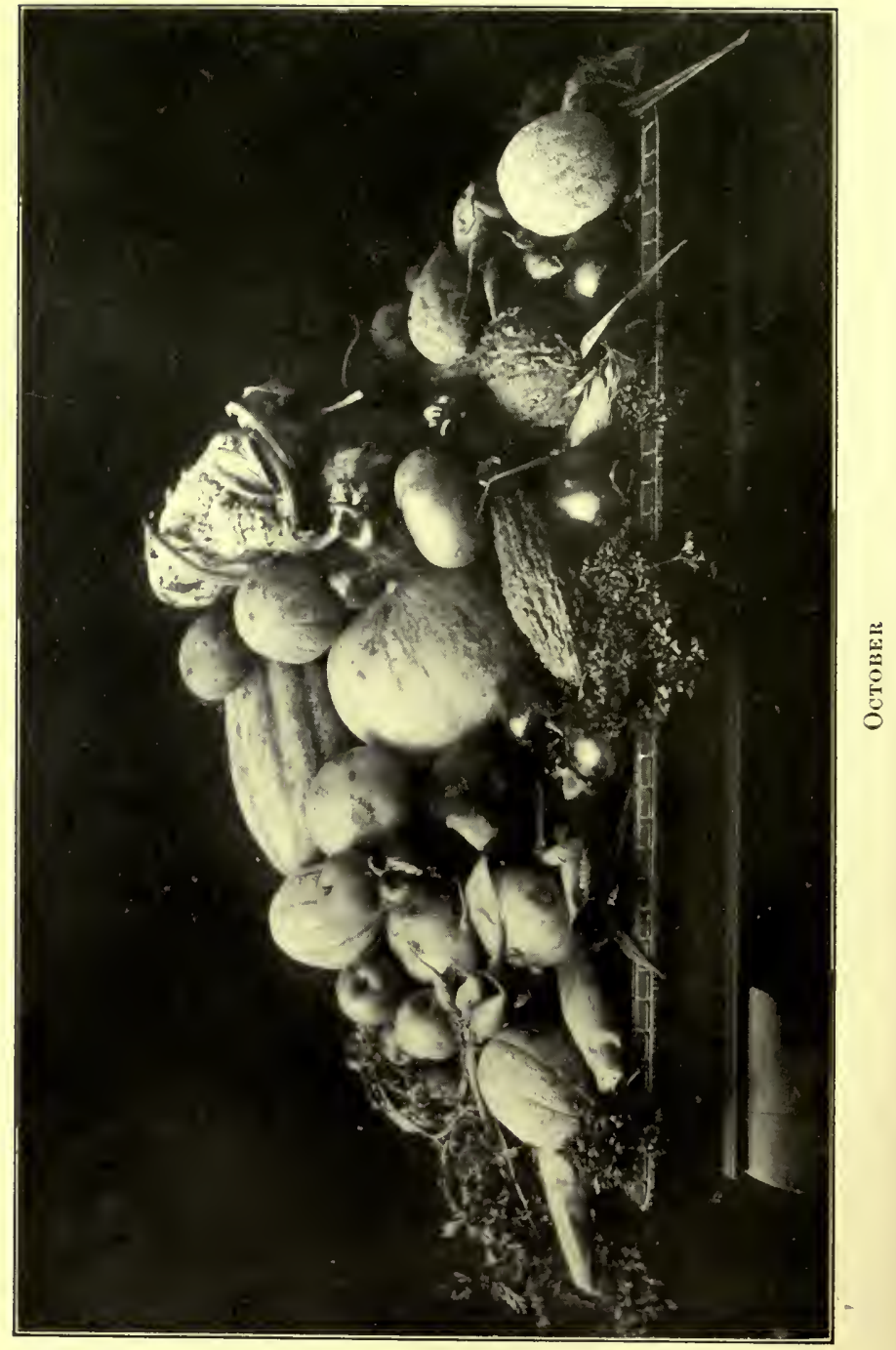




\section{A SELF-SUPPORTING HOME}

Make a thorough examination of all roofs. Don't let a sappy-looking place in the covering of the coop pass. Lay a strip of fresh roofing paper over it and nail down securely. See that all windows and doors will close easily and perfectly, leaving no cracks to make draughts.

Guinea fowls should be called up and fed near the house or shed you want them to roost in. Remember, a little trouble now will prevent loss during the winter, and will save time in spring hunting nests and eggs.

Cockerels, to introduce new blood for the breeding pens, can be bought cheaper now than in the spring. If you are going in for winter broilers, pens should be made up now and incubators started. Even if you are only going to get the high prices that genuinely early spring chickens fetch, incubators should not be delayed beyond January. Orders for incubators and brooders must be sent in now, or you may have to wait weeks for machines - there is always such a de- 


\section{A SELF-SUPPORTING HOME}

mand for them from October to March. White Wyandottes and Plymouth Rocks are the best broilers. Seven hens of these breeds are sufficient to run with a cockerel. More only cause waste of eggs and time. Infertile eggs or weak germs, which have to be removed when you discover them on testing the eggs on the seventh or fifteenth day, will cause you to run the incubator for perhaps only half its capacity.

\section{PIGEONS NEED ATTENTION NOW}

If you started pigeons for fancy stock or squabs last spring, and kept the first lots of young ones for stock, they should now be mated and put into the house they are to remain in. Young birds are occasionally neglectful about building nests in time, so look for dropped eggs; locate the careless pair, and unless they select a box and build for the second laying, take them out of the house and turn them into pigeon pie. 


\section{A SELF-SUPPORTING HOME}

If you haven't tried squab raising for market, this is the best time to start; because, like all poultry, the supply is more plentiful and the stock better now than later.

On the other hand, if you have been raising fancy birds and want to exhibit at the coming poultry shows, now is the time to select the most promising. Put them into a small coop or cage, and begin the training necessary to prevent their being frightened when shipped. All the old birds should be recovering from moulting, so you can judge the plumage pretty accurately. A little hemp seed will add lustre to the plumage, but don't be too generous with it, or there will be danger of fat. Remember that they need grit and salt as much, or even more, when cooped than when in the pigeon house.

\section{FALL CHICKENS}

For several seasons we have made a specialty of raising fall chickens for winter kill291 


\section{A SELF-SUPPORTING HOME}

ing, and find it very profitable. Of course it necessitates making up a yard of breeding birds about the middle of August, but some of the older hens can be used before they are sold off. One or two incubators are filled the first week in September, which brings out the chicks when the weather is still bright but cool, and gives them fully six weeks of free range, which insures growth and health at a minimum cost; for there are more insects now than in the spring, weed and grass seeds galore.

Another advantage of fall rearing is the absence of spring showers and heavy dews. Of course they must have good housing, for the October nights are chilly; but houses should be in order by October. Young, plump roasters will bring from 20 to 25 cents a pound during the holidays.

The business end of the farm needs caring for now. Try to make arrangements with some private persons to take regular quantities of eggs, roasters, squabs, during the 292 



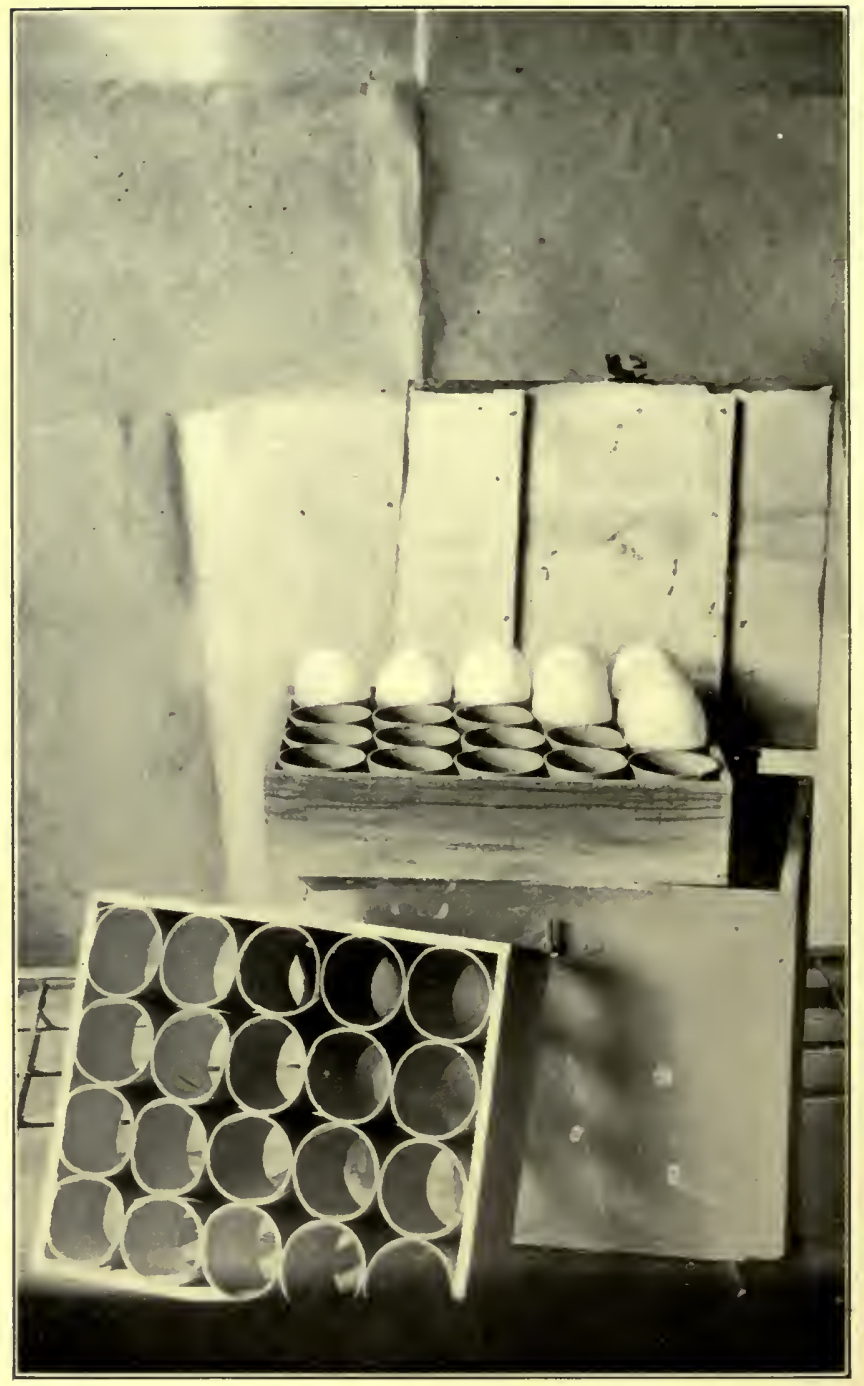

Twelve-dozex Egg Box 


\section{A SELF-SUPPORTING HOME}

fall and winter. If you can approximate your customers' wants now, you can arrange your stock, and buy grain, etc., at harvest time, at a lower price than will be possible later.

If you are living in a "way-out farm," where personal touch with customers is impossible, put an advertisement into the Sunday paper of your nearest town, stating that you can supply fresh eggs at _ (naming the price) to a few customers who will pay express charges, amounting to only 25 cents for twelve dozen.

If you are going to have guineas, turkeys, ducks, or geese, say so plainly and simply. When people write for more information, reply at once and write distinctly.

Another good plan I know three or four women to have followed is to write to the Women's Exchange, asking it to take orders; also to permit you to send to its office twelve, twenty-four, or thirty-six dozen eggs at once,

- it will cost no more than a single dozen, 293 


\section{A SELF-SUPPORTING HOME}

then customers can fetch their smaller orders.

No matter how the custom is obtained, the utmost care must be taken to fulfil punctually all agreements. For instance, arrange on what day shipments are to be made, and, rain or shine, never fail to despatch them. Never keep eggs over and then mix with perfectly fresh ones. One stale egg will destroy faith in your goods. If you should find a nest that has been hidden away, destroy the eggs rather than let one destroy your reputation for honesty.

If the weather is rainy and mud is about, and eggs get smeared in the nest, wipe them with a damp cloth before packing. Also try to maintain a uniformity of size. Use up small ones on your own table, or get a home market for them at a lower price.

A hint about packing: If you are going to ship to private persons, send to a poultry-supply store for egg boxes to hold six or twelve dozen each. They are strong, neat cases, furnished with two or four carrying trays, 294 


\section{A SELF-SUPPORTING HOME}

which are quite safe and will last for years, and are well worth the price $-\$ 1.50$ each. Have your name and address painted on the box, and above it the words, "When empty return to." All express companies return shipping boxes and crates free of charge. The customer's name and address can be written on a tag, or on a card tacked to the lid. Inside the lid place a written request to empty and return to expressman on receipt of next box. As empty "returns" are apt to be delayed, you should have three boxes for each customer.

In sending thirty-six dozen at a time to one person to distribute, ordinary egg crates will do; but address in the same manner, to prevent mistakes and loss.

The following is an item clipped from a farm paper, and sent me six or seven years ago:- -

"He who puts the finest product on the market reaps the richest harvest.

"Eggs are refined wheat, corn, grass, and 295 


\section{A SELF-SUPPORTING HOME}

contain, besides, much that on the farm would otherwise go to waste. In winter a basket of fifty dozen will bring more money than a load of hay it took a large patch of land to grow, a team to cut, a horse and man to rake, two men to stack, and a team, wagon, and man to market. Sell fresh eggs or none at all. Get just as far as possible from the lot dumped on the corner grocery. Seek for regular customers and get retail prices. Stop crying about low rates and cheap goods by rising above them. Herein is the gospel of successful poultry raising."

The above is so true that every poultry farmer should take it for a text.

\section{NEW CHICKEN-HOUSES}

September should find the farm so overrun with half-grown poultry that new houses will be a necessity. It would be foolish to spend money in poor, inconvenient makeshifts, when one or two sections of a well296 


\section{A SELF-SUPPORTING HOME}

constructed building can be erected for almost the same price, and easily added to, as increase of stock or business warrant the outlay. Another consideration is time. The old house, patched up for use last year, was all very well for sheltering a few hens you had plenty of time to attend to; but work for the coming winter makes it imperative that buildings should be arranged with due consideration for saving of time in the distribution of food and water, gathering of eggs, etc.

The plan with this article, which has a hallway from which all such work can be done, especially appeals to me as a most appropriate house for a flock of hens destined to become egg machines. The description of the building has been supplied by the architect, a thoroughly experienced poultryman who has tested the working practicability of the house by years of personal use, as follows:-

Where market eggs are the chief object, I . 297 


\section{A SELF-SUPPORTING HOME}

prefer this house to any other. The interior arrangements are such that the feeding, watering, and gathering of eggs can be done from the passageway. The house is also built on the open scratching-shed plan, with separate enclosed roosting rooms.

For cold climates glass windows are used where protection is needed in the houses, made to slide on the sill by means of small rollers at the bottom of the sash. One half of the window may be stationary, the other half to slide. Wire netting may be fastened to the windows on the inside, which will allow the windows to be open in warm weather when the fowls love to roll and scratch in the sun. This will keep them active and in good health. Too much cannot be said about windows in planning for the scratching shed. The roof may be either shingles or tar paper. I prefer the former. The front elevation is six feet from sill to top of plate. The north side is also six feet, and ten feet six inches to hip of roof. Two roosting 298 


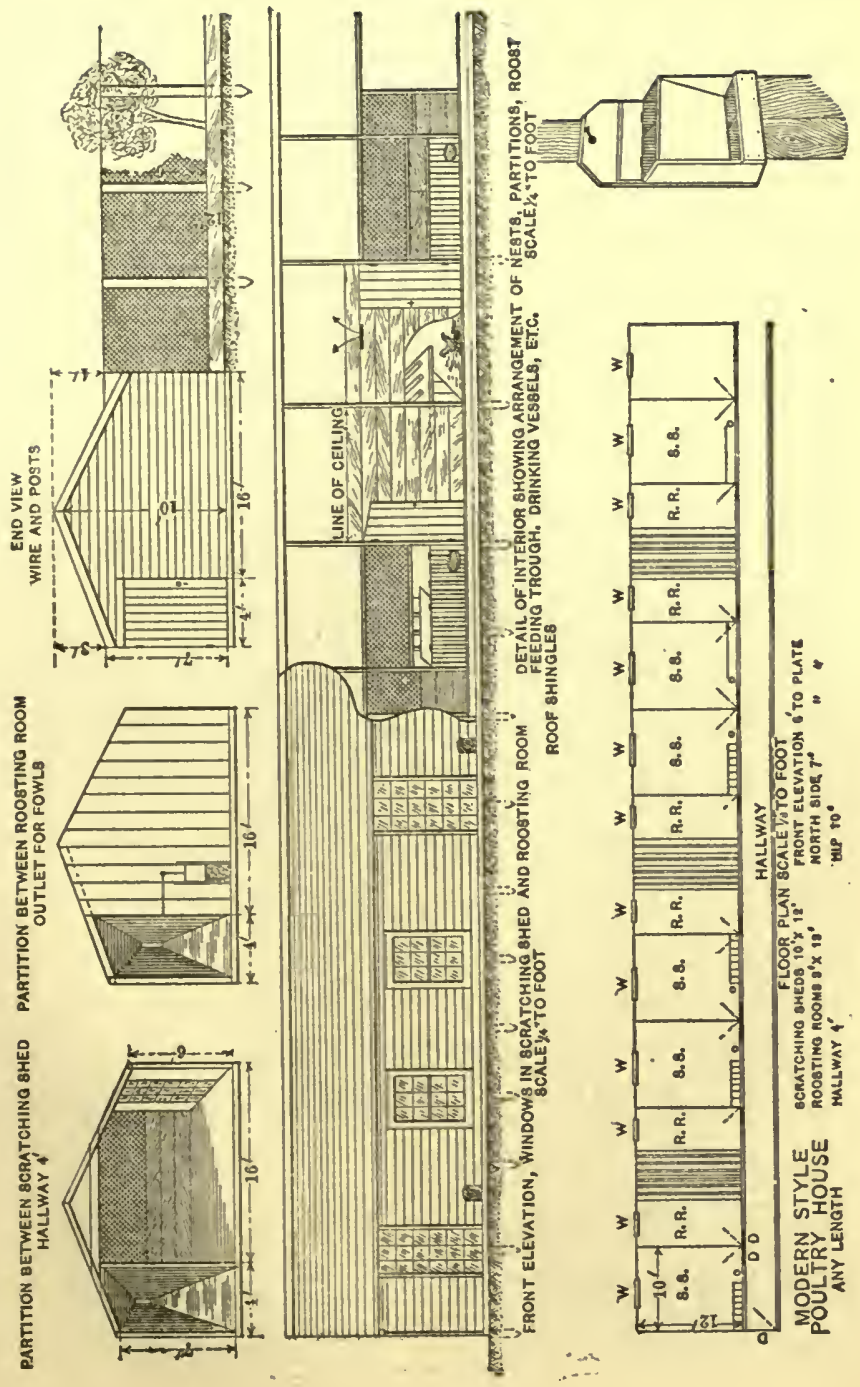




\section{A SELF-SUPPORTING HOME}

rooms and two scratching sheds can come together, as shown in Fig. 2. The hallway is four feet. A track may be laid and a small car used, which will be found very convenient in a long house in carrying water and feed; also in cleaning roosts, carrying litter, etc., for the scratching sheds.

In Fig. 1 is shown the arrangement of nests with four to a section, and a small drop door opening into the hallway, through which to gather the eggs. The nests are two feet from the floor, and in size are fifteen inches deep and one foot high. Muslin, or wire netting, may be used above as desired. The slats through which the fowls feed are two and one-half inches apart, two inches wide, and the edges rounded so as not to tear the feathers of the fowls while feeding. The feed troughs may be the full length of each apartment and are easily removed and cleaned.

The drinking dish illustrated in Fig. 1 is simply a two-quart, or larger, pan, set in a 300 


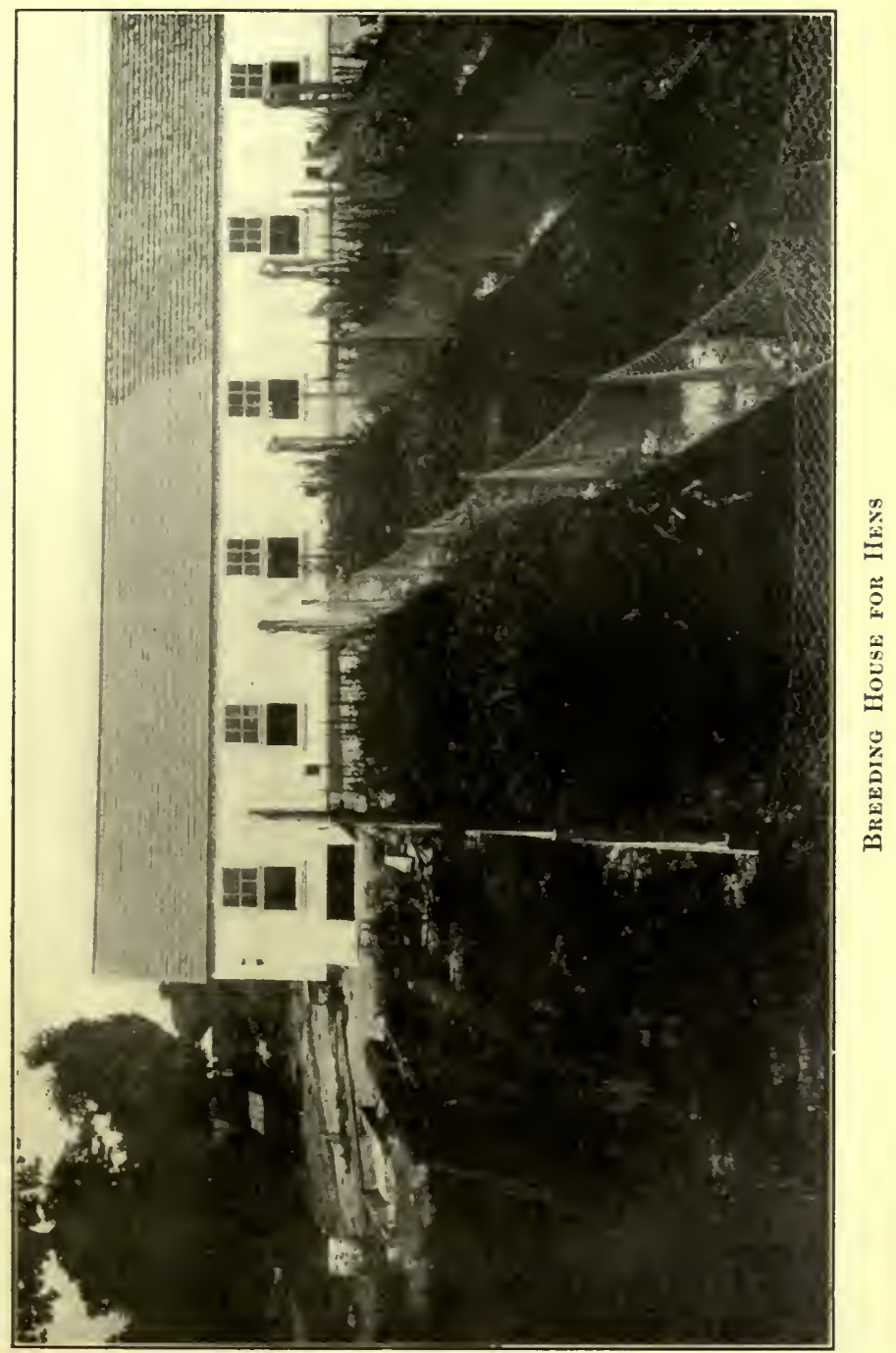





\section{A SELF-SUPPORTING HOME}

recess with slats all around it to protect it from flying scratching materials. It plainly shows how it is made and how it fits into the partition between the walk and the pen, the pan extending into the pen. The top and bottom boards are cut the exact size of the top edge of the pan, half round, and extend back square, to and through the partition, so the pans can be drawn out into the walk to be rinsed and refilled.

The roosting rooms are eight by twelve feet, with windows in front as shown in Fig. 1. The roosting platform is two feet from the floor and runs the full length of the room. Three perches are used, rounded on top, made of two by threes, and six inches above the platform. Thirty or forty fowls can be accommodated in each room. The partitions between the roosting rooms and the scratching sheds are boarded up tight, and between the scratching sheds are three boards high, the balance of the partitions being wire netting. A space of two inches 301 


\section{A SELF-SUPPOR'TING HOME}

is left between the boards of the ceiling over the roosting rooms, over and on top of which is laid plenty of straw and hay. The moisture from the fowls passes up through the openings, and is absorbed by the straw, etc.; and by leaving the doors on each end of the passageway open for a short time during the day in winter, all moisture is carried out, leaving your building perfectly dry and free from dampness.

THE PIG

However small the farm, a pig seems a necessary and undoubtedly a profitable adjunct. During our first summer, waste vegetables and fruits had made us realize the necessity for adding a pig to the livestock; but we had decided to wait until the following spring before acquiring an animal which we all had a certain dread of caring for. But, as usual, destiny shaped our intent her own way by sending an attractive young sow our way early in September.

302 


\section{A SELF-SUPPORTING HOME}

She was medium-sized, all white, and looked peaceful; so, knowing that we had plenty of fodder, we bought her. In February of the following year she had nine little ones, four pairs of which were sold six weeks later for $\$ 6$ a pair. The odd one was kept until eight months old, and killed for home consumption, weighing two hundred and three pounds. Home-cured ham and bacon are luxuries not to be bought at the best market.

Pigs are by no means the dirty, uninteresting animals they are generally supposed to be. Of course, I am referring to the family pig. Extensive hog raising I know nothing about. Like all other creatures, environment has much influence on behavior. A well-housed, well-fed pig will be selfrespecting and well behaved.

Peggy had a house equipped with modern improvements, and from being a dirty, wallowing food consumer, she gradually acquired a well-groomed appearance and a 303 


\section{A SELF-SUPPORTING HOME}

good-tempered affection for us all. The pen was built on the English plan: A sleeping compartment six feet square, five feet high in front and three feet at the back; the outer compartment of corresponding size, with walls three feet high, floor slanting slightly to a drain at the front, and a trough at each

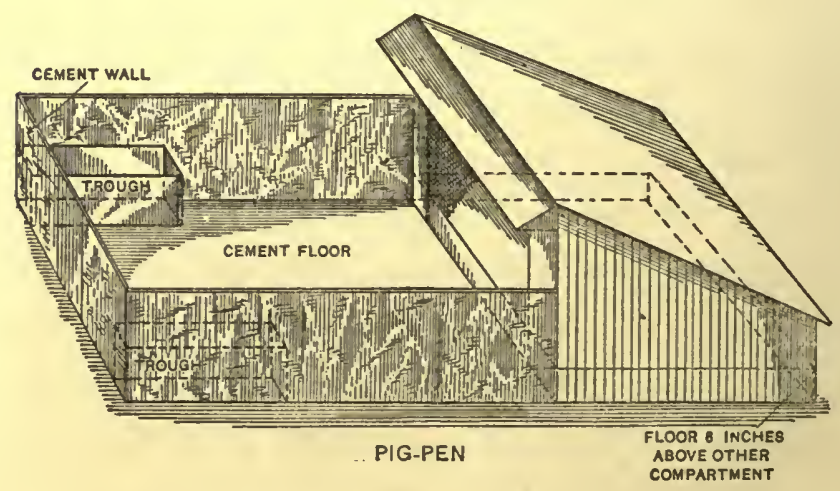

side. The walls, floor, and trough were all made of cement, like the cow stable, which, by daily changing the bedding and weekly sluicing out, insured Peggy's being as clean and sweet to visit as Rachel.

If feeding affects the flavor and quality 304 


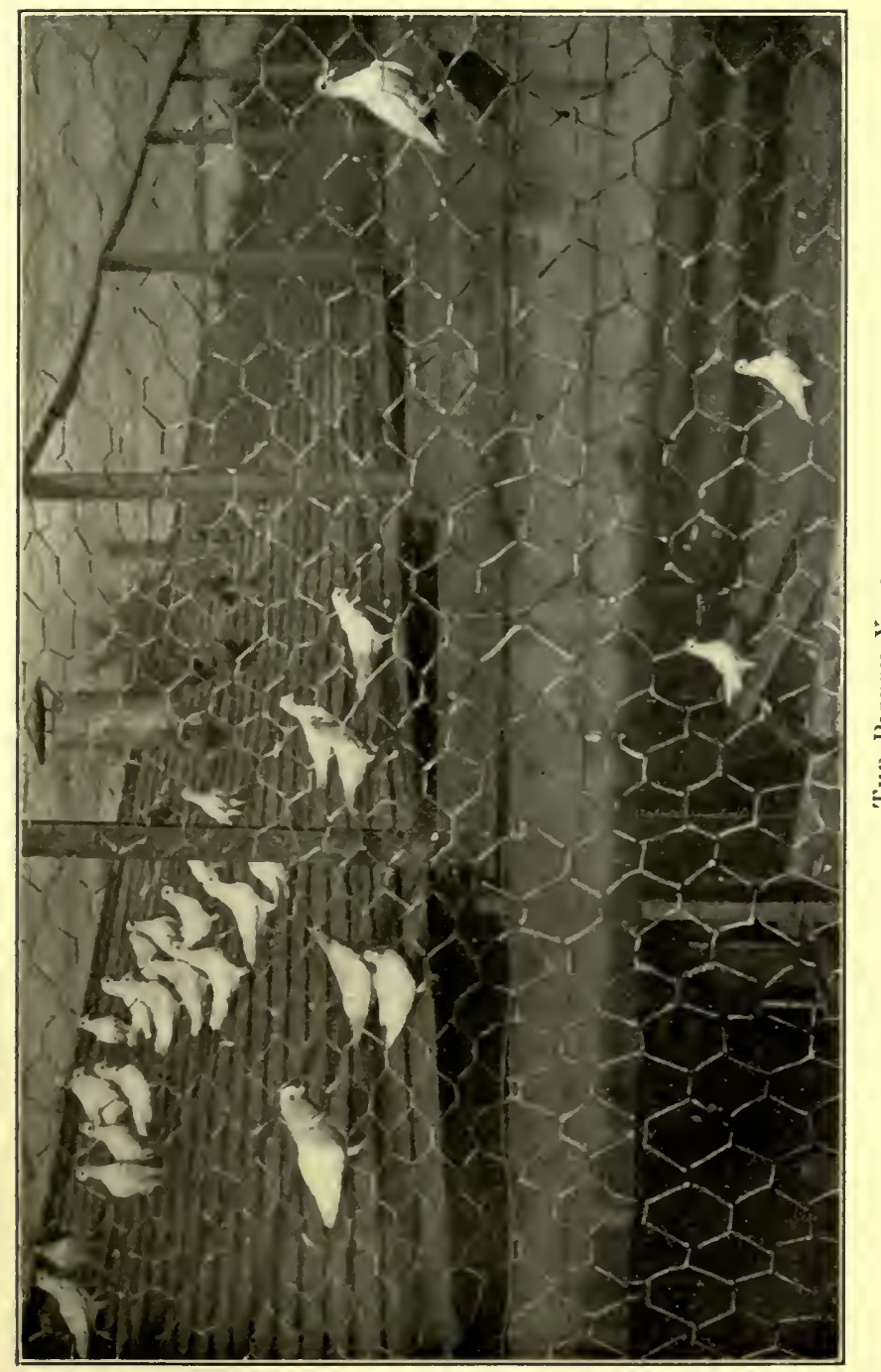





\section{A SELF-SUPPORTING HOME}

of poultry and eggs, why not of pork? On this line of reasoning our pigs are fed. No horrible, half-mouldy swill barrel stands around. Waste matter, such as vegetable peelings, small potatoes, apples, and other unmarketable products, corn stalks, or hay cut into inch lengths, and a small quantity of salt are all boiled in a feed stove until quite tender. Then shorts, middlings, crushed oats, or bran are stirred into it and left to steam and become cold. Skim-milk and buttermilk, when there is any to spare, also go to the pig; but no fat or flesh meat of any description.

Mature stock have a pailful of such feed night and morning, with a milk or milk-andwater drink, and some chopped fodder at noon. Water stands before them all the time in one of the cement troughs, into which, twice a week, a pailful of coal or wood ashes is put, which affords the pig much pleasure as well as aiding digestion. Once a week half an ounce of sulphur and a pint of char- 


\section{A SELF-SUPPORTING HOME}

coal are added to the feed, and a bag of oak leaves are thrown into the yard at least as often.

In the wall at the side of the outer compartment a trap only large enough for a baby pig to get through opens, and behind it a yard three feet square in which a small trough stands. When the babies are two weeks old, the trap is opened and the trough filled three times a day with a mixture of skim-milk and crushed oat gruel. The latter is made by boiling one quart of crushed oats in four quarts of water for half an hour, and then straining. Of course fattening pigs should have all they can eat at a time, and be fed four times a day.

An expert has described the appearance of a good sow as follows: Wide between the eyes, neck moderately thin, shoulders deep, back wide and straight, deep chest, and wellsprung ribs. Our pigs have all been of the Essex breed, simply because such a boar was kept on an adjacent farm. Peggy was 306 


\section{A SELF-SUPPORTING HOME}

supposed to be a Chester White, so I suppose, to be accurate, I should have said her descendants are Essex-Chesters.

\section{ORCHARD}

Apples should all be picked during the beginning of the month. Keeping for winter in a small way for the home can be satisfactorily done if only some fruit is used gathered by hand from the tree. Get sugar or flour barrels (sugar are the best), put a layer of hay at the bottom, pack the apples one by one, stems down, in even layers as tightly as can be done without bruising. Hay or paper placed between the layers will aid their preservation. When the barrel is full, replace the end and stand in a cool outhouse on its side, until really cold weather. Then either cover with bedding or remove to a cellar or a store pit.

If cider is to be made of the windfalls, buy an empty sherry or whiskey cask if you 307 


\section{A SELF-SUPPORTING HOME}

would have sweet tasting cider; for it is a mistake to use the same keg season after season, unless you wish the cider to stand and turn to vinegar.

\section{VEGETABLE GARDEN}

Have a hotbed made before the ground freezes, even if you don't intend using it before March. Select a sheltered position near the house, preferably on land that slopes if that is possible. Have a pit dug six feet long, three feet wide, and three feet deep. Board up all round, allowing the wood to project eighteen inches above the earth's surface at the top, and about eight inches at the bottom, the sides sloping down from the top to join the bottom, so making a slope that will catch all the sun and shed water. Regular hotbed sashes fit these dimensions and cost $\$ 3$; but a home-made sash of oiled muslin and shingle slats, like those used for water-cress, will answer almost as well. 308 


\section{A SELF-SUPPORTING HOME}

Bank the earth up all round even with the edge of the projecting boards, and if not to be used until March, fill with coarse stable manure to keep out frost.

As a cold frame, put into the bottom of the pit a layer of small stones some two inches deep; then fill to within fourteen inches of the top with rich sandy soil. Transplant young lettuce, cabbage, and cauliflower from the ground at the end of the month; but don't use the sash until next month - then only at nights or on frosty days. After severe cold sets in, keep covered; ventilate only when you are sure it is discreet to do so. Cover the sash with straw mats during the zero weather. The object is only to keep plants uninjured until weather permits their being again planted in the ground. For that reason, no artificial heat is provided in the cold frame.

Filling for the hotbed, whether to be used for the development of winter salad or seeding next spring, is, of course, the same. Put in a layer of stone as before; then prepare 309 


\section{A SELF-SUPPORTING HOME}

a compost as follows: Equal quantities of rotted leaves from the woods and fresh horse droppings; mix thoroughly, and in severe weather pack into a conical heap in a shed. During early fall the heap can be made and kept outside. After heat commences to rise, fork the heap very thoroughly and reshape. This should be done twice, to allow the rank steam to escape.

After the sweetening process, place in the frame to the depth of two feet, packing down firmly. Insert a thermometer and put on the sash. Examine within two days. The heat should have commenced to rise and will run up to, or over, a hundred. Wait until it subsides to eighty or ninety degrees; then cover the manure with six inches of rich, sandy soil. Then the bed is ready for use. The sash must be covered at night by straw mats or some adequate protecting material. Ventilate every day, if the sun is shining, for a few minutes - time to be regulated by the outer atmosphere. 


\section{A SELF-SUPPORTING HOME}

Many hotbeds are made entirely above the surface, but the pit retains the heat much better, making the filling last longer than in a surface bed. A cold frame is useful and easy to manage, but the hotbed in midwinter is a difficult undertaking for the amateur. So be advised! Make your first experiment in spring, when climatic conditions will improve each day, so mitigating the danger that might arise from a lapse of memory about covering, overheating, or like important points.

Onion sets planted out the end of the month, and covered about the end of October with straw or leaves, will supply green onions for the table two or three weeks earlier in the spring than it is possible to get others.

Kale sown now will grow rapidly and stand out all through the winter, a slight, nay, rather heavy, frost only improving it. During January and February it is well to throw bedding of some sort each side of the rows, and a light covering over the top - to 


\section{A SELF-SUPPORTING HOME}

be removed in March, when the kale will start a fresh growth, producing succulent greens at a season when most desired.

Clean up weeds and brush. Keep the unplanted ground cultivated as long as frost will permit. You will reap the benefit next year.

FLOWER GARDEN

By the end of the month most of the tender plants should be taken in, for a severe frost may visit you without warning. Large old geraniums can stand quite cold weather, but don't be too venturesome. Such plants can be taken up and hung by the roots in a cellar, where they will remain in a dormant condition until planted next year. Plants that were not taken from the pots last May or June when put into the ground should now be repotted in one size larger receptacles. A spoonful of bone meal dug into the roots of potted plants two or three times during the winter will insure plenty of blossoms to cheer the home. 


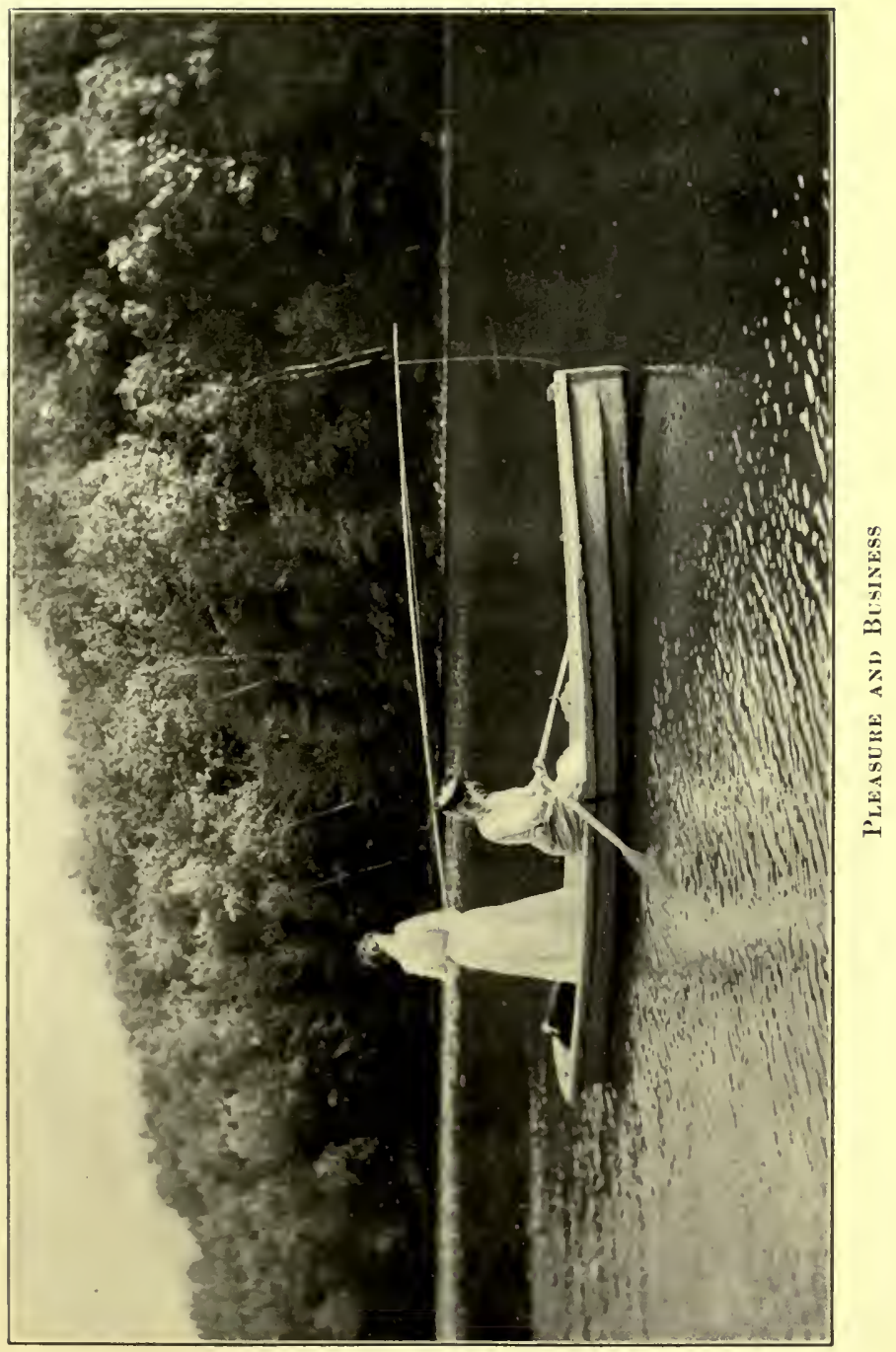





\section{CHAPTER XIV}

\section{POULTRY AILMENTS}

ROUP

ROUP is a disease that gives worry to $\mathbf{R}$ the poultry men and women. Like cholera, it is contagious, runs a rapid course, and even if some birds are brought back to apparent health, they are not safe to breed from, as their progeny are sure to have a predilection for colds, sore eyes, or swollen heads, which sooner or later break out and cause endless trouble. Many people scoff at the idea of roup being transmitted to future generations. I did myself at one time, and bought two sittings of eggs from two different farmers whose fowls had suffered an attack of roup the preceding winter, and proved myself - all wrong!

Of the first sitting twelve hatched, - rather 313 


\section{A SELF-SUPPORTING HOME}

weakly, pinched-looking little fellows. One died when two weeks old; nothing the matter - just a want of energy. Another followed the third week in the same way. Four had colds in eyes and heads when six weeks old, and though doctored and fussed with, quietly died one after the other. Of the six remaining two were cockerels, so they were killed. The four pullets matured slowly, and proved poor layers, easily affected by any change of atmosphere; so at the end of the tenth month they were killed, cooked, and fed to the kennels. The second year was just as disastrously convincing. Thus the experiment convinced me beyond doubt that roup at least transmits weakness, and should therefore be guarded against as a double danger.

Being transferable, roup can be brought into your poultry by a strange bird. It is therefore wise to segregate all new birds when first purchased. The most frequent cause of outbreaks is, however, right on your 


\section{A SELF-SUPPORTING HOME}

own farm. A neglected cold which develops into roup is passed along, becomes contagious, and spreads like wildfire through the flock.

Watch your birds closely, especially at morning feed, now when the nights are cold; and should one look dumpy or sneeze, pick it up and remove it to a sunny, dry coop. The symptoms of a common cold, catarrh, and roup are identical at first - watery eyes, bubbling in the nostrils, sometimes diarrhœa. The discharge is at first thin and scanty, then abundant, and finally thick and drying on the surface. If it is roup, the odor is most disagreeable. The victim at once begins to lose strength. Should the head begin to swell, it is an extra proof of the severity of the attack - frequently incurable. If you examine the sick bird's throat, you will find it inflamed, with small irregular patches of gray or yellow at the back. They increase rapidly and run together, forming a tough membrane, almost closing the throat. If you try to move it, 315 


\section{A SELF-SUPPORTING HOME}

blood oozes. If there are no spots or bad odor and the membrane comes away easily, the bird has only catarrh - bad enough, but not contagious.

Bronchitis, canker, pneumonia, and influenza are also nearly alike in symptoms, and are easily mistaken for roup. As they are still all kindred diseases, springing from cold, my advice is: Don't wait to diagnose the case, but at once use means to kill the embryo germs without losing time to determine the particular family they belong to.

Having removed and quarantined the suspected bird, start treatment, if there is any discharge anywhere, by thoroughly scrubbing with some antiseptic solution night and morning. Dr. Woods recommends hydrogen dioxide and fifteen drops of tincture of phytolacca root in each pint of drinking water, with light, nourishing food. He also gives as a good remedy for all forms of cold: tincture of aconite, ten drops; bryonia, ten drops; tincture spongia, ten drops; alcohol, 


\section{A SELF-SUPPORTING HOME}

enough to make one fluid ounce. Mix this, one spoonful to be added to every quart of drinking water.

My entire drug supply for family, animals, and poultry consists of permanganate of potassium, which comes in little flaky, deep-lake colored crystals. Dissolve a thimbleful of them in a quart of w̧ater, and you have a splendid disinfectant. A dessert-spoonful of that mixture, diluted again by half a pint of water, becomes an antiseptic solution that meets every requirement for internal or external use on man or beast. Fifty cents' worth will last a year, even generously used as a purifier in and out of the house. It has also the added advantage of being easily sent through the mail without fear of breakage. If kept in a tin with a closely fitting lid, or a wide-mouthed bottle severely corked, it will last indefinitely.

Crude carbolic acid comes next. Castor oil, camphor, borax, and turpentine complete the list, but they are seldom used. 


\section{A SELF-SUPPORTING HOME}

When we have a bird with a cold, it goes into a coop with plenty of straw on the bottom, which stands where it gets all the sun. At night a curtain made of bags is hung in front for extra warmth. Mouth, eyes, and nostrils are swabbed with warm water to which the permanganate of potassium mixture has been added; half a teaspoonful is poured down the invalid's throat. Food consists of stale bread, moistened with milk in which onions have been boiled. If the diarrhœa is bad, half a thimbleful of poppy seed is added; or water in which mullein seed has been boiled is given as a drink.

A change of food is made by boiling rice and mixing it with chopped parsley and green sprouts of onions, chopped fine; and powdered charcoal is mixed in once a day. When we have any of the milky puddings for dinner, some of it goes to the patient. In fact, any sort of nourishing food you would give a child is appropriate. This "homey" doctoring has always answered 318 


\section{A SELF-SUPPORTING HOME}

with my poultry, and is much better than dosing with drugs, which are not always on hand when wanted on a farm.

But prevention is always better than cure. Use common sense combined with humane thoughtfulness towards your stock. When you notice that the night has changed suddenly, or that the morning is raw and damp, causing you and the family to specially enjoy the hot cup of coffee, just add a dessert-spoonful of kerosene to each quart of drinking water for all the birds. Give a little less mash for breakfast. Half an hour after empty a bed of leaves into each house, and a couple of handfuls of millet seed, thus insuring an extra amount of exercise. Work that circulates the blood is the best way of warding off a cold. If you haven't any millet, brush up the barn and throw the sweepings into the houses if it is raining; into the yards if it is dry. Dry cold does not hurt fowls, but there is danger in damp or draught. 


\section{A SELF-SUPPORTING HOME}

\section{GAPES}

Gapes causes so much mortality among young chickens that you should be prepared to fight the pest as soon as symptoms of its presence are observed. Gapes is not a disease, as many people imagine, but a parasite worm, which is supposed to exist only on ground on which birds have been distributing droppings for more than one season. Game preserves where quail, pheasants, or grouse are bred extensively will occasionally have epidemics of this scourge that will sweep off hundreds of young birds. The pest is about five-sixteenths of an inch long, and as thick as a fine thread. It seems certain from the information gathered about it that after entering the windpipe of a chick it produces young; for bunches of little ones, not more than three-sixteenths of an inch long, have been found on making a post-mortem examination, but only when a mature worm was also present. At least, such is the 


\section{A SELF-SUPPORTING HOME}

result of the investigations of one of the most reliable poultry experts, who has devoted much time to the study of the subject, and who also gives the following directions for exterminating the pests:-

Mix salt and water, or steep tobacco in water ten minutes. Pour a teaspoonful down the bird's throat. Keep the head up and the two holes at the base of the beak closed with your thumb and forefinger while you count five slowly. Then suddenly release and turn the bird's head downward, holding it by its feet. It will gasp, sputter, and usually eject the worms.

However, as we have never had a case of gapes on our place, I firmly believe that chopped garlic or green onion in the feed is a sovereign preventive, and more potent than all the torturing cures.

\section{SCALY LEGS}

Some of the old broody hens bought for hatching the first year are almost sure to 


\section{A SELF-SUPPORTING HOME}

have rough legs. Don't make the mistake of thinking that is merely the sign of old age, for though scaly legs does not seem to injure the general health in any way, it looks so disagreeable it should not be allowed to spread to the younger chickens, which it is sure to do unless checked, because it is caused by a parasite and is contagious. Bathe the afflicted bird's legs and feet in moderately strong permanganate of potassium and warm water. The best plan is to fill a two-quart lard pail and hold the bird's legs and shanks in it for a few minutes, to soak and soften the scaly substance. Then wash thoroughly, using a plain white soap and nail brush. Wipe dry, and rub in carbolic vaseline. - Repeat every three days until cured.

\section{FEATHER PULLING}

is scarcely a disease, yet as it requires a cure, it seems as if it should come within the doctor's jurisdiction. It is really a bad 322 


\section{A SELF-SUPPORTING HOME}

habit which springs from the natural desire for animal food, being denied which creates an abnormal desire. A fight or some accident causes a few feathers to be torn from a bird's body and some one of the flock discovers the animal secretion in the quills; the habit is acquired to alleviate the craving and, like most evils, spreads quickly throughout the pen, and it will be only a short time before the entire flock will be demoralized. Remedies are very inefficient in this case, so be careful to furnish a perpetual preventive in the shape of meat scraps or green bone.

The following receipts are from cuttings made years ago for my own guidance, so unfortunately the original sources are lost in the oblivion of time.

CHOLERA

In the majority of cases the so-called wholesale destruction of flocks from cholera 323 


\section{A SELF-SUPPORTING HOME}

is not cholera at all, but the work of lice. On some farms where the hens hide away at night here and there, for want of some kind of suitable shelter, the trees, wood pile, sheds, and under the barns will be swarming with lice; and dead hens may be found every morning, being literally eaten alive by myriads of lice, the cause being attributed to cholera or some disease, simply because the owner cannot comprehend how lice can be so destructive. On such farms there may also be found an apology for a hen-house, the floor of which will be covered for a foot or more with droppings, being the accumulation of years; but which house will be found useless, as the hens will prefer exposure to all kinds of weather rather than venture in the pest hole filled with lice and called a poultry house. Some farmers wonder how it is that they get no eggs, and they naturally ascribe their failure to "there being no money in chickens"; when the fact is that if they were as negligent of their horses, 


\section{A SELF-SUPPORTING HOME}

cows, sheep, and hogs as they are of their hens, they would go into bankruptcy the first year. Before undertaking to cure cholera, examine for lice, as in many instances the lice are at the root of all difficulties.

Genuine cholera is a disease that exists, however. It is shown by great thirst, greenish, profuse droppings, and prostration. It can be distinguished from indigestion or roup, as it kills the bird in from twentyfour to forty-eight hours, or else recovery ensues. There is no lingering illness connected with it. The best remedy is carbolic acid. Add twenty drops to a gill of water, and with the water mix together meal and shorts, slightly parched and browned, and force a tablespoonful of such soft food down their throats twice a day. Give no water to drink at all. If it is given, however, add ten drops of the acid to each gill of water. Keep the sick birds in a dry, warm place, and separate from the others. 


\section{A SELF-SUPPORTING HOME}

\section{INDIGESTION}

This is frequently mistaken for cholera and is caused by overfeeding, especially when grain is largely used. The symptoms are the same as for cholera, except the intense thirst and the death of the bird in a few hours. The remedy is to give no food whatever for three days, and also add a teaspoonful of tincture of nux vomica to each quart of the drinking water, at the end of three days allowing one ounce of lean meat once a day for a week. Be sure and provide sharp grit.

\section{CROP BOUND}

Whenever a fowl is crop bound it is due to eating something that will not pass into the gizzard, such as hay, old rope, rags, dried hay or grass, or anything that is liable to become packed. The opening from the crop to the gizzard may be clogged with a small piece of hemp or rag, and as no food passes to the gizzard, the fowl is all the time hun326 


\section{A SELF-SUPPORTING HOME}

gry and eats and eats, only to add more to the crop, yet not satisfying hunger. It starves with a full crop. As it eats to satisfy hunger, yet fails to do so, the crop is filled to its utmost, every little space being packed, and the crop in a few days becomes as hard as a wooden ball. On the first symptoms give the bird a tablespoonful of warm lard, and work the crop with the hand until it becomes soft, as by so doing the passage to the gizzard may be cleared and the food begin to move out of the crop; but if this fails, which may be known by examining the bird four or five hours after manipulating the crop, then the crop must be opened. To do this, make an incision lengthwise in the upper part of the crop about an inch or an inch and a half in length. This should be very cleanly made with a sharp lancet or penknife. As there is an outer and inner skin, draw the outer skin aside when cutting, so that it will go in place again and cover the inner skin. 


\section{A SELF-SUPPORTING HOME}

Through this incision the contents of the crop may be removed, using for that purpose a small egg spoon. Sometimes the mass is so hard that it cannot pass through the aperture, and in that case it must be broken up, which can be done with care and patience. This mass is usually very offensive indeed, and to remove any contaminating matter from the crop, this organ should be washed out with a half teaspoonful of carbolic acid in a quart of water. It is also desirable to pass the finger, well pared and oiled, into the orifice, so as to be certain that there is no obstruction there; for if so, the whole process may have to be gone over again. This done, the incision must be sewed up, and for this a small bent needle is best, as by it the skin can be most easily gathered together, and silk used not thread. Sew the inner skin first and then the outer one. Do not sew in the usual way, but pass the needle through, cut the threads of silk, and tie the ends of silk to328 


\section{A SELF-SUPPORTING HOME}

gether. Before making the incision, pull off the feathers, so as to have a clean skin to work on. When finished, smear on a little tar to prevent fly blowing. No water must be supplied until the suture has completely healed up. For a time it is advisable to keep strict watch on a fowl that has been crop bound, as there will be a tendency to a recurrence of it.

EYE TROUBLES

Conjunctivitis. - A catarrhal inflammation of the mucous membrane of the eye. Caused by cold, exposure, bad hygiene, injuries, or maybe extension of inflammation of nasal passages. Symptoms are gumming together of eyelids, discharge of fluid from the eye, and swelling of face about the eye. May occur on one side of head only, or on both. Swelling sometimes out of all proportion to apparent inflammation. Purulent cases may result in keratitis. 


\section{A SELF-SUPPORTING HOME}

Treatment. - Conjunctivitis usually yields to daily bathing with hydrogen dioxide one part, in two parts cold water. Ten drops of tincture euphrasia in each pint of drinking water often proves efficient.

Even hopeless cases should receive treatment if the fowl is to be allowed to live, since if the case is neglected, the other eye may suffer also. As in most of these eye cases there is an ulcerative condition of the mucous membrane of the nasal tract, the nose should come in for its share of cleansing. After cleansing nose, it will be well to inject into it the iodoform.

AN OLD AND TRIED CURE FOR GAPES

Gapes is easily prevented by cleanliness, but so far we have found no trouble in curing it by the following method: Shut up the sick chicks in a soap box. Pour in a little tar and spirits of turpentine mixed, on an oyster shell, set it on fire, and let the 330 


\section{A SELF-SUPPORTING HOME}

smoke fill the box completely. The chicks may be nearly suffocated to advantage, but be careful not to go to an extreme. Now take them out, and five minutes afterwards give each chick a mouthful of corn-meal dough, to which spirits of turpentine has been added in proportion of a teaspoonful of turpentine to half a pint of corn meal. The smoke of the tar and turpentine is harmless, and it is also excellent for roup, colds, and debility. There is a notion among some that they must remove what they call the "pip" from the end of the bill of each young chick, which is useless and unnecessary; and red pepper is often given when there is no occasion for doing so. 


\section{CHAPTER XV}

VEGETABLES FOR TABLE AND HEALTH

\section{SQUASH CUTLETS}

SELECT a young squash, peel it, cut it $N$ into slices about half an inch thick, fry in butter until tender. Pour parsley and butter sauce over it. For breakfast it is always appreciated.

Green tomatoes and cucumbers are also appropriate for frying, but they must be really green. After they commence to turn, a pungent, bitter taste develops that is most disagreeable.

\section{IRISH STEW}

Peel potatoes, ripe tomatoes, and onions; cut into quarters; half fill a four-quart saucepan with alternate layers; scatter half 332 


\section{A SELF-SUPPORTING HOME}

a teaspoonful of salt and pepper between each. Just cover with cold water and cook for one hour.

\section{MOCK DUCK}

Large marrow or white squash, whole, unskinned. Put it in boiling water, cook half an hour; when cool, skin it. If a marrow, cut off three inches to the end; if a white squash, knife out a circle about three inches in diameter round the stalk. In either case, scoop out all the seeds and fibre.

Make a dressing by mixing a pint of grated bread crumbs, three onions chopped fine, a tablespoonful of dried sage leaves rubbed fine, a teaspoonful of dried mustard, two ounces of butter cut into small pieces, half a teaspoonful of salt; moisten with a beaten egg. Replace the small piece you cut out, put it in a dripping pan, and bake for two hours, using bacon or salt pork dripping to baste with.

The brown gravy to go over will come 333 


\section{A SELF-SUPPORTING HOME}

from a sliced onion fried golden brown in butter. Add a tablespoonful of flour, brown, salt and pepper to taste, pour in boiling water until you have a sufficient quantity, stirring all the time.

Place the duck on a hot dish, strain the gravy over it. Serve with apple sauce, mashed potatoes, mashed turnips.

FURMITY

If you are near a farm where wheat is being thrashed, try an old English dish called "furmity," which is a delicious concoction farmers in Lincolnshire make for the harvest feasts, and is composed of new wheat principally. The receipt for the luxury is as follows:-

Ten quarts of new wheat put in twenty quarts of water and stewed until quite soft, but whole. Add more boiling water as it cooks, if necessary. It should be like stiff oatmeal porridge when taken from the stove. 334 


\section{A SELF-SUPPORTING HOME}

Let it stand until the next day; then add two pounds of the best beef suet, chopped until it is as fine as stale bread crumbs; stir into the cold wheat, adding two pounds of stoneless raisins and two pounds of currants washed and dried, two pounds of the best brown sugar, a quarter of a pound each of candied citron and orange peel chopped fine, ounce of pudding spice, and, unless you object, half a pint of brandy. When all is thoroughly mixed, add six quarts of new milk, and simmer for four or five hours. Remove, let it stand until the next day, and serve with thick cream. Care must be taken not to let it burn.

We make half the quantity at a time, using a large brown stone jar with a lid, which is placed in a round boiler half filled with boiling water.

\section{OKRA}

A savory dish for lunch or dinner is made in the following manner: Butter a pud335 


\section{A SELF-SUPPORTING HOME}

ding dish, put a layer of cooked or halfcooked rice, a layer of sliced okra, a layer of ripe sliced tomatoes, butter, pepper, salt, and a little sugar if the acid of the tomatoes be objectionable. Repeat the layers until the dish is filled. Grate bread crumbs on top, with pieces of butter; pour in as much boiling water as the dish will hold; bake long enough to cook; serve hot.

Okra soup any cook-book will give you.

\section{POT-CHEESE}

The pans of sour milk can be converted into pot-cheese by being placed near the stove until whey starts and covers the top; then poured into a cheese-cloth and hung up to drip for twenty-four hours. Then turn it out, break up with a fork, sprinkle with salt, and beat a little fresh cream through it if it is for table use. Naturally, omit the cream if for your chickens.

A Swede taught me another way to use 336 


\section{A SELF-SUPPORTING HOME}

the curds, which we like extremely. Put about two quarts into a small bag, and let it hang in a dry, cool place for four or five days until quite dry. Then take it out and grate finely; add half a pound of currants, half a cup of sugar, and three beaten eggs, and fry like batter-cakes, only much thicker.

\section{SAVORY POT-CHEESE}

If the milk has soured rapidly into a thick clabber, it may be put at once into a cheesecloth bag and hung to drip until every bit of whey has run out. If not so thick, turn boiling water from the tea-kettle into the pan of sour milk and let it stand for a few moments for the curds and whey to separate. As soon as this is accomplished, put into the bag to drip. When the whey has been disposed of, turn the curd into a basin and add butter, salt, and cream, sweet or sour, to make rather moist and of good flavor. Add paprika, black pepper, minced sweet green

$z$ 


\section{A SELF-SUPPOR'TING HOME}

pepper, or fine-cut pepper grass, as you like. Then mould on crisp, green lettuce leaves, or make into tiny soft balls no larger than English walnuts. Never fall into the mistake of making these balls big, round, and hard, like the pot-cheese of commerce, which is dry, crumbly, and suggestive of overmuch handling.

\section{POTATO CHEESE-CAKES}

Pound well together three ounces of boiled mealy potato, two ounces of melted butter, four tablespoonfuls of sugar, and the grated yellow rind of two lemons. Stir until smooth, then add the yolks of two eggs and the white of one, well beaten. Line some patty pans with puff paste, fill them and bake twenty minutes in a good oven.

\section{CURD CHEESE-CAKES}

Boil one pint of milk, and add it gradually to three well-beaten eggs. Let it simmer until the milk curdles; then pour off the 338 


\section{A SELF-SUPPORTING HOME}

whey and allow the curd to drain a little over a sieve. Then beat it up with a fork, add two tablespoonfuls of sugar, a pinch of salt, four ounces of currants (cleaned and dried), one ounce of melted butter, and a little mixed spice. Mix well. Line patty pans with puff paste; fill three parts with the curd mixture and bake in a good oven. A very old-fashioned sweet.

\section{HOWELL HONEY-CAKE}

It is a hard cake.

Take $6 \mathrm{lb}$. flour, $3 \mathrm{lb}$. honey, $1 \frac{1}{2} \mathrm{lb}$. sugar, $1 \frac{1}{2} \mathrm{lb}$. butter, 6 eggs, $\frac{1}{2}$ oz. saleratus, ginger to your taste. Directions for mixing: Have the flour in a pan or tray. Pack a cavity in the centre. Beat the honey and yolks of eggs together well. Beat the butter and sugar to cream, and put into the cavity in the flour; then add the honey and yolks of eggs. Mix well with the hand, adding a little at a time during the mixing, the $\frac{1}{2} \mathrm{oz}$. 339 


\section{A SELF-SUPPOR'TING HOME}

saleratus dissolved in boiling water until it is all in. Add the ginger, and finally add the whites of the 6 eggs, well beaten. Mix well with the hand to a smooth dough. Divide the dough into seven equal parts, and roll out like gingerbread. Bake in ordinary square pans made for pies from $10 \times 14$ tin. After putting into the pans, mark off the top in $\frac{1}{2}$-inch strips with something sharp. Bake an hour in a moderate oven. Be careful not to burn, but bake well. Dissolve sugar to glaze over top of cake. To keep the cake, stand on end in an oak tub, tin can, or stone crock - crock is the best. Stand the cards up so the flat sides will not touch each other. Cover tight. Keep in a cool, dry place. Don't use until three months old at least. The cake improves with age, and will keep good as long as you will let it. I find any cake sweetened with honey does not dry out like sugar or molasses cake, and age improves or develops the honey flavor. E. D. Howelu. 


\section{A SELF-SUPPORTING HOME}

\section{HONEY APPLE-BUTTER}

1 gallon good cooking apples, 1 quart honey, 1 quart honey vinegar, 1 heaping teaspoonful ground cinnamon. Cook several hours, stirring often to prevent burning. If the vinegar is very strong, use part water.

- Mrs. R. C. Aiken.

\section{SUMMER HONEY-DRINK}

1 spoonful fruit juice and 1 spoonful honey, in $\frac{1}{2}$ glass water; stir in as much soda as will lie on a silver dime, and then stir in half as much tartaric acid, and drink at once.

\section{GENERALITIES}

Hippocrates, the father of medicine, considered cabbage one of the most valuable of remedies. Erastratus deemed it a valuable remedy against paralysis. Cato, in his writings, claimed it to be a panacea for all diseases, and believed its use made it possible 341 


\section{A SELF-SUPPORTING HOME}

for the Romans to do without the use of physicians for six hundred years, they having expelled them from their country for that length of time. M. Chevreul, a former scientist, says the odor caused by the boiling of cabbage is due to the liberation of sulphuretted hydrogen. Cabbage can be cooked so that this principle will not be liberated and will remain as an aid to its digestion. If put on in salted boiling water and allowed to simmer, never boil, from one-half to three-quarters of a hour, drained, and served either with melted butter or cream sauce poured over it, even those of weak digestion can indulge in its use.

The onion is of special value to the country family far removed from doctor or drug store. Nothing alleviates croup more quickly than a poultice of onions fried in goose greese; or if that is wanting, any fat. Fill a bag large enough to fit up round the throat and reach to the pit of the stomach. Use as hot as can be borne. If the poultice is made 


\section{A SELF-SUPPORTING HOME}

about two inches thick, it will retain the heat for some thirty or forty minutes, during which time another should be made to take its place. It is a good plan to place two or three folds of flannel between the patient and the poultice, for then it can be applied whilst very hot, pieces of flannel being slipped aside as the heat moderates. The effect is soothing, alleviating the pain and lulling the patient to sleep. In extremely severe cases, when the child seems in danger of choking, grate a large onion, mix one teaspoonful of the juice with a little sugar, and pour down the child's throat. I once saved a baby of two years old, after the doctor had given up all hope, with this household remedy.

The juice of a roasted onion will cure a bee or wasp sting as by magic. The heart of a roasted onion will work the same relief for earache. Eating a raw onion at night stimulates the secretions and purifies the blood.

Celery contains an aromatic oil, sugar, mucilage, starch, and manna sugar. The :343 


\section{A SELF-SUPPOR'TING HOME}

daily moderate use of celery is said to remove nervousness and even palpitation of the heart. For rheumatism and kidney troubles it is considered excellent. Those having weak digestion should eat celery cooked, as the fibre of celery makes it difficult of digestion.

Rhubarb should be eaten as a matter of duty, for it is one of nature's pleasantest remedies, counteracting the ill effects of heavy winter diet.

Water-cress is a splendid tonic, and the country home should manage to have a plentiful supply.

Asparagus and lettuce are so universally liked that the family are sure to eat quantities without regard to the medical qualities, which are many and varied. 


\title{
A Woman's Hardy Garden
}

\section{By HELENA RUTHERFURD ELY}

With many Illustrations from Photographs taken in the Author's

Garden by Professor C. F. Chandler
Cloth
$12 \mathrm{mo}$
$\$ 1.75$ net

"It is never for a noment vague or general, and Mrs. Ely is certainly inspiring and helpful to the prospective gardener."

- Boston Herald.

"Mrs. Ely gives copious details of the cost of plants, the exact dates of planting, the number of plants required in a given space for beauty of effect and advantage to free growth, the protection needed from sun and frost, the precautions to take against injury from insects, the satisfaction to be expected from the different varieties of plants in the matter of luxuriant bloom and length of time for blossoming, and much information to be appreciated only by those who have raised a healthy garden by the slow teachings of personal experience." -New York Times Saturday Review.

\section{Another Hardy Garden Book}

\section{BY HELENA RUTHERFURD ELY}

With forty-nine Illustrations from Photographs taken in the Author's

Garden by Professor C. F. ChandLer

\section{Cloth \\ I2mo \\ $\$ 1.75$ net}

"Mrs. Ely is the wisest and most winning teacher of the fascinating art of gardening that we have met in modern print."

-Nero York Tribune.

\section{THE MACMILLAN COMPANY}

\author{
64-66 Fifth Avenue, New York
}




\section{THE FAT OF THE LAND \\ The Story of an American Farm}

By JOHN WILLIAMS STREETER

\section{Cloth I $2 \mathrm{mo} \quad \$ \mathrm{r} .50$ net}

" "The Fat of the Land' is the sort of book that ought to be epochmaking in its character, for it tells what can be accomplished through the application of business methods to the farming business - a pursuit which, too often, is woefully lacking in that sort of method of doing business. It is wonderfully attractive. Never was the freshness, the beauty, the joy, the freedom of country life put in a more engaging fashion. From cover to cover it is a fascinating book . . . and withal is as practical and as full of common sense as a balance sheet. It is a book that cannot fail to do good in every circle into which it finds its way." - The Brooklyn Eagle.

"The importance and value of such a book as "The Fat of the Land" is incalculable. It takes us back to the soil, to the country, the farm, the forest, and all their delights and pleasures. . . . The story of the purchase of the farm, of the hiring of help, of the setting out of fruit trees, the purchase of stock, and the gradual putting of the establishment upon a substantial footing, is told by Dr. Streeter with a frankness, a vivacity, a good-humor, and a practicality which make it more interesting to the nature-loving reader than if it were a modern novel of the most exciting kind." - The Boston Transcript.

\section{THE GARDEN OF A COMMUTER'S WIFE}

\section{RECORDED BY THE GARDENER} WITH EIGHT PHOTOGRAVURE ILLUSTRATIONS

\section{Cloth r2mo $\$ r .50$}

“'The Garden of a Commuter's Wife' is a legend that gives no hint of the wit and wisdom and graceful phrase within its covers. The Commuter's charming woman writes of her suburban garden, her original servants, and various other incidents which come in the course of living in a thoroughly human way. She reminds one of Elizabeth of "German Garden" fame in more ways than one, but being American she is broader, more versatile and humorous, if not also more poetic. It breathes an air of cheery companionship, of flowers, birds, all nature, and the warm affection of human friendship." - Chicago Post.

\section{THE MACMILLAN COMPANY 64-66 FIFTH AVENUE, NEW YORK}









THE LIBRARY

UNIVERSITY OF CALIFORNIA

Santa Barbara

THIS BOOK IS DUE ON THE LAST DATE STAMPED BELOW.

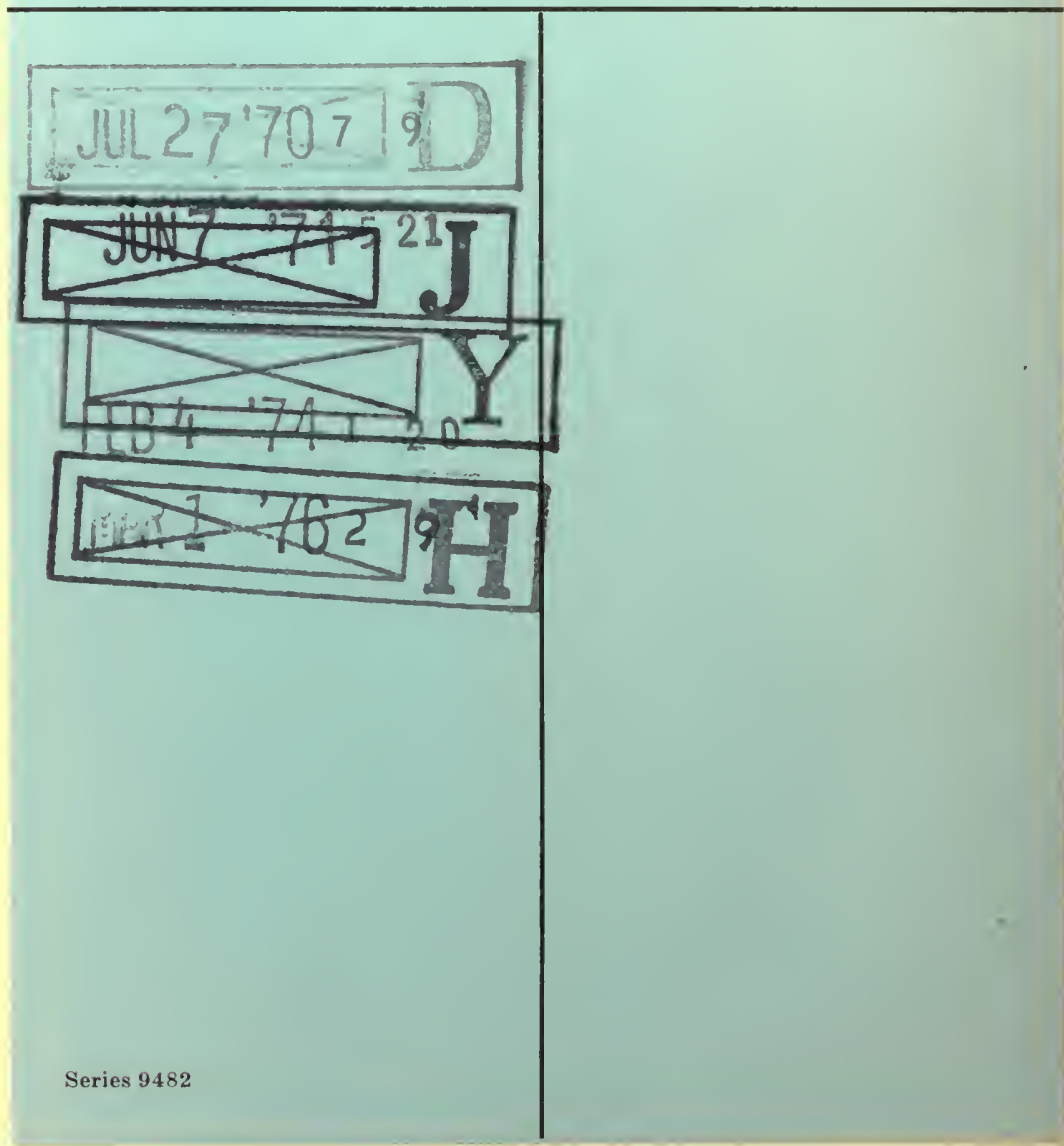




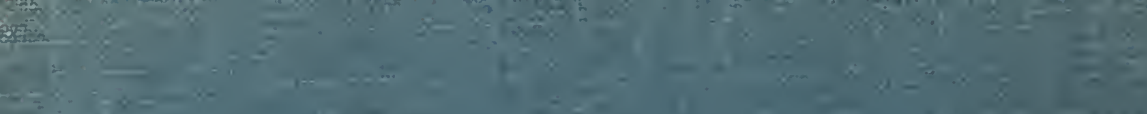

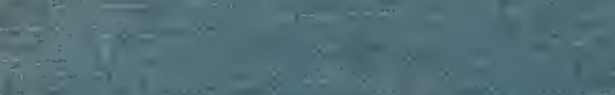

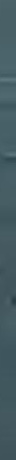

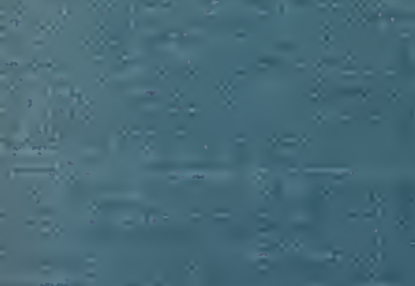

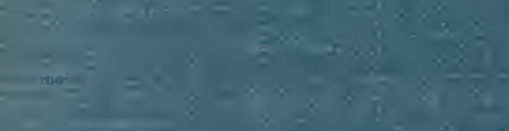

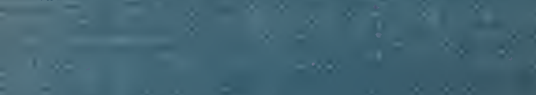

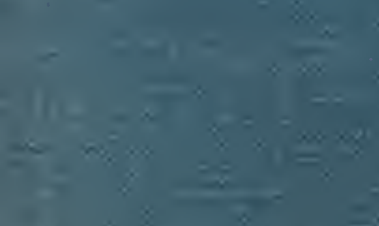
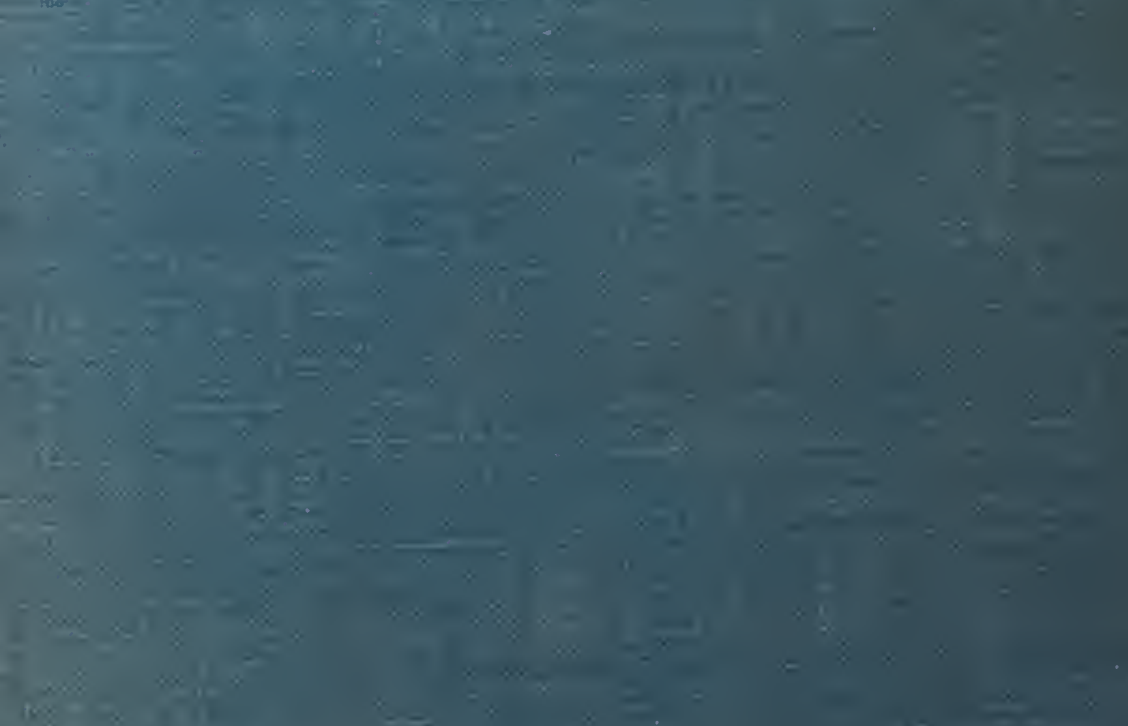

$10920=10$

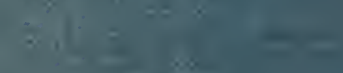

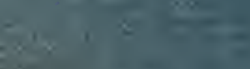
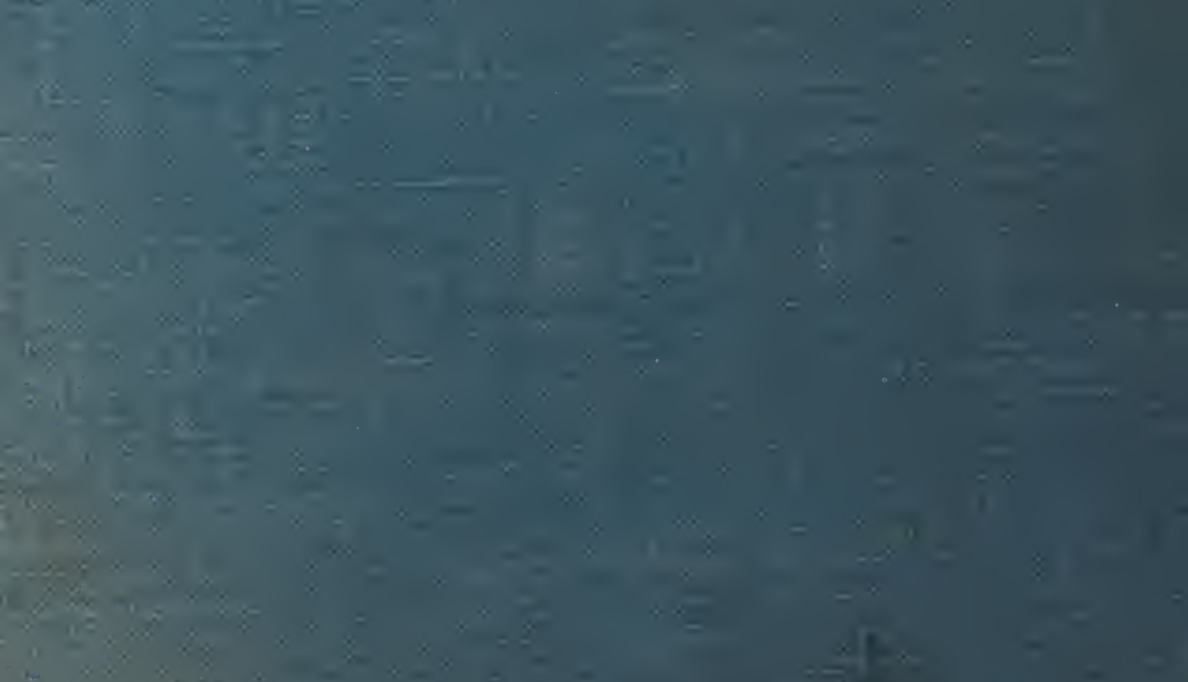